\title{
Immune control by the autonomic nervous system: Towards clinical implementation of enriched enteral nutrition
}

Citation for published version (APA):

de Haan, J. J. (2012). Immune control by the autonomic nervous system: Towards clinical implementation of enriched enteral nutrition. [Doctoral Thesis, Maastricht University]. Universiteit Maastricht. https://doi.org/10.26481/dis.20121122jh

Document status and date:

Published: 01/01/2012

DOI:

10.26481/dis.20121122jh

Document Version:

Publisher's PDF, also known as Version of record

\section{Please check the document version of this publication:}

- A submitted manuscript is the version of the article upon submission and before peer-review. There can be important differences between the submitted version and the official published version of record.

People interested in the research are advised to contact the author for the final version of the publication, or visit the DOI to the publisher's website.

- The final author version and the galley proof are versions of the publication after peer review.

- The final published version features the final layout of the paper including the volume, issue and page numbers.

Link to publication

\footnotetext{
General rights rights.

- You may freely distribute the URL identifying the publication in the public portal. please follow below link for the End User Agreement:

www.umlib.nl/taverne-license

Take down policy

If you believe that this document breaches copyright please contact us at:

repository@maastrichtuniversity.nl

providing details and we will investigate your claim.
}

Copyright and moral rights for the publications made accessible in the public portal are retained by the authors and/or other copyright owners and it is a condition of accessing publications that users recognise and abide by the legal requirements associated with these

- Users may download and print one copy of any publication from the public portal for the purpose of private study or research.

- You may not further distribute the material or use it for any profit-making activity or commercial gain

If the publication is distributed under the terms of Article $25 \mathrm{fa}$ of the Dutch Copyright Act, indicated by the "Taverne" license above, 


\section{Immune control by the autonomic nervous system}

towards clinical implementation of enriched enteral nutrition 
(C) Copyright JJ de Haan, Maastricht 2012

ISBN : 978-90-6464-603-4

Cover design: Heike Heineman

Cover picture: mobile, Alexander Calder (1898-1976)

Lay out: $\quad$ Tiny Wouters

Production: $\quad$ GVO printers \& designers B.V. | Ponsen \& Looijen

Printing of this thesis was financially supported by de Nederlandse Vereniging voor Gastroenterologie, Novartis Pharma, Greiner Bio-One, KNMG Twente, Hycult Biotechnology and Nutricia Advanced Medical Nutrition, Danone Research - Centre for Specialised Nutrition.

The studies in this thesis were performed within the Nutrition and Toxicology Research Institute Maastricht (NUTRIM).

The studies presented in this thesis were funded by Nutricia Advanced Medical Nutrition, Danone Research - Centre for Specialised Nutrition, Wageningen, the Netherlands.

\section{iffition




\title{
Immune control by the autonomic nervous system towards clinical implementation of enriched enteral nutrition
}

\author{
Proefschrift
}

ter verkrijging van de graad van doctor

aan de Universiteit Maastricht, op gezag van de Rector Magnificus, Prof. dr. L.L.G. Soete, volgens het besluit van het College van Decanen, in het openbaar te verdedigen op donderdag 22 november 2012 om 14.00 uur

door

Jacco-Juri de Haan 


\section{Promotores}

Prof. dr. W.A. Buurman

Prof. dr. J.W.M. Greve

\section{Beoordelingscommissie}

Prof. dr. H. ten Cate (voorzitter)

Prof. dr. L.M.A. Akkermans (Universitair Medisch Centrum Utrecht)

Prof. dr. G.E. Boeckxstaens (Katholieke Universiteit Leuven)

Prof. dr. A.M.W.J. Schols

Prof. dr. P.B. Soeters 


\section{Contents}

Chapter 1 General introduction 7

PART I The afferent arm of the nutritional anti-inflammatory reflex 37

Chapter 2 Cholecystokinin/Cholecystokinin-1 receptor-mediated peripheral 39 activation of the afferent vagus by enteral nutrients attenuates inflammation in rats

PART II Effects of the nutritional anti-inflammatory reflex on intestinal integrity

Chapter 3 Rapid development of intestinal cell damage following severe trauma: 59 a prospective observational cohort study

Chapter 4 Intestinal cytoskeleton degradation precedes tight junction loss 73 following hemorrhagic shock

Chapter 5 Protection against early intestinal compromise by lipid-rich enteral nutrition via cholecystokinin receptors

Chapter 6 Lipid-rich enteral nutrition regulates mucosal mast cell activation via 107 the vagal anti-inflammatory reflex

PART III Explorations on the applicability of the nutritional anti-inflammatory 127 reflex in surgical, trauma and critical care settings

Chapter 7 Post-shock intervention with high-lipid enteral nutrition reduces inflammation and tissue damage

Chapter 8 Prevention of hemolysis-induced organ damage by nutritional activation of the vagal anti-inflammatory reflex

Chapter 9 Lipid-enriched enteral nutrition controls the inflammatory response 161 in murine gram-negative sepsis

Chapter 10 Lipid-rich enteral nutrition reduces immunosuppression during polymicrobial sepsis

PART IV The nutritional anti-inflammatory reflex: preclinical human studies

Chapter 11 Application of vagus stimulation with enriched enteral feeding in man: selection of an optimal nutritional composition

Chapter 12 Exploring the link between inflammation and the vagus nerve 209

Chapter 13 Continuous administration of enteral lipid- and protein-rich nutrition limits inflammation in a human endotoxemia model

Chapter 14 Summary and discussion

Nederlandse samenvatting

Curriculum Vitae

List of publications 



\section{CHAPTER 1}

General introduction 


\section{Introduction}

Inflammation is the response of the immune system to noxious stimuli or conditions ${ }^{1,2}$. Normally, the immune response ensures neutralization and removal of the harmful stimulus and initiates repair of injured tissue. Therefore, inflammation is a fundamentally protective process ${ }^{2,3}$. Under certain circumstances however, the immune response derails and can result in sepsis or related syndromes. Sepsis, defined as an inappropriate and systemic inflammatory response to microbial infection, can be a devastating complication of major surgery and severe trauma ${ }^{4}$. The development of sepsis is associated with an increased susceptibility to secondary infections, multiple organ failure and death ${ }^{5,6}$. Even under optimal care, mortality rates of severe sepsis are as high as $30-40 \%$. Worldwide, millions of patients develop sepsis annually, which poses a major burden on health care costs ${ }^{7,8}$. Obviously, novel therapies to control inflammation and prevent or treat septic syndromes are needed ${ }^{9}$.

In this thesis, activation of the vagal anti-inflammatory reflex through enriched enteral nutrition is presented as a physiologic and clinically feasible approach to modulate the inflammatory response and preserve organ integrity. In particular, beneficial effects of lipid-rich nutrition on early loss of gut wall integrity are shown.

\section{Cornerstones of the immune response}

The human body is surrounded and inhabited by an enormous load of microbes. The microbe population contains both commensal bacteria that are in balance with the host, and pathogens that challenge the host by many different mechanisms and potentially cause severe diseases ${ }^{10}$.

An intricate immune system has evolved that mobilizes an appropriate response to pathogens while avoiding damage to host organs or beneficial, commensal microbes. A key function of the immune apparatus is to respond appropriately to situations of danger, while remaining unresponsive under non-dangerous conditions ${ }^{11}$. The immune system is well-equipped to sense pathogen-associated molecular patterns (PAMPs) and endogenous signals derived from stressed or damaged host tissue, which are termed damage-associated molecular patterns (DAMPs). To these DAMPs, also called alarmins, belong high mobility group box 1 (HMGB1), heat shock proteins, defensins, cathelicidins and more ${ }^{12,13}$. Also the proteolytic activity of pancreatic enzymes that enter the body through the compromised gut wall leads to activation of the immune system $^{14}$. PAMPs and DAMPs are recognized by specialized pattern-recognition receptors (PRRs) that are broadly expressed by immune cells ${ }^{15-17}$. PRRs located on the cell membrane include toll-like receptors (TLRs) and C-type lectin receptors (CLRs). Cytosolic surveillance is ensured by intracellular PRR families, such as Nod-like 
receptors (NLRs) and Rig-like receptors (RLRs). Intracellularly, the transduction of PRRderived signals is tightly regulated, e.g. by suppressors of cytokine signaling (SOCS $)^{18}$. Signal transduction converges on a common set of signaling modules, often including NF-kB and AP-1 transcription factors. Several intracellular PRRs are capable to assemble into high-molecular weight, caspase-1-activating complexes called inflammasomes, that drive maturation and secretion of potent pro-inflammatory cytokines like interleukin (IL)-1 $\beta$ and IL-18 ${ }^{19}$.

Activation of PRRs triggers the production of a wide variety of cytokines, chemokines, lipid mediators, proteolytic enzymes and vasoactive peptides ${ }^{10}$. Important regulatory cytokines that characterize the onset of inflammation include tumor necrosis factor (TNF)- $\alpha$, IL-1 $\beta$, IL- 6 and interferons (IFN). These mediators are either produced newly or are preformed and stored, for example in granules of mast cells or basophils ${ }^{20}$. In addition, various mediators like complement factors, defensins and ficolins are constitutively present in body fluids in biologically active form or as inactive precursors. Release of vasoactive mediators promotes vascular leakage, which allows plasma proteins and leukocytes to enter the infected or damaged site. Whereas the initial inflammatory response is orchestrated predominantly by resident macrophages and mast cells, rapidly recruited monocytes and in particular neutrophils are important in final pathogen clearance and repair of damaged tissue ${ }^{2,10}$. The inflammatory response is further regulated by leukotrienes, prostaglandins and tromboxanes.

Classically, a distinction is made between the innate and the adaptive immune system $^{21}$. The innate immune system forms the body's first defense against invading pathogens or tissue injury by continuous surveillance of tissue integrity and, if appropriate, induction of a rapid and generic response. After identification by cells of the innate immune system, pathogens are either directly destroyed or internalized, after which pathogenic patterns are presented by antigen presenting cells (APC) to the adaptive immune system ${ }^{22}$. The complementary adaptive immune system forms the second line of defense, that distinguishes itself from the innate immune system by manifesting exquisite specificity for its target antigens ${ }^{21}$. This system is highly adaptable due to random genetic recombination in the primary lymphoid tissue (VDJ recombination) and, upon exposure to antigens, the programmed mutation of the immunoglobulin genes (somatic hypermutation) and subsequent expression of antigen-specific receptors. A second key feature of the adaptive immune system is generating immune memory by the production of memory cells that persist in a dormant state, but that can reactivate after another encounter with the specific antigen. While the innate and adaptive immune responses are fundamentally different in their mechanisms of action, synergy between them is considered essential for an intact, fully effective immune response ${ }^{10}$. 
Parallel to the pro-inflammatory process, a counterbalancing anti-inflammatory response develops. Crucial cytokines in the limitation of pro-inflammatory signaling are IL-6, IL-10, tumor growth factor (TGF)- $\beta$, soluble TNF receptors and the IL-1 receptor antagonist. Interestingly, many inflammatory mediators share both pro-inflammatory and anti-inflammatory capacities, the dominance of which depends on the concentration, location and moment of release. Together, the components of the immune response, for instance stimulation of the hypothalamic-pituitaryadrenocortical (HPA)-axis, increased sympathetic output, development of fever and release of acute phase proteins, effectively keep inflammation contained ${ }^{23}$. Usually, homeostasis and health are restored rapidly by a balanced reaction of the immune system.

\section{Dysregulated inflammation: the septic syndrome}

Whereas inflammation is usually a discrete local event, in surgical and critical care settings the tightly regulated immune response can expand beyond the local environment. Sepsis occurs when such systemic response develops in a setting of infection ${ }^{4}$. Similar processes that take place in a non-infectious situation are referred to as a systemic inflammatory response syndrome (SIRS). Crucial in the development of sepsis and related syndromes is excessive immune cell activation, leading to abundant release of bioactive mediators, including cytokines, chemokines and activation of coagulation and complement factors ${ }^{5,7,8,24}$. Whereas both pro- and anti-inflammatory mediators are released during the early phase of inflammation, it is the proinflammatory response that prevails (Figure 1.1). Exposure to mediators like TNF $\alpha$, IL-1 $\beta$ and HMGB1 as well as gut-derived proteases, combined with the occurrence of ischemia and an altered rate of apoptosis, contribute to the development of generalized endothelial and parenchymal cellular injury that precedes organ dysfunction $^{25-27}$.

The initial hyperinflammatory phase of sepsis is succeeded by a state of immunosuppression that can last for prolonged periods of time (Figure 1.1). Such immune dysfunction is characterized by leukocyte hyporeactivity, massive apoptosisinduced depletion of neutrophils, T cells, B cells and dendritic cells and decreased expression of the cell-surface antigen-presenting complex HLA-DR ${ }^{6,28-31}$. Enhanced IL-10 levels, produced by several cell lines including dendritic cells, macrophages, regulatory $T$ cells and in particular by cells in apoptosis, are considered crucial in the sustainment of immunosuppression ${ }^{32-34}$. IL-10 suppresses dendritic cells and macrophages, thereby shifting the Th1 profile towards a Th2 type response that is less effective in the eradication of pathogens ${ }^{6,35,36}$. Traditionally, the severity and duration of immunosuppression are considered to be a consequence of the magnitude of initial 
septic hyperinflammation. Currently, also other factors, including the amount and virulence of the invading microorganisms, the genetic predisposition of the host and coexistent medical conditions are regarded as contributory to the phenotype of the immune response ${ }^{29,37-39}$. As a result of immunosuppression, survivors of the early period of excessive inflammation in sepsis are at risk to develop secondary and persistent infections caused by opportunistic pathogens that are normally controlled by a functioning immune system. Such infections are particularly hard-to-treat and are responsible for the major part of sepsis mortality.

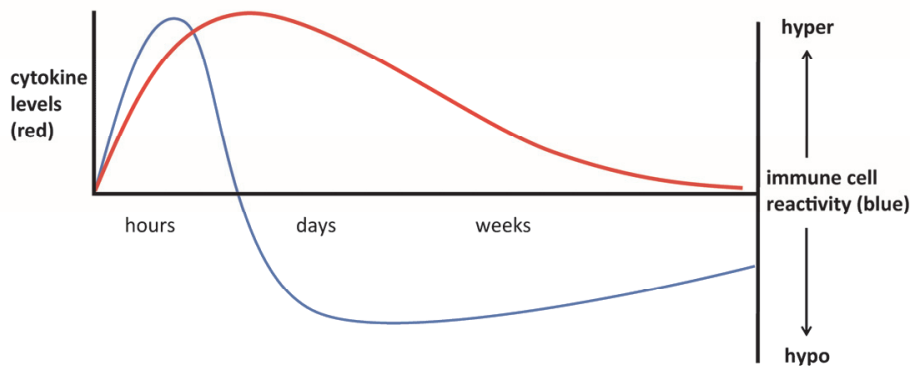

Figure 1.1 Time course of the septic response. Immune cell activation leads to a rapid increase of both pro- and anti-inflammatory mediators, such as cytokines. The initial phase of increased immune cell reactivity is succeeded by a prolonged state of immunosuppression.

\section{The clinical demand for immunomodulatory interventions}

The excessive release of early inflammatory mediators following trauma and surgery is correlated with the development of sepsis ${ }^{37,40}$. This notion led to numerous trials that aimed at neutralization of cytokines and toxins that were considered crucial in the progression to sepsis, including TNF- $\alpha$, IL-1 and lipopolysaccharide (LPS). Although promising data were obtained in experimental animal settings, these interventions failed to improve or even decreased survival of septic patients ${ }^{40-43}$. Also interventions with platelet-activating factor inhibitors, bradykinin antagonists and ibuprofen did not increase survival of sepsis in well-designed trials ${ }^{44-47}$. Taken together, it is unlikely that selective inhibition of single inflammatory mediators will be able to modulate the entire complex septic response. Further reasons frequently given for the discongruence between experimental success and lack of effect in septic patients are the heterogeneity of patient cohorts and underestimation of the differences between the biochemical and immunological responses of mostly elderly patients with a clinical diagnosis of sepsis compared to young animals with selective bacterial infections or 
endotoxemia $^{9,48,49}$. Indeed, compared to straight-forward inflammatory models like endotoxemia, effects of anti-inflammatory interventions were usually limited in more complex models, such as cecal ligation and puncture that resembles the clinical scenario of polymicrobial sepsis. Another issue that may explain the lack of effect of anti-inflammatory therapies in sepsis is the moment at which the intervention is initiated. Starting anti-inflammatory treatment during ongoing sepsis may be too late to effectively prevent inflammatory complications and in addition might strengthen immunosuppressive signaling and increase the vulnerability to infections ${ }^{50,51}$.

Despite these disappointments, the outcome of sepsis has improved gradually over the past years. In the immediate management of sepsis, early goal-directed therapies including lung-protective ventilation and broad-spectrum antibiotics have become standard practice ${ }^{52-54}$. The use of activated protein C, corticosteroids, vasopressin and tight glucose control remain subject of debate ${ }^{9,55-57}$. In addition, the growing appreciation of immunosuppression as a determining factor in septic mortality led to the development of interventions aimed at restoring immune competence, for instance by administration of granulocyte and macrophage colony stimulating factor (GM-CSF), IFN- $\gamma$ and inhibitors of apoptosis ${ }^{58-60}$.

A major contributor to the recent improvement of sepsis outcome was the Surviving Sepsis Campaign in 2002, aimed at optimizing the treatment of sepsis by developing up-to-date and evidence-based guidelines ${ }^{61}$. First trials indicated that implementation of these guidelines improves survival considerably ${ }^{62}$. Nevertheless, severe sepsis remains the leading cause of death at intensive care units. Therefore, novel broadacting treatment modalities are needed that 1 . attenuate initial hyperinflammation, 2. alleviate the subsequent state of immunosuppression and 3. can be initiated when the immune response is already unfolding.

\section{Neural responses to peripheral inflammation}

The understanding is growing that the autonomic nervous system plays an important regulatory role in the host defense against infections and tissue damage. Bidirectional communications between the immune system and the autonomic nervous system, that share many mediators and receptors, optimize the effectiveness of both ${ }^{63-65}$. Therefore, interference in neural signaling is a potential way to modulate the immune response ${ }^{65,66}$.

Afferent neural signals provide the brain with constant information about the immune status in the periphery (Figure 1.2) ${ }^{67}$. Activated immune cells release inflammatory mediators, such as TNF- $\alpha$ and IL-1 $\beta$, that stimulate afferent vagus fibers ${ }^{68-72}$. In addition, sensory neurons express TLR4, which indicates that both PAMPs and DAMPs are capable to activate the afferent vagus directly ${ }^{73}$. Next to the neural pathway, 
cytokines signal the brain via the circulation, although this route appears to be of significance only in settings of excessive cytokine production ${ }^{74}$.

The afferent sensory pathway represents a highly organized detection system that, when activated, results in a sickness response that comprises fever, increased sleep, anorexia and metabolic mobilization of energy substrates ${ }^{75}$. Vice versa, the brain modulates the immune system directly via the circulation and via neural signaling. The hypothalamic-pituitary-adrenal (HPA) axis is the well-known neuro-endocrine pathway that regulates the immune system ${ }^{64,76}$. Via corticotropin releasing hormone (CRH), the hypothalamus induces secretion of adrenocorticotropic hormone (ACTH) from the pituitary gland. In the adrenal gland, circulatory ACTH increases the production and release of cortisol. These glucocorticoids inhibit cytokine synthesis via intracellular signal transduction ${ }^{64,77}$.

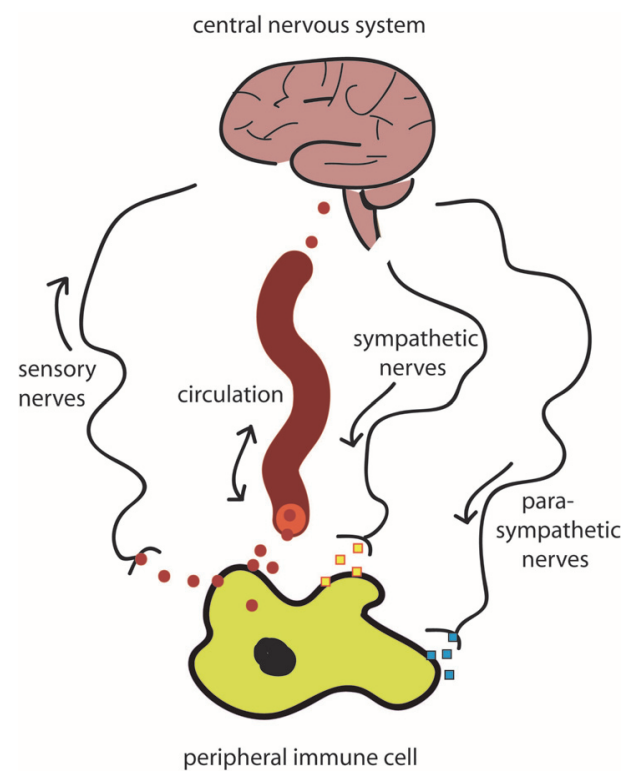

Figure 1.2 Neuroimmune interactions. Peripheral immune cells signal the brain via sensory nerves and via the circulation. In response, the central nervous system regulates inflammation in the periphery via mediators released in circulation as well as via sympathetic and parasympathetic output.

The diffuse innervation of all major organs allows the brain to sense local attacks or injury via sensory nerves. In response, direct neural regulation of immune cell activity in these specific areas is exerted via the sympathetic and parasympathetic arms of the autonomic nervous system (Figure 1.2). At the onset of sepsis, sympathetic outflow, via $\beta$-adrenergic signaling, is essential to uphold adequate cardiovascular functioning. 
In addition, $\beta$-adrenergic receptors play a major role in the initiation of the hypermetabolic response that characterizes the acute phase of sepsis. Prolonged $\beta$-adrenergic stimulation has been implicated in the development of immunosuppression. Therefore, effects of adrenoreceptor modulation in settings of sepsis are currently investigated ${ }^{77,78}$.

\section{Vagal modulation of the inflammatory response}

The parasympathetic nervous system has been identified as a strong inhibitor of the inflammatory response ${ }^{79}$. In septic mice, electrical stimulation of the vagus nerve was demonstrated to reduce circulatory TNF- $\alpha$ levels and improve survival. In this so-called cholinergic anti-inflammatory pathway, binding of vagal neurotransmitter acetylcholine to the $\alpha 7$-subunit of the nicotinic acetylcholine ( $\mathrm{nACh}$ ) receptor was shown to be crucial ${ }^{80}$. This finding led to the development of specific $\alpha 7 n A C h$ receptor agonists such as GTS-21, that indeed reduced inflammation and mortality in mice ${ }^{81,82}$. The anti-inflammatory actions of $\alpha 7 \mathrm{nACh}$ receptor activation are mediated by inhibition of NF-KB via activation of the transcription factor STAT3, which is phosphorylated by the tyrosine kinase JAK $2^{83,84}$. Recently, $\alpha 4 / \beta 2$ subunits of the nACh receptor were shown to be crucial in the enhancement of phagocytosis by vagal nerve stimulation, implicating involvement also of non- $\alpha 7$ subunits of the nACh receptor in cholinergic anti-inflammatory signaling ${ }^{85}$. At the level of the central nervous system, intraventricularly administered agonists of the muscarinic receptor, and the $\mathrm{M} 1$ receptor in particular, were shown to dampen peripheral inflammation via stimulation of the vagus nerve ${ }^{86}$.

Following studies on vagal inhibition of cytokine release by macrophages, inhibitory vagal effects on lymphocytes, bronchial epithelial cells and endothelium have been demonstrated $^{87-89}$. The spleen was identified as an important effector organ in the anti-inflammatory effects of electrical vagus stimulation ${ }^{90,91}$. Vagal signaling to the spleen resulted in a reduction of cytokine release in the spleen and downregulation of the surface expression of major histocompatibility complex HLA-DR molecules and other activation markers on the cells that leave the spleen. These cellular alterations may contribute to the inhibition of inflammation at the sites of injury and infection ${ }^{92}$.

The experimental evidence for vagus nerve stimulation as a potent means to modulate inflammation is compelling. Signal transduction through the nACh receptor was demonstrated to be beneficial in murine, rat and porcine models of polymicrobial sepsis, ischemia-reperfusion, arthritis, colitis, pancreatitis, ileus and hemorrhagic shock $^{83,85,93-97}$. Apart from electrical and pharmacological stimulation, also behavioral conditioning, meditation, hypnosis, acupuncture and psychoactive drugs were proposed as triggers of the vagal anti-inflammatory pathway (Figure 1.3) ${ }^{98,99}$. 


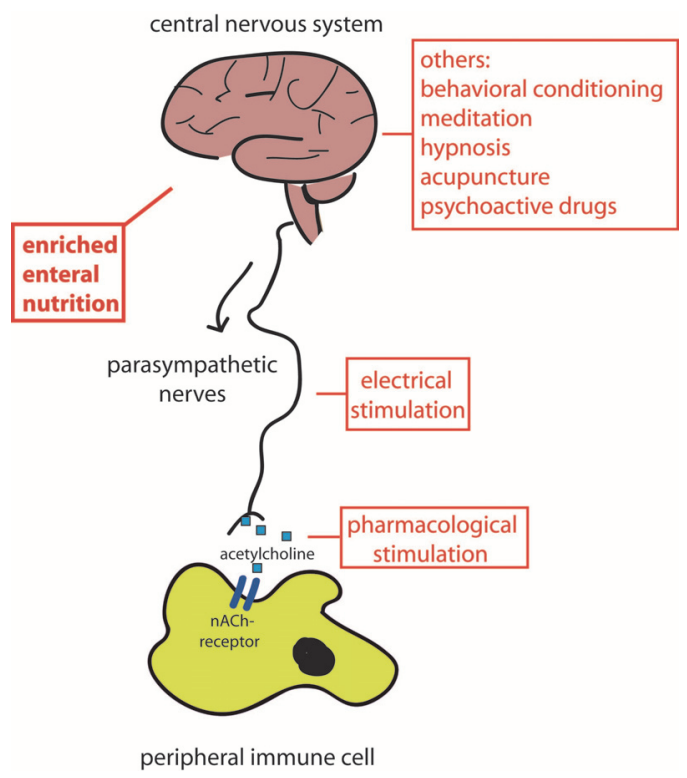

Figure 1.3 Stimulation of the vagal anti-inflammatory pathway. Next to electrical stimulation and pharmacological agents that bind to peripheral nicotinic acetylcholine (nACh) receptors, various approaches have been suggested to enhance parasympathetic signaling at a central level. Lipid-rich enteral nutrition is proposed as a physiological alternative.

In man, a standard clinical means to assess the function of the autonomic nervous system is measurement of heart rate variability (HRV), which records both sympathetic and parasympathetic signaling to the heart. In health and disease, an inverse relationship between vagal output and inflammatory markers was observed ${ }^{100,101}$. Furthermore, autonomic dysfunction was associated with morbidity and mortality following myocardial infarction and sepsis as well as disease severity in various autoimmune diseases ${ }^{102-108}$. These data implicate restoration of the autonomic nervous balance by vagus nerve stimulation as a potential therapeutic approach in man. However, the effectiveness of enhancing the parasympathetic output to treat inflammatory conditions in clinical setting remains to be elucidated. A potential sideeffect of electrical or pharmacological approaches is activation of non-associated cells $^{109}$. As effects of electrical vagal stimulation on cardiac function and inflammation were demonstrated to be dissociable, a cautious approach may enable specific stimulation of target cells or organs ${ }^{110}$. Another drawback of electrical stimulation in man is the invasive procedure needed to gain access to the vagus nerve. Also clinical implementation of pharmacological agents warrants caution, as detrimental effects of selective $\alpha 7 n A C h$ receptor stimulation were recently reported in a colitis model ${ }^{111}$. 


\section{Nutritional activation of the vagal anti-inflammatory pathway}

A physiological alternative means to activate the vagal anti-inflammatory pathway is enteral administration of nutrition enriched with lipids. Studies of the immunomodulatory effects of lipid-rich nutrition were based upon in vitro work showing endotoxin-binding properties of lipoproteins. Of all lipoproteins, chylomicrons, which are formed following lipid absorption in the intestine, displayed strongest neutralization of endotoxin ${ }^{112}$. In a rodent model of hemorrhagic shock, nutrition enriched with lipids strongly reduced circulatory endotoxin levels ${ }^{113}$. Moreover, lipid-rich feeding was demonstrated to decrease systemic cytokine release and preserve the gut barrier function ${ }^{113,114}$. Using a second hit model of hemorrhagic shock preceded by exposure to bacterial DNA, lipid-rich nutrition was shown to reduce liver injury ${ }^{115}$. Further investigations defined the vagal anti-inflammatory pathway as the major underlying mechanism of the anti-inflammatory nutritional effects. Bilateral vagotomy performed shortly prior to shock as well as administration of a nACh receptor antagonist abrogated the nutritional protection ${ }^{116}$. With regard to the sensory arm of the pathway, stimulation of cholecystokinin (CCK) receptors was shown to be crucial in the activation of the autonomic nervous system by enteral lipid-rich nutrition $^{116}$.

\section{The gut-brain axis}

The immunomodulatory effects of enteral lipids shed new light upon the preservation of homeostasis in the body during and following food intake. Profound knowledge of the neural response to enteral nutrients is required to define the possibilities and limits of nutritional anti-inflammatory signaling and to facilitate the translation of the experimental findings to patient settings.

Sensing of nutrients enables the autonomic nervous system to regulate food intake and preserve long-term energy homeostasis ${ }^{117}$. The gastrointestinal (GI) tract communicates with the brain via hard-wired neural pathways and circulatory mediators, the so-called gut-brain axis (Figure 1.4$)^{118,119}$. The nutritional response is initiated by the cephalic phase that relies mainly on gustatory and olfactory input. Taste receptors of sweet, salt, bitter, sour and umami enable evaluation of the nutritious content and help to prevent the ingestion of toxic substances ${ }^{120}$. In addition, visual and auditory cues and the mere thought and anticipation of food provide additional neural activation. The cephalic reflexes regulate the digestion, absorption and metabolism of nutrients in a coordinated fashion by controlling oral and gut 
secretions and several digestive, endocrine, thermogenic, cardiovascular and renal responses $^{121,122}$.

Next to cephalic reflexes, the regulation of appetite and satiation by the central nervous system depends on afferent vagus nerve input from the Gl tract via mechanoreceptors and chemoreceptors ${ }^{118,123}$. Two types of mechanoreceptors have been identified. Intraganglionic laminar endings (IGLEs), distributed globally throughout the GI tract, are a general type of tension receptors that detect mixing movements and peristaltic propulsion. Next, intramuscular arrays (AMIs) sense muscle stretch in regions which exhibit frequent and sustained non-rhythmic adjustments, such as the lower esophageal sphincter and the pyloric sphincter ${ }^{124}$.

Whereas gastric signals arise primarily from mechanical distention, those from the intestine are derived largely from the chemical effects of food (Figure 1.4) ${ }^{125}$. A range of gut peptides is secreted by enteroendocrine cells in response to ingested macronutrients carbohydrates, proteins and fat. These messengers diffuse through the intestinal wall to activate nearby nerve fibers or enter the bloodstream to function as hormones $^{117}$.

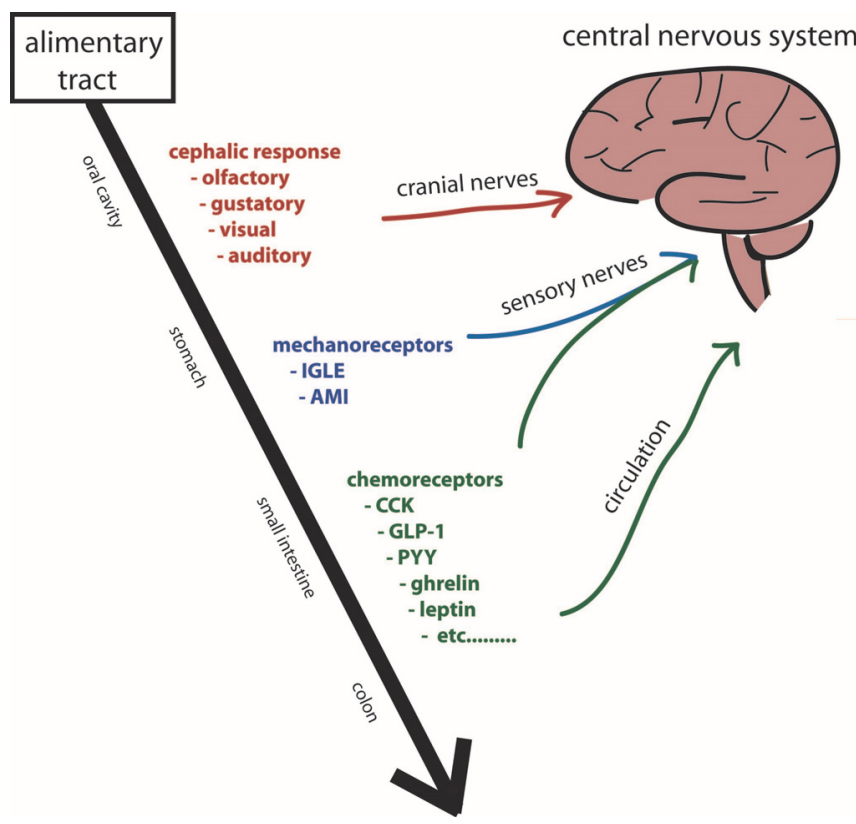

Figure 1.4 The central nervous system is informed about food intake at various levels of the gastrointestinal tract. Cephalic reflexes are mediated by the cranial nerves. In the stomach, and to a lesser extent more distal in the intestine, stretch or propulsion activates sensory nerves via mechanoreceptors. Various gut hormones stimulate the autonomic nervous system via stimulation of sensory nerves and via the circulation. 
Neuropeptide CCK, the receptors of which were found to be essential in the antiinflammatory effects of lipid-rich nutrition, is released by I-cells in the proximal small intestine upon exposure of luminal lipids and hydrolyzed proteins ${ }^{117}$. The release of CCK following the uptake of lipids depends on the formation of chylomicrons, which transport dietary lipids from the intestine to distant parts of the body ${ }^{126}$. The CCK receptor family consists of CCK receptor 1 (CCK-1R), which predominates in the GI tract, and CCK receptor 2 (CCK-2R), that is mostly localized in the brain. Hormonal effects of CCK include stimulation of pancreatic secretion, gall bladder contraction, inhibition of gastric emptying and promotion of intestinal motility ${ }^{127}$. Satiating effects of CCK have been confirmed in numerous species, including humans ${ }^{128}$. The CCK-1R on the afferent vagus nerve were demonstrated to mediate the anorectic effects of peripheral $\mathrm{CCK}^{129-132}$. Also regulatory effects of dietary lipids on metabolic processes such as postprandial glucose homeostasis are mediated by CCK-1R dependent stimulation of the autonomic nervous system ${ }^{133}$. Although CCK-1R predominate in the periphery, to a lesser extent CCK-1R are also found in the brain. Interestingly, CCK-1R expressed in the hindbrain and hypothalamus are involved in food intake regulation ${ }^{134-136}$. It remains to be clarified whether centrally located CCK-1R respond to CCK that is locally released in the brain or to CCK released in the intestine that signals the brain via the circulation.

CCK was demonstrated to determine the capacity of other gut peptides to influence food intake via vagal afferent neurons, thus acting as a gatekeeper ${ }^{137-139}$. However, also GLP-1 and PYY, released by L-cells in the distal intestine, were shown to affect the intake and propulsion of food. GLP-1 and PYY are either produced directly in response to dietary lipids and carbohydrates, or indirectly upon stimulation of the enteral nervous system in the proximal small intestine. Both peptides are crucial in the ileal brake', a feedback phenomenon whereby signals from ingested food in the distal intestine inhibit proximal GI motility ${ }^{140}$. Neuropeptides that were reported to signal the brain further include oxyntomodulin, enterostatin, apolipoprotein A-IV and the pancreas-derived pancreatic polypeptide and amylin ${ }^{117}$. In the absence of food, ghrelin is released, which is considered a cephalic response induced by sympathetic signals ${ }^{141,142}$. Ghrelin, thus far the only orexogenic peptide identified, contributes to long-term body-weight regulation and also influences neuronal activity in several areas of the brain. Via specific receptors, afferent vagal nerves are inhibited by ghrelin ${ }^{143}$.

Taken together, neural and hormonal signals from various levels of the digestive tract inform the brain about the intake, content and processing of food (Figure 1.4). Cephalic input is projected to the primary sensory cortices and subsequently processed and integrated with information about motivational state and information from memory ${ }^{144}$. The hindbrain is the principal site that receives feedback signals from 
mechanoreceptors, chemoreceptors and hormones released in the stomach and intestine. For example, vagal afferents project to the nucleus of the solitary tract, whereas circulatory gut peptides act directly on the area postrema, which lies outside the blood-brain barrier. Pathways relaying short-acting signals from the gut interact at various levels with long-acting hormones involved in body-weight regulation, such as leptin and insulin ${ }^{117,118,145}$. The integrated information is used to steer bodily processes and behavior. Although nutrient perception clearly involves higher cognitive centers, conscious awareness of gastrointestinal feedback signals is not required for the induction of effector mechanisms.

\section{Intestinal compromise in surgical and critical care settings}

Activation of the vagal anti-inflammatory pathway exerts a strong protective effect on intestinal integrity. Lipid-rich nutrition was demonstrated to reduce bacterial translocation from the gut lumen and decrease intestinal permeability to horseradish peroxidase via stimulation of the vagus nerve ${ }^{113,114,116}$. Van der Zanden et al. demonstrated that $\mathrm{nACh}$ receptor activation enhanced endocytosis and phagocytosis in isolated intestinal and peritoneal macrophages ${ }^{85}$. These findings are supported by earlier studies that reported on close anatomical and functional relationships between nerve endings and immune cells in the gut mucosa ${ }^{146,147}$.

Intestinal integrity loss is considered to be important in the development of inflammatory complications such as sepsis since decades ${ }^{148}$. Based on clinical observations that the gut wall becomes more permeable following surgery and that microbes causing sepsis are often identical to microbes cultured from mesenteric lymph nodes, it was postulated that the barriers that prevent microbes from entering the intestinal wall become compromised during major surgery or following severe trauma ${ }^{149-153}$. In the consecutive years, this hypothesis was supported by various lines of experimental evidence. Deitch and colleagues demonstrated in a rodent model of hemorrhagic shock that ligation of mesenteric lymphatic ducts prevented pulmonary injury and cardiac contractile dysfunction ${ }^{154,155}$. In line, intravenous administration of lymph derived from animals in shock induced pulmonary injury in healthy littermates ${ }^{156}$. In addition, a gradual increase of intestinal permeability modulated the level of mucosal immune activation and increased the vulnerability to subsequent inflammatory triggers ${ }^{157-159}$. These data implicated preservation of the intestinal barrier as a potential therapeutic target to prevent or treat dysregulated inflammation. Indeed, interventions that specifically aim to improve intestinal integrity, including enterocyte-specific growth factor, high-molecular weight polyethylene glycol, inhibition of pancreatic enzyme activity in the gut lumen and modulation of the intestinal flora, were shown to reduce distant organ damage and improve survival 
during sepsis ${ }^{14,160-164}$. Interestingly, the notion that the intestine may become a proinflammatory organ that contributes to the development of infections including ventilator-associated pneumonias in critically ill patients has led to the implementation of selective gut decontamination at intensive care units ${ }^{165,166}$.

\section{Components of the intestinal barrier}

The intestine has a dual function of digestion and absorption of ingested nutrients, while sustaining a barrier to prevent the invasion of food antigens, microbes and toxins. This barrier between the internal milieu and the gut lumen consists of physical and immunological components ${ }^{167,168}$. Also the colonization of the gut with commensal microbes is considered a mechanism of protection by limiting the growth of pathogenic microbes.

The physical barrier is formed by an epithelial monolayer which constitutes of five different cell types that possess different immunological functions (Figure 1.5) ${ }^{169}$. The majority of epithelial cells consist of enterocytes that are important for the absorption of nutrients. Furthermore, enterocytes express PRRs, thus enabling an active role in the development of intestinal inflammation ${ }^{170}$. Next, goblet cells produce mucus, that forms an impermeable layer covering the apical side of the epithelium. The mucus is divided in a sterile inner layer that borders the epithelium and a luminal layer that is inhabited by commensal bacteria ${ }^{171}$. Paneth cells reside at the bottom of the crypts. In response to microbes that are actively sensed as well as constitutively, these cells secrete lysozyme, defensins, zinc and other antimicrobial molecules ${ }^{172}$. Finally, M-cells and enteroendocrine cells function as important sensors of intestinal luminal content. M-cells, overlying the Peyer's patches and lymphoid follicles, possess receptors that facilitate the recognition of microbes and the subsequent presentation of these microbes to the immune system. Although the main task of enteroendocrine cells is sensing of nutrients and secretion of neuropeptides such as CCK, GLP1 and PYY, the expression of TLRs indicate that these cells also have immunological properties ${ }^{173}$. The epithelial layer undergoes rapid and continuous renewal, which is fuelled by pluripotent stem cells located in the crypts.

Adjacent epithelial cells are connected by tight junctions that prevent penetration of luminal microbes and antigens through paracellular channels, while permitting passive diffusion of solutes (Figure 1.5) ${ }^{174}$. These tight junctions are formed by complexes of proteins including claudins, occludins and zonula occludens proteins. Tight junctions are anchored in the cell via the actin skeleton, a dynamic structure that maintains cell shape.

In addition to the immunological properties of the epithelial cells, the intestinal wall hosts $90 \%$ of the immune cells of the body. Intestinal immune cells are found 
dispersed in the epithelium and underlying lamina propria, but also aggregated in mesenteric lymph nodes, lymphoid follicles and Peyer's patches ${ }^{167}$. Dendritic cells, macrophages and epithelial cells, in particular M-cells, continuously sense and sample luminal antigens via PRRs and present these to T and B lymphocytes. An important aspect of the subsequent response is the secretion of antigen-specific IgA by plasma cells. IgA is found in high concentrations in the mucus and plays a significant role in preventing antigens from passing the epithelial barrier. Interestingly, IgA deficiency does not lead to continuous immune activation, indicating that the intestinal barrier is a redundant system consisting of many components that are not individually crucial ${ }^{175}$.

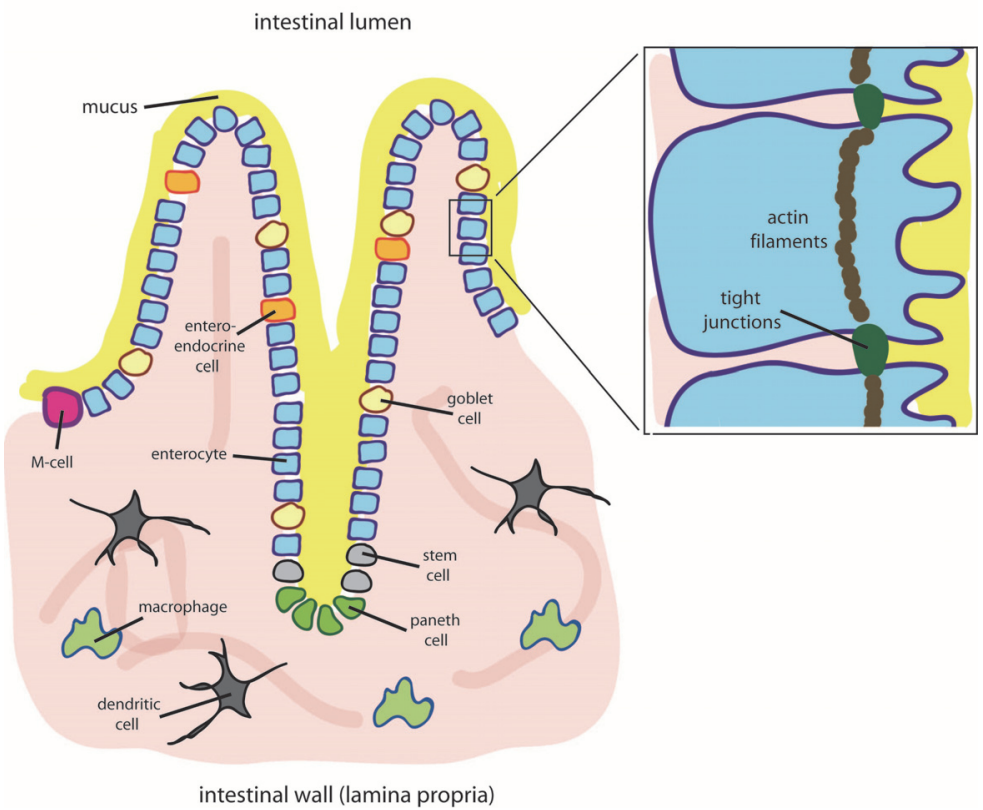

Figure 1.5 The epithelium, an important barrier between the intestinal lumen and the body, consists largely of enterocytes that are interconnected by tight junctions. Goblet cells produce the mucus layer that covers the epithelium. Paneth cells, residing in the crypts, secrete antimicrobial proteins that keep the crypts sterile. M-cells and dendritic cells are important in the sensing and uptake of antigens. Diverse immune cells including macrophages reside in the intestinal wall. 


\section{Loss and repair of gut barrier integrity}

Splanchnic hypoperfusion is an important contributor to the loss of intestinal integrity during surgery and trauma ${ }^{176-178}$. In settings of blood loss or lowered blood pressure, sympathetic signaling restricts perfusion of the splanchnic area in order to preserve blood flow to vital organs such as the heart and brain ${ }^{179,180}$. The extent of splanchnic hypoperfusion correlates with the development of multiple organ failure and length of stay in the $\mathrm{ICU}^{181}$. Diverse lines of evidence indicate that enterocyte damage, increased gut wall permeability and local intestinal inflammation are parallel and interacting events that develop early after hypoperfusion of the splanchnic area (Figure 1.6).

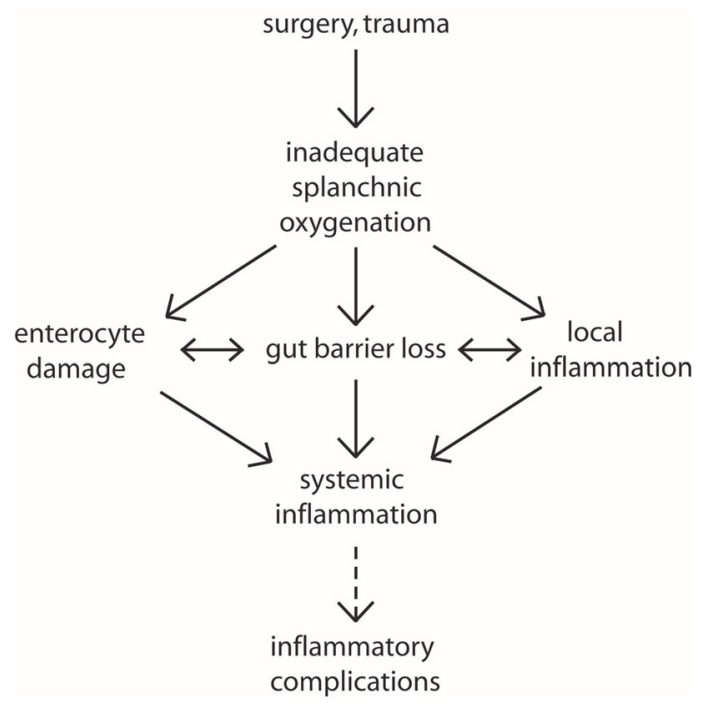

Figure 1.6 Splanchnic perfusion is considered a driving factor in early compromise of intestinal integrity during major surgery and following trauma. Cellular damage, increased intestinal permeability and a local inflammatory response are parallel and interdependent events that occur rapidly in settings of hypoperfusion. Together, these events may contribute to systemic inflammation and the development of sepsis and distant organ failure.

In a human ischemia and reperfusion model in which an isolated jejunal segment was clamped and reperfused, sloughing of villus tips was observed rapidly following ischemia $^{178}$. These microscopic observations were paralleled by increased venous concentrations of intestinal fatty acid binding protein (I-FABP). I-FABP is a cytosolic protein expressed by maturated enterocytes that are found at the tips of the villi. Following cell damage, these proteins are readily measurable in plasma ${ }^{182}$. The strong increase of plasma I-FABP in the initial phase of non-abdominal sepsis and non- 
abdominal surgery points at widespread occurrence of enterocyte damage in clinical settings that are characterized by decreased splanchnic perfusion ${ }^{177,178,183}$. Moreover, the early increase of enterocyte damage was associated with the development of complications and survival $^{177,178}$.

Next to the development of cellular damage, decreased intestinal blood flow leads to increased permeability of the gut wall. The occurrence of decreased gut barrier function has been reported in diverse clinical settings of inflammatory disease ${ }^{184-187}$. Depletion of adenosine triphosphate (ATP) resulting in disruption of the cellular actin cytoskeleton and disconnection with the tight junctions has been postulated as a major factor in the increase of gut wall permeability following ischemia ${ }^{188,189}$. As a consequence of the loss of tight junction integrity, paracellular permeability and exposure of inflammatory cells to translocated microbes and toxins is increased ${ }^{190}$. Next, endoplasmatic reticulum stress-related apoptosis of Paneth cells was shown to contribute to the increase of bacterial translocation and systemic inflammation following ischemia ${ }^{191}$. Activated mast cells further enhance gut wall permeability $^{190,192-194}$. Due to exocytosis of granules in which preformed mediators are stored, mast cells are among the first immune cells to regulate local intestinal inflammation ${ }^{20}$.

The loss of intestinal integrity observed in various surgical and intensive care settings is counterbalanced by mechanisms that effectively preserve the gut barrier in situations of intestinal ischemia. The sloughing of the villus tips during ischemia was shown to be followed by rapid resealing of the epithelial lining ${ }^{195,196}$. This mechanism effectively prevents PAMPs and DAMPs from entering the subepithelial mucosa, thus limiting the development of local inflammation and infections. The presence of such protective reflexes have prompted several authors to question the extent to which early intestinal cell damage, barrier loss and local inflammation contribute to the development of sepsis and related syndromes ${ }^{197,198}$. In addition, it has been suggested that loss of intestinal integrity should be regarded as a representation of generalized epithelial barrier loss ${ }^{169}$.

\section{Clinical application of nutritional anti-inflammatory signaling}

Malnutrition in hospitalized patients is recognized as an important determinant in the development of inflammatory complications, increased hospital stay and mortality ${ }^{199}$. Therefore, the assessment and optimization of the nutritional state has become an integrated part of standard care in surgical and critical care patients. Although the optimal timing to commence feeding remains subject of debate, current guidelines advocate early delivery of nutritional support following surgery or in critically ill patients, preferably via the enteral route ${ }^{200-203}$. In addition, the pre-operative period of 
fasting has been shortened and pre-operative loading with carbohydrates is provided, without leading to an increased risk of aspiration. The protective effects of enteral feeding are attributed to the reversion of the catabolic state, preservation of intestinal health and promotion of digestive, metabolic and immunologic homeostasis $^{116,201,204-207}$. In addition, adequate nutrition is supposed to prevent immunodeficiency due to caloric deficits. In several patient groups, the supplemental use of omega-3 polyunsaturated fatty acids and other immunonutrients such as arginine and glutamine was shown to be beneficial ${ }^{203,208,209}$. Direct inhibition of NFKBmediated proinflammatory signaling and modification of the pattern of diverse lipid mediators are supposed to underlie the immune-modulating effects of omega-3 fatty acids $^{210,211}$.

A different mechanism via which enteral nutrition regulates the inflammatory response is activation of the autonomic nervous system. The quantities of lipid-rich nutrition that attenuated inflammation via vagus nerve stimulation in rodent studies are small, consisting of as little as 10 energy percent of total rodent daily energy intake. Interestingly, De Bruin et al. reported on protective effects of dietary restriction in surgical settings, which is seemingly in discrepancy with the large body of literature favoring adequate caloric intake nutrition. In rodent models of renal and hepatic ischemia and reperfusion, benefits of restricted access to food and pre-operative fasting were described in comparison to a normal dietary intake $e^{212,213}$. Furthermore, in human live kidney donors, preoperative dietary restriction reduced the postoperative acute phase response ${ }^{214}$. To what extent alterations in the autonomic nervous system are involved in the reported benefits of dietary restriction remains to be investigated $^{215,216}$. Together, profound knowledge of the nutritional impact on the immune system and energy homeostasis is required to define the optimal dietary support in the individual patient. The additional value of lipid-rich nutrition as a physiological means to attenuate the immune response and promote intestinal health via stimulation of the autonomic nervous system in surgical and critical care settings is subject of the current thesis.

\section{Aims of this thesis}

Insight in the neuro-immune axis that is activated by enteral nutrition is a prerequisite to translate the experimental findings into clinical application and improve the design of future clinical trials. Therefore the first aim of this thesis is to increase the understanding of the afferent arm (part I) and efferent arm (part II) of the nutritioninduced vagal pathway. First, the involvement of afferent vagus fibers and the role of CCK and CCK-receptors is explored (chapter 2). Next, after investigating the presence of compromised gut wall integrity in man and rodents (chapter 3 and 4), the impact of 
nutritional vagus signaling on early loss of intestinal integrity during inflammation is assessed (chapter 5). Special attention is paid to nutritional regulation of mucosal mast cell activity (chapter 6).

A second aim of this thesis is to explore the therapeutic window of enriched nutrition in rodent models of trauma and sepsis (part III). To test the potential applicability in trauma patients, the efficacy of lipid-rich nutrition during ongoing inflammation and tissue damage is tested in a model of hemorrhagic shock (chapter 7). Next, the effects of nutritional intervention and the involvement of the vagal anti-inflammatory pathway are investigated on the acute inflammatory response and loss of organ integrity during acute hemolysis, Gram-negative sepsis and polymicrobial sepsis (chapter 8, 9 and 10 respectively). In addition, nutritional effects on the protracted phase of immunosuppression during sepsis are studied (chapter 10). The third aim of this thesis is to translate the experimental findings to a human setting of acute inflammation (part IV). The responses of circulatory CCK and vagus nerve activity to several nutritional compositions are measured to identify a suitable feeding for further human studies (chapter 11). Furthermore, the limitations of such surrogate parameters is discussed (chapter 12). Finally, in a proof-of-principle study, the antiinflammatory potential of enriched enteral nutrition is investigated in man (chapter 13). For this, a human endotoxemia model is used in which a bolus of endotoxin is administered to healthy volunteers. A custom-made lipid- and protein-enriched nutrition is administered postpylorically and effects on circulatory markers of acute inflammation are assessed. 


\section{References}

1. Kumar V, Abbas A, Fousto N. Robbins and Cotran Pathological Basis of Disease, 7th edn: Elsevier Saunders; 2005.

2. Medzhitov R. Origin and physiological roles of inflammation. Nature 2008;454:428-435.

3. Fauci AS, Braunwald E, Kasper DL, Hauser SL, Longo DL, Jameson JL, Loscalzo J. Harrison's Principles of Internal Medicine 17th edn. New York: McGraw-Hill Medical Publishing Division; 2008.

4. American College of Chest Physicians/Society of Critical Care Medicine Consensus Conference: definitions for sepsis and organ failure and guidelines for the use of innovative therapies in sepsis. Crit Care Med 1992;20:864-874.

5. Cohen J. The immunopathogenesis of sepsis. Nature 2002;420:885-891.

6. Benjamim CF, Hogaboam CM, Kunkel SL. The chronic consequences of severe sepsis. J Leukoc Biol 2004;75:408-412.

7. Angus DC, Linde-Zwirble WT, Lidicker J, Clermont G, Carcillo J, Pinsky MR. Epidemiology of severe sepsis in the United States: analysis of incidence, outcome, and associated costs of care. Crit Care Med 2001;29:1303-1310.

8. Dombrovskiy VY, Martin AA, Sunderram J, Paz HL. Rapid increase in hospitalization and mortality rates for severe sepsis in the United States: a trend analysis from 1993 to 2003. Crit Care Med 2007;35:1244-1250.

9. Russell JA. Management of sepsis. N Engl J Med 2006;355:1699-1713.

10. Chaplin DD. Overview of the immune response. J Allergy Clin Immunol 2010;125(2 Suppl 2):S3-23.

11. Matzinger P. Tolerance, danger, and the extended family. Annu Rev Immunol 1994;12:991-1045.

12. Bianchi ME. DAMPs, PAMPs and alarmins: all we need to know about danger. J Leukoc Biol 2007;81:1-5.

13. Adib-Conquy M, Cavaillon JM. Stress molecules in sepsis and systemic inflammatory response syndrome. FEBS Lett 2007;581:3723-3733.

14. Chang M, Kistler EB, Schmid-Schonbein GW. Disruption of the mucosal barrier during gut ischemia allows entry of digestive enzymes into the intestinal wall. Shock 2012;37:297-305.

15. Takeuchi O, Akira S. Pattern recognition receptors and inflammation. Cell;140:805-820.

16. Kumar $\mathrm{H}$, Kawai T, Akira S. Pathogen recognition by the innate immune system. Int Rev Immunol 2011;30:16-34.

17. Kawai T, Akira S. The role of pattern-recognition receptors in innate immunity: update on Toll-like receptors. Nat Immunol 2010;11:373-384.

18. Kubo M, Hanada T, Yoshimura A. Suppressors of cytokine signaling and immunity. Nat Immunol 2003; 4:1169-1176.

19. Schroder K, Tschopp J. The inflammasomes. Cell 2010;140:821-832.

20. Abraham SN, St John AL. Mast cell-orchestrated immunity to pathogens. Nat Rev Immunol 2010; 10:440-452.

21. Jonathan Brostoff DR, Ivan M. Roitt, David K. Male Immunology, 7th edn: Elsevier; 2010.

22. Eisenbarth SC, Flavell RA. Innate instruction of adaptive immunity revisited: the inflammasome. $E M B O$ Mol Med 2009;1:92-98.

23. Munford RS, Pugin J. Normal responses to injury prevent systemic inflammation and can be immunosuppressive. Am J Respir Crit Care Med 2001;163:316-321.

24. van der Poll T, Opal SM. Host-pathogen interactions in sepsis. Lancet Infect Dis 2008;8:32-43.

25. Tracey KJ, Beutler B, Lowry SF, Merryweather J, Wolpe S, Milsark IW, Hariri RJ, Fahey TJ, 3rd, Zentella A, Albert JD et al. Shock and tissue injury induced by recombinant human cachectin. Science 1986; 234:470-474.

26. Wang $\mathrm{H}$, Bloom $\mathrm{O}$, Zhang $\mathrm{M}$, Vishnubhakat JM, Ombrellino $\mathrm{M}$, Che J, Frazier A, Yang H, Ivanova S, Borovikova L et al. HMG-1 as a late mediator of endotoxin lethality in mice. Science 1999;285:248-251.

27. Altshuler AE, Penn AH, Yang JA, Kim GR, Schmid-Schonbein GW. Protease activity increases in plasma, peritoneal fluid, and vital organs after hemorrhagic shock in rats. PLoS One 2012;7:e32672.

28. Reddy RC, Chen GH, Tekchandani PK, Standiford TJ. Sepsis-induced immunosuppression: from bad to worse. Immunol Res 2001;24:273-287.

29. Hotchkiss RS, Karl IE. The pathophysiology and treatment of sepsis. N Engl J Med 2003;348:138-150. 
30. Adib-Conquy M, Cavaillon JM. Compensatory anti-inflammatory response syndrome. Thromb Haemost 2009;101:36-47.

31. Delano MJ, Thayer T, Gabrilovich S, Kelly-Scumpia KM, Winfield RD, Scumpia PO, Cuenca AG, Warner E, Wallet SM, Wallet MA et al. Sepsis induces early alterations in innate immunity that impact mortality to secondary infection. J Immunol 2011;186:195-202.

32. Couper KN, Blount DG, Riley EM. IL-10: the master regulator of immunity to infection. J Immunol 2008; 180:5771-5777.

33. Chang J, Kunkel SL, Chang CH. Negative regulation of MyD88-dependent signaling by IL-10 in dendritic cells. Proc Natl Acad Sci U S A 2009;106:18327-18332.

34. Flohe SB, Flohe S, Schade FU. Invited review: deterioration of the immune system after trauma: signals and cellular mechanisms. Innate Immun 2008;14:333-344.

35. Moser M, Murphy KM. Dendritic cell regulation of TH1-TH2 development. Nat Immunol 2000;1: 199-205.

36. Pastille E, Didovic S, Brauckmann D, Rani M, Agrawal H, Schade FU, Zhang Y, Flohe SB. Modulation of dendritic cell differentiation in the bone marrow mediates sustained immunosuppression after polymicrobial sepsis. J Immunol 2011;186:977-986.

37. Harbarth S, Holeckova K, Froidevaux C, Pittet D, Ricou B, Grau GE, Vadas L, Pugin J. Diagnostic value of procalcitonin, interleukin-6, and interleukin-8 in critically ill patients admitted with suspected sepsis. Am J Respir Crit Care Med 2001;164:396-402.

38. Carson WF, Cavassani KA, Dou Y, Kunkel SL. Epigenetic regulation of immune cell functions during post-septic immunosuppression. Epigenetics 2011;6: 273-283.

39. Osuchowski MF, Welch K, Siddiqui J, Remick DG. Circulating cytokine/inhibitor profiles reshape the understanding of the SIRS/CARS continuum in sepsis and predict mortality. J Immunol 2006; 177: 1967-1974.

40. Abraham E, Laterre PF, Garbino J, Pingleton S, Butler T, Dugernier T, Margolis B, Kudsk K, Zimmerli W, Anderson $\mathrm{P}$ et al. Lenercept (p55 tumor necrosis factor receptor fusion protein) in severe sepsis and early septic shock: a randomized, double-blind, placebo-controlled, multicenter phase III trial with 1,342 patients. Crit Care Med 2001;29:503-510.

41. Ziegler EJ, Fisher CJ, Jr., Sprung CL, Straube RC, Sadoff JC, Foulke GE, Wortel CH, Fink MP, Dellinger RP, Teng NN et al. Treatment of gram-negative bacteremia and septic shock with HA-1A human monoclonal antibody against endotoxin. A randomized, double-blind, placebo-controlled trial. The HA1A Sepsis Study Group. N Engl J Med 1991;324:429-436.

42. Abraham E, Wunderink R, Silverman H, Perl TM, Nasraway S, Levy H, Bone R, Wenzel RP, Balk R, Allred $R$ et al. Efficacy and safety of monoclonal antibody to human tumor necrosis factor alpha in patients with sepsis syndrome. A randomized, controlled, double-blind, multicenter clinical trial. TNF-alpha MAb Sepsis Study Group. JAMA 1995;273:934-941.

43. Fisher CJ, Jr., Dhainaut JF, Opal SM, Pribble JP, Balk RA, Slotman GJ, Iberti TJ, Rackow EC, Shapiro MJ, Greenman RL et al. Recombinant human interleukin 1 receptor antagonist in the treatment of patients with sepsis syndrome. Results from a randomized, double-blind, placebo-controlled trial. Phase III rhIL1ra Sepsis Syndrome Study Group. JAMA 1994;271:1836-1843.

44. Bernard GR, Wheeler AP, Russell JA, Schein R, Summer WR, Steinberg KP, Fulkerson WJ, Wright PE, Christman BW, Dupont WD et al. The effects of ibuprofen on the physiology and survival of patients with sepsis. The Ibuprofen in Sepsis Study Group. N Engl J Med 1997;336:912-918.

45. Fein AM, Bernard GR, Criner GJ, Fletcher EC, Good JT, Jr., Knaus WA, Levy H, Matuschak GM, Shanies $\mathrm{HM}$, Taylor RW et al. Treatment of severe systemic inflammatory response syndrome and sepsis with a novel bradykinin antagonist, deltibant (CP-0127). Results of a randomized, double-blind, placebocontrolled trial. CP-0127 SIRS and Sepsis Study Group. JAMA 1997;277:482-487.

46. Opal S, Laterre PF, Abraham E, Francois B, Wittebole X, Lowry S, Dhainaut JF, Warren B, Dugernier T, Lopez $A$ et al. Recombinant human platelet-activating factor acetylhydrolase for treatment of severe sepsis: results of a phase III, multicenter, randomized, double-blind, placebo-controlled, clinical trial. Crit Care Med 2004;32:332-341.

47. Poeze M, Froon AH, Ramsay G, Buurman WA, Greve JW. Decreased organ failure in patients with severe SIRS and septic shock treated with the platelet-activating factor antagonist TCV-309: a prospective, multicenter, double-blind, randomized phase II trial. TCV-309 Septic Shock Study Group. Shock 2000;14:421-428. 
48. Ulloa L, Tracey KJ. The "cytokine profile": a code for sepsis. Trends Mol Med 2005;11:56-63.

49. Abraham E. Why immunomodulatory therapies have not worked in sepsis. Intensive Care Med 1999; 25:556-566.

50. Lorente JA, Marshall JC. Neutralization of tumor necrosis factor in preclinical models of sepsis. Shock 2005;24 Suppl 1:107-119.

51. Rijneveld AW, Florquin S, Branger J, Speelman P, Van Deventer SJ, van der Poll T. TNF-alpha compensates for the impaired host defense of IL-1 type I receptor-deficient mice during pneumococcal pneumonia. J Immunol 2001;167:5240-5246.

52. Ventilation with lower tidal volumes as compared with traditional tidal volumes for acute lung injury and the acute respiratory distress syndrome. The Acute Respiratory Distress Syndrome Network. $N$ Engl J Med 2000, 342(18):1301-1308.

53. Rivers E, Nguyen B, Havstad S, Ressler J, Muzzin A, Knoblich B, Peterson E, Tomlanovich M. Early goaldirected therapy in the treatment of severe sepsis and septic shock. N Engl J Med 2001;345: 1368-1377.

54. Harbarth S, Garbino J, Pugin J, Romand JA, Lew D, Pittet D. Inappropriate initial antimicrobial therapy and its effect on survival in a clinical trial of immunomodulating therapy for severe sepsis. Am J Med 2003;115:529-535.

55. Marti-Carvajal A, Salanti G, Cardona AF. Human recombinant activated protein C for severe sepsis. Cochrane Database Syst Rev 2008:CD004388.

56. Griesdale DE, de Souza RJ, van Dam RM, Heyland DK, Cook DJ, Malhotra A, Dhaliwal R, Henderson WR, Chittock DR, Finfer $S$ et al. Intensive insulin therapy and mortality among critically ill patients: a metaanalysis including NICE-SUGAR study data. CMAJ 2009;180:821-827.

57. Holmes CL, Walley KR, Chittock DR, Lehman T, Russell JA. The effects of vasopressin on hemodynamics and renal function in severe septic shock: a case series. Intensive Care Med 2001;27:1416-1421.

58. Meisel C, Schefold JC, Pschowski R, Baumann T, Hetzger K, Gregor J, Weber-Carstens S, Hasper D, Keh $\mathrm{D}$, Zuckermann $\mathrm{H}$ et al. Granulocyte-macrophage colony-stimulating factor to reverse sepsis-associated immunosuppression: a double-blind, randomized, placebo-controlled multicenter trial. Am J Respir Crit Care Med 2009;180:640-648.

59. Docke WD, Randow F, Syrbe U, Krausch D, Asadullah K, Reinke P, Volk HD, Kox W. Monocyte deactivation in septic patients: restoration by IFN-gamma treatment. Nat Med 1997;3:678-681.

60. Hotchkiss RS, Nicholson DW. Apoptosis and caspases regulate death and inflammation in sepsis. Nat Rev Immunol 2006;6:813-822.

61. Slade E, Tamber PS, Vincent JL. The Surviving Sepsis Campaign: raising awareness to reduce mortality. Crit Care 2003;7:1-2.

62. Levy MM, Dellinger RP, Townsend SR, Linde-Zwirble WT, Marshall JC, Bion J, Schorr C, Artigas A, Ramsay G, Beale R et al. The Surviving Sepsis Campaign: results of an international guideline-based performance improvement program targeting severe sepsis. Crit Care Med 2010;38:367-374.

63. Shepherd AJ, Downing JE, Miyan JA. Without nerves, immunology remains incomplete -in vivo veritas. Immunology 2005;116:145-163.

64. Turnbull AV, Rivier CL. Regulation of the hypothalamic-pituitary-adrenal axis by cytokines: actions and mechanisms of action. Physiol Rev 1999;79:1-71.

65. Kumar V, Sharma A. Is neuroimmunomodulation a future therapeutic approach for sepsis? Int Immunopharmacol 2010;10:9-17.

66. Tracey KJ. Reflex control of immunity. Nat Rev Immunol 2009;9:418-428.

67. Guyon A, Massa F, Rovere C, Nahon JL. How cytokines can influence the brain: a role for chemokines? J Neuroimmunol 2008;198:46-55.

68. Sehic E, Blatteis CM. Blockade of lipopolysaccharide-induced fever by subdiaphragmatic vagotomy in guinea pigs. Brain Res 1996;726:160-166.

69. Goehler LE, Gaykema RP, Hansen MK, Anderson K, Maier SF, Watkins LR. Vagal immune-to-brain communication: a visceral chemosensory pathway. Auton Neurosci 2000, 85:49-59.

70. Watkins LR, Goehler LE, Relton JK, Tartaglia N, Silbert L, Martin D, Maier SF. Blockade of interleukin-1 induced hyperthermia by subdiaphragmatic vagotomy: evidence for vagal mediation of immune-brain communication. Neurosci Lett 1995;183:27-31. 
71. Fleshner M, Goehler LE, Schwartz BA, McGorry M, Martin D, Maier SF, Watkins LR. Thermogenic and corticosterone responses to intravenous cytokines (IL-1beta and TNF-alpha) are attenuated by subdiaphragmatic vagotomy. J Neuroimmunol 1998;86:134-141.

72. Goehler LE, Gaykema RP, Hammack SE, Maier SF, Watkins LR. Interleukin-1 induces c-Fos immunoreactivity in primary afferent neurons of the vagus nerve. Brain Res 1998;804:306-310.

73. Hosoi T, Okuma Y, Matsuda T, Nomura Y. Novel pathway for LPS-induced afferent vagus nerve activation: possible role of nodose ganglion. Auton Neurosci 2005;120:104-107.

74. Rosas-Ballina M, Tracey KJ. Cholinergic control of inflammation. J Intern Med 2009;265:663-679.

75. Watkins LR, Maier SF: Implications of immune-to-brain communication for sickness and pain. Proc Natl Acad Sci U S A 1999;96:7710-7713.

76. John CD, Buckingham JC. Cytokines: regulation of the hypothalamo-pituitary-adrenocortical axis. Curr Opin Pharmacol 2003;3:78-84.

77. Barnes SJ, Ackland GL. Beta-adrenoreceptor modulation of metabolic, endocrine and immunologic function during critical illness. Endocr Metab Immune Disord Drug Targets 2010;10:292-300.

78. Zhang F, Wu R, Qiang X, Zhou M, Wang P. Antagonism of alpha2A-adrenoceptor: a novel approach to inhibit inflammatory responses in sepsis. J Mol Med 2010;88:289-296.

79. Borovikova LV, Ivanova S, Zhang M, Yang H, Botchkina GI, Watkins LR, Wang H, Abumrad N, Eaton JW, Tracey KJ. Vagus nerve stimulation attenuates the systemic inflammatory response to endotoxin. Nature 2000;405:458-462.

80. Wang H, Yu M, Ochani M, Amella CA, Tanovic M, Susarla S, Li JH, Yang H, Ulloa L, Al-Abed Y et al. Nicotinic acetylcholine receptor alpha7 subunit is an essential regulator of inflammation. Nature 2003; 421:384-388.

81. Pavlov VA, Ochani M, Yang LH, Gallowitsch-Puerta M, Ochani K, Lin X, Levi J, Parrish WR, Rosas-Ballina $\mathrm{M}, \mathrm{Czura} \mathrm{CJ}$ et al. Selective alpha7-nicotinic acetylcholine receptor agonist GTS-21 improves survival in murine endotoxemia and severe sepsis. Crit Care Med 2007;35(4):1139-1144.

82. Rosas-Ballina M, Goldstein RS, Gallowitsch-Puerta M, Yang L, Valdes-Ferrer SI, Patel NB, Chavan S, AlAbed Y, Yang H, Tracey KJ. The selective alpha7 agonist GTS-21 attenuates cytokine production in human whole blood and human monocytes activated by ligands for TLR2, TLR3, TLR4, TLR9, and RAGE. Mol Med 2009;15:195-202.

83. Guarini S, Altavilla D, Cainazzo MM, Giuliani D, Bigiani A, Marini H, Squadrito G, Minutoli L, Bertolini A, Marini $R$ et al. Efferent vagal fibre stimulation blunts nuclear factor-kappaB activation and protects against hypovolemic hemorrhagic shock. Circulation 2003;107:1189-1194.

84. de Jonge WJ, van der Zanden EP, The FO, Bijlsma MF, van Westerloo DJ, Bennink RJ, Berthoud HR, Uematsu S, Akira S, van den Wijngaard RM et al. Stimulation of the vagus nerve attenuates macrophage activation by activating the Jak2-STAT3 signaling pathway. Nat Immunol 2005;6(8):844851.

85. Zanden EP, Snoek SA, Heinsbroek SE, Stanisor OI, Verseijden C, Boeckxstaens GE, Peppelenbosch MP, Greaves DR, Gordon S, de Jonge WJ. Vagus nerve activity augments intestinal macrophage phagocytosis via nicotinic acetylcholine receptor alpha4beta2. Gastroenterology 2009;137:1029-1039.

86. Pavlov VA, Ochani M, Gallowitsch-Puerta M, Ochani K, Huston JM, Czura CJ, Al-Abed Y, Tracey KJ. Central muscarinic cholinergic regulation of the systemic inflammatory response during endotoxemia. Proc Natl Acad Sci U S A 2006;103:5219-5223.

87. Huang $\mathrm{H}$, Lavoie-Lamoureux A, Lavoie JP. Cholinergic stimulation attenuates the IL-4 induced expression of E-selectin and vascular endothelial growth factor by equine pulmonary artery endothelial cells. Vet Immunol Immunopathol 2009;132:116-121.

88. Nomura J, Hosoi T, Okuma Y, Nomura Y. The presence and functions of muscarinic receptors in human T cells: the involvement in IL-2 and IL-2 receptor system. Life Sci 2003;72:2121-2126.

89. Koyama S, Rennard SI, Robbins RA. Acetylcholine stimulates bronchial epithelial cells to release neutrophil and monocyte chemotactic activity. Am J Physiol 1992;262:L466-471.

90. Rosas-Ballina M, Ochani M, Parrish WR, Ochani K, Harris YT, Huston JM, Chavan S, Tracey KJ. Splenic nerve is required for cholinergic antiinflammatory pathway control of TNF in endotoxemia. Proc Natl Acad Sci U S A 2008;105:11008-11013.

91. Huston JM, Ochani M, Rosas-Ballina M, Liao H, Ochani K, Pavlov VA, Gallowitsch-Puerta M, Ashok M, Czura CJ, Foxwell B et al. Splenectomy inactivates the cholinergic antiinflammatory pathway during lethal endotoxemia and polymicrobial sepsis. J Exp Med 2006;203:1623-1628. 
92. Tracey KJ. Understanding immunity requires more than immunology. Nat Immunol 2010;11:561-564.

93. van Maanen MA, Lebre MC, van der Poll T, LaRosa GJ, Elbaum D, Vervoordeldonk MJ, Tak PP. Stimulation of nicotinic acetylcholine receptors attenuates collagen-induced arthritis in mice. Arthritis Rheum 2009;60:114-122.

94. van Westerloo DJ, Giebelen IA, Florquin S, Bruno MJ, Larosa GJ, Ulloa L, Tracey KJ, van der Poll T. The vagus nerve and nicotinic receptors modulate experimental pancreatitis severity in mice. Gastroenterology 2006;130:1822-1830.

95. Bai A, Guo Y, Lu N. The effect of the cholinergic anti-inflammatory pathway on experimental colitis. Scand J Immunol 2007;66:538-545.

96. The FO, Boeckxstaens GE, Snoek SA, Cash JL, Bennink R, Larosa GJ, van den Wijngaard RM, Greaves DR, de Jonge WJ. Activation of the cholinergic anti-inflammatory pathway ameliorates postoperative ileus in mice. Gastroenterology 2007;133:1219-1228.

97. Czura CJ, Schultz A, Kaipel M, Khadem A, Huston JM, Pavlov VA, Redl H, Tracey KJ. Vagus nerve stimulation regulates hemostasis in swine. Shock 2010;33:608-613.

98. Tracey KJ. The inflammatory reflex. Nature 2002;420:853-859.

99. Oke SL, Tracey KJ. The inflammatory reflex and the role of complementary and alternative medical therapies. Ann N Y Acad Sci 2009;1172:172-180.

100. Sloan RP, McCreath H, Tracey KJ, Sidney S, Liu K, Seeman T. RR interval variability is inversely related to inflammatory markers: the CARDIA study. Mol Med 2007;13:178-184.

101. Thayer JF, Fischer JE. Heart rate variability, overnight urinary norepinephrine and C-reactive protein: evidence for the cholinergic anti-inflammatory pathway in healthy human adults. J Intern Med 2009; 265:439-447.

102. La Rovere MT, Bigger JT, Jr., Marcus FI, Mortara A, Schwartz PJ. Baroreflex sensitivity and heart-rate variability in prediction of total cardiac mortality after myocardial infarction. ATRAMI (Autonomic Tone and Reflexes After Myocardial Infarction) Investigators. Lancet 1998;351:478-484.

103. Schmidt H, Muller-Werdan U, Hoffmann T, Francis DP, Piepoli MF, Rauchhaus M, Prondzinsky R, Loppnow H, Buerke M, Hoyer D et al. Autonomic dysfunction predicts mortality in patients with multiple organ dysfunction syndrome of different age groups. Crit Care Med 2005;33:1994-2002.

104. Sharma P, Makharia GK, Ahuja V, Dwivedi SN, Deepak KK. Autonomic dysfunctions in patients with inflammatory bowel disease in clinical remission. Dig Dis Sci 2009;54:853-861.

105. Stojanovich L, Milovanovich B, de Luka SR, Popovich-Kuzmanovich D, Bisenich V, Djukanovich B, Randjelovich T, Krotin M. Cardiovascular autonomic dysfunction in systemic lupus, rheumatoid arthritis, primary Sjogren syndrome and other autoimmune diseases. Lupus 2007;16:181-185.

106. Bruchfeld A, Goldstein RS, Chavan S, Patel NB, Rosas-Ballina M, Kohn N, Qureshi AR, Tracey KJ. Whole blood cytokine attenuation by cholinergic agonists ex vivo and relationship to vagus nerve activity in rheumatoid arthritis. J Intern Med 2010;268:94-101.

107. Garrard CS, Kontoyannis DA, Piepoli M. Spectral analysis of heart rate variability in the sepsis syndrome. Clin Auton Res 1993;3:5-13.

108. Aydemir M, Yazisiz V, Basarici I, Avci AB, Erbasan F, Belgi A, Terzioglu E. Cardiac autonomic profile in rheumatoid arthritis and systemic lupus erythematosus. Lupus 2010;19:255-261.

109. Luyer M, Greve JW, de Haan J, Lubbers T, Buurman W. Are we finally taming inflammation? Crit Care Med 2007;35:2003-2004.

110. Huston JM, Gallowitsch-Puerta M, Ochani M, Ochani K, Yuan R, Rosas-Ballina M, Ashok M, Goldstein RS, Chavan S, Pavlov VA et al. Transcutaneous vagus nerve stimulation reduces serum high mobility group box 1 levels and improves survival in murine sepsis. Crit Care Med 2007;35:2762-2768.

111. Snoek SA, Verstege MI, van der Zanden EP, Deeks N, Bulmer DC, Skynner M, Lee K, Te Velde AA, Boeckxstaens GE, de Jonge WJ. Selective alpha7 nicotinic acetylcholine receptor agonists worsen disease in experimental colitis. Br J Pharmacol 2010;160:322-333.

112. Vreugdenhil AC, Rousseau CH, Hartung $\mathrm{T}$, Greve JW, van 't Veer C, Buurman WA. Lipopolysaccharide (LPS)-binding protein mediates LPS detoxification by chylomicrons. J Immunol 2003;170:1399-1405.

113. Luyer MD, Jacobs JA, Vreugdenhil AC, Hadfoune $M$, Dejong $C H$, Buurman WA, Greve JW. Enteral administration of high-fat nutrition before and directly after hemorrhagic shock reduces endotoxemia and bacterial translocation. Ann Surg 2004;239:257-264. 
114. Luyer MD, Buurman WA, Hadfoune M, Jacobs JA, Konstantinov SR, Dejong CH, Greve JW. Pretreatment with high-fat enteral nutrition reduces endotoxin and tumor necrosis factor-alpha and preserves gut barrier function early after hemorrhagic shock. Shock 2004;21:65-71.

115. Luyer MD, Derikx JP, Beyaert R, Hadfoune M, van Kuppevelt TH, Dejong CH, Heineman E, Buurman WA, Greve JW. High-fat nutrition reduces hepatic damage following exposure to bacterial DNA and hemorrhagic shock. J Hepatol 2009;50:342-350.

116. Luyer MD, Greve JW, Hadfoune M, Jacobs JA, Dejong CH, Buurman WA. Nutritional stimulation of cholecystokinin receptors inhibits inflammation via the vagus nerve. J Exp Med 2005;202:1023-1029.

117. Cummings DE, Overduin J. Gastrointestinal regulation of food intake. J Clin Invest 2007;117:13-23.

118. Berthoud HR. Vagal and hormonal gut-brain communication: from satiation to satisfaction. Neurogastroenterol Motil 2008;20 Suppl 1:64-72.

119. Woods SC. Gastrointestinal satiety signals I. An overview of gastrointestinal signals that influence food intake. Am J Physiol Gastrointest Liver Physiol 2004;286:G7-13.

120. Chandrashekar J, Hoon MA, Ryba NJ, Zuker CS. The receptors and cells for mammalian taste. Nature 2006;444:288-294.

121. Power ML, Schulkin J. Anticipatory physiological regulation in feeding biology: cephalic phase responses. Appetite 2008;50:194-206.

122. Zafra MA, Molina F, Puerto A. The neural/cephalic phase reflexes in the physiology of nutrition. Neurosci Biobehav Rev 2006;30:1032-1044.

123. Ritter RC. Gastrointestinal mechanisms of satiation for food. Physiol Behav 2004;81:249-273.

124. Phillips RJ, Powley TL. Tension and stretch receptors in gastrointestinal smooth muscle: re-evaluating vagal mechanoreceptor electrophysiology. Brain Res Brain Res Rev 2000;34:1-26.

125. Powley TL, Phillips RJ. Gastric satiation is volumetric, intestinal satiation is nutritive. Physiol Behav 2004;82:69-74.

126. Glatzle J, Wang Y, Adelson DW, Kalogeris TJ, Zittel TT, Tso P, Wei JY, Raybould HE. Chylomicron components activate duodenal vagal afferents via a cholecystokinin A receptor-mediated pathway to inhibit gastric motor function in the rat. J Physiol 2003;550:657-664.

127. Rehfeld JF. Clinical endocrinology and metabolism. Cholecystokinin. Best Pract Res Clin Endocrinol Metab 2004;18:569-586.

128. Kissileff HR, Pi-Sunyer FX, Thornton J, Smith GP. C-terminal octapeptide of cholecystokinin decreases food intake in man. Am J Clin Nutr 1981;34:154-160.

129. Kopin AS, Mathes WF, McBride EW, Nguyen M, Al-Haider W, Schmitz F, Bonner-Weir S, Kanarek R, Beinborn $M$. The cholecystokinin-A receptor mediates inhibition of food intake yet is not essential for the maintenance of body weight. J Clin Invest 1999;103:383-391.

130. Moran TH, Kinzig KP. Gastrointestinal satiety signals II. Cholecystokinin. Am J Physiol Gastrointest Liver Physiol 2004;286:G183-188.

131. Moran TH, Baldessarini AR, Salorio CF, Lowery T, Schwartz GJ. Vagal afferent and efferent contributions to the inhibition of food intake by cholecystokinin. Am J Physiol 1997;272:R1245-1251.

132. Lal S, Kirkup AJ, Brunsden AM, Thompson DG, Grundy D. Vagal afferent responses to fatty acids of different chain length in the rat. Am J Physiol Gastrointest Liver Physiol 2001;281:G907-915.

133. Cheung GW, Kokorovic A, Lam CK, Chari M, Lam TK. Intestinal cholecystokinin controls glucose production through a neuronal network. Cell Metab 2009;10:99-109.

134. Edwards GL, Ladenheim EE, Ritter RC. Dorsomedial hindbrain participation in cholecystokinin-induced satiety. Am J Physiol 1986;251:R971-977.

135. Blevins JE, Stanley BG, Reidelberger RD. Brain regions where cholecystokinin suppresses feeding in rats. Brain Res 2000;860:1-10.

136. Baptista V, Browning KN, Travagli RA. Effects of cholecystokinin-8s in the nucleus tractus solitarius of vagally deafferented rats. Am J Physiol Regul Integr Comp Physiol 2007;292:R1092-1100.

137. Dockray GJ. The versatility of the vagus. Physiol Behav 2009;97:531-536.

138. Beglinger S, Drewe J, Schirra J, Goke B, D'Amato M, Beglinger C. Role of fat hydrolysis in regulating glucagon-like Peptide-1 secretion. J Clin Endocrinol Metab 2010;95:879-886.

139. Degen L, Drewe J, Piccoli F, Grani K, Oesch S, Bunea R, D'Amato M, Beglinger C. Effect of CCK-1 receptor blockade on ghrelin and PYY secretion in men. Am J Physiol Regul Integr Comp Physiol 2007; 292:R1391-1399. 
140. Maljaars PW, Peters HP, Mela DJ, Masclee AA. Ileal brake: a sensible food target for appetite control. A review. Physiol Behav 2008, 95(3):271-281.

141. Mundinger TO, Cummings DE, Taborsky GJ, Jr.. Direct stimulation of ghrelin secretion by sympathetic nerves. Endocrinology 2006, 147(6):2893-2901.

142. Cummings DE, Foster-Schubert KE, Overduin J. Ghrelin and energy balance: focus on current controversies. Curr Drug Targets 2005, 6(2):153-169.

143. Date Y, Murakami N, Toshinai K, Matsukura S, Niijima A, Matsuo H, Kangawa K, Nakazato M. The role of the gastric afferent vagal nerve in ghrelin-induced feeding and growth hormone secretion in rats. Gastroenterology 2002, 123(4):1120-1128.

144. Smeets PA, Erkner A, de Graaf C. Cephalic phase responses and appetite. Nutr Rev 2010;68:643-655.

145. Bray GA. Afferent signals regulating food intake. Proc Nutr Soc 2000;59:373-384.

146. Stead RH, Dixon MF, Bramwell NH, Riddell RH, Bienenstock J. Mast cells are closely apposed to nerves in the human gastrointestinal mucosa. Gastroenterology 1989;97:575-585.

147. MacQueen G, Marshall J, Perdue M, Siegel S, Bienenstock J. Pavlovian conditioning of rat mucosal mast cells to secrete rat mast cell protease II. Science 1989;243:83-85.

148. Wilmore DW, Smith RJ, O'Dwyer ST, Jacobs DO, Ziegler TR, Wang XD. The gut: a central organ after surgical stress. Surgery 1988;104:917-923.

149. Moore FA. The role of the gastrointestinal tract in postinjury multiple organ failure. Am J Surg 1999; 178:449-453.

150. Rowlands BJ, Soong CV, Gardiner KR. The gastrointestinal tract as a barrier in sepsis. Br Med Bull 1999; 55:196-211.

151. Rotstein OD. Pathogenesis of multiple organ dysfunction syndrome: gut origin, protection, and decontamination. Surg Infect (Larchmt) 2000;1:217-223.

152. Carrico CJ, Meakins JL, Marshall JC, Fry D, Maier RV. Multiple-organ-failure syndrome. Arch Surg 1986; 121:196-208.

153. MacFie J, O'Boyle C, Mitchell CJ, Buckley PM, Johnstone D, Sudworth P. Gut origin of sepsis: a prospective study investigating associations between bacterial translocation, gastric microflora, and septic morbidity. Gut 1999;45:223-228.

154. Sambol JT, Xu DZ, Adams CA, Magnotti $\amalg$, Deitch EA. Mesenteric lymph duct ligation provides long term protection against hemorrhagic shock-induced lung injury. Shock 2000;14:416-419.

155. Sambol JT, Lee MA, Caputo FJ, Kawai K, Badami C, Kawai T, Deitch EA, Yatani A. Mesenteric lymph duct ligation prevents trauma/hemorrhage shock-induced cardiac contractile dysfunction. J Appl Physiol 2009;106:57-65.

156. Glatzle J, Kasparek MS, Mueller MH, Binder F, Meile T, Kreis ME, Konigsrainer A, Steurer W. Enteral immunonutrition during sepsis prevents pulmonary dysfunction in a rat model. J Gastrointest Surg 2007;11:719-724.

157. Su L, Shen L, Clayburgh DR, Nalle SC, Sullivan EA, Meddings JB, Abraham C, Turner JR. Targeted epithelial tight junction dysfunction causes immune activation and contributes to development of experimental colitis. Gastroenterology 2009;136:551-563.

158. Olson TS, Reuter BK, Scott KG, Morris MA, Wang XM, Hancock LN, Burcin TL, Cohn SM, Ernst PB, Cominelli $\mathrm{F}$ et al. The primary defect in experimental ileitis originates from a nonhematopoietic source. J Exp Med 2006;203:541-552.

159. Laukoetter MG, Nava P, Lee WY, Severson EA, Capaldo CT, Babbin BA, Williams IR, Koval M, Peatman E, Campbell JA et al. JAM-A regulates permeability and inflammation in the intestine in vivo. J Exp Med 2007;204:3067-3076.

160. Clark JA, Gan H, Samocha AJ, Fox AC, Buchman TG, Coopersmith CM. Enterocyte-specific epidermal growth factor prevents barrier dysfunction and improves mortality in murine peritonitis. Am J Physiol Gastrointest Liver Physiol 2009;297:G471-479.

161. Wu L, Zaborina O, Zaborin A, Chang EB, Musch M, Holbrook C, Shapiro J, Turner JR, Wu G, Lee KY et al. High-molecular-weight polyethylene glycol prevents lethal sepsis due to intestinal Pseudomonas aeruginosa. Gastroenterology 2004;126:488-498.

162. Mitsuoka H, Kistler EB, Schmid-Schonbein GW. Generation of in vivo activating factors in the ischemic intestine by pancreatic enzymes. Proc Natl Acad Sci U S A 2000;97:1772-1777. 
163. Cohen DB, Magnotti L, Lu Q, Xu DZ, Berezina TL, Zaets SB, Alvarez C, Machiedo G, Deitch EA. Pancreatic duct ligation reduces lung injury following trauma and hemorrhagic shock. Ann Surg 2004; 240:885-891.

164. Ewaschuk J, Endersby R, Thiel D, Diaz H, Backer J, Ma M, Churchill T, Madsen K. Probiotic bacteria prevent hepatic damage and maintain colonic barrier function in a mouse model of sepsis. Hepatology 2007; 46:841-850.

165. Silvestri L, van Saene HK, Zandstra DF, Marshall JC, Gregori D, Gullo A. Impact of selective decontamination of the digestive tract on multiple organ dysfunction syndrome: systematic review of randomized controlled trials. Crit Care Med 2010;38:1370-1376.

166. Reed RL. Prevention of hospital-acquired infections by selective digestive decontamination. Surg Infect (Larchmt) 2011;12:221-229.

167. Garrett WS, Gordon JI, Glimcher LH. Homeostasis and inflammation in the intestine. Cell 2010; 140:859-870.

168. Turner JR. Intestinal mucosal barrier function in health and disease. Nat Rev Immunol 2009;9:799-809.

169. Fink MP, Delude RL. Epithelial barrier dysfunction: a unifying theme to explain the pathogenesis of multiple organ dysfunction at the cellular level. Crit Care Clin 2005;21:177-196.

170. Gribar SC, Anand RJ, Sodhi CP, Hackam DJ. The role of epithelial Toll-like receptor signaling in the pathogenesis of intestinal inflammation. J Leukoc Biol 2008;83:493-498.

171. Kim YS, Ho SB. Intestinal goblet cells and mucins in health and disease: recent insights and progress. Curr Gastroenterol Rep 2010;12:319-330.

172. Vaishnava S, Behrendt CL, Ismail AS, Eckmann L, Hooper LV. Paneth cells directly sense gut commensals and maintain homeostasis at the intestinal host-microbial interface. Proc Natl Acad Sci U S A 2008;105:20858-20863.

173. Palazzo M, Balsari A, Rossini A, Selleri S, Calcaterra C, Gariboldi S, Zanobbio L, Arnaboldi F, Shirai YF, Serrao $\mathrm{G}$ et al. Activation of enteroendocrine cells via TLRs induces hormone, chemokine, and defensin secretion. J Immunol 2007;178:4296-4303.

174. Fasano A. Zonulin and its regulation of intestinal barrier function: the biological door to inflammation, autoimmunity, and cancer. Physiol Rev 2011;91:151-175.

175. Brandtzaeg P. Update on mucosal immunoglobulin A in gastrointestinal disease. Curr Opin Gastroenterol 2010;26:554-563.

176. Tamion F, Richard V, Sauger F, Menard JF, Girault C, Richard JC, Thuillez C, Leroy J, Bonmarchand G. Gastric mucosal acidosis and cytokine release in patients with septic shock. Crit Care Med 2003; 31:2137-2143.

177. Derikx JP, Poeze M, van Bijnen AA, Buurman WA, Heineman E. Evidence for intestinal and liver epithelial cell injury in the early phase of sepsis. Shock 2007;28:544-548.

178. Derikx JP, van Waardenburg DA, Thuijls G, Willigers HM, Koenraads M, van Bijnen AA, Heineman E, Poeze M, Ambergen T, van Ooij A et al. New Insight in Loss of Gut Barrier during Major Non-Abdominal Surgery. PLoS One 2008;3:e3954.

179. Ceppa EP, Fuh KC, Bulkley GB. Mesenteric hemodynamic response to circulatory shock. Curr Opin Crit Care 2003;9:127-132.

180. Matheson PJ, Wilson MA, Garrison RN. Regulation of intestinal blood flow. J Surg Res 2000;93: 182-196.

181. Kirton OC, Windsor J, Wedderburn R, Hudson-Civetta J, Shatz DV, Mataragas NR, Civetta JM. Failure of splanchnic resuscitation in the acutely injured trauma patient correlates with multiple organ system failure and length of stay in the ICU. Chest 1998;113:1064-1069.

182. van de Poll MC, Derikx JP, Buurman WA, Peters WH, Roelofs HM, Wigmore SJ, Dejong CH. Liver manipulation causes hepatocyte injury and precedes systemic inflammation in patients undergoing liver resection. World J Surg 2007;31:2033-2038.

183. Derikx JP, Bijker EM, Vos GD, van Bijnen AA, Heineman E, Buurman WA, van Waardenburg DA. Gut mucosal cell damage in meningococcal sepsis in children: relation with clinical outcome. Crit Care Med 2010;38:133-137.

184. Messick WJ, Koruda M, Meyer A, Zimmerman K. Differential changes in intestinal permeability following burn injury. J Trauma 1994;36:306-311. 
185. Ascione R, Talpahewa S, Rajakaruna C, Reeves BC, Lovell AT, Cohen A, Angelini GD. Splanchnic organ injury during coronary surgery with or without cardiopulmonary bypass: a randomized, controlled trial. Ann Thorac Surg 2006;81(1):97-103.

186. Hietbrink F, Besselink MG, Renooij W, de Smet MB, Draisma A, van der Hoeven H, Pickkers P. Systemic inflammation increases intestinal permeability during experimental human endotoxemia. Shock 2009; 32:374-378.

187. Besselink MG, van Santvoort HC, Renooij W, de Smet MB, Boermeester MA, Fischer K, Timmerman HM, Ahmed Ali U, Cirkel GA, Bollen TL et al. Intestinal barrier dysfunction in a randomized trial of a specific probiotic composition in acute pancreatitis. Ann Surg 2009;250:712-719.

188. Schwartz N, Hosford M, Sandoval RM, Wagner MC, Atkinson SJ, Bamburg J, Molitoris BA. Ischemia activates actin depolymerizing factor: role in proximal tubule microvillar actin alterations. Am J Physiol 1999;276:F544-551.

189. Theriot JA. Accelerating on a treadmill: ADF/cofilin promotes rapid actin filament turnover in the dynamic cytoskeleton. J Cell Biol 1997;136:1165-1168.

190. Theoharides TC, Kempuraj D, Tagen M, Conti P, Kalogeromitros D. Differential release of mast cell mediators and the pathogenesis of inflammation. Immunol Rev 2007;217:65-78.

191. Grootjans J, Hodin CM, de Haan JJ, Derikx JP, Rouschop KM, Verheyen FK, van Dam RM, Dejong CH, Buurman WA, Lenaerts K. Level of activation of the unfolded protein response correlates with Paneth cell apoptosis in human small intestine exposed to ischemia/reperfusion. Gastroenterology 2011; 140:529-539 e523.

192. Scudamore CL, Thornton EM, McMillan L, Newlands GF, Miller HR. Release of the mucosal mast cell granule chymase, rat mast cell protease-II, during anaphylaxis is associated with the rapid development of paracellular permeability to macromolecules in rat jejunum. J Exp Med 1995; 182:1871-1881.

193. Jacob C, Yang PC, Darmoul D, Amadesi S, Saito T, Cottrell GS, Coelho AM, Singh P, Grady EF, Perdue M et al. Mast cell tryptase controls paracellular permeability of the intestine. Role of protease-activated receptor 2 and beta-arrestins. J Biol Chem 2005;280:31936-31948.

194. Dawicki W, Marshall JS. New and emerging roles for mast cells in host defence. Curr Opin Immunol 2007;19:31-38.

195. Grootjans J, Thuijls G, Derikx JP, van Dam RM, Dejong CH, Buurman WA. Rapid lamina propria retraction and zipper-like constriction of the epithelium preserves the epithelial lining in human small intestine exposed to ischaemia-reperfusion. J Pathol 2011;224:411-419.

196. Matthijsen RA, Derikx JP, Kuipers D, van Dam RM, Dejong CH, Buurman WA. Enterocyte shedding and epithelial lining repair following ischemia of the human small intestine attenuate inflammation. PLoS One 2009;4:e7045.

197. Soeters PB, Luyer MD, Greve JW, Buurman WA. The significance of bowel permeability. Curr Opin Clin Nutr Metab Care 2007;10:632-638.

198. Clark JA, Coopersmith CM. Intestinal crosstalk: a new paradigm for understanding the gut as the "motor" of critical illness. Shock 2007;28:384-393.

199. Correia MI, Waitzberg DL. The impact of malnutrition on morbidity, mortality, length of hospital stay and costs evaluated through a multivariate model analysis. Clin Nutr 2003;22:235-239.

200. Elke G, Schadler D, Engel C, Bogatsch H, Frerichs I, Ragaller M, Scholz J, Brunkhorst FM, Loffler M, Reinhart $\mathrm{K}$ et al. Current practice in nutritional support and its association with mortality in septic patients--results from a national, prospective, multicenter study. Crit Care Med 2008;36:1762-1767.

201. Kreymann KG, Berger MM, Deutz NE, Hiesmayr M, Jolliet $P$, Kazandjiev G, Nitenberg G, van den Berghe G, Wernerman J, Ebner C et al. ESPEN Guidelines on Enteral Nutrition: Intensive care. Clin Nutr 2006; 25:210-223.

202. Soreide $E$, Ljungqvist $O$. Modern preoperative fasting guidelines: a summary of the present recommendations and remaining questions. Best Pract Res Clin Anaesthesiol 2006;20:483-491.

203. Martindale RG, McClave SA, Vanek VW, McCarthy M, Roberts P, Taylor B, Ochoa JB, Napolitano L, Cresci G. Guidelines for the provision and assessment of nutrition support therapy in the adult critically ill patient: Society of Critical Care Medicine and American Society for Parenteral and Enteral Nutrition: Executive Summary. Crit Care Med 2009;37:1757-1761.

204. Tappenden KA. Mechanisms of enteral nutrient-enhanced intestinal adaptation. Gastroenterology 2006;130(2 Suppl 1):S93-99. 
205. Wang PY, Caspi L, Lam CK, Chari M, Li X, Light PE, Gutierrez-Juarez R, Ang M, Schwartz GJ, Lam TK. Upper intestinal lipids trigger a gut-brain-liver axis to regulate glucose production. Nature 2008, 452:1012-1016.

206. Chandra R, Liddle RA. Cholecystokinin. Curr Opin Endocrinol Diabetes Obes 2007;14:63-67.

207. Matarese G, Moschos S, Mantzoros CS. Leptin in immunology. J Immunol 2005;174:3137-3142.

208. Cerantola Y, Hubner M, Grass F, Demartines N, Schafer M: Immunonutrition in gastrointestinal surgery. Br J Surg 2011;98:37-48.

209. Marik PE, Zaloga GP. Immunonutrition in critically ill patients: a systematic review and analysis of the literature. Intensive Care Med 2008;34:1980-1990.

210. Pontes-Arruda A, Martins LF, de Lima SM, Isola AM, Toledo D, Rezende E, Maia M, Magnan GB. Enteral nutrition with eicosapentaenoic acid, gamma-linolenic acid and antioxidants in the early treatment of sepsis: results from a multicenter, prospective, randomized, double-blinded, controlled study: the INTERSEPT study. Crit Care 2011;15:R144.

211. Wendel M, Paul R, Heller AR. Lipoproteins in inflammation and sepsis. II. Clinical aspects. Intensive Care Med 2007;33:25-35.

212. Verweij M, van Ginhoven TM, Mitchell JR, Sluiter W, van den Engel S, Roest HP, Torabi E, ljzermans JN, Hoeijmakers JH, de Bruin RW. Preoperative fasting protects mice against hepatic ischemia/reperfusion injury: mechanisms and effects on liver regeneration. Liver Transp/ 2011;17:695-704.

213. Mitchell JR, Verweij M, Brand K, van de Ven M, Goemaere N, van den Engel S, Chu T, Forrer F, Muller $\mathrm{C}$, de Jong $\mathrm{M}$ et al. Short-term dietary restriction and fasting precondition against ischemia reperfusion injury in mice. Aging Cell 2010;9:40-53.

214. van Ginhoven TM, Dik WA, Mitchell JR, Smits-te Nijenhuis MA, van Holten-Neelen C, Hooijkaas $H$, Hoeijmakers JH, de Bruin RW, Ijzermans JN. Dietary restriction modifies certain aspects of the postoperative acute phase response. J Surg Res 2011;171:582-589.

215. Van Ginhoven TM, Van Den Berg JW, Dik WA, ljzermans JN, De Bruin RW. Preoperative fasting induces protection against renal ischemia/reperfusion injury by a corticosterone-independent mechanism. Transpl Int 2010;23:1171-1178.

216. van Ginhoven TM, Huisman TM, van den Berg JW, ljzermans JN, Delhanty PJ, de Bruin RW. Preoperative fasting induced protection against renal ischemia/reperfusion injury is independent of ghrelin in mice. Nutr Res 2010;30:865-869. 


\section{Part I}

The afferent arm of the nutritional anti-inflammatory reflex 


\section{CHAPTER 2}

\section{Cholecystokinin/cholecystokinin-1 receptor-}

mediated peripheral activation of the afferent vagus

by enteral nutrients attenuates inflammation in rats

Tim Lubbers, Jacco J. de Haan, Misha D. Luyer, Isabelle Verbaeys, M'hamed Hadfoune, Cornelis H. Dejong, Wim A. Buurman, Jan-Willem M. Greve 


\section{Abstract}

Introduction: Enteral nutrition activates humoral and neural pathways to regulate food intake and sustain energy balance. Recently, we demonstrated that enteral nutrition and in particular lipid-rich nutrition modulates inflammation and prevents organ damage. The current study investigates activation of the nutritional antiinflammatory pathway by lipid-rich nutrition.

Methods: Male rats were fasted or fed lipid-rich nutrition prior to hemorrhagic shock. Disruption of afferent vagal fibers with capsaicin (deafferentation) was used to investigate involvement of afferent fibers. Peripheral activation of afferent vagal fibers via cholecystokinin (CCK)-mediated activation of CCK-1 receptors was investigated using administration of the selectively peripheral acting CCK-1 receptor antagonist, A70104 and PEGylated-CCK9. Tissue and blood were collected 90 minutes after shock to assess systemic inflammation and intestinal integrity.

Results: Deafferentation reversed the inhibitory effect of lipid-rich nutrition on systemic levels of TNF- $\alpha$ and IL- 6 and on intestinal leakage of horseradish peroxidase and bacterial translocation. Furthermore, the protective effects of lipid-rich nutrition were negated by A70104, indicating that lipid-rich nutrition triggers peripheral cholecystokinin-1 receptors on vagal afferents to modulate inflammation. These findings were substantiated by the fact that pre-treatment of fasted rats with PEGylated-cholecystokinin9, which acts on peripheral CCK-1 receptors, attenuated systemic inflammation and loss of intestinal integrity.

Conclusions: These data demonstrate that enteral lipid-rich nutrition modulates inflammation and preserves intestinal integrity via cholecystokinin release which activates cholecystokinin-1 receptors located on afferent vagal fibers. Taken together, the current study reveals a novel gut-brain-immune axis and provides new insight into the applicability of enteral nutrition to treat inflammatory conditions. 


\section{Introduction}

Nutrient sensing is an essential feature of the autonomic nervous system to regulate food intake and maintain energy homeostasis. The gastrointestinal tract communicates with the autonomic nervous system via circulating mediators and hard-wired connections, the so-called gut-brain axis ${ }^{1}$. Many of these physiologic processes, such as satiety and regulation of digestive activity, depend on the vagus nerve $\mathrm{e}^{2-4}$. In addition to a role in nutrient sensing, the vagus nerve has an important immuno-modulatory function. Peripheral vagal afferents are able to sense circulating cytokines, resulting in a thermogenic and humoral anti-inflammatory response ${ }^{5-7}$. Additionally, stimulation of the vagus nerve modulates inflammation and improves outcome in several inflammatory models via the cholinergic anti-inflammatory pathway ${ }^{8-10}$.

Recently, we described that lipid-rich nutrition regulates the inflammatory response via activation of the autonomic nervous system ${ }^{11,12}$. Subsequently nicotinic receptors on inflammatory cells are activated via the vagus nerve, leading to a reduction of cytokine release and organ damage ${ }^{12,13}$. Activation of this anti-inflammatory pathway via administration of lipid-rich nutrition is an appealing and physiologic intervention to counteract excessive inflammation and organ damage in several diseases ${ }^{13-15}$. Furthermore, this nutritional anti-inflammatory pathway might contribute to the largely unexplained unresponsiveness of the intestinal immune system to dietary and bacterial antigens.

Here, we report on studies directed at the molecular mechanism responsible for the sensing of luminal nutrients by the autonomic nervous system and the creation of a subsequent immuno-modulatory response. First, the involvement of the afferent vagus was assessed via vagal deafferentation with capsaicin. Next, the role of the cholecystokinin (CCK)-1 receptor and the CCK-2 receptor was investigated using selective receptor antagonists. In addition, activation of the nutritional pathway by peripheral CCK-1 receptors was studied with a selective CCK-1 receptor antagonist, which does not cross the blood-brain barrier, and administration of PEGylated-CCK9 (PEG-CCK9), a CCK-agonist that solely acts on peripheral CCK-1 receptors .

The current study reveals a novel gut-brain axis in which enteral nutrients trigger a potent anti-inflammatory response via CCK-mediated activation of peripheral CCK-1 receptors on afferent vagal fibers. Furthermore, our data point at lipid-rich nutrition as an effective and physiologic intervention to modulate inflammation. 


\section{Methods}

\section{Animals and experimental groups}

Male Sprague-Dawley rats, weighing 300-350 g were purchased from Charles River Laboratories (Maastricht, the Netherlands) and housed under controlled conditions of temperature and humidity. Prior to the experiments, rats were fed standard rodent chow ad libitum and had free access to water. The experimental protocols were approved by the Animal Ethics Committee of the Maastricht University Medical Center. A non-lethal hemorrhagic shock model was used, as previously described ${ }^{12,16}$. In short, rats were anesthetized with isoflurane (induction 4\%, maintenance 1.5\%); the femoral artery was cannulated with polyethylene tubing (PE-10) containing heparinized saline $(10 \mathrm{lU} / \mathrm{ml})$. At the time of shock, $2.1 \mathrm{ml}$ blood per $100 \mathrm{~g}$ body weight was withdrawn at a rate of $1 \mathrm{ml} /$ minute. In all experiments, rats were fasted overnight (18 h) or fed lipidrich nutrition by oral gavage prior to hemorrhagic shock. The lipid-rich liquid nutrition contained 50.4 energy percent (en\%) fat of which $30 \%$ were phospholipids, 8.7 en\% protein and 40.9 en\% carbohydrates. Rats received $3 \mathrm{ml}$ enteral nutrition 18 hours before shock and $0.75 \mathrm{ml}$ was given at 2 hours and at 45 minutes before hemorrhagic shock. All rats were sacrificed 90 minutes after shock.

\section{Vagal deafferentation}

To determine the role of afferent vagal fibers in the activation of the nutritional antiinflammatory pathway, rats were vagally deafferented $10-14$ days prior to hemorrhagic shock as previously described ${ }^{17}$. In short, animals were anesthetized with isoflurane (induction $4 \%$, maintenance $2.5 \%$ ) and injected with atropine $(0.5 \mathrm{mg} / \mathrm{kg}$ s.c.) to counteract the acute systemic effects of capsaicin on the respiratory and cardiovascular system. The vagal nerve was carefully dissected from the carotid artery at the cervical level bilaterally. Capsaicin (10 mg/ml. Sigma, St Louis, MO) was applied via a cotton swab and added every ten minutes for a total of 30 minutes. The total amount of capsaicin applied to each rat did not exceed $1 \mathrm{mg}$. Surrounding tissue was protected with parafilm to prevent leakage. Sham animals were treated with vehicle (90\% olive oil, $10 \%$ Tween 80 ).

\section{Assessment of deafferentation}

The deafferentation procedure was functionally verified by CCK satiety test ${ }^{18}$. Rats $(n=8)$ were challenged with i.p. injection of either sulphated CCK-8 (CCK8s. Bachem AG, Weil am Rhein, Germany; $4 \mu \mathrm{g} / \mathrm{kg}$ ) or saline after 4 hours starvation. Two minutes after i.p. injection, rats were given access to a pre-weighed amount of standard rat chow. Food consumption was measured after a 30 minute interval. The difference in food 
intake after saline or CCK8s injection was calculated and served as a marker for CCKinduced satiety.

The deafferentation procedure was histologically confirmed by neuronal tracing of the afferent vagus ${ }^{19}$. One week after deafferentation or sham operation, rats $(n=6)$ were injected intraperitoneally with the retrograde neuronal tracer fluorogold (Invitrogen, Carlsbad, CA) dissolved in PBS (1 mg/ml). Three days after fluorogold administration rats received an overdose of pentobarbital, followed by transcardial perfusion fixation with $4 \%$ paraformaldehyde in $0.1 \mathrm{M}$ phosphate buffer (PB; $\mathrm{pH} 7.4$ ). Nodose ganglia were removed, post-fixed and cryoprotected in 20\% sucrose/0.1 M PB. Tissues were sectioned at $16 \mu \mathrm{m}$ using a cryostat, air dried and coverslipped with $80 \%$ glycerol in TBS. Sections were examined for the presence and distribution of fluorogold in the perykaria of afferent vagal neurons using fluorescence microscopy. Photomicrographs were recorded with a DCC camera. Per rat, three coronal sections of nodose ganglia were used as separate values for quantitative analyses of fluorogold staining. The number of fluorogold positive cells per square micrometer in the nodose ganglion was counted using the computer assisted digital analysis program Leica Qwin (Leica Microsystems Imaging solutions Ltd, Cambridge, UK).

\section{Receptor antagonists}

Rats $(n=8)$ were fed lipid-rich nutrition and treated intravenous with receptor antagonists 30 minutes prior to induction of shock to investigate involvement of CCK-receptors in the nutritional anti-inflammatory pathway. To discriminate between a CCK-1 or CCK-2 receptor dependent mechanism, either the CCK-1 receptor antagonist devazepide or the CCK-2 receptor antagonist L365,260 (gifts from ML Laboratories PLC, Nottingham, UK; both $500 \mu \mathrm{g} / \mathrm{kg}$ ) or vehicle $(90 \%$ saline, $5 \%$ Tween 20, 5\% DMSO) were administered. Involvement of peripherally localized CCK-1 receptors was investigated using $A 70104^{20}$, also known as A65186 (100 $\mu \mathrm{g} / \mathrm{kg}$, kindly provided by Abbott Laboratories, Abbott Park, IL) or vehicle ( $99 \%$ saline, $1 \%$ DMSO).

\section{CCK administration and measurement}

Activation of the nutritional anti-inflammatory pathway by peripherally acting CCK was studied by administration of PEG-CCK9, which solely acts on peripheral CCK-1 receptors, or vehicle ${ }^{21}$. PEG-CCK9 was dissolved in sterile saline and administered intravenous ( $6 \mu \mathrm{g} / \mathrm{kg}$; bolus injection) in fasted rats 30 minutes prior to shock. The involvement of peripheral CCK-1 receptors in activation of the vagal anti-inflammatory pathway by PEG-CCK9 was investigated by co-administration of A70104 with PEG-CCK9.

To determine whether continuous infusion of exogenous CCK reaching high physiologic arterial levels could mimic the anti-inflammatory response, CCK8s was dissolved in 
sterile saline and infused at $500 \mathrm{pmol} / \mathrm{kg} / \mathrm{h}$ intravenous (based on previous studies ${ }^{22-24}$ and own experiments; data not shown). The infusion-protocol started 30 minutes before shock and was maintained until sacrifice. Systemic levels of CCK were measured in arterial plasma at time of shock and at sacrifice using a CCK-radioimmunoassay (Euro-diagnostica, Malmö, Sweden).

\section{Cytokine analysis}

TNF- $\alpha$ and IL- 6 concentrations in arterial blood were measured using a standard ELISA for rat TNF- $\alpha$ (kindly provided by HBT, Uden, the Netherlands) and IL-6 (BD Biosciences, Franklin Lakes, NJ).

\section{Intestinal permeability assay and bacterial translocation}

Intestinal permeability for macromolecules was assessed by measuring translocation of the 44-kD enzyme horseradish peroxidase (HRP) by the everted gut sac method as previously described ${ }^{25}$. Segments of the distal ileum $(8 \mathrm{~cm})$ were washed, everted, filled with $1 \mathrm{ml}$ of Tris buffer $(125 \mathrm{mmol} / \mathrm{l} \mathrm{NaCl}, 10 \mathrm{mmol} / \mathrm{l}$ fructose, $30 \mathrm{mmol} / \mathrm{l}$ Tris, $\mathrm{pH}$ 7.5) and ligated at both ends. The filled segments were incubated in Tris buffer containing $40 \mu \mathrm{g} / \mathrm{ml}$ of HRP. After incubation at room temperature for $45 \mathrm{~min}$, the ileum was removed from the buffer and the content was carefully collected in a 1-ml syringe. HRP-activity was measured spectophotometrically at $450 \mathrm{~nm}$ after addition of tetramethyl benzidine as a substrate for HRP.

Bacterial translocation to distant organs was assessed as described ${ }^{11}$. In short, mesenteric lymph nodes, the mid-section of the spleen and a liver-segment (IV) were collected aseptically in pre-weighed thioglycolate broth tubes (Becton Dickinson, Franklin Lakes, NJ). Tissue-fragments were weighed, homogenized and the entire suspension was transferred to agar plates (Columbia III blood agar base supplemented with $5 \% \mathrm{vol} / \mathrm{vol}$ sheep blood (BBL, Franklin Lakes, NJ) and Chocolate PolyviteX agar (BioMérieux, Marcy l'Etoile, France). After 48 hours of incubation, colonies were counted, determined using conventional techniques, adjusted to tissue weight, and expressed as number of CFU's per gram of tissue.

\section{Statistical analysis}

Data are represented as median, range and interquartile range. A Mann-Whitney $U$ test was used for between-group comparisons. Differences were considered statistically significant at $P<0.05$. Statistical analysis was performed using Graphpad Prism 4.0 (GraphPad Software Inc., San Diego, CA, USA). 


\section{Results}

\section{The nutritional anti-inflammatory pathway is mediated via afferent vagal fibers}

Involvement of the afferent vagus in the nutritional anti-inflammatory pathway was investigated in rats after perineural application of capsaicin (deafferentation). Prolonged exposure of nerves to capsaicin typically destroys afferent fibers, while leaving efferents intact ${ }^{26}$. Before entering the experiment, the efficacy of deafferentation was determined using a CCK satiety test. In line with previous reports $^{18,27}$, intraperitoneal administration of sulphated CCK8 (CCK8s) reduced 30-min food intake after 4-hour starvation with $51 \pm 2 \%$ in sham operated rats compared with $26 \pm 3 \%$ in deafferented rats $(P<0.05$; Figure $2.1 \mathrm{~A})$, indicating a successful deafferentation. It is known that perineural application of capsaicin results in subtotal elimination of afferent vagal fibers ${ }^{26}$. Therefore, the amount of remnant vagal afferent fibers was histologically assessed in a number of rats $(n=6)$ using the retrograde neuronal tracer fluorogold ${ }^{19}$. Deafferentation resulted in an $80 \%$ reduction of fluorogold positive cell bodies in the nodose ganglia, i.e. 0.25 [0.25 to 0.39] positive cells $/ \mu \mathrm{m}^{2}$ in sham compared with 0.06 [0.03 to 0.16] positive cells $/ \mu \mathrm{m}^{2}$ in deafferented animals $(P<0.0001$; Figure $2.1 \mathrm{~B}-\mathrm{C})$. These findings demonstrate that the majority of afferent fibers were destroyed.

The protective effects of lipid-rich nutrition on systemic inflammation and intestinal integrity were replicated in sham operated animals, indicating that these rats effectively respond to enteral lipid-rich nutrition. Next, we observed that deafferentation in fasted rats resulted in higher shock-induced TNF- $\alpha$ levels compared with fasted sham rats $(P<0.05$; Figure 2.2A). More interestingly, the protective effects of lipid-rich nutrition on shock-induced systemic inflammation (plasma levels of TNF- $\alpha$ and IL-6; both $P<0.001$. Figure 2.2A-B) and loss of intestinal integrity (bacterial translocation and leakage of HRP; both $P<0.01$. Figure 2.2C-D) were inhibited by disruption of vagal afferent fibers with capsaicin. Administration of lipid-rich nutrition reduced plasma concentration TNF- $\alpha$ and leakage of HRP in deafferent animals to some extent, which is likely attributable to the remnant afferent vagal fibers. Taken together, these findings point at an important role for afferent vagal fibers in the nutritional anti-inflammatory pathway. 

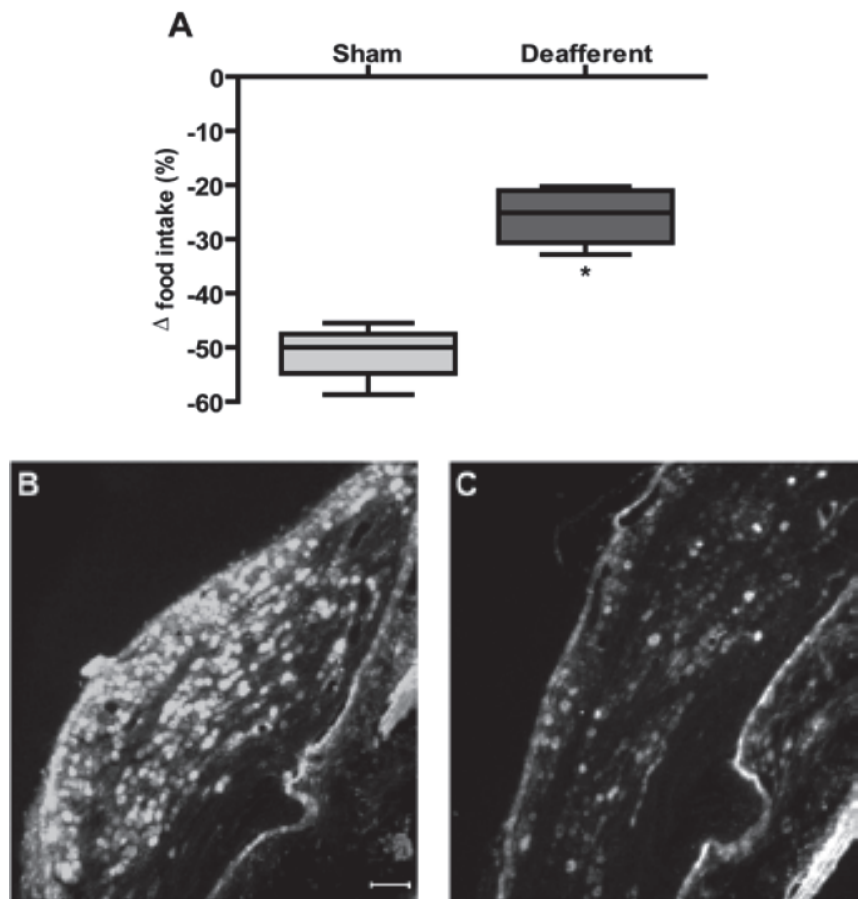

Figure 2.1 Intraperitoneal administration of CCK8s $(4 \mu \mathrm{g} / \mathrm{kg} ; \mathrm{n}=8)$ potently reduced food intake compared with saline administration in sham operated rats (A). Destruction of afferent vagal fibers by perineural application of capsaicin significantly inhibited the satiety response induced by intraperitoneal administration of CCK8s. (B, C) Fluorogold was administered intraperitoneally in deafferented and sham operated rats $(n=6)$. Deafferentation $(C)$ resulted in significant loss of positively-labelled afferent vagal cell bodies in the nodose ganglia (80\%) compared with sham operated animals (B). Data represented as median, range and interquartile range. Scale bar represents $100 \mu \mathrm{m} . * P<0.05$ compared with sham.

\section{Both the CCK-1 and CCK-2 receptor are involved in the nutritional anti- inflammatory pathway}

Previously, we demonstrated that activation of the anti-inflammatory mechanism triggered by lipid-rich nutrition was dependent on CCK-receptors ${ }^{12}$. Separate intravenous administration of the CCK-1 receptor antagonist, devazepide or the CCK-2 receptor antagonist, L365,260 demonstrated that the beneficial effects of lipid-rich nutrition depend on both receptor subtypes (Figure 2.3). The CCK-1 receptor antagonist inhibited the effects of lipid-rich nutrition on systemic inflammation and intestinal integrity to a greater extent than the CCK-2 receptor. Since both receptor antagonists readily cross the blood-brain barrier, a distinction between a peripheral or central activation of the nutritional anti-inflammatory pathway could not be made. 

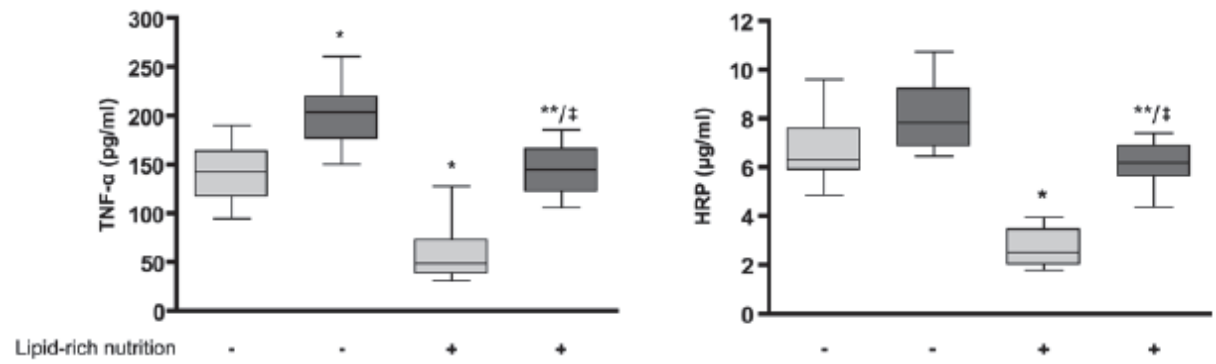

A

C
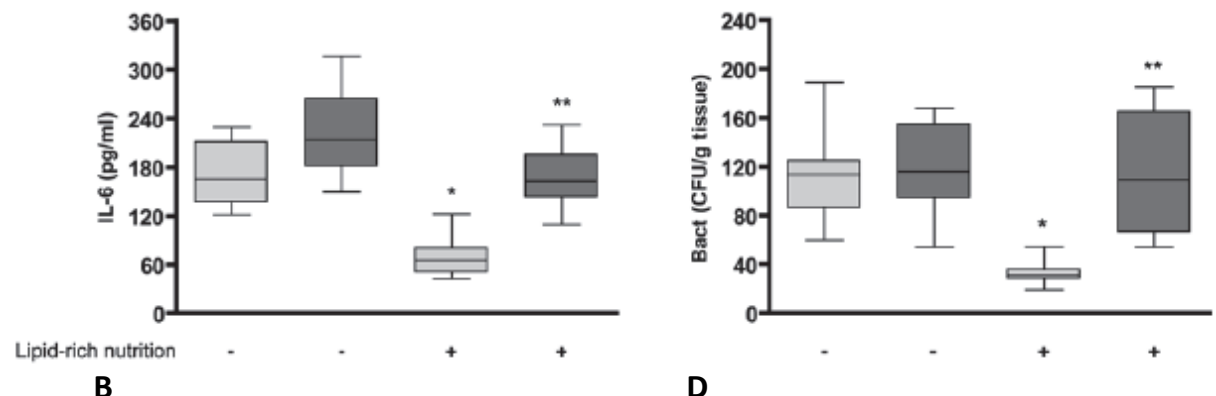

Figure 2.2 Administration of lipid-rich enteral nutrition in sham operated rats (light bars) inhibited shockinduced systemic levels of TNF- $\alpha$ (A) and IL-6 (B) compared with fasted rats. Furthermore, intestinal permeability to HRP (C) and bacterial translocation (D) were effectively reduced by lipid-rich nutrition in sham rats. Deafferentation (dark bars) negated the inhibitory effect of lipid-rich enteral nutrition on systemic inflammation and gut barrier failure. Furthermore, deafferentation increased systemic TNF- $\alpha$ in fasted rats. Administration of lipid-rich nutrition reduced TNF- $\alpha$ release and intestinal permeability to HRP in these animals. Data represented as median, range and interquartile range, $\mathrm{n}=8$. ${ }^{*} P<0.01$ compared with fasted sham, ${ }^{* *} P<0.01$ compared with lipid-rich sham, ${ }^{\ddagger} P<0.05$ compared with fasted deafferent. 

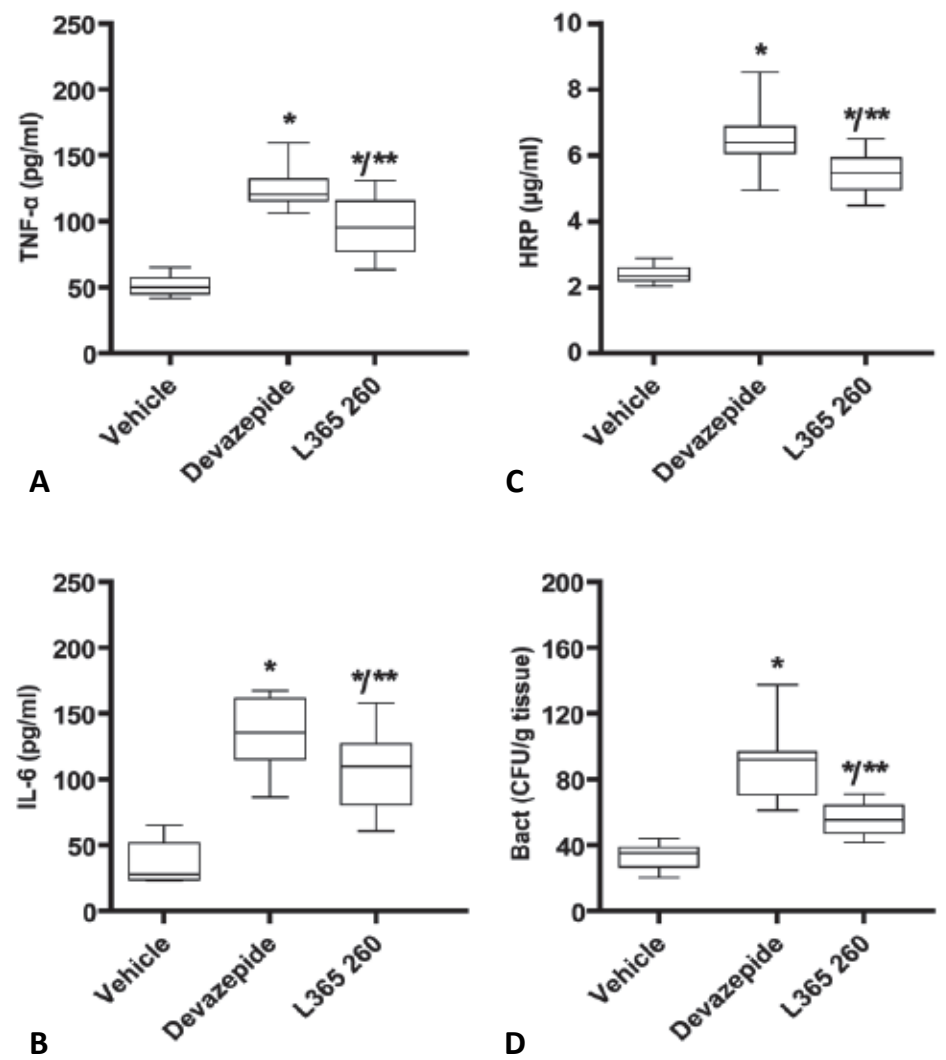

Figure 2.3 Administration of the CCK-1 or CCK-2 receptor antagonist inhibited the effect of lipid-rich nutrition on TNF- $\alpha$ (A), IL-6 (B), leakage of HRP in ileal segments (C) and bacterial translocation (D). The inhibitory effect of the CCK-1 receptor antagonist (devazepide) was stronger than the CCK-2 receptor antagonist $(L 365,260)$. Data represented as median, range and interquartile range. ${ }^{*} P<0.001$ compared with vehicle, $* * P<0.05$ compared with $\mathrm{CCK}-1$ receptor antagonist $(n=8)$.

\section{Lipid-rich nutrition modulates inflammation via the peripheral CCK-1 receptor}

To substantiate a peripheral activation of the vagal anti-inflammatory pathway by lipid-rich nutrition, rats were treated intravenously with the peripherally acting CCK-1 receptor antagonist, A70104. A70104 does not cross the blood-brain barrier ${ }^{20}$. Pretreatment with A-70104 abrogated the inhibitory effect of lipid-rich nutrition on systemic inflammation (plasma levels of TNF- $\alpha$ and IL-6; Figure 2.4A) and intestinal integrity (leakage of HRP and bacterial translocation; Figure 2.4B), underlining a critical role for peripherally localized CCK-1 receptors in the activation of the nutritional antiinflammatory pathway. 


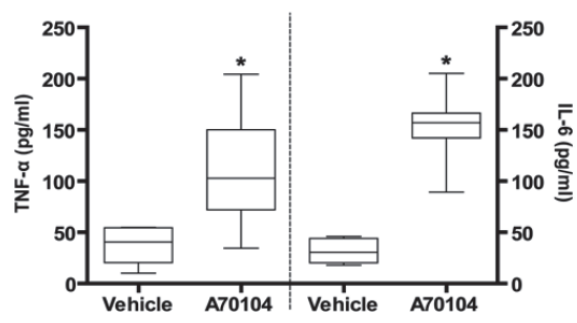

A

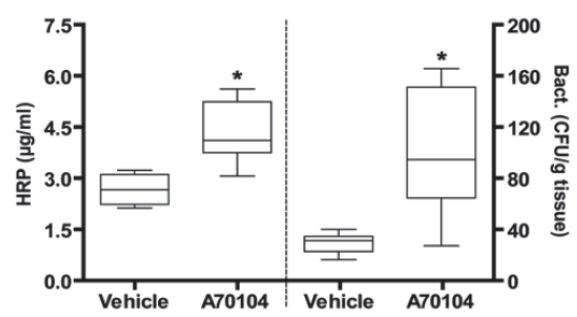

B

Figure 2.4 Pre-treatment with the solely peripherally acting CCK-1 receptor antagonist (A70104) abrogated the protective effects of lipid-rich nutrition. Data represented as median, range and interquartile range. ${ }^{*} P<0.001$ compared with vehicle $(n=8)$.

\section{Peripherally acting CCK triggers the nutritional anti-inflammatory mechanism}

To investigate a role for CCK-mediated activation of peripheral CCK-1 receptors in the nutritional anti-inflammatory pathway, we administered an intravenous bolus of PEG-CCK9. This CCK9 conjugate shows complete retention of biological activity and acts solely on peripheral CCK-1 receptors ${ }^{21,28}$. Administration of PEG-CCK9 reduced plasma levels of TNF- $\alpha$ and IL-6 (Figure 2.5A-B) and ameliorated leakage of HRP and bacterial translocation compared with vehicle (Figure 2.5C-D), mimicking the antiinflammatory effect of lipid-rich nutrition. Co-administration of A70104 blunted the effect of PEG-CCK9 on systemic inflammation and intestinal integrity (Figure 2.5). Taken together, these data denote that the anti-inflammatory effects of lipid-rich nutrition are triggered via CCK-mediated activation of peripheral CCK-1 receptors.

Administration of supraphysiologic concentrations of CCK in clinical situations has several limitations, since it can lead to pancreatitis and anxiety ${ }^{29,30}$. Therefore, we investigated whether infusion of CCK resulting in physiologic plasma concentrations activates the nutritional anti-inflammatory pathway. Infusion of CCK8s in fasted rats, reaching arterial concentrations of 11 [7 to 22] pM at shock and 20 [9 to 25] pM at sacrifice, did not reduce systemic TNF- $\alpha$ (170 [113 to 230] pg/ml vs. vehicle: 178 [147 to 234$] \mathrm{pg} / \mathrm{ml}$ ) and IL-6 (196 [130 to 204] pg/ml vs. vehicle: 198 [175 to 250] $\mathrm{pg} / \mathrm{ml}$ ). In addition, shock-induced leakage of HRP (2.9 [1.6 to 4.0$] \mu \mathrm{g} / \mathrm{ml}$ vs. vehicle: 3.6 [2.6 to 5.0] $\mu \mathrm{g} / \mathrm{ml}$ ) and bacterial translocation (97 [60 to 115] CFU/g tissue vs. vehicle: 98 [90 to 123] CFU/g tissue) remained unaltered after CCK8s infusion. These data demonstrate that circulating exogenous CCK8s at physiologic arterial concentrations is unable to attenuate inflammation and cannot prevent gut barrier failure. 

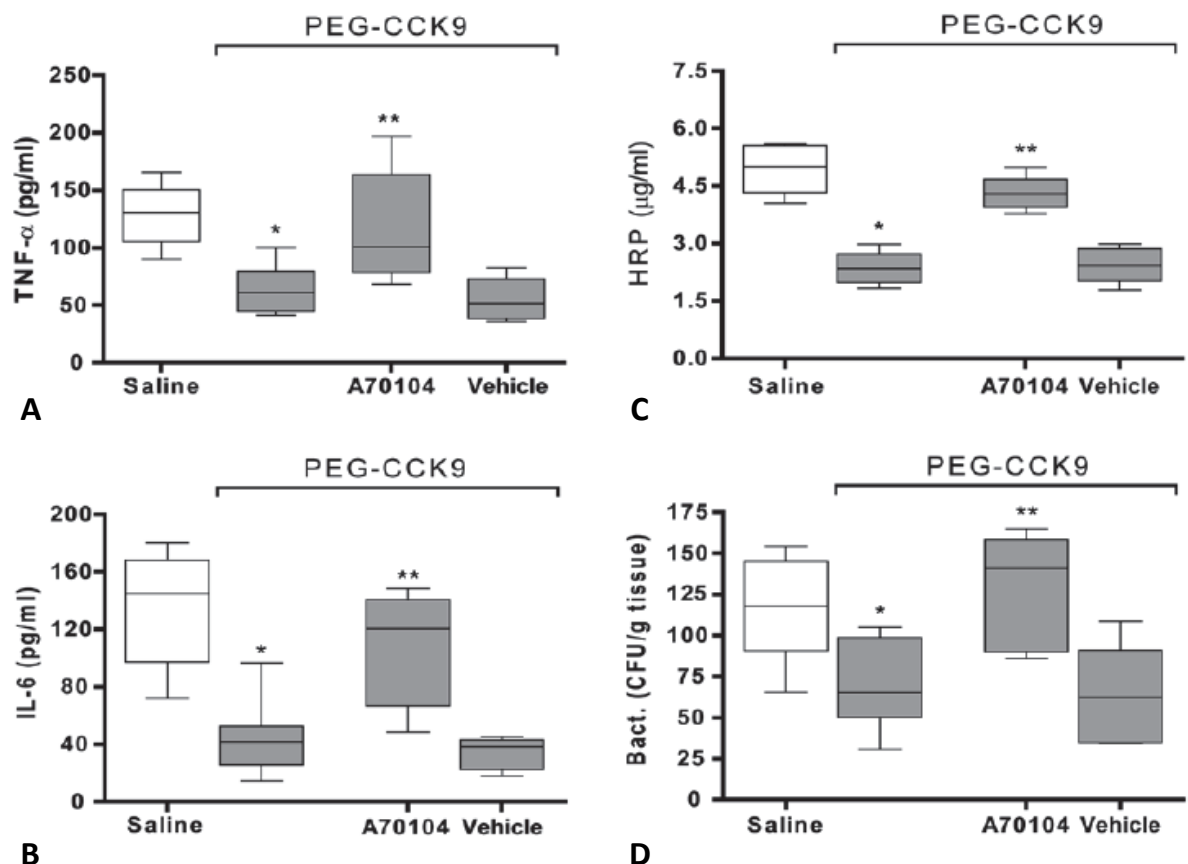

Figure 2.5 Bolus intravenous injection of PEG-CCK9 attenuated TNF- $\alpha$ (A), IL-6 (B), leakage of HRP in ileal segments (C) and bacterial translocation (D) compared with vehicle (dark bars. $n=8$ ). The protective effect of PEG-CCK9 was abrogated by intravenous administration of A70104 ( $n=6)$. Data represented as median, range and interquartile range. ${ }^{*} P<0.01$ compared with saline, ** $P<0.01$ compared with A70104 vehicle.

\section{Discussion}

The current manuscript demonstrates for the first time that enteral nutrients activate a previously unidentified gut-brain-immune axis. Administration of lipid-rich nutrition attenuates systemic inflammation and preserves intestinal integrity via release of CCK which activates peripheral CCK-1 receptors on the afferent vagus nerve.

The afferent vagus nerve is essential to monitor the condition of the body. Afferent vagal fibers relay a variety of signals from the periphery, such as food-related, digestive, immune and noxious stimuli ${ }^{2,3,31}$. In concordance with previous studies showing that vagal capsaicin treatment or vagotomy in rodents increased inflammation in experimentally-induced colitis ${ }^{32-34}$, disruption of afferent vagal fibers resulted in increased shock-induced circulating TNF- $\alpha$ levels in fasted rats. Interestingly, deafferentation abrogated the protective effects of lipid-rich nutrition on systemic inflammation and loss of intestinal integrity, indicating that the nutritional 
anti-inflammatory pathway is peripherally activated. Our data are in agreement with several studies demonstrating that signal transmission from peripheral stimuli acting on the afferent vagus can be blocked by vagal deafferentation ${ }^{19,35,36}$. A limited protective effect of lipid-rich nutrition was observed in deafferent animals, which can be attributed to remnant afferent fibers ${ }^{26}$. Together, these findings not only underline a regulatory role for the vagus nerve in the immune response, but also implicate the afferent vagus nerve as a vital component of the nutritional anti-inflammatory pathway.

The CCK-receptor family consists of two subtypes, the CCK-1 and the CCK-2 receptor ${ }^{30}$. Enteral lipids activate the autonomic nervous system predominantly via CCK-1 receptors on the afferent vagus nerve, whereas certain brain areas are activated by both receptor subtypes ${ }^{37,38}$. The current data demonstrate that the peripheral CCK-1 receptor is involved in the activation of the nutritional anti-inflammatory pathway, since both devazepide and the peripherally acting A70104 inhibited the antiinflammatory effects of lipid-rich nutrition. The exact role of CCK-2 receptors in the nutritional anti-inflammatory pathway remains to be established. The observed inhibitory effect of L365,260 could be mediated via peripheral or central CCK-2 receptors, since this receptor antagonist readily crosses the blood-brain barrier ${ }^{39}$. However, the fact that most experimental evidence indicates that activation of brain neurons by enteral lipids and exogenous CCK is dependent on peripheral CCK-1 receptors and central CCK-2 receptors, hints at a central involvement of CCK-2 receptors in the nutritional anti-inflammatory pathway ${ }^{38,40,41}$.

Ingestion of lipid-rich nutrition results in release of endogenous CCK, capable of activating both CCK-receptor subtypes ${ }^{42}$. There is competing evidence that CCK can activate the autonomic nervous system via the afferent vagus nerve as well as via a humoral route ${ }^{1,43-45}$. Administration of the solely peripherally acting PEG-CCK9 mimicked the protective effects of lipid-rich nutrition ${ }^{21}$. The PEG-CCK9 induced antiinflammatory response was shown to be dependent on peripheral CCK-1 receptors. In line with these findings, Bozkurt et al. demonstrated that exogenous CCK8s attenuates inflammation via capsaicin-sensitive vagal afferents in an experimental colitis model ${ }^{35}$. Taken together, these data substantiate that the nutritional anti-inflammatory pathway is peripherally activated by a cholecystokinin-mediated stimulation of peripheral CCK-1 receptors on the afferent vagus.

Infusion of exogenous CCK is potentially a promising clinical application to treat inflammatory conditions. Administration of CCK8s at supraphysiologic concentrations has been shown to attenuate inflammation in experimental models both in vivo 35,46 and in vitro ${ }^{47,48}$. However, caution should be taken since high doses of exogenous CCK and PEG-CCK9 are known to result in pancreatic hyperplasia, pancreatitis and anxiety disorders in rodents and humans ${ }^{29,30,49,50}$. Circulating physiologic levels of exogenous 
CCK8s, obtained by our infusion protocol, were unable to attenuate systemic inflammation and prevent loss of intestinal integrity. The concentration of CCK8s reaching the local environment of the vagal afferent nerve endings may have been insufficient to activate an anti-inflammatory response, since the CCK peptide is rapidly inactivated in the circulation ${ }^{51,52}$. Recently, it has been shown that local CCK levels are more important to trigger the vagus nerve than circulating levels, since intestinal administration of CCK stimulates vagal afferents, without affecting plasma levels ${ }^{53}$.

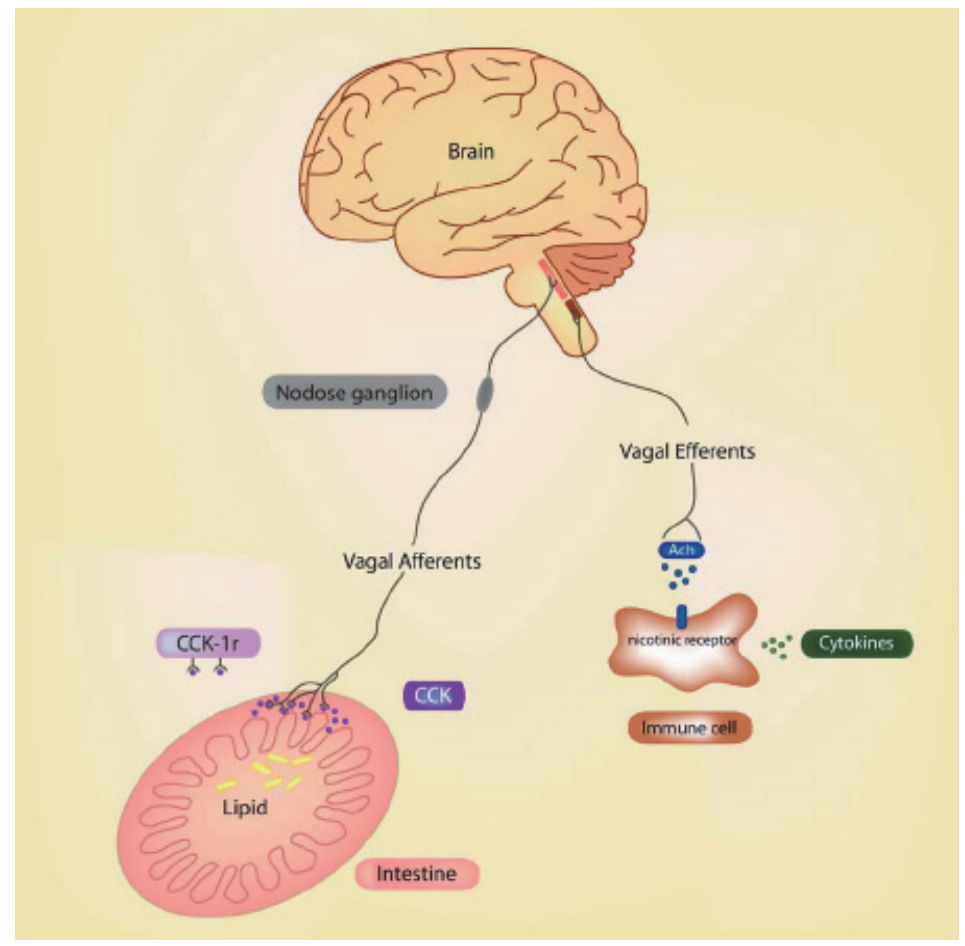

Figure 2.6 The enteral presence of lipid-rich nutrition results in release of cholecystokinin (CCK) from the gut wall, which binds to peripheral CCK-1 receptors (CCK-1r) located on afferent vagal nerve endings. The anti-inflammatory signal is processed in the vagal circuitry via a neural pathway in which CCK-1 and CCK-2 receptors are involved, resulting in inhibition of the inflammatory response via the efferent vagus. Production of inflammatory cytokines is attenuated by binding of acetylcholine (Ach) to nicotinic receptors on inflammatory cells.

Therefore, administration of lipid-rich nutrition appears to be a more physiologic and efficient intervention to activate the CCK/CCK-1 receptor mediated vagal antiinflammatory pathway. In addition, enteral administration of lipid-rich nutrition has been demonstrated to inhibit inflammation and attenuate organ damage in several 
situations, such as hemorrhagic shock and postoperative ileus ${ }^{12-15}$, indicating that lipidrich enteral nutrition could be a safe and subtle intervention to attenuate inflammatory conditions in the clinical setting.

In the gastrointestinal tract essential nutrients are sensed and absorbed, while potential harmful agents need to be prevented from invading the host. The mechanisms behind this dual role are largely unexplained. Uptake of nutrients inevitably exposes the host to antigenic substances ${ }^{54}$. A highly selective intestinal immune response is required to maintain intestinal barrier function and homeostasis in the face of constant threat. Together with previous work from our group ${ }^{12}$, the current study reveals that the intestine directly communicates with the immune system via a nutritional vagovagal reflex (Figure 2.6). We hypothesize that this neural feedback loop is involved in the unresponsiveness of the dietary tract to luminal antigens. 


\section{References}

1. Cummings DE, Overduin J. Gastrointestinal regulation of food intake. J Clin Invest 2007;117:13-23.

2. Woods SC. Gastrointestinal satiety signals I. An overview of gastrointestinal signals that influence food intake. Am J Physiol Gastrointest Liver Physiol 2004;286:G7-13.

3. Berthoud HR. Vagal and hormonal gut-brain communication: from satiation to satisfaction. Neurogastroenterol Motil 2008;20 Suppl 1:64-72.

4. Berthoud HR. The vagus nerve, food intake and obesity. Regul Pept 2008;149:15-25.

5. Fleshner M, Goehler LE, Schwartz BA, et al. Thermogenic and corticosterone responses to intravenous cytokines (IL-1beta and TNF-alpha) are attenuated by subdiaphragmatic vagotomy. J Neuroimmunol 1998;86:134-141.

6. Goehler LE, Gaykema RP, Hammack SE, et al. Interleukin-1 induces c-Fos immunoreactivity in primary afferent neurons of the vagus nerve. Brain Res 1998;804:306-310.

7. Tracey KJ. The inflammatory reflex. Nature 2002;420:853-859.

8. Borovikova LV, Ivanova $\mathrm{S}$, Zhang $\mathrm{M}$, et al. Vagus nerve stimulation attenuates the systemic inflammatory response to endotoxin. Nature 2000;405:458-462.

9. de Jonge WJ, van der Zanden EP, The FO, et al. Stimulation of the vagus nerve attenuates macrophage activation by activating the Jak2-STAT3 signaling pathway. Nat Immunol 2005;6:844-851.

10. Guarini S, Altavilla D, Cainazzo MM, et al. Efferent vagal fibre stimulation blunts nuclear factor-kappaB activation and protects against hypovolemic hemorrhagic shock. Circulation 2003;107:1189-1194.

11. Luyer MD, Buurman WA, Hadfoune M, et al. Pretreatment with high-fat enteral nutrition reduces endotoxin and tumor necrosis factor-alpha and preserves gut barrier function early after hemorrhagic shock. Shock 2004;21:65-71.

12. Luyer MD, Greve JW, Hadfoune M, et al. Nutritional stimulation of cholecystokinin receptors inhibits inflammation via the vagus nerve. J Exp Med 2005;202:1023-1029.

13. Luyer MD, Derikx JP, Beyaert R, et al. High-fat nutrition reduces hepatic damage following exposure to bacterial DNA and hemorrhagic shock. J Hepatol 2009;50:342-350.

14. de Haan JJ, Lubbers T, Hadfoune M, et al. Postshock Intervention With High-Lipid Enteral Nutrition Reduces Inflammation and Tissue Damage. Ann Surg 2008;248:842-848.

15. Lubbers T, Luyer MD, de Haan JJ, et al. Lipid-Rich Enteral Nutrition Reduces Postoperative Ileus in Rats via Activation of Cholecystokinin-Receptors. Ann Surg 2009;249:481-487.

16. Luyer MD, Jacobs JA, Vreugdenhil AC, et al. Enteral administration of high-fat nutrition before and directly after hemorrhagic shock reduces endotoxemia and bacterial translocation. Ann Surg 2004;239:257-264.

17. Raybould HE, Holzer P, Reddy SN, et al. Capsaicin-sensitive vagal afferents contribute to gastric acid and vascular responses to intracisternal TRH analog. Peptides 1990;11:789-795.

18. Ritter RC, Ladenheim EE. Capsaicin pretreatment attenuates suppression of food intake by cholecystokinin. Am J Physiol 1985;248:R501-504.

19. Ferrari B, Arnold M, Carr RD, et al. Subdiaphragmatic vagal deafferentation affects body weight gain and glucose metabolism in obese male Zucker (fa/fa) rats. Am J Physiol Regul Integr Comp Physiol 2005;289:R1027-1034.

20. Ebenezer IS, Parrott RF. A70104 and food intake in pigs: implication for the CCK 'satiety' hypothesis. Neuroreport 1993;4:495-498.

21. Verbaeys I, Leon-Tamariz F, Buyse J, et al. PEGylated cholecystokinin prolongs satiation in rats: dose dependency and receptor involvement. Br J Pharmacol 2007;152:396-403.

22. Brenner L, Yox DP, Ritter RC. Suppression of sham feeding by intraintestinal nutrients is not correlated with plasma cholecystokinin elevation. Am J Physiol 1993;264:R972-976.

23. Lewis LD, Williams JA. Regulation of cholecystokinin secretion by food, hormones, and neural pathways in the rat. Am J Physiol 1990;258:G512-518.

24. Mamoun AH, Bergstrom J, Sodersten P. Cholecystokinin octapeptide inhibits carbohydrate but not protein intake. Am J Physiol 1997;273:R972-980.

25. Carter EA, Harmatz PR, Udall JN, et al. Barrier defense function of the small intestine: effect of ethanol and acute burn trauma. Adv Exp Med Biol 1987;216A:829-833. 
26. Raybould HE, Tache Y. Cholecystokinin inhibits gastric motility and emptying via a capsaicin-sensitive vagal pathway in rats. Am J Physiol 1988;255:G242-246.

27. Arnold M, Mura A, Langhans $W$, et al. Gut vagal afferents are not necessary for the eating-stimulatory effect of intraperitoneally injected ghrelin in the rat. J Neurosci 2006;26:11052-11060.

28. Leon-Tamariz F, Verbaeys I, Van Boven M, et al. PEGylation of cholecystokinin prolongs its anorectic effect in rats. Peptides 2007;28:1003-1011.

29. Niederau C, Liddle RA, Ferrell LD, et al. Beneficial effects of cholecystokinin-receptor blockade and inhibition of proteolytic enzyme activity in experimental acute hemorrhagic pancreatitis in mice. Evidence for cholecystokinin as a major factor in the development of acute pancreatitis. J Clin Invest 1986;78:1056-1063.

30. Wank SA. Cholecystokinin receptors. Am J Physiol 1995;269:G628-646.

31. Holzer P. Role of visceral afferent neurons in mucosal inflammation and defense. Curr Opin Pharmacol 2007;7:563-569.

32. Mazelin L, Theodorou V, More J, et al. Protective role of vagal afferents in experimentally-induced colitis in rats. J Auton Nerv Syst 1998;73:38-45.

33. Ghia JE, Blennerhassett P, Collins SM. Vagus nerve integrity and experimental colitis. Am J Physiol Gastrointest Liver Physiol 2007;293:G560-567.

34. O'Mahony $\mathrm{C}$, van der Kleij H, Bienenstock J, et al. Loss of vagal anti-inflammatory effect: in vivo visualization and adoptive transfer. Am J Physiol Regul Integr Comp Physiol 2009;297:R1118-1126.

35. Bozkurt A, Cakir B, Ercan F, et al. Anti-inflammatory effects of leptin and cholecystokinin on acetic acid-induced colitis in rats: role of capsaicin-sensitive vagal afferent fibers. Regul Pept 2003;116: 109-118.

36. Wang PY, Caspi L, Lam CK, et al. Upper intestinal lipids trigger a gut-brain-liver axis to regulate glucose production. Nature 2008;452:1012-1016.

37. Glatzle J, Kreis ME, Kawano K, et al. Postprandial neuronal activation in the nucleus of the solitary tract is partly mediated by CCK-A receptors. Am J Physiol Regul Integr Comp Physiol 2001;281:R222-229.

38. Monnikes H, Lauer G, Bauer C, et al. Pathways of Fos expression in locus ceruleus, dorsal vagal complex, and PVN in response to intestinal lipid. Am J Physiol 1997;273:R2059-2071.

39. Lin $\mathrm{TH}$, Lin JH. Effects of protein binding and experimental disease states on brain uptake of benzodiazepines in rats. J Pharmacol Exp Ther 1990;253:45-50.

40. Lo CM, Ma L, Zhang DM, et al. The mechanism of the induction of brain c-fos expression by lipid absorption. Am J Physiol Regul Integr Comp Physiol 2007;292:R268-273.

41. Brenner LA, Ritter RC. Intracerebroventricular cholecystokinin A-receptor antagonist does not reduce satiation by endogenous CCK. Physiol Behav 1998;63:711-716.

42. Liddle RA. Cholecystokinin cells. Annu Rev Physiol 1997;59:221-242.

43. Tirassa $\mathrm{P}$, Stenfors $\mathrm{C}$, Lundeberg $\mathrm{T}$, et al. Cholecystokinin-8 regulation of NGF concentrations in adult mouse brain through a mechanism involving $\mathrm{CCK}(\mathrm{A})$ and $\mathrm{CCK}(\mathrm{B})$ receptors. $\mathrm{Br} J$ Pharmacol 1998;123:1230-1236.

44. Baptista V, Browning KN, Travagli RA. Effects of cholecystokinin-8s in the nucleus tractus solitarius of vagally deafferented rats. Am J Physiol Regul Integr Comp Physiol 2007;292:R1092-1100.

45. Bueno L. Involvement of brain CCK in the adaptation of gut motility to digestive status and stress: a review. J Physiol Paris 1993;87:301-306.

46. Ling $\mathrm{YL}$, Meng AH, Zhao XY, et al. Effect of cholecystokinin on cytokines during endotoxic shock in rats. World J Gastroenterol 2001;7:667-671.

47. Cong B, Li SJ, Yao YX, et al. Effect of cholecystokinin octapeptide on tumor necrosis factor alpha transcription and nuclear factor-kappaB activity induced by lipopolysaccharide in rat pulmonary interstitial macrophages. World J Gastroenterol 2002;8:718-723.

48. Li S, Ni Z, Cong B, et al. CCK-8 inhibits LPS-induced IL-1beta production in pulmonary interstitial macrophages by modulating PKA, p38, and NF-kappaB pathway. Shock 2007;27:678-686.

49. Verbaeys I, Leon-Tamariz F, De Buyser K, Buyse J, Decuypere E, Pottel H, Cokelaere M. Dose-response effects of PEGylated cholecystokinin on the behavioral satiety sequence. Physiol Behav 2009;98: 198-204.

50. Modlin IM, Bilchik AJ, Zucker KA, et al. Cholecystokinin augmentation of 'surgical' pancreatitis. Benefits of receptor blockade. Arch Surg 1989;124:574-578. 
51. Koulischer D, Moroder L, Deschodt-Lanckman M. Degradation of cholecystokinin octapeptide, related fragments and analogs by human and rat plasma in vitro. Regul Pept 1982;4:127-139.

52. Greenberg D, Smith GP, Gibbs J. Infusion of CCK-8 into hepatic-portal vein fails to reduce food intake in rats. Am J Physiol 1987;252:R1015-1018.

53. Cheung GW, Kokorovic A, Lam CK, et al. Intestinal cholecystokinin controls glucose production through a neuronal network. Cell Metab 2009;10:99-109.

54. Erridge C, Attina T, Spickett CM, et al. A high-fat meal induces low-grade endotoxemia: evidence of a novel mechanism of postprandial inflammation. Am J Clin Nutr 2007;86:1286-1292. 


\section{Part II}

Effects of the nutritional anti-inflammatory reflex on intestinal integrity 


\title{
CHAPTER 3
}

\section{Rapid development of intestinal cell damage}

\author{
following severe trauma:
}

a prospective observational cohort study

Jacco J. de Haan, Tim Lubbers, Joep P. Derikx, Borna Relja, Dirk Henrich, Jan-Willem M. Greve, Ingo Marzi, Wim A. Buurman 


\section{Abstract}

Introduction: Loss of intestinal integrity has been implicated as an important contributor to the development of excessive inflammation following severe trauma. Thus far, clinical data concerning the occurrence and significance of intestinal damage after trauma remain scarce. This study investigates whether early intestinal epithelial cell damage occurs in trauma patients and, if present, whether such cell injury is related to shock, injury severity and the subsequent inflammatory response.

Methods: Prospective observational cohort study in 96 adult trauma patients. Upon arrival at the emergency room (ER) plasma levels of intestinal fatty acid binding protein (i-FABP), a specific marker for damage of differentiated enterocytes, were measured. Factors that potentially influence the development of intestinal cell damage after trauma were determined, including the presence of shock and the extent of abdominal trauma and general injury severity. Furthermore, early plasma levels of i-FABP were related to inflammatory markers interleukin-6 (IL-6), procalcitonin (PCT) and C-reactive protein (CRP).

Results: Upon arrival at the ER, plasma i-FABP levels were increased compared with healthy volunteers, especially in the presence of shock $(P<0.01)$. The elevation of i-FABP was related to the extent of abdominal trauma as well as general injury severity $(P<0.05)$. Circulatory i-FABP concentrations at ER correlated positively with IL-6 and PCT levels at the first day $\left(r^{2}=0.19 ; P<0.01\right.$ and $r^{2}=0.36 ; P<0.001$ respectively $)$ and CRP concentrations at the second day after trauma $\left(r^{2}=0.25 ; P<0.01\right)$.

Conclusions: This study reveals early presence of intestinal epithelial cell damage in trauma patients. The extent of intestinal damage is associated with the presence of shock and injury severity. Early intestinal damage precedes and is related to the subsequent developing inflammatory response. 


\section{Introduction}

Severe trauma and major surgery frequently result in the development of inflammatory complications, including systemic inflammatory response syndrome, sepsis, and organ failure. These conditions are associated with a poor clinical prognosis $^{1,2}$. For many years, the gut has been an organ of interest in the initiation and perpetuation of the inflammatory response following trauma or surgery ${ }^{3-6}$. In a rodent model of hemorrhagic shock that resembles the clinical situation of severe blood lossinduced splanchnic hypoperfusion, intestinal cell damage developed within one hour after shock induction ${ }^{7}$. Enterocyte damage following shock was paralleled by disruption of tight junction complexes and subsequent failure of the gut barrier. This resulted in translocation of luminal bacteria and toxins into the gut wall, which has been associated with the development of the inflammatory response ${ }^{8-12}$. Moreover, intracellular proteins that are released by damaged cells may contribute to the unfolding systemic inflammatory response by acting as damage-associated molecular patterns $^{13-15}$.

Although various animal studies indicate a role for gut integrity loss in the development of excessive inflammation following trauma, it remains to be clarified whether intestinal damage is present early after trauma in humans ${ }^{16}$. Some reports indicate that gut permeability as measured by sugar absorption tests is increased within 48 hours after trauma, which suggests that the intestine is compromised ${ }^{17,18}$. However, it is not resolved whether this is the cause or the consequence of systemic inflammation. Data on the state of the gut early after trauma are absent because the value of standard permeability tests is limited in the first hours ${ }^{19}$.

This study aimed to clarify the early presence of enterocyte damage following trauma. To this end, on arrival at the emergency room (ER) circulating intestinal fatty acid binding protein (i-FABP), a specific biomarker for damage of differentiated enterocytes, was measured ${ }^{20-24}$. A second aim of this study was to gain insight into the factors that influence the development of intestinal cell damage following multiple traumas, such as presence of shock and injury severity. In addition, the relation between intestinal cell damage and the inflammatory response to trauma was explored.

\section{Materials and methods}

\section{Patient selection}

This prospective observational cohort study was approved by the Ethics Committee of J.W. Goethe University, performed in accordance with the Declaration of Helsinki and reported following the STrengthening the Reporting of OBservational studies in 
Epidemiology (STROBE) guidelines ${ }^{25}$. Informed consent was obtained by all patients or their relatives. Between April 2006 and December 2007, all trauma patients between 18 and 65 years were included at admittance to the ER. Exclusion criteria were burns, acute myocardial infarction, chronic inflammatory diseases, and lethal injury, resulting in a cohort of 96 patients.

\section{Assessment of shock and injury severity}

Upon arrival at the ER, vital parameters of all patients were recorded. The shock index (SI) was calculated as a ratio between the first heart rate and systolic blood pressure registered. A normal SI was defined as a ratio of 0.7 or less ${ }^{26}$. Next, each injury was assigned an abbreviated injury scale (AIS) score ranging from 0 to 5 . Each AIS score was allocated to one of six body regions (head/neck, face, chest, abdomen, extremities, and external) ${ }^{27}$. Of each body region, the highest AIS score was used. The injury severity score (ISS) was determined by squaring and adding together the scores of the three most severely injured body regions ${ }^{28}$.

\section{Blood processing and analysis}

Blood was withdrawn on arrival at the ER and daily during the patient's stay in the J.W. Goethe University Hospital until the second day after trauma. Samples were collected in pre-chilled EDTA vacuum tubes (BD vacutainer, Becton Dickinson Diagnostics, Aalst, Belgium) and kept on ice. Blood was centrifuged at $2000 \mathrm{~g}$ for 15 minutes at $4^{\circ} \mathrm{C}$. The supernatant was stored at $-80^{\circ} \mathrm{C}$ until batch sample analysis. Blinded specimens $(n=7)$ from trauma patients were used for duplicate measurement of i-FABP levels. i-FABP was determined using ELISA (kindly provided by Hycult Biotechnology, Uden, the Netherlands). i-FABP levels were also determined in 57 healthy volunteers between 18 and 65 years. For statistical analyses, the detection limit for i-FABP of $41 \mathrm{pg} / \mathrm{ml}$ was adjusted to samples in which i-FABP was not detectable (ER: 2 samples, day 1: 7 samples, day 2: 17 samples; and control: 20 samples). In the first 68 trauma patients, sufficient plasma was stored to study inflammatory parameters. Plasma concentrations of IL-6 were measured by ELISA (Diaclone, Hoelzel Diagnostica, Cologne, Germany) and C-reactive protein (CRP) using the Tina-quant CRP assay (Roche, Mannheim, Germany). Procalcitonin (PCT) levels were detected using a Kryptor-Assay (Brahms, Henningsdorf, Germany).

\section{Statistical analysis}

First, the plasma i-FABP levels of all trauma patients on admittance and at days 1 and 2 were compared with healthy control values. Next, the relation between i-FABP values and the presence of shock and extent of injury severity were studied (general injury: ISS classified in five categories and abdominal injury: AIS). IL-6, PCT, and CRP levels in 
plasma were measured to analyze the inflammatory response in relation to early intestinal cell damage. A Kolmogorov-Smirnov test showed that plasma concentrations of i-FABP and inflammatory markers were not Gaussian distributed. Kruskal-Wallis test was used to analyze differences between groups with regard to the presence of shock, injury severity, and inflammatory markers. Mann-Whitney $U$ test was used to compare separate groups. Data are expressed as median, 25th and 75th percentiles, and range in the figures and as median (range) in the text. A $P$ value below 0.05 was considered to indicate statistical significance. After transformation of the data into natural logarithms, Spearman's correlation was used to assess the association between i-FABP and peak inflammatory parameters. Prism 4.0 for Windows (GraphPad Software Inc., San Diego, CA, USA) was used for computations.

\section{Results}

\section{Intestinal cell damage is increased in trauma patients arriving at the emergency room}

The mean age of trauma patients ( $n=96)$ was 40 years; $83 \%$ was male. Blood samples at admission to the ER were collected at a mean period of 85 minutes following trauma induction. Concentrations of i-FABP in trauma patients were significantly increased in comparison with healthy controls (303 (41 to 84,846$) \mathrm{pg} / \mathrm{ml}$ vs. 87 (41 to 413 ) pg/ml; $P<0.001$; Figure 3.1). i-FABP levels at ER were also elevated compared with levels at day 1 (174 (41 to 1805) pg/ml; $P<0.001$ ) and day 2 (103 (41 to 1049) pg/ml; $P<0.001$ ). At day 1 , i-FABP concentrations were still increased compared with day 2 in control samples (both $P<0.001$ ). i-FABP at day 2 was not significantly increased compared with control values $(P=0.21)$. Of all trauma patients at the ER, i-FABP levels of 89 patients ( $93 \%$ of all trauma patients) exceeded $87 \mathrm{pg} / \mathrm{ml}$, which is the median of i-FABP plasma concentration in healthy controls.

\section{The extent of intestinal cell damage is related to presence of shock and injury severity}

To investigate the relation between hemodynamic stability and intestinal cell damage, i-FABP concentrations in trauma patients in shock were compared with patients without shock ( $\mathrm{SI}>0.7$ vs. $\leq 0.7$, respectively). On admittance to the ER, the $\mathrm{SI}$ was increased in $42 \%$ of the patients. Plasma i-FABP concentrations were significantly higher in patients with an elevated $\mathrm{SI}$ in comparison with patients with a normal $\mathrm{SI}$ (455 (41 to 84,242$) \mathrm{pg} / \mathrm{ml}$ vs. 259 (41 to 1957$) \mathrm{pg} / \mathrm{ml} ; P<0.01$ ) or healthy controls $(P<0.01$, Figure $3.2 \mathrm{~A})$. Also in trauma patients with a $\mathrm{SI}$ in the normal range, i-FABP levels were elevated in comparison to healthy controls $(P<0.01)$. 


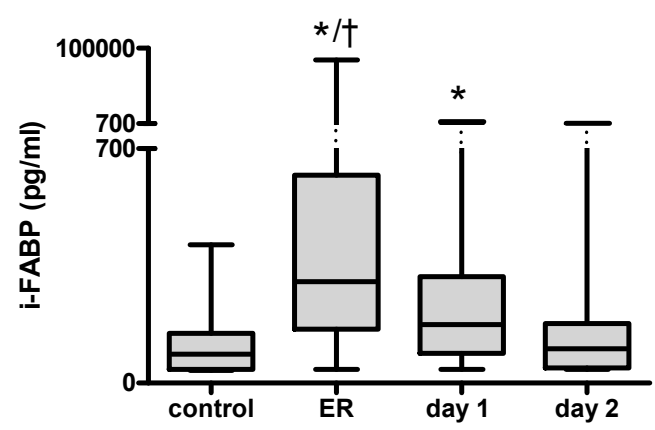

Figure 3.1 Intestinal cell damage increased rapidly following severe trauma. Plasma intestinal fatty acid binding protein (i-FABP) in trauma patients at the emergency room (ER) was significantly higher compared with samples collected at day $1(+P<0.001)$, day 2 and healthy controls (both * $P<0.001)$. i-FABP concentrations at day 1 were elevated in comparison with day 2 and controls (both $* P<0.001$ ).

On admittance, the ISS of all patients was calculated and categorized. All ISS categories comprised 12 patients or more. i-FABP levels in patients with high ISS scores (ISS 31 to 40 and 41 to 50 ) were significantly increased compared with ISS 0 to 10,11 to 20 , and 21 to 30 categories (428 (142 to 84,846) pg/ml and 682 (52 to 8206) pg/ml vs. 189 (41 to 735 ) pg/ml, 210 (58 to 1860 ) pg/ml and 235 (54 to 1957) pg/ml, each $P<0.05$; Figure 3.2B). In all ISS categories, intestinal cell damage was increased compared with healthy controls $(P<0.01)$.

Next, the severity of local abdominal trauma was assessed using the AIS scores of the abdomen. Scores of 0 (no abdominal injury), 3, and 4 (serious and severe abdominal injury) occurred most frequently ( $n=48,21$, and 14 patients, respectively), whereas scores of 1,2 , and 5 were assigned less often ( $n=8,1$, and 4 patients, respectively). As the abdominal AIS score of 2 was assigned only once, the i-FABP concentration detected in this patient $(783 \mathrm{pg} / \mathrm{ml})$ was not used for statistical evaluation. Taken together, at the ER abdominal trauma was diagnosed in $50 \%$ of the patients. i-FABP levels were significantly increased in patients with serious, severe, and critical abdominal injury (AIS 3: 364 (122 to 1194 ) pg/ml, AIS 4: 1185 (52 to 2753) pg/ml and AIS 5: 1806 (287 to 8206$) \mathrm{pg} / \mathrm{ml}$ ) compared with patients without abdominal injury (AIS 0: 231 (41 to 84,846) pg/ml; all $P<0.01$ ) and healthy controls (all $P<0.001$; Figure $3.2 \mathrm{C}$ ). Interestingly, also i-FABP concentrations in patients without abdominal trauma were significantly elevated compared with healthy controls $(P<0.001)$. 

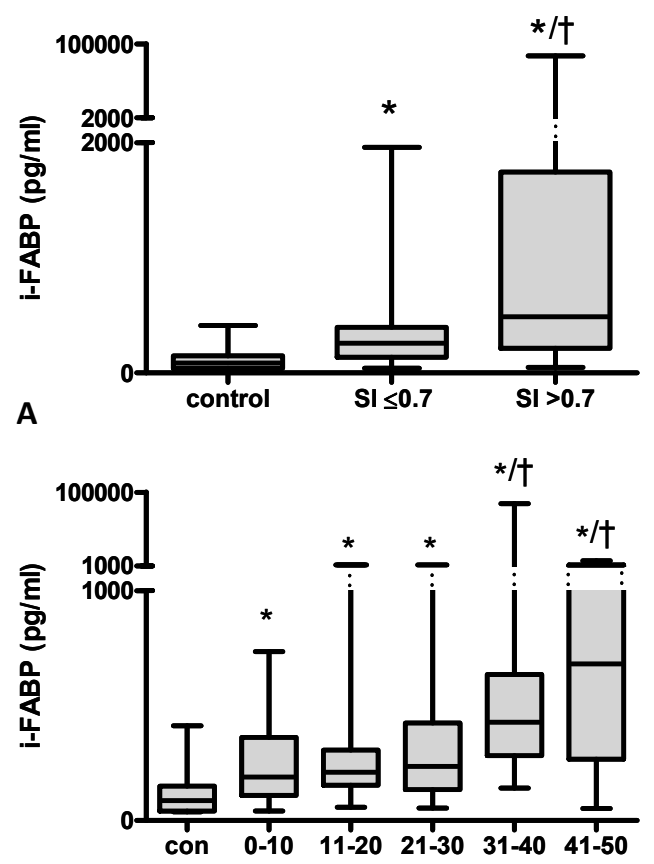

B

ISS

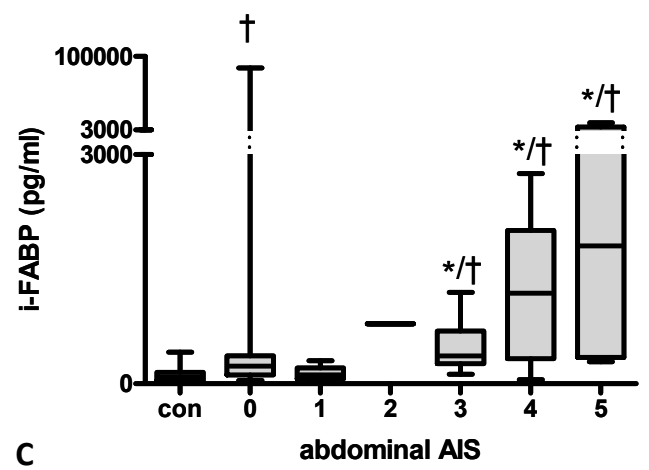

Figure 3.2 Early intestinal cell damage is related to presence of shock and the extent of injury severity. A. Plasma intestinal fatty acid binding protein (i-FABP) concentrations were significantly increased in patients with an elevated shock index $(\mathrm{SI}>0.7)$ compared with patients with a normal $\mathrm{SI}$ $(\leq 0.7)(+P<0.01)$ or healthy controls $(* P<0.01)$. Also in trauma patients with a normal $\mathrm{SI}, \mathrm{i}-$ FABP levels were higher in comparison to healthy controls $(* P<0.01)$. B. i-FABP concentrations in patients with an injury severity score (ISS) of more than 30 were significantly elevated compared with ISS of 30 categories or less $(+P<0.05)$. Intestinal cell damage in all ISS categories was increased compared with healthy controls $(* P<0.01)$. C. i-FABP levels in patients with severe abdominal trauma (abbreviated injury scale (AIS) $\geq 3$ ) were significantly increased compared with patients without abdominal injury (AIS $=0 ;{ }^{*} P<0.01$ ) and healthy controls ( $+P<0.001)$. i-FABP levels in patients without abdominal trauma were significantly higher compared with healthy controls $(+P<0.001)$. 


\section{Remarkably elevated i-FABP values at admittance indicate abdominal emergencies}

In a few patients extremely elevated i-FABP levels were measured, far exceeding the values of other patients (Figure 3.3). Examination of the medical records revealed that the highest $10 \%$ of i-FABP values at ER belonged to patients with severe abdominal trauma that required acute surgical intervention, such as ruptures of the diaphragm, liver, and spleen. The highest i-FABP concentration $(84,846 \mathrm{pg} / \mathrm{ml})$ was measured in a patient assigned an AIS score of 0 at ER admission who was diagnosed at day 2 with intestinal perforation. In this patient, i-FABP concentrations at day 1 and 2 were $1181 \mathrm{pg} / \mathrm{ml}$ and $175 \mathrm{pg} / \mathrm{ml}$, respectively.

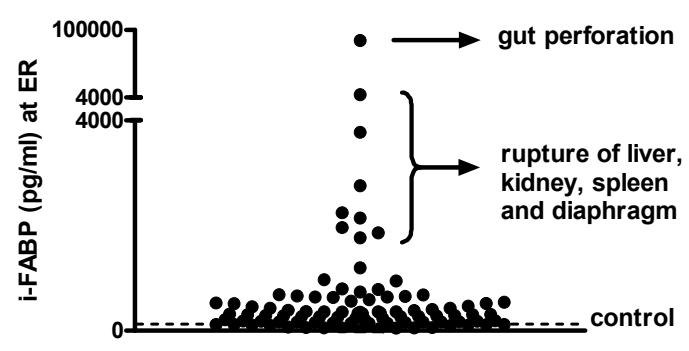

Figure 3.3 Strongly elevated i-FABP levels at ER indicate major abdominal trauma requiring immediate surgery. The highest $10 \%$ of intestinal fatty acid binding protein (i-FABP) values at emergency room (ER) were found in patients with severe abdominal trauma requiring acute intervention, such as rupture of the intestine, diaphragm, kidney, liver, or spleen.

\section{Intestinal mucosal cell damage correlates with the subsequent inflammatory response}

Circulating levels of IL-6, PCT, and CRP were measured on arrival at the ER and the following days to explore the inflammatory response following trauma. Plasma IL- 6 strongly increased at the first day $(0.11(0.01$ to 18.35$) \mathrm{ng} / \mathrm{ml}$ vs. ER: 0.04 (0.00 to $5.16) \mathrm{ng} / \mathrm{ml}, P<0.05)$ and remained elevated at the second day $(0.12$ (0.00 to $11.37) \mathrm{ng} / \mathrm{ml}$ ). Levels of PCT were barely detectable on presentation (0.06 (0.02 to 1.06) $\mathrm{ng} / \mathrm{ml}$ ), whereas elevated levels were measured at day 1 and 2 (0.22 (0.04 to 18.23) $\mathrm{ng} / \mathrm{ml}$ and 0.22 (0.03 to 18.55$) \mathrm{ng} / \mathrm{ml}$, each $P<0.001$ to ER). Consecutive measurements of acute phase protein CRP showed highest plasma values on the second day post-trauma (1.21 (0.06 to 2.72$) \mathrm{mg} / \mathrm{ml}$ ) compared with the first day $(0.42$ ( 0.05 to 1.57$) \mathrm{mg} / \mathrm{ml}, P<0.001$ ) and to CRP concentrations on admittance (0.01 (0.00 to $0.28) \mathrm{mg} / \mathrm{ml}, P<0.001$; Figure $3.4 \mathrm{~A}$ ). Next we analyzed the relation between intestinal 
cell damage and the development of inflammation. Concentrations of i-FABP at admittance correlated positively with values of IL-6 $\left(r^{2}=0.19, P<0.01\right.$; Figure 3.4B) and PCT $\left(r^{2}=0.36, P<0.001\right.$, Figure $\left.3.4 C\right)$ on the first day after trauma. Furthermore, early i-FABP levels correlated with CRP in plasma at the second day $\left(r^{2}=0.25, P<0.01\right.$; Figure 3.4D).

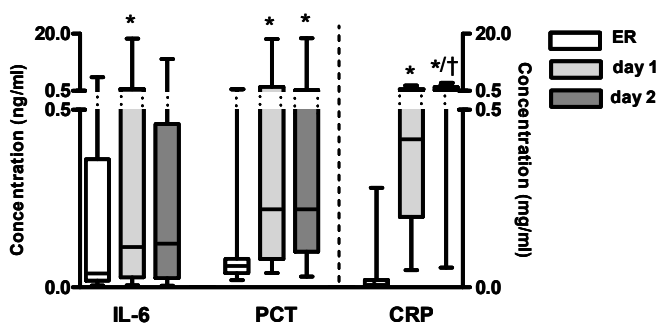

A

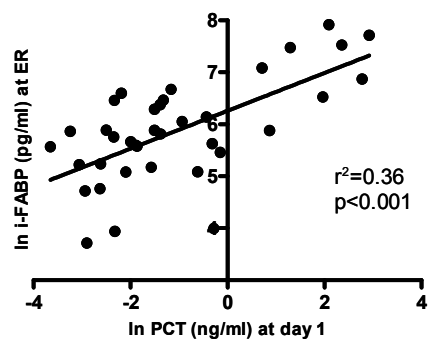

C

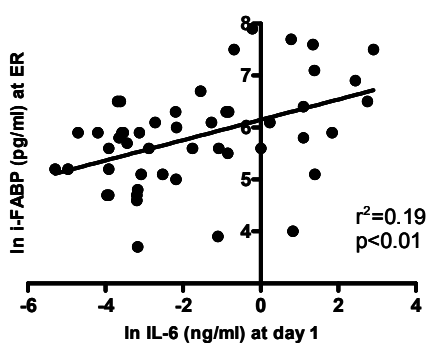

B

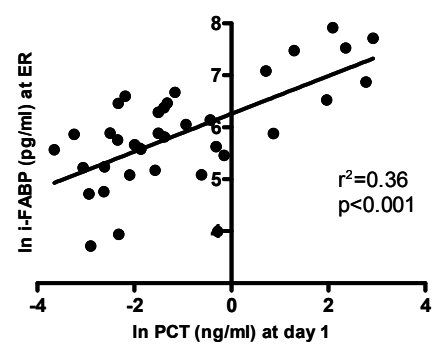

D

Figure 3.4 Intestinal mucosal cell damage after trauma correlates positively with the inflammatory response. A. Peak concentrations of circulating IL-6 and procalcitonin (PCT) were reached at the first day after trauma, whereas highest levels of C-reactive protein (CRP) were measured at the second day (all parameters: $* P<0.05$ vs. emergency room (ER); $+P<0.001$ vs. day 1 ). $\mathbf{B}, \mathbf{C}$, D. i-FABP concentrations at ER correlated positively with peak concentrations of IL- $6\left(r^{2}=0.19\right.$, $P<0.01)$, PCT $\left(r^{2}=0.36, P<0.001\right)$, and CRP $\left(r^{2}=0.25, P<0.01\right)$. All data are shown in natural logarithmic scale.

\section{Discussion}

Compromised intestinal integrity is considered to contribute to the inflammatory response to trauma ${ }^{12}$. This study sought to clarify the occurrence of intestinal damage and thus compromised integrity in the direct phase following severe trauma. Here, we 
showed presence of intestinal epithelial cell damage in a cohort of 96 trauma patients on arrival at the ER.

In the current study, evidence for intestinal cell damage after trauma was provided by increased plasma i-FABP levels. i-FABP is a small intracellular protein (14 kD) solely expressed in differentiated enterocytes of the small intestine and to a lower extent in the colon ${ }^{20,22,24}$. Following cell damage, i-FABP is released and readily detectable in circulation $^{22}$. The fast clearance of FABP (T1/2=11 minutes) implies that the enhanced plasma i-FABP levels reflect ongoing intestinal damage in our study ${ }^{29}$.

A strong increase of i-FABP was observed in trauma patients in shock. In the setting of shock, blood flow to the splanchnic region is hampered in favor of perfusion of vital organs such as the brain ${ }^{30,31}$. Therefore, the finding that $\mathrm{i}$-FABP release is increased in shock is in line with studies that established splanchnic hypoperfusion as a major cause of $\mathrm{i}$-FABP release. In a human model of gut ischemia and reperfusion, short-term ischemia induced a strong increase of plasma i-FABP, paralleled by histological damage of the epithelial layer and breakdown of intestinal barrier ${ }^{22}$. Moreover, elevated i-FABP levels were detected in settings of splanchnic hypoperfusion during non-abdominal surgery and critically illness ${ }^{23,32}$. In the present study shock was determined using the $\mathrm{SI}$, which is considered more sensitive for shock than standard vital signs alone ${ }^{26,33}$. The observed mucosal epithelial damage in this patient cohort stresses the importance of rapid and adequate fluid administration after severe trauma ${ }^{34}$.

An increase of intestinal cell damage was also present in patients with a normal SI, so the relation between intestinal damage and other trauma characteristics was explored. The ISS is a frequently used anatomical scoring system that correlates linearly with mortality, morbidity, hospital stay, and other measures of trauma severity ${ }^{28}$. In the current study, the extent of intestinal cell damage was found to be related to the ISS. It should be noted that the ISS is a composite of the scores of six body regions, including the abdomen. As abdominal trauma is a likely cause of intestinal cell damage, the relation between abdominal trauma and intestinal cell damage was then investigated. Half of the patients included in this study had trauma in the abdominal region, as determined using the AIS score. The highest i-FABP levels after trauma were detected in patients with severe abdominal trauma that required acute surgical intervention, such as rupture of the intestine, diaphragm, liver, and spleen. Further studies are needed to explore the sensitivity and specificity of i-FABP as an early marker for small intestinal organ damage following trauma. In addition to accepted diagnostic tools such as computed tomography, i-FABP assessment may help to detect abdominal emergencies in the early phase after trauma and support the decision to perform surgical intervention ${ }^{24,34,35,36}$. In conclusion, the extent of intestinal cell damage is related to shock, ISS, and abdominal trauma. 
In search for a potential role of the compromised gut in the development of inflammation following trauma, the relation between intestinal cell damage and the early inflammatory response was investigated. i-FABP levels on arrival at the ER correlated with concentrations at day 1 of IL-6, a potent cytokine in the early postinjury immune response that was identified as a useful predictor of complications as well as mortality ${ }^{37,38}$. Furthermore, i-FABP levels strongly correlated with day 1 plasma levels of PCT, an inflammation marker that is used to distinguish septic from non-septic patients $^{39}$. In line, CRP concentrations at day 2 also correlated positively to early i-FABP values. Taken together, early intestinal cell damage clearly precedes and is related to the subsequent inflammatory response to severe trauma. Further studies are required to determine the causative involvement and predictive value of early enterocyte damage and gut barrier loss in the development of inflammatory complications.

The gut has long since been considered to play a role in the pathophysiology of complications following trauma ${ }^{3-6}$. Clarification of the role of the intestine in the development of excessive inflammation after trauma is not only interesting from an etiologic viewpoint, but may also contribute to the selection of patients for novel therapeutic strategies directed at preservation of intestinal integrity and attenuation of the inflammatory response $e^{40}$.

\section{Conclusions}

To the best of the authors' knowledge, this paper is the first to show that a significant proportion of trauma patients rapidly develops intestinal mucosal cell damage. The extent of intestinal damage is readily detectable in blood withdrawn on presentation at the ER. Circulatory concentrations of enterocyte damage marker i-FABP are related to the presence of shock and the extent of general injury as well as abdominal trauma, indicating that the level of intestinal cell damage is determined by both systemic and local factors. Moreover, early i-FABP values correlate positively with the inflammatory response that develops in the days following trauma. Further studies are needed to clarify the importance of early intestinal damage in the pathophysiologic response to trauma and its diagnostic and therapeutic implications. 


\section{References}

1. Osborn TM, Tracy JK, Dunne JR, Pasquale M, Napolitano LM. Epidemiology of sepsis in patients with traumatic injury. Crit Care Med 2004;32:2234-2240.

2. Angus DC, Linde-Zwirble WT, Lidicker J, Clermont G, Carcillo J, Pinsky MR. Epidemiology of severe sepsis in the United States: analysis of incidence, outcome, and associated costs of care. Crit Care Med 2001;29:1303-1310.

3. Rotstein OD. Pathogenesis of multiple organ dysfunction syndrome: gut origin, protection, and decontamination. Surg Infect 2000;1:217-223.

4. Carrico CJ, Meakins JL, Marshall JC, Fry D, Maier RV. Multiple-organ-failure syndrome. Arch Surg 1986; 121:196-208.

5. Rowlands BJ, Soong CV, Gardiner KR. The gastrointestinal tract as a barrier in sepsis. Br Med Bull 1999; 55:196-211.

6. Moore FA. The role of the gastrointestinal tract in postinjury multiple organ failure. Am J Surg 1999; 178:449-453.

7. Thuijls G, de Haan JJ, Derikx JP, Daissormont I, Hadfoune M, Heineman E, Buurman WA. Intestinal cytoskeleton degradation precedes tight junction loss following hemorrhagic shock. Shock 2009; 31:164-169.

8. Deitch EA, Xu D, Kaise VL. Role of the gut in the development of injury- and shock induced SIRS and MODS: the gut-lymph hypothesis, a review. Front Biosci 2006;11:520-528.

9. Fink MP, Delude RL. Epithelial barrier dysfunction: a unifying theme to explain the pathogenesis of multiple organ dysfunction at the cellular level. Crit Care Clin 2005;21:177-196.

10. Luyer MD, Buurman WA, Hadfoune M, Jacobs JA, Konstantinov SR, Dejong CH, Greve JW. Pretreatment with high-fat enteral nutrition reduces endotoxin and tumor necrosis factor-alpha and preserves gut barrier function early after hemorrhagic shock. Shock 2004;21:65-71.

11. Van Leeuwen PA, Boermeester MA, Houdijk AP, Ferwerda CC, Cuesta MA, Meyer S, Wesdorp RI. Clinical significance of translocation. Gut 1994;35:S28-34.

12. Clark JA, Coopersmith CM. Intestinal crosstalk: a new paradigm for understanding the gut as the "motor" of critical illness. Shock 2007;28:384-393.

13. Coopersmith CM, Stromberg PE, Dunne WM, Davis CG, Amiot DM, Buchman TG, Karl IE, Hotchkiss RS. Inhibition of intestinal epithelial apoptosis and survival in a murine model of pneumonia-induced sepsis. JAMA 2002;287:1716-1721.

14. Matzinger $P$. The danger model: a renewed sense of self. Science 2002;296:301-305.

15. Rubartelli A, Lotze MT. Inside, outside, upside down: damage-associated molecular-pattern molecules (DAMPs) and redox. Trends Immunol 2007;28:429-436.

16. Soeters PB, Luyer MD, Greve JW, Buurman WA. The significance of bowel permeability. Curr Opin Clin Nutr Metab Care 2007;10:632-638.

17. Langkamp-Henken B, Donovan TB, Pate LM, Maull CD, Kudsk KA. Increased intestinal permeability following blunt and penetrating trauma. Crit Care Med 1995;23:660-664.

18. Kompan L, Kompan D. Importance of increased intestinal permeability after multiple injuries. Eur $J$ Surg 2001;167:570-574.

19. Bjarnason I, MacPherson A, Hollander D. Intestinal permeability: an overview. Gastroenterology 1995; 108:1566-1581.

20. Lieberman JM, Sacchettini J, Marks C, Marks WH. Human intestinal fatty acid binding protein: report of an assay with studies in normal volunteers and intestinal ischemia. Surgery 1997;121:335-342.

21. Pelsers MM, Namiot Z, Kisielewski W, Namiot A, Januszkiewicz M, Hermens WT, Glatz JF. Intestinaltype and liver-type fatty acid-binding protein in the intestine. Tissue distribution and clinical utility. Clin Biochem 2003;36:529-535.

22. Derikx JP, Matthijsen RA, de Bruine AP, van Bijnen AA, Heineman E, van Dam RM, Dejong CH, Buurman WA. Rapid reversal of human intestinal ischemia-reperfusion induced damage by shedding of injured enterocytes and reepithelialisation. PLOS ONE 2008;3:e3428.

23. Derikx JP, van Waardenburg DA, Thuijls G, Willigers HM, Koenraads M, van Bijnen AA, Heineman E, Poeze $M$, Ambergen T, van Ooij A, van Rhijn LW, Buurman WA. New insight in loss of gut barrier during major non-abdominal surgery. PLOS ONE 2008;3:e3954. 
24. Derikx JP, Vreugdenhil AC, Van den Neucker AM, Grootjans J, van Bijnen AA, Damoiseaux JG, van Heurn LW, Heineman E, Buurman WA. A pilot study on the noninvasive evaluation of intestinal damage in celiac disease using I-FABP and L-FABP. J Clin Gastroenterol 2009;43:727-733.

25. von Elm E, Altman DG, Egger M, Pocock SJ, Gotzsche PC, Vandenbroucke JP. The Strengthening the Reporting of Observational Studies in Epidemiology (STROBE) statement: guidelines for reporting observational studies. Bull World Health Organ 2007;85:867-872.

26. Rady MY, Smithline HA, Blake H, Nowak R, Rivers E. A comparison of the shock index and conventional vital signs to identify acute, critical illness in the emergency department. Ann Emerg Med 1994; 24:685-690.

27. The Abbreviated Injury Scale, 1990 Revision, Update 98. Association for the Advancement of Automotive Medicine; Barrington, IL 1998.

28. Baker SP, O'Neill B, Haddon W, Jr., Long WB. The injury severity score: a method for describing patients with multiple injuries and evaluating emergency care. J Trauma 1974;14:187-196.

29. van de Poll MC, Derikx JP, Buurman WA, Peters WH, Roelofs HM, Wigmore SJ, Dejong CH. Liver manipulation causes hepatocyte injury and precedes systemic inflammation in patients undergoing liver resection. World J Surg 2007;31:2033-2038.

30. Ceppa EP, Fuh KC, Bulkley GB. Mesenteric hemodynamic response to circulatory shock. Curr Opin Crit Care 2003;9:127-132.

31. Tamion F, Richard V, Sauger F, Menard JF, Girault C, Richard JC, Thuillez C, Leroy J, Bonmarchand G. Gastric mucosal acidosis and cytokine release in patients with septic shock. Crit Care Med 2003; 31:2137-2143.

32. Derikx JP, Poeze M, van Bijnen AA, Buurman WA, Heineman E. Evidence for intestinal and liver epithelial cell injury in the early phase of sepsis. Shock 2007;28:544-548.

33. King RW, Plewa MC, Buderer NM, Knotts FB. Shock index as a marker for significant injury in trauma patients. Acad Emerg Med 1996;3:1041-1045.

34. Blow O, Magliore L, Claridge JA, Butler K, Young JS. The golden hour and the silver day: detection and correction of occult hypoperfusion within 24 hours improves outcome from major trauma. $J$ Trauma 1999;47:964-969.

35. Evennett NJ, Petrov MS, Mittal A, Windsor JA. Systematic review and pooled estimates for the diagnostic accuracy of serological markers for intestinal ischemia. World J Surg 2009;33:1374-1383.

36. Relja B, Szermutzky M, Henrich D, Maier M, de Haan JJ, Lubbers T, Buurman WA, Marzi I. IntestinalFABP and liver-FABP: Novel markers for severe abdominal injury. Acad Emerg Med 2010;17:729-735.

37. Stensballe J, Christiansen M, Tonnesen E, Espersen K, Lippert FK, Rasmussen LS. The early IL-6 and IL10 response in trauma is correlated with injury severity and mortality. Acta Anaesthesiol Scand 2009; 53:515-521.

38. Biffl WL, Moore EE, Moore FA, Peterson VM. Interleukin-6 in the injured patient. Marker of injury or mediator of inflammation? Ann Surg 1996;224:647-664.

39. Tang BM, Eslick GD, Craig JC, McLean AS: Accuracy of procalcitonin for sepsis diagnosis in critically ill patients: systematic review and meta-analysis. Lancet Infect Dis 2007;7:210-217.

40. de Haan JJ, Lubbers T, Hadfoune M, Luyer MD, Dejong CH, Buurman WA, Greve JW. Postshock intervention with high-lipid enteral nutrition reduces inflammation and tissue damage. Ann Surg 2008; 248:842-848. 


\title{
CHAPTER 4
}

\section{Intestinal cytoskeleton degradation}

\author{
precedes tight junction loss
}

following hemorrhagic shock

Geertje Thuijls, Jacco J. de Haan, Joep P. Derikx, Isabelle Daissormont, M'hamed Hadfoune, Erik Heineman, Wim A. Buurman 


\section{Abstract}

Introduction: Hemorrhagic shock leads to intestinal barrier loss, causing systemic inflammation, which in turn can ultimately lead to multi-organ dysfunction syndrome (MODS). Barrier function is based on tight junctions (TJ) between intact epithelial cells. These TJ are anchored in the cell via the filamentous actin (F-actin) cytoskeleton. We hypothesize that hemorrhagic shock (HS) causes hypoperfusion, leading to loss of F-actin, via activation of Actin Depolymerizing Factor/cofilin (AC), and consequently TJ loss. This study is aimed at unravelling the changes in cytoskeleton and tight junction integrity following HS in organs commonly affected in MODS (liver, kidney and intestine) and to elucidate the events preceding cytoskeleton loss.

Methods: Adult rats were subjected to a nonlethal HS and sacrificed, along with unshocked controls, at 15, 30, 60 and 90 min after induction of shock. Cytoskeleton, tight junction integrity loss and its consequences were studied by assessment of globular actin (G-actin), F-actin, AC, ZO-1 and Claudin-3 and bacterial translocation.

Results: In the liver and kidney TJ and the F-actin cytoskeleton remained intact at all time-points studied. However, in the intestine, significant loss of F-actin and increase of G-actin was seen from 15 min after shock. This change preceded statistically significant loss of the tight junction proteins Claudin-3 and ZO-1 which were observed starting at $60 \mathrm{~min}$ after induction of shock $(P<0.05$ versus controls). Early after induction of shock (15 and $30 \mathrm{~min}$ ) the non active $A C$ (phosphorylated AC) in the intestine was significantly decreased (by $21 \%$ and $27 \%, P<0.05$ versus control) whereas total $A C$ remained constant, reflecting an increase in activated $A C$ in the intestine from 15 min after shock. Bacterial translocation to mesenteric lymph nodes, liver and spleen was present from 30 min after shock.

Conclusions: This study shows for the first time that HS results in AC activation, selective intestinal actin cytoskeleton disruption and tight junction loss, very early after the onset of shock. Loss of this intestinal barrier results in translocation of toxins and bacteria, which enhances inflammation and leads to infections. 


\section{Introduction}

Hemorrhagic shock (HS) is a clinical condition characterized by insufficient tissue perfusion to meet the demand for oxygen and nutrients. This hypoperfusional state can trigger a systemic inflammatory response, sepsis and ultimately multi-organ dysfunction syndrome (MODS) ${ }^{1-3}$. MODS commonly affects the intestine, liver, kidney and lung.

The proper function of these visceral organs depends on generation and maintenance of compositionally distinct compartments by a barrier formed by epithelial cells sealed by tight junctions (TJ) ${ }^{4}$. TJ serve as a fence dividing cells into apical and basolateral domains. These TJ are anchored in the cell via the filamentous actin (F-actin) cytoskeleton. Hypoperfusion or ischemia can cause disruption of the F-actin cytoskeleton, with subsequent barrier failure. Gut wall integrity loss leads to paracellular leakage of microbial products ${ }^{5-8}$. Hepatic barrier dysfunction leads to toxins and bile escaping into the systemic circulation ${ }^{6,9}$. Barrier failure in the kidney causes backleakage of tubular fluid ${ }^{6,10}$. These clinical consequences of epithelial tight junction loss are potential triggers for an innate immune response. Derangement in the formation and function of TJ has a prominent role in liver, gut and kidney dysfunction not only during sepsis, but also in $\operatorname{MODS}^{6,7,11}$. However, HS does not result in early pulmonary tight junction loss, pulmonary dysfunction or leak of the alveolarcapillary membrane, in absence of severe associated factors, like massive inflammation ${ }^{2,12}$.

The actin cytoskeleton is a dynamic structure that maintains cell shape and tight junction stability. Increasing evidence implicates Actin Depolymerizing Factor/cofilin (AC) as a mediator of cellular actin dynamics by binding to F-actin and enhancing its severing and turnover (recycling) ${ }^{13-16}$. Cofilin is expressed in the mouse small intestine $^{17}$. Adenosine triphosphate (ATP) depletion, as occurs in hypoperfusion, results in AC activation (dephosphorylation). Dephosphorylated AC binds F-actin and at relatively low stoichiometry to F-actin subunits, AC can sever F-actin and enhance subunit turnover. At higher stoichiometry $A C$ can stabilize and bundle F-actin into aggregates or rods ${ }^{18,19}$. As a result of low stoichiometric activation of AC, the actin cytoskeleton is disrupted, losing connections with tight junction proteins and causing disassembly of TJ, a process that also is dependent on myosin II based contractility ${ }^{20}$. Indeed, in renal ischemia reperfusion injury, a situation with great resemblance to HS, ATP depletion in the kidney causes activation of AC, its relocalization to the apical membrane, and consequent alterations in the apical actin cytoskeleton ${ }^{15,21}$. This study is aimed at unravelling the changes in cytoskeleton and tight junction integrity after HS in the organs commonly affected in MODS (liver, kidney and intestine) and to elucidate $\mathrm{AC}$ activity preceding and during cytoskeleton loss. 


\section{Materials and methods}

\section{Reagents}

Rabbit anti-Zonula Occludens protein 1 (ZO-1) (61-7300) and Rabbit anti-Claudin-3 (34-1700) were purchased from Invitrogen (San Francisco, CA). Mouse anti-G-actin (globular actin) (JLA20) was purchased from Developmental Studies Hybridoma Bank, University of lowa (Ames, lowa). Mouse anti-actin (C4) was purchased from MP Biomedicals (Aurora, Ohio). Oregon Green-Phalloidin (07465) was purchased from Invitrogen. Rabbit anti-Actin Depolymerizing Factor/Cofilin (total AC (tAC)) (rabbit 1439) and Rabbit anti-phosphorylated-AC (pAC) were previously characterized ${ }^{22,23}$. Mouse anti-beta Actin (A 2228) was purchased from Sigma (Saint Louis, MO). Texas red conjugated goat anti-rabbit antibody, Texas red conjugated rat anti-rabbit antibody, goat anti-rabbit horseradish peroxidise (HRP)-conjugated secondary antibody and rat anti-mouse HRP-conjugated secondary antibody were purchased from Jackson (West Grove, PA).

\section{Animals}

This study was performed according to the guidelines of the Animal Care Committee of Maastricht University. Sprague-Dawley rats, healthy males weighing 266-450 g (average, $349 \mathrm{~g}$ ) purchased from Charles River (Maastricht, the Netherlands) were housed under controlled conditions of temperature and humidity. Before the start of the experiments, rats were fed water and chow ad libitum.

\section{Experimental design and hemorrhagic shock procedure}

Rats were allocated to 5 groups ( $n=6$ per group) before the start of the experiments. Control rats (group 1) were sacrificed without intervention. The other rats were exposed to non-lethal HS after 18 hours fasting as previously described ${ }^{24}$. Briefly, rats were anesthetized with isoflurane (induction $4 \%$, maintenance $1.5 \%$ ). The femoral artery was aseptically dissected and cannulated with polyethylene tubing (PE-10) containing heparinized saline $(10 \mathrm{lU} / \mathrm{ml})$. Mean arterial blood pressure (MAP) and heart rate (HR) were assessed continuously. After 30 min acclimatization period, $2.1 \mathrm{ml}$ blood /100 g of body weight was withdrawn (representing approximately $30-40 \%$ of the circulating volume) at a rate of $1 \mathrm{ml} /$ minute. Groups $2,3,4$, and 5 were sacrificed at 15, 30, 60 and 90 min after shock, respectively. At sacrifice blood and tissue samples were taken.

The severity of the HS as reflected by changes in MAP, HR, and hematocrit was similar for all animals studied. Immediately after induction of shock $(t=0)$, mean MAP-values decreased from 89 (80-105) $\mathrm{mmHg}$ to $24(20-32) \mathrm{mmHg}$, and the HR decreased from 397 (350-470) beats per minute (bpm) to 226 (160-270) bpm in all shock groups. 
Hematocrit was reduced from $43 \pm 2.0 \%$ to $35 \pm 2.9 \%$ after shock at all time-intervals studied (Table 4.1). These data are comparable with previously published data, using the same HS model ${ }^{25,26}$.

Table 2.1 The severity of the hemorrhagic shock as reflected by mean changes in mean arterial pressure (MAP), heart rate (HR), and hematocrit $(\mathrm{Ht})$ was similar for all animals studied. ${ }^{1,2,3}$

\begin{tabular}{lccccccccc}
\hline Time after shock & MAP & \multicolumn{3}{c}{ HR } & \multicolumn{3}{c}{$\mathrm{Ht}$} \\
(min) & 0 & $10 \mathrm{~min}$ & $\Delta(\%)$ & 0 & $10 \mathrm{~min}$ & $\Delta(\%)$ & 0 & sacrifice & $\Delta(\%)$ \\
\hline Group 15 & 91 & 24 & 73 & 405 & 238 & 41 & 44 & 35 & 20 \\
Group 30 & 90 & 25 & 73 & 397 & 221 & 44 & 43 & 35 & 19 \\
Group 60 & 86 & 26 & 70 & 383 & 227 & 41 & 43 & 34 & 22 \\
Group 90 & 87 & 23 & 73 & 406 & 236 & 42 & 43 & 35 & 20 \\
\hline
\end{tabular}

${ }^{1}$ All groups consist of 6 animals; ${ }^{2}$ Group 15, 30, 60 and 90 represent animals sacrificed 15, 30, 60 and 90 minutes after shock; ${ }^{3} \mathrm{MAP}$ and HR are given at 0 minutes (just before shock) and at 10 minutes after the onset of shock. Ht is given at 0 minutes and at sacrifice. $\Delta$ is the percentage of decrease of MAP, HR and $\mathrm{Ht}$ between time-point 0 and time-point 10 minutes/sacrifice.

\section{Immunohistochemistry}

Tight junction distribution and the actin cytoskeleton were examined by immunofluorescent staining of frozen sections ( $3 \mu \mathrm{m}$ ) for ZO-1, Claudin-3, G-actin and F-actin. lleum, liver and kidney sections were fixed with $4 \%$ paraformaldehyde. Nonspecific binding sites were blocked with $10 \%$ goat serum and incubated overnight at $4^{\circ} \mathrm{C}$ with anti-ZO-1, anti-Claudin-3, or anti-G-actin. Thereafter, the sections were incubated $45 \mathrm{~min}$ with Texas red conjugated goat anti-rabbit antibody or with Texas red-conjugated rat anti-rabbit antibody. F-actin sections were stained with Oregon green-Phalloidin for $45 \mathrm{~min}$, followed by 2 min incubation with 4',6-diamino-2-phenyl indole (DAPI), dehydrated in ascending ethanol series and mounted in Fluorescence Mounting Solution (Dakocytomation, Glostrup, Denmark). The distribution of TJ and the actin cytoskeleton was recorded at a magnification of $200 x / 400 x$ using the Metasystems Image Pro System (black and white charge-couple device camera; Metasystems, Sandhausen, Germany) mounted on a Leica DM-RE fluorescence microscope (Leica, Wetzler, Germany). All images were taken at equal time-exposures after being normalized to negative control sections without primary antibody, to exclude for non-specific binding of the secondary antibody or autofluorescence. At least 25 microscopic fields for each tissue section were examined. 


\section{Epithelial cell isolation and protein extraction}

Intestinal epithelial cells of rats were isolated using a modification of a previously published method ${ }^{27,28}$. In short, a fresh section of intestine was inverted and washed in $4^{\circ} \mathrm{C}$ phosphate buffered saline (PBS) containing $50 \mathrm{nM}$ of the phosphatase inhibitor calyculin A (Merck Biosciences, Nottingham, UK). Next the tissue was transferred to $\mathrm{Ca}^{2+}$ - and Mg+-free Hank's balanced salt solution containing 30mM EDTA and 50nM calyculin $A$ and incubated for $20 \mathrm{~min}$ at $4^{\circ} \mathrm{C}$. After incubation, the tissue was transferred to a fresh tube containing CMF-HBSS with $0.3 \mathrm{U} / \mathrm{ml}$ dispase (Boehringer Mannheim, Germany) and $50 \mathrm{nM}$ calyculin A. After incubation at $37^{\circ} \mathrm{C}$ for $20 \mathrm{~min}$, epithelial cells were dislodged by scraping the epithelial surface. Isolated cells were analysed microscopically and only epithelial cells were observed.

The isolated intestinal epithelial cells, liver samples and kidney samples were lysed in lysis buffer containing $200 \mathrm{mM} \mathrm{NaCl}, 5 \mathrm{mM}$ EDTA, $10 \mathrm{mM}$ Tris, $10 \%$ glycine, $1 \mathrm{mM}$ phenylmethanesulfonyl fluoride, $1 \mu \mathrm{g} / \mathrm{ml}$ leupeptine and $28 \mu \mathrm{g} / \mathrm{ml}$ aprotinine and centrifuged at $40,000 \mathrm{~g}$ for $10 \mathrm{~min}$ at $4^{\circ} \mathrm{C}$. The protein concentration of the supernatants was measured using the Bradford method (Biorad, Hercules, CA).

\section{Western Blotting}

Aliquots with equal amounts of protein determined with the Bradford method (extracts from isolated rat intestinal epithelial cells, liver and kidney) were heated at 100 ㄷ for $5 \mathrm{~min}$ in SDS sample buffer, separated on SDS-polyacrylamide gels and transferred to polyvinylidene fluoride membrane (Immobilin P, Millipore, Bedford, $\mathrm{MA})$. For G-actin non-reducing western blotting was performed. After transfer of proteins, a blocking step was performed in Tris buffered saline (TBS) with $5 \%$ non-fat dry milk and $0.05 \%$ Tween. Membranes were probed using primary antibodies to ZO-1, Claudin-3, tAC, PAC, Actin and beta-Actin in TBS $0.05 \%$ Tween. To confirm equal protein loading, immunoblotting was performed with beta-Actin. After incubation with goat anti-rabbit or rat anti-mouse HRP-conjugated secondary antibody, signal was detected by chemiluminescence on film (Pierce Biotechnology Inc., Rockland, IL). Band intensity was quantitatively analyzed using Quantity One (Biorad).

\section{Bacterial translocation}

In all rats mesenteric lymph nodes (MLN), the midsection of the spleen, and segment IV of the liver were collected aseptically in $2 \mathrm{ml}$ pre-weighed thioglycolate broth tubes (Becton Dickinson (BBL) Microbiology Europe, Maylan, France). After weighing, the tissue specimens were homogenized and subsequently transferred onto the following agar plates: Columbia III blood agar base supplemented with $5 \%$ vol/vol sheep blood (BBL) (duplicate plates) and Chocolate PolyviteX agar (BioMe'rieux, Marcy L'Etoile, 
France). After 48 hours incubation, the colonies were counted, adjusted to the weight of the tissue and expressed as number of colony forming units (CFU) per gram tissue.

\section{Statistical analyses}

Gaussian distribution was tested using the Kolmogorov-Smirnov test. One-way ANOVA followed by Dunnett's Multiple Comparison Test was used for between-group comparisons. $P<0.05$ was considered statistically significant. Data are presented as mean $\pm \mathrm{SEM} /$ range.

\section{Results}

\section{Actin filament severing}

The turnover of F-actin into G-actin after shock in ileum, liver and kidney was investigated by immunofluorescence and western blotting. Immunofluorescence showed increased G-actin from $15 \mathrm{~min}$ after induction of HS in the ileum, with simultaneous decrease in F-actin. The intensity of G-actin was still increased at 30 and 60 min after induction of shock. Rats sacrificed ninety min after induction of HS also showed a an upregulation of G-actin and significant loss of F-actin compared to control rats, although less G-actin and more F-actin was observed compared to rats sacrificed 15, 30 and 60 min after HS (Figure 4.1A). Western blot of G-actin showed a statistically significant increase in densitometric intensity at 15 minutes after shock compared to controls $\left({ }^{*} P<0.05\right)$ (Figure $\left.4.1 \mathrm{~B}\right)$.

In liver and kidney sections F-actin cytoskeleton remained intact and there was no G-actin detectable at the investigated time-points (Figure 4.2, G-actin staining not shown).

\section{Intestinal AC activation after hemorrhagic shock}

We report the presence of both $\mathrm{tAC}$ and $\mathrm{pAC}$ in normal ileum, using western blot with antibodies against tAC and PAC. Furthermore, the effect of HS on the relative amounts of tAC and PAC was studied. Figure 4.3 shows the densitometric analysis of western blot data of intestinal epithelial cell homogenates using antibodies to tAC and PAC. The total concentration of tAC in gut epithelial cells did not change significantly after $\mathrm{HS}$ (Figure 4.3A). pAC expression was statistically significant decreased 15, 30 and $60 \mathrm{~min}$ after induction of shock (by 21,27 and $26 \%$ respectively, $P<0.05$ ) (Figure $4.3 \mathrm{~B}$ ). This decrease in PAC values reflects $A C$ activation. 
G-actin

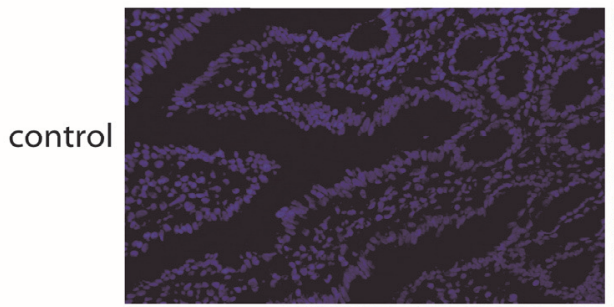

$15 \min$

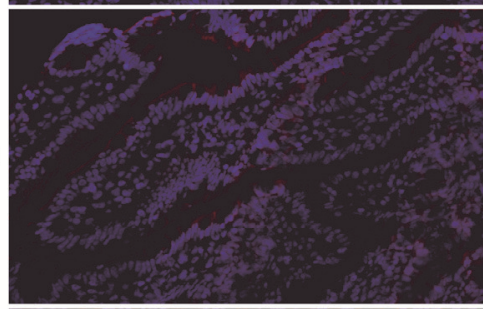

$30 \mathrm{~min}$

$60 \mathrm{~min}$
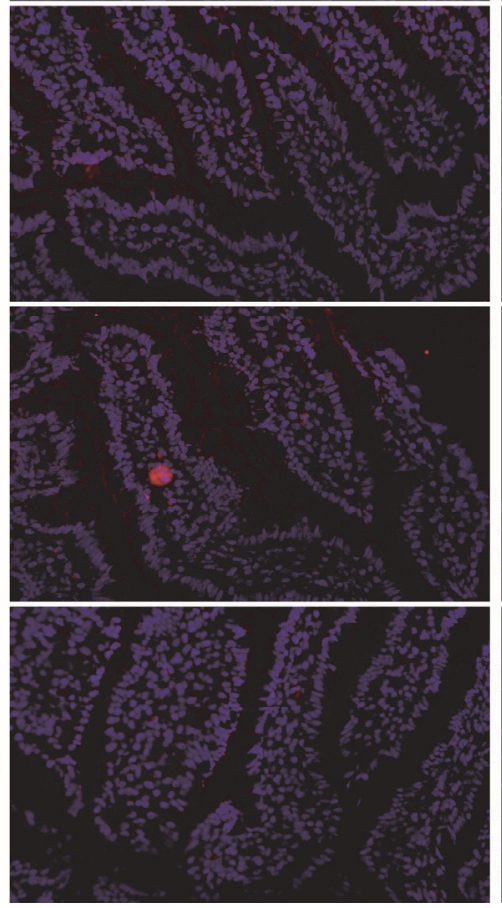

F-actin
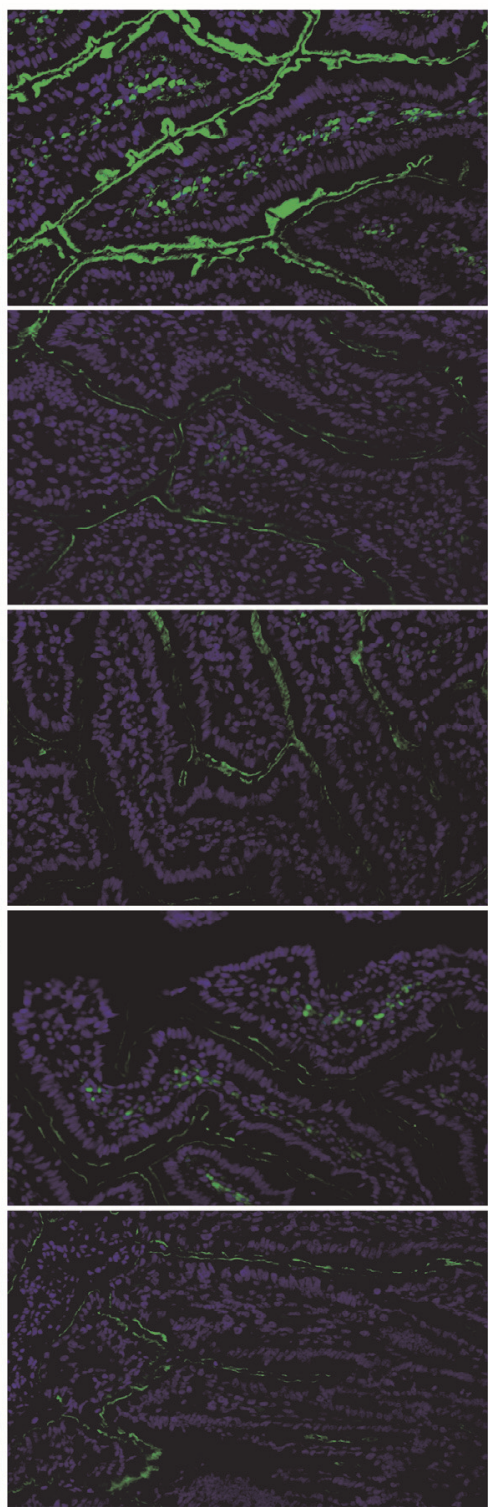

Figure 4.1A Immunolocalisation of G-Actin (red) and F-actin (green) in the ileum following hemorrhagic shock. Nuclei are stained with DAPI (blue). Control rats showed a regular distribution of F-actin and no detectable G-actin. Rats sacrificed 15, 30 and 60 min after induction of hemorrhagic shock showed an upregulation of G-actin and significant loss of F-actin. Rats sacrificed 90 min after induction of hemorrhagic shock also showed an upregulation of G-actin and a significant loss of F-actin and compared to control rats, although less G-actin and more F-actin was observed compared to rats sacrificed 15, 30 and 60 min after hemorrhagic shock. (200x magnification) 


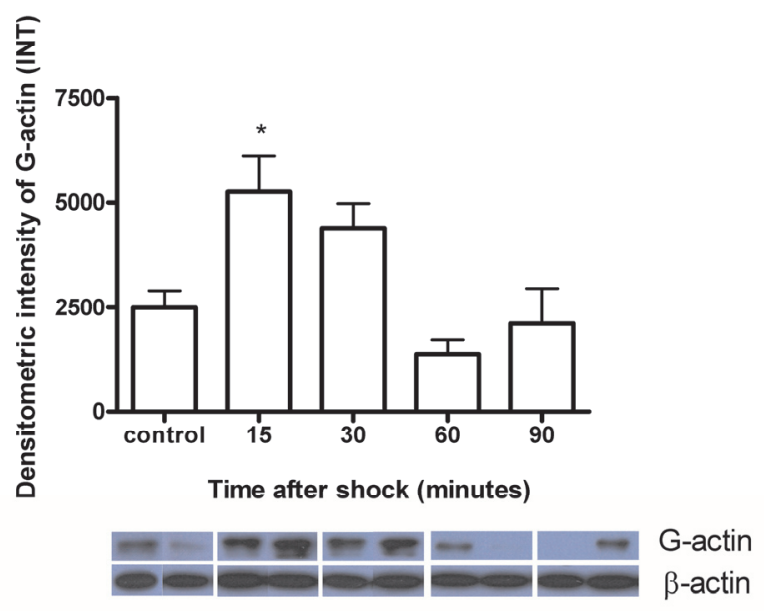

Figure 4.1B Densitometric analysis of western blot of $\mathrm{G}$-actin in rat intestinal epithelial cells. Western blot of $\mathrm{G}$-actin showed a significant increase in densitometric intensity at 15 minutes after shock compared to controls $\left({ }^{*} P<0.05\right)$. Beta-Actin was used to confirm equal protein loading. Values are expressed as mean \pm SEM.

\section{Intestinal, liver and renal tight junction loss}

A significant loss of the most important transmembrane tight junction protein Claudin-3 and the intracellular tight junction protein ZO-1 from $30 \mathrm{~min}$ after induction of shock was observed by immunofluorescent staining of microscopic sections of the ileum (Figure 4.4). This loss was quantified using western blotting of rat epithelial cell homogenates. Statistically significant loss of Claudin-3 and ZO-1 was seen from 60 min after induction of shock (Figure 4.5).

In liver and kidney sections immunofluorescent staining showed no difference in ZO-1 and Claudin-3 immunolocalization between control rats and rats sacrificed 15, 30, 60 and 90 min after induction of HS (data not shown). Also western blot analysis showed no significant loss of Claudin-3 in the liver and kidney at any time point after induction of HS as compared to control rats (data not shown). 

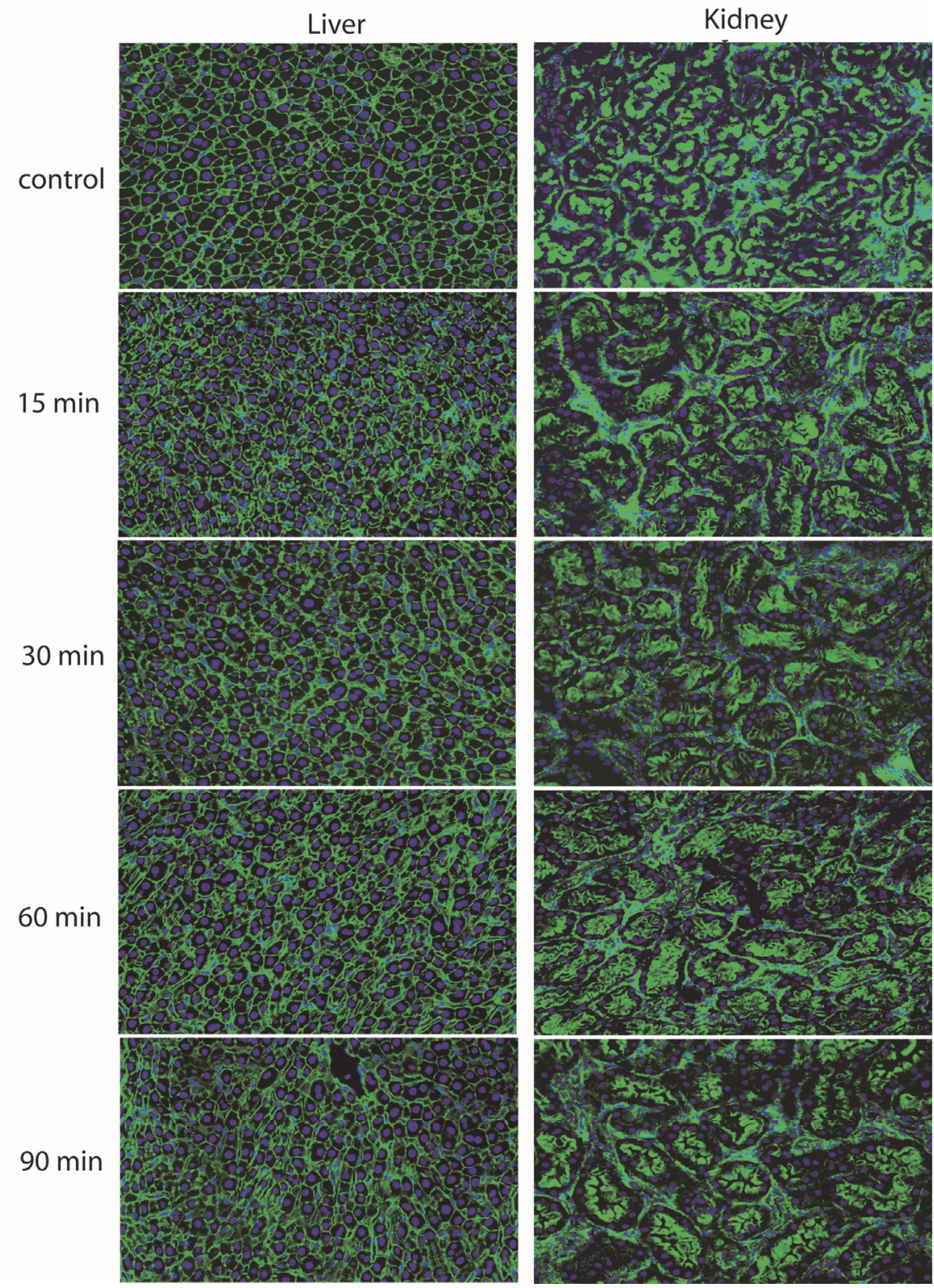

Figure 4.2 Immunolocalisation of F-Actin in liver and in kidney (green) following hemorrhagic shock. Nuclei are stained with DAPI (blue). F-actin distribution did not change following hemorrhagic shock in the time period studied. (200x magnification) 

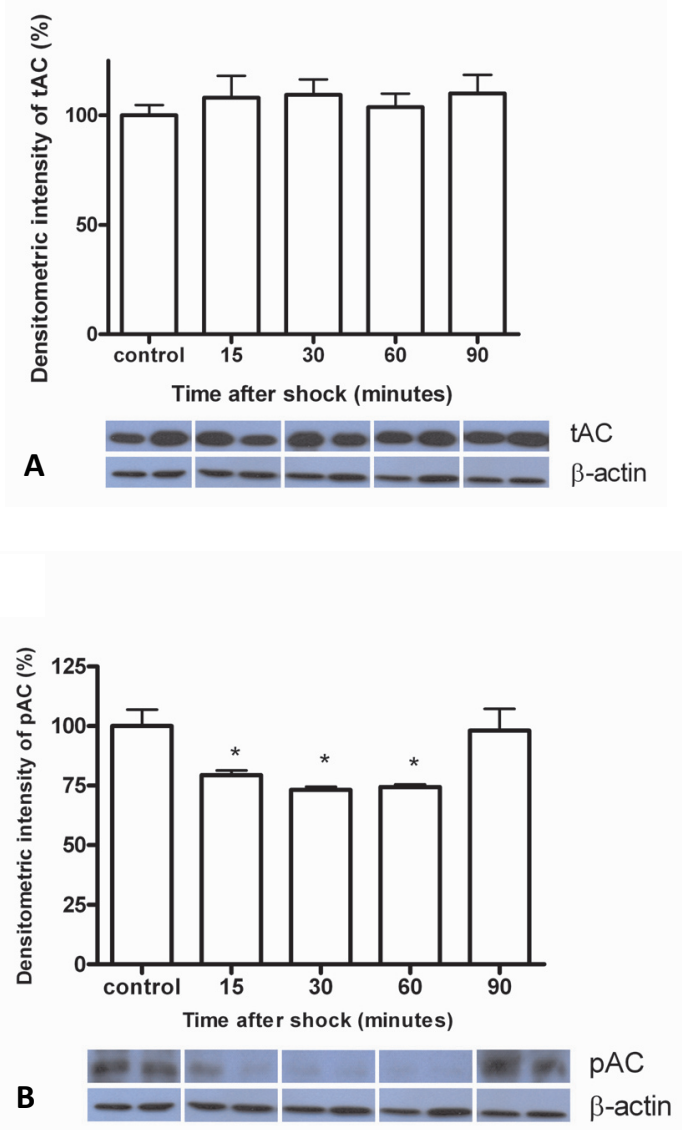

Figure 4.3 Densitometric analysis of western blot of total $A C$ (tAC) and phosphorylated AC (pAC) in rat intestinal epithelial cells. A. Western blot of tAC showed no significant attenuation in densitometric intensity after shock compared to controls. B. Western blot of pAC showed a significant attenuation in densitometric intensity at 15, 30 and 60 min after shock compared to controls $\left({ }^{*} P<0.05\right)$. Signal intensity of the specific band from the untreated control rats was set as $100 \%$ and was compared with the after-shock values. Beta-Actin was used to confirm equal protein loading. Values are expressed as mean \pm SEM. 
ZO-1

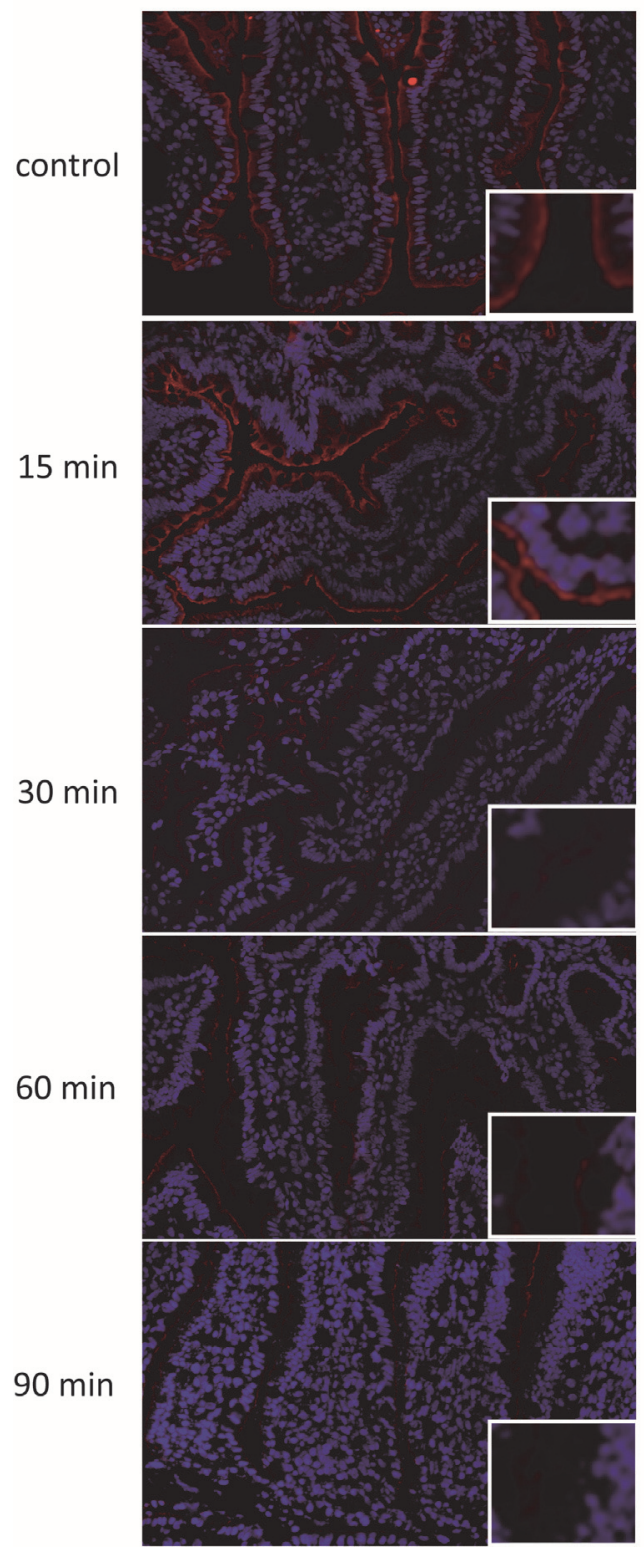

Claudin-3
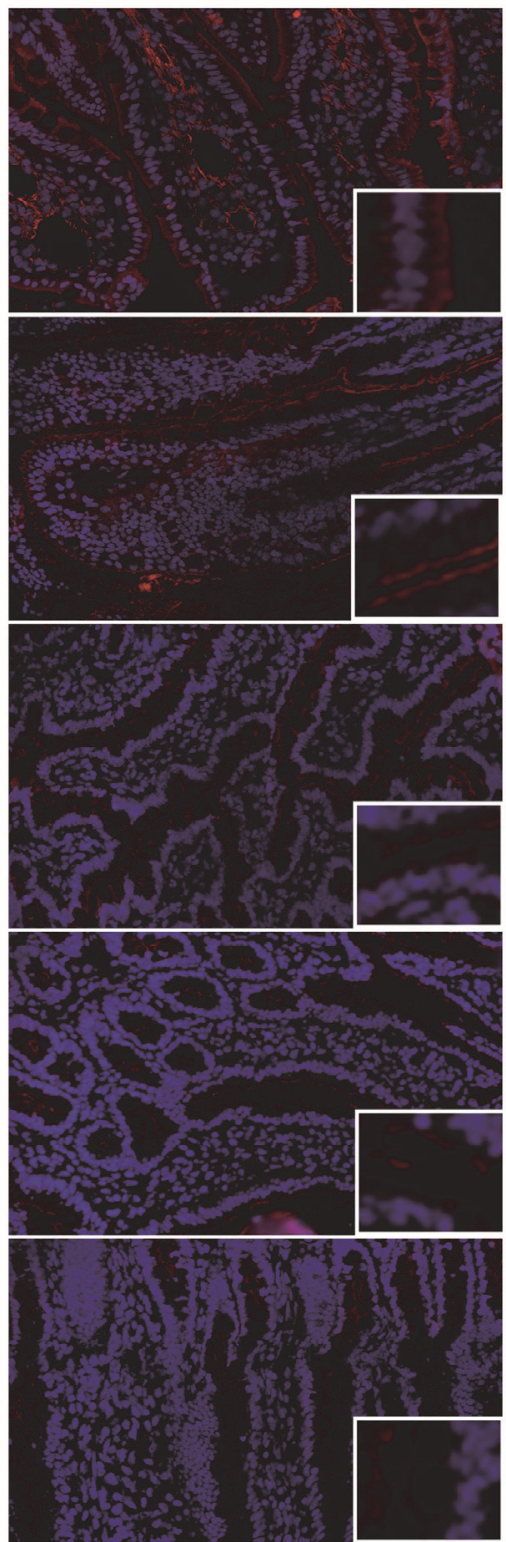

Figure 4.4 Immunolocalisation of ZO-1 and Claudin-3 (both in red) in ileum showed a regular distribution in control rats and in animals sacrificed $15 \mathrm{~min}$ after induction of shock. Already at $30 \mathrm{~min}$ after hemorrhagic shock a significant loss of Claudin-3 and ZO-1 was found, which persisted up to 90 min after shock. Nuclei are stained with DAPI (blue, original magnification 200x; for insert, original magnification 400x) 


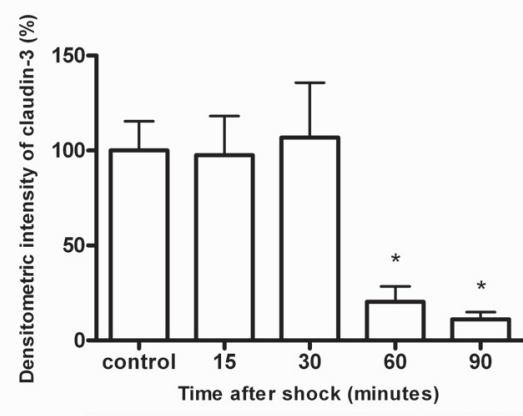

A

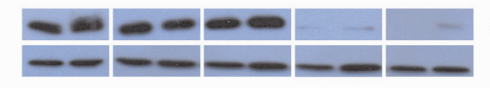

claudin-3

$\beta$-actin

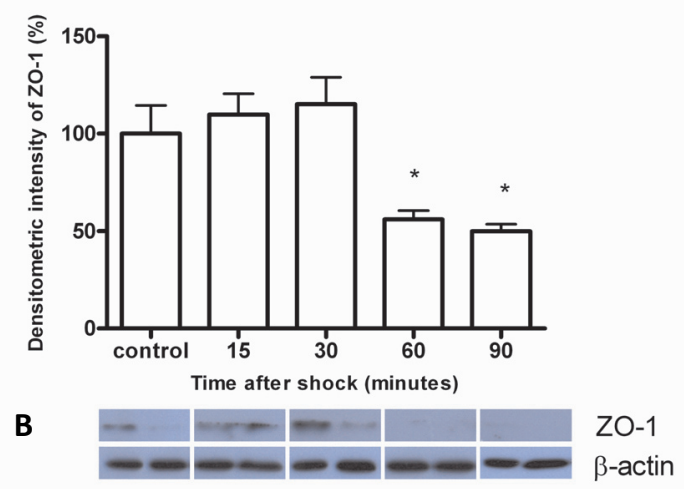

Figure 4.5 Densitometric analysis of western blot of Claudin-3 and ZO-1 in rat intestinal epithelial cells. A. Western blot of Claudin-3 showed a significant attenuation in densitometric intensity at 60 and $90 \mathrm{~min}$ after shock compared to earlier time-points $\left({ }^{*} P<0.05\right)$. B. Western blot of ZO-1 showed a significant attenuation in densitometric intensity at 60 and 90 min after shock compared to earlier time-points $\left({ }^{*} P<0.05\right)$. Signal intensity of the specific band from the untreated control rats was set as $100 \%$ and was compared with the after-shock values. BetaActin was used to confirm equal protein loading. Values are expressed as mean \pm SEM.

\section{Intestinal permeability to bacteria}

To determine whether hemorrhage leads to increased intestinal permeability we measured bacterial translocation to distant organs (Figure 4.6). As expected, cultures from tissues taken from the control group were mostly sterile. Bacterial translocation was significantly elevated in animals sacrificed 30, 60 and 90 min after induction of HS as compared to control animals $(P<0.05)$. Colony forming units per gram tissue (CFU/g tissue) found in mesenteric lymph nodes (MLN), spleen, and liver were 0.4 (0.0-1.0), 8.4 (0.0-21.4), 35.0 (19.7-58.7), 50.1 (21.9-75.7), 133.3 (95.7-199.8) for controls rats 
and rats sacrificed at 15, 30, 60 and 90 min after HS, respectively. The most frequently found bacteria in the cultures were gut derived Escherichia coli, Enterococcus faecalis and Staphylococcus aureus. Bacteria were more often found in MLN than spleen or liver.

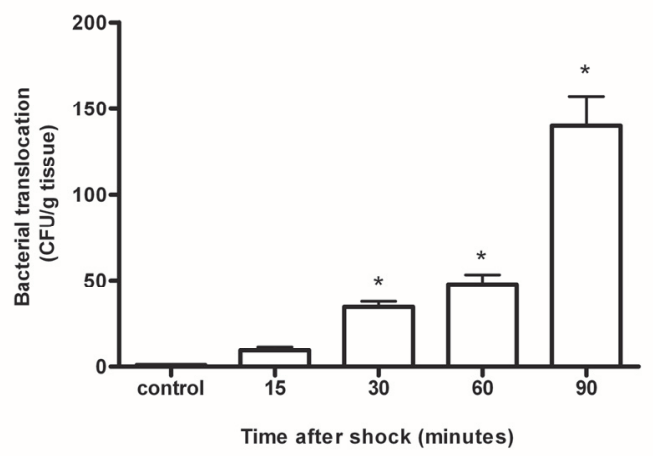

Figure 4.6 Bacterial translocation to mesenteric lymph nodes (MLN), spleen, and liver was significantly elevated 30, 60 and 90 min after hemorrhagic shock as compared to control animals $\left({ }^{*} P<0.05\right)$. Values are expressed as mean \pm SEM.

\section{Discussion}

This study was aimed at unravelling the changes in tight junction integrity after HS in the organs commonly affected in MODS (liver, kidney and intestine) and to elucidate the events preceding tight junction loss. Intestinal severing of the F-actin cytoskeleton, which intactness is necessary for tight junction integrity, was observed very early after shock, starting as soon as 15 min after the onset of shock. In contrast, F-actin cytoskeleton disruption in liver and kidney was not seen at any investigated time point, e.g. up to 90 min after shock.

In the current study we found that both $\mathrm{tAC}$ and $\mathrm{pAC}$ are present in intestinal epithelial cells under physiological conditions. Phosphorylated AC decreased statistically significant 15 min after induction of shock, which is expected to be responsible for actin cytoskeleton severing. Consequently, the interaction of tight junction proteins with F-actin was disrupted leading to tight junction loss. AC binding to F-actin causes a twist in F-actin that destabilizes the filament. Furthermore, this twist in F-actin eliminates the binding sites for phalloidin, such that AC-saturated filaments are not stained with fluorescent phalloidin ${ }^{29}$. However, the increased staining of G-actin showed disruption of the actin filaments into monomers. 
Tight junction protein loss was seen from 30 min after shock. The immunofluorescence data indicate that the presence of claudin-3 and ZO-1 at the side of tight junctions is strongly reduced from $30 \mathrm{~min}$ following hemorrhagic shock. These proteins however do not immediately disappear but rather dislodge and finally end up in the lysosomal compartments ${ }^{30,31}$. This results in a spreading of the proteins over the cytoplasm which reduces the local concentration and thus detection by immunofluorescence. The western blot data clearly show that the tight junction proteins Claudin-3 and ZO1-1 in intestinal epithelial cells are diminished from 60 minutes after shock. No tight junction loss in liver and kidney was seen at any investigated time point. Bacterial translocation started as soon as 30 min after shock and increased markedly over time. This occurrence of bacterial translocation characterizes the functional intestinal barrier loss. Taken together, HS induced activation of AC, cytoskeleton severing and tight junction loss was restricted to the intestine and was followed by bacterial translocation.

Our data are consistent with the work of Molitoris group, showing presence of both AC and $\mathrm{PAC}$ in the kidney under physiological conditions, and $\mathrm{AC}$ activation and actin cytoskeleton degradation after ATP depletion caused by ischemia ${ }^{15}$. Changes in actin cytoskeleton structure contribute to tight junction integrity loss ${ }^{27,32,33}$.

Besides AC mediated tight junction loss by cytoskeleton filament severing and depolymerization after ATP depletion, Myosin Light Chain (MLC) is described as regulator of actin dynamics in the enterocyte ${ }^{33,34}$. Phosphorylation of MLC (pMLC), by Myosin Light Chain Kinase (MLCK) leads to contraction of the actin cytoskeleton and opening of the tight junction in the intestine. Tight junction permeability is regulated by phosphorylated MLC by myosin ATPase-mediated contraction of the peri-junctional actomyosin ring and subsequent physical tension on the $\mathrm{TJ}^{35,36}$. This mechanism is suggested to be responsible for tight junction integrity loss in inflammatory bowel disease ${ }^{37}$. In summary, actin filament reorganisation and stabilization is regulated by $A C$ or MLC, with tight junction loss caused by either AC after energy depletion or MLC in an energy rich environment.

\section{Conclusions}

This study shows that HS results in intestinal AC activation, actin depolymerization, tight junction loss and bacterial translocation, very early after the onset of shock, while in kidney and liver no actin cytoskeleton disruption and tight junction loss is observed. 


\section{References}

1. Moore FA, Sauaia A, Moore EE, Haenel JB, Burch JM, Lezotte DC. Postinjury multiple organ failure: a bimodal phenomenon. J Trauma 1996;40:501-512.

2. Peitzman AB, Billiar TR, Harbrecht BG, Kelly E, Udekwu AO, Simmons RL. Hemorrhagic shock. Curr Probl Surg 1995;32:925-1002.

3. Hassoun HT, Kone BC, Mercer DW, Moody FG, Weisbrodt NW, Moore FA. Post-injury multiple organ failure: the role of the gut. Shock 2001;15:1-10.

4. Stevenson BR. Understanding tight junction clinical physiology at the molecular level. J Clin Invest 1999;104:3-4.

5. Baker JW, Deitch EA, Li M, Berg RD, Specian RD. Hemorrhagic shock induces bacterial translocation from the gut. J Trauma 1988;28:896-906.

6. Fink MP, Delude RL. Epithelial barrier dysfunction: a unifying theme to explain the pathogenesis of multiple organ dysfunction at the cellular level. Crit Care Clin 2005;21:177-196.

7. Han X, Fink MP, Yang R, Delude RL. Increased iNOS activity is essential for intestinal epithelial tight junction dysfunction in endotoxemic mice. Shock 2004;21:261-270.

8. Xu DZ, Lu Q, Deitch EA. Nitric oxide directly impairs intestinal barrier function. Shock 2002;17:139-145.

9. Anderson JM. Leaky junctions and cholestasis: a tight correlation. Gastroenterology 1996;110:16621665.

10. Kwon O, Nelson WJ, Sibley R, Huie P, Scandling JD, Dafoe D, Alfrey E, Myers BD. Backleak, tight junctions, and cell- cell adhesion in postischemic injury to the renal allograft. J Clin Invest 1998; 101:2054-2064.

11. Fink MP. Intestinal epithelial hyperpermeability: update on the pathogenesis of gut mucosal barrier dysfunction in critical illness. Curr Opin Crit Care 2003;9:143-151.

12. Deitch EA, Forsythe R, Anjaria D, Livingston $D H, L u Q, X u D Z, R e d l ~ H$. The role of lymph factors in lung injury, bone marrow suppression, and endothelial cell dysfunction in a primate model of traumahemorrhagic shock. Shock 2004;22:221-228.

13. Lappalainen P, Drubin DG. Cofilin promotes rapid actin filament turnover in vivo. Nature 1997;388: 7882.

14. Rosenblatt J, Agnew BJ, Abe H, Bamburg JR, Mitchison TJ. Xenopus actin depolymerizing factor/cofilin (XAC) is responsible for the turnover of actin filaments in Listeria monocytogenes tails. J Cell Biol 1997;136:1323-1332.

15. Schwartz N, Hosford M, Sandoval RM, Wagner MC, Atkinson SJ, Bamburg J, Molitoris BA. Ischemia activates actin depolymerizing factor: role in proximal tubule microvillar actin alterations. Am J Physiol 1999;276:F544-551.

16. Theriot JA. Accelerating on a treadmill: ADF/cofilin promotes rapid actin filament turnover in the dynamic cytoskeleton. J Cell Biol 1997;136:1165-1168.

17. Carothers AM, Javid SH, Moran AE, Hunt DH, Redston M, Bertagnolli MM. Deficient E-cadherin adhesion in C57BL/6J-Min/+ mice is associated with increased tyrosine kinase activity and RhoAdependent actomyosin contractility. Exp Cell Res 2006;312:387-400.

18. Andrianantoandro E, Pollard TD. Mechanism of actin filament turnover by severing and nucleation at different concentrations of ADF/cofilin. Mol Cell 2006;24:13-23.

19. Minamide LS, Striegl AM, Boyle JA, Meberg PJ, Bamburg JR. Neurodegenerative stimuli induce persistent ADF/cofilin-actin rods that disrupt distal neurite function. Nat Cell Biol 2000;2:628-636.

20. Ivanov AI, McCall IC, Parkos CA, Nusrat A. Role for actin filament turnover and a myosin II motor in cytoskeleton-driven disassembly of the epithelial apical junctional complex. Mol Biol Cell 2004;15: 2639-2651.

21. Ashworth SL, Sandoval RM, Hosford M, Bamburg JR, Molitoris BA. Ischemic injury induces ADF relocalization to the apical domain of rat proximal tubule cells. Am J Physiol Renal Physiol 2001;280: F886-894.

22. Shaw AE, Minamide LS, Bill CL, Funk JD, Maiti S, Bamburg JR. Cross-reactivity of antibodies to actindepolymerizing factor/cofilin family proteins and identification of the major epitope recognized by a mammalian actin-depolymerizing factor/cofilin antibody. Electrophoresis 2004;25:2611-2620. 
23. Meberg PJ, Ono S, Minamide LS, Takahashi M, Bamburg JR. Actin depolymerizing factor and cofilin phosphorylation dynamics: response to signals that regulate neurite extension. Cell Motil Cytoskeleton 1998;39:172-190.

24. Luyer MD, Buurman WA, Hadfoune M, Jacobs JA, Konstantinov SR, Dejong CH, Greve JW. Pretreatment with high-fat enteral nutrition reduces endotoxin and tumor necrosis factor-alpha and preserves gut barrier function early after hemorrhagic shock. Shock 2004;21:65-71.

25. Bark T, Katouli M, Ljungqvist $O$, Mollby $R$, Svenberg T. Bacterial translocation after non-lethal hemorrhage in the rat. Circ Shock 1993;41:60-65.

26. Luyer MD, Jacobs JA, Vreugdenhil AC, Hadfoune M, Dejong CH, Buurman WA, Greve JW. Enteral administration of high-fat nutrition before and directly after hemorrhagic shock reduces endotoxemia and bacterial translocation. Ann Surg 2004;239:257-264.

27. Clayburgh DR, Barrett TA, Tang Y, Meddings JB, Van Eldik LJ, Watterson DM, Clarke LL, Mrsny RJ, Turner JR. Epithelial myosin light chain kinase-dependent barrier dysfunction mediates $T$ cell activation-induced diarrhea in vivo. J Clin Invest 2005;115:2702-2715.

28. Grossmann J, Maxson JM, Whitacre CM, Orosz DE, Berger NA, Fiocchi C, Levine AD. New isolation technique to study apoptosis in human intestinal epithelial cells. Am J Pathol 1998;153:53-62.

29. McGough A, Pope B, Chiu W, Weeds A. Cofilin changes the twist of F-actin: implications for actin filament dynamics and cellular function. J Cell Biol 1997;138:771-781.

30. Matsuda M, Kubo A, Furuse M, Tsukita S. A peculiar internalization of claudins, tight junction-specific adhesion molecules, during the intercellular movement of epithelial cells. J Cell Sci 2004;117:12471257.

31. Ivanov Al, Nusrat A, Parkos CA. Endocytosis of the apical junctional complex: mechanisms and possible roles in regulation of epithelial barriers. Bioessays 2005;27:356-365.

32. Clayburgh DR, Rosen S, Witkowski ED, Wang F, Blair S, Dudek S, Garcia JG, Alverdy JC, Turner JR. A differentiation-dependent splice variant of myosin light chain kinase, MLCK1, regulates epithelial tight junction permeability. J Biol Chem 2004;279:55506-55513.

33. Turner JR, Rill BK, Carlson SL, Carnes D, Kerner R, Mrsny RJ, Madara JL. Physiological regulation of epithelial tight junctions is associated with myosin light-chain phosphorylation. Am J Physiol 1997;273: C1378-1385.

34. Shen L, Black ED, Witkowski ED, Lencer WI, Guerriero V, Schneeberger EE, Turner JR. Myosin light chain phosphorylation regulates barrier function by remodeling tight junction structure. J Cell Sci 2006;119:2095-2106.

35. Hartel FV, Rodewald CW, Aslam M, Gunduz D, Hafer L, Neumann J, Piper HM, Noll T. Extracellular ATP induces assembly and activation of the myosin light chain phosphatase complex in endothelial cells. Cardiovasc Res 2007;74:487-496.

36. Kushida M, Takeuchi T, Fujita A, Hata F. Dependence of Ca2+-induced contraction on ATP in alphatoxin-permeabilized preparations of rat femoral artery. J Pharmacol Sci 2003;93:171-179.

37. Blair SA, Kane SV, Clayburgh DR, Turner JR. Epithelial myosin light chain kinase expression and activity are upregulated in inflammatory bowel disease. Lab Invest 2006;86:191-201. 


\title{
CHAPTER 5
}

\section{Protection against early intestinal compromise}

\author{
by lipid-rich enteral nutrition via
}

cholecystokinin receptors

Jacco J. de Haan, Geertje Thuijls, Tim Lubbers, M'hamed Hadfoune, Kostan Reisinger, Erik Heineman, Jan-Willem M. Greve, Wim A. Buurman J de Haan and G Thuijls contributed equally to this study 


\section{Abstract}

Introduction: Early gut wall integrity loss and local intestinal inflammation are associated with the development of inflammatory complications in surgical and trauma patients. Prevention of these intestinal events is a potential target for therapies aimed to control systemic inflammation. Previously, we demonstrated in a rodent shock model that lipid-rich enteral nutrition attenuated systemic inflammation and prevented organ damage via a cholecystokinin receptor (CCK-r) dependent vagal pathway. Here, influence of lipid-rich nutrition on very early intestinal compromise as seen after shock is investigated. Next, the involvement of CCK-r on the nutritional modulation of immediate gut integrity loss and intestinal inflammation is studied.

Methods: Liquid lipid-rich nutrition or control low-lipid feeding was administered per gavage to male Sprague Dawley rats prior to hemorrhagic shock. CCK-r antagonists were used to investigate involvement of the vagal anti-inflammatory pathway.

Results: Gut permeability to horseradish peroxidase (HRP) increased as soon as 30 minutes post-shock and was prevented by lipid-rich nutrition compared with lowlipid $(P<0.01)$ and fasted controls $(P<0.001)$. Furthermore, lipid-rich nutrition reduced plasma levels of enterocyte damage marker ileal lipid binding protein (ILBP) at 60 minutes $(P<0.05)$. Early gut barrier dysfunction correlated with rat mast cell protease (RMCP) plasma concentrations at 30 minutes $\left(r_{s}=0.67 ; P<0.001\right)$ and intestinal myeloperoxidase (MPO) levels at 60 minutes $\left(r_{s}=0.58 ; P<0.05\right)$. Lipid-rich nutrition significantly reduced plasma RMCP $(P<0.01)$ and MPO $(P<0.05)$ before systemic inflammation was detectable. Protective effects of lipid-rich nutrition were abrogated by CCK-r antagonists (HRP; $P<0.05$ and RMCP; $P<0.05$ ).

Conclusions: Lipid-rich enteral nutrition prevents early gut barrier loss, enterocyte damage and local intestinal inflammation prior to systemic inflammation in a CCK-r dependent manner. This study identifies activation of the vagal anti-inflammatory pathway with lipid-rich nutrition as a potential therapy in patients prone to develop a compromised gut. 


\section{Introduction}

Loss of intestinal integrity has been implicated in the development of inflammatory complications including respiratory dysfunction, organ damage and sepsis ${ }^{1-4}$. Based on these experimental findings, preservation of gut wall integrity is considered a potential target for therapies aimed at preventing excessive inflammation in surgical and critical care settings.

Increased gut wall permeability, enterocyte damage and local intestinal inflammation are regarded as crucial interrelated events that transform the intestine into a proinflammatory organ ${ }^{5}$. A growing number of studies demonstrates that a decrease in gut barrier function occurs also in several patient groups ${ }^{6-10}$. Furthermore, the associations that were established between the level of enterocyte damage in septic patients and poor clinical outcome indicate that events in the gut wall may be of extraintestinal significance ${ }^{11,12}$. Recently, evidence was provided that intestinal epithelial damage is an early event in surgical and trauma patients that is related to the subsequently developing systemic inflammatory response and the occurrence of complications $^{13,14}$. These clinical observations support the importance of preserving early intestinal integrity under certain surgical conditions as a potential target for antiinflammatory therapies. To test the direct effects of novel therapies on various aspects of intestinal integrity and local inflammation, animal models provide a straightforward approach.

A novel and promising means to control the acute inflammatory response is administration of lipid-rich enteral nutrition. Previously, we showed that lipid-rich nutrition activates the autonomic nervous system via activation of cholecystokininreceptors $(\mathrm{CCK}-r)^{15}$. Cytokine release is subsequently inhibited via activation of nicotinic receptors on inflammatory cells via the vagus nerve ${ }^{15-17}$. Also several organs including the intestine were strongly protected following either pre- or post-treatment with lipid-rich nutrition ${ }^{15,18,19}$.

The current study investigates the impact of lipid-rich enteral nutrition on the condition of the intestine early after hemorrhagic shock. For this, a rodent model was used in which previously early disruption of epithelial cell cytoskeleton and tight junctions was reported ${ }^{20}$. Next, the involvement of the CCK-r mediated vagal antiinflammatory pathway in the effects of lipid-rich nutrition on early intestinal compromise was determined. 


\section{Materials and methods}

\section{Animals}

Male Sprague-Dawley rats, weighing 300-350 g, were purchased from Charles River Laboratories (Maastricht, the Netherlands) and housed under controlled conditions of temperature and humidity. Prior to the experiments, rats were fed standard rodent chow ad libitum and had free access to water. The experimental protocols were approved by the Animal Ethics Committee of the Maastricht University Medical Center.

\section{Experimental design and procedures}

Non-lethal hemorrhagic shock was induced as previously described ${ }^{18}$. In short, rats were anesthetized with isoflurane (induction $4 \%$, maintenance $1.5 \%$ until sacrifice) and bupivacaine was used for analgesia. Anesthetized animals were placed on a heating pad (Gaymar, New York, NY) to maintain body temperature at $37^{\circ} \mathrm{C}$. The femoral artery was cannulated with polyethylene tubing (PE-10) containing heparinized saline $(10 \mathrm{lU} / \mathrm{ml})$, which was connected to a computer-assisted external pressure transducer (Kent Scientific, Torrington, CT). After 30 minutes of acclimatization, $2.1 \mathrm{ml}$ blood/100 g of body weight was withdrawn (representing $30-40 \%$ of the circulating volume) at a rate of $1 \mathrm{ml} / \mathrm{minute}$.

The severity of shock was reflected by profound alterations in mean arterial pressure (99 $\pm 4 \mathrm{mmHg}$ vs. $28 \pm 2 \mathrm{mmHg}$ at 10 minutes post-shock) and heart rate (383 \pm 11 bpm vs. $240 \pm 14 \mathrm{bpm}$ ). These changes were comparable with our previous studies with the shock model ${ }^{20,21}$. No differences were observed between fasted animals and intervention groups. Animals were sacrificed at 30, 60 or 90 minutes after shock (Figure 5.1). Each study group consisted of 6 animals. To determine pre-shock values of intestinal integrity and inflammation, fasted or fed groups were sacrificed without operative procedures.

Before shock, rats were either fasted overnight or received liquid lipid-rich or low-lipid feeding (both $1.3 \mathrm{kcal} / \mathrm{ml}$ ) per gavage at time points displayed in Figure 5.1. The lipidrich diet contained 50.4 energy percent (en\%) fat, of which $30 \%$ constituted of phospholipids, 8.7 en $\%$ protein, and 40.9 en $\%$ carbohydrates. The low-lipid control nutrition contained $16.0 \mathrm{en} \%$ fat, $8.7 \mathrm{en} \%$ proteins, and $75.3 \mathrm{en} \%$ carbohydrates. The protein and carbohydrate composition of the two feedings were identical. The amount of fat in the control nutrition was isocaloric to that present in standard rodent chow and the lipid-rich nutrition was isocaloric and isonitrogenous to the control nutrition. In both feeding regimens, animals received a total of $5.9 \mathrm{kcal}$ which equivalates $10-12 \%$ of their daily caloric intake. The response to shock of animals with unrestricted access to standard rodent chow is comparable with animals receiving low-lipid nutrition per gavage (not shown). 


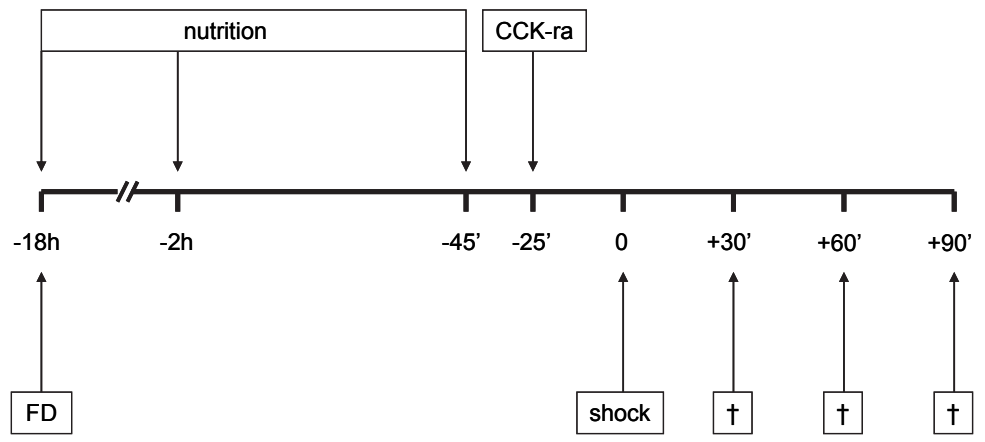

Figure 5.1 Experimental design. Rats were food deprived (FD) 18 hours before induction of shock and sacrificed at 30,60 or 90 minutes post-shock. A liquid lipid-rich or low-lipid enteral nutrition was administered at -18 hours, -2 hours and -45 minutes. Cholecystokinin receptor antagonists (CCK-ra) were given at 25 minutes before shock.

To investigate CCK-r involvement in the nutritional effects on early intestinal compromise, antagonists to the CCK-1 receptor, Devazepide, and the CCK-2 receptor, L365,260 (both $500 \mu \mathrm{g} / \mathrm{kg}$ ), were administered intraperitoneally at 25 minutes before shock induction in lipid-rich fed animals. Devazepide and L365,260 (kind gifts from ML Laboratories PLC, Nottingham, UK) were dissolved in 90\% saline, 5\% Tween 20 and 5\% DMSO.

\section{Intestinal permeability}

Intestinal permeability was assessed by an ex vivo everted sac-method. Segments of $8 \mathrm{~cm}$ terminal ileum (distal end is located at $5 \mathrm{~cm}$ of the ileocecal valve) were washed, everted and filled with $1 \mathrm{ml}$ of Tris buffer $(125 \mathrm{mmol} / \mathrm{l} \mathrm{NaCl}, 10 \mathrm{mmol} / \mathrm{l}$ fructose, $30 \mathrm{mmol} / \mathrm{I}$ Tris; $\mathrm{pH} \mathrm{7.5)}$ and ligated at both ends. The filled segments were incubated in Tris buffer containing $40 \mu \mathrm{g} / \mathrm{ml}$ of the $44 \mathrm{kD}$ enzyme horseradish peroxidase (HRP) (Sigma, St. Louis, MO). After incubation at room temperature for $45 \mathrm{~min}$, ileal content was carefully collected. HRP activity was measured spectrophotometrically at $450 \mathrm{~nm}$ after addition of TMB as a substrate.

\section{Western Blot}

The amount of protein in extracts from isolated rat esophagus, stomach, jejunum, ileum, colon, liver, spleen, kidney, heart and lung was determined with the Bradford method (Biorad, Hercules, CA). Next, aliquots with equal protein amounts were made. Aliquots were heated at $100^{\circ} \mathrm{C}$ for 5 minutes in SDS sample buffer, separated on SDSpolyacrylamide gels and transferred to polyvinylidene fluoride membrane (Immobilin 
P, Millipore, Bedford, MA). After transfer of proteins, a blocking step was performed in TBS with $5 \%$ non-fat dry milk and $0.05 \%$ Tween. Membranes were probed with $1^{\circ} \mathrm{\mu g} / \mathrm{ml}$ rabbit anti human ILBP that cross-reacts with rat ${ }^{22}$ in TBS $0.05 \%$ Tween. After incubation with $0.1 \mu \mathrm{g} / \mathrm{ml}$ goat anti-rabbit HRP-conjugated secondary antibody (Hycult Biotech, Uden, the Netherlands), the signal was detected by chemiluminescence on film.

\section{Immunohistochemistry}

Localization of ILBP was investigated by immunohistochemistry performed on $3 \mu \mathrm{m}$ paraffin sections of esophagus, stomach, jejunum, ileum, colon, liver, spleen, kidney, heart and lung. Slides were deparaffinized and blocked for endogenous peroxidases. Non-specific binding sites were blocked with 5\% BSA. All incubation steps were performed at room temperature. Sections were incubated for 50 minutes with $1 \mu \mathrm{g} / \mathrm{ml}$ rabbit anti-mouse ILBP cross-reacting with rat (Hycult Biotech). Thereafter, sections were incubated for 30 minutes with $2 \mu \mathrm{g} / \mathrm{ml}$ biotin labeled swine anti-rabbit IgG conjugate (Dako, Glostrup, Denmark), followed by 30 minutes incubation with $A B$-complex and AEC staining. Nuclear staining was performed with hematoxylin. Pictures were taken using the Metasystems Image Pro System (black and white chargecouple device camera; Metasystems, Sandhausen, Germany) mounted on a Leica DM-RE microscope (Leica, Wetzler, Germany). Images were taken at equal timeexposures after being normalized to negative control sections without primary antibody, to exclude for non-specific binding of the secondary antibody or autofluorescence. At least 25 microscopic fields for each tissue section were examined.

\section{ELISA}

Intestinal cell damage was detected by measuring levels of ILBP (synonym: I-BABP) in arterial blood using a standard ELISA for rat-ILBP (Hycult Biotech). Mast cell degranulation was assessed in plasma with a Rat Mast Cell Protease II (RMCP II) ELISA (Moredun, Midlothian, UK). Myeloperoxidase (MPO) was assessed as described previously ${ }^{18}$. Systemic inflammation was determined by measuring tumor necrosis factor- $\alpha$ (TNF $\alpha$ ) and interleukin-6 (IL-6) concentrations in arterial blood using standard ELISA for rat TNF $\alpha$ and rat IL-6 (R\&D Systems, Minneapolis, MN). Detection limits for TNF $\alpha$ and IL- 6 were $30 \mathrm{pg} / \mathrm{ml}$ and $10 \mathrm{pg} / \mathrm{ml}$ respectively.

\section{Statistical Analysis}

For between-group comparisons, a two-tailed Mann-Whitney $U$ test was used. Differences were considered statistically significant at $P \leq 0.05$. The results of the HRP permeability test and ILBP ELISA are represented as median, $25^{\text {th }}$ and $75^{\text {th }}$ percentile. For RMCP II and MPO concentrations and data obtained with CCK-r antagonists, also 
the range is displayed. The median, $25^{\text {th }}$ and $75^{\text {th }}$ percentile of TNF $\alpha$ and IL- 6 are given in the text. Spearman's correlation was used to assess the association between intestinal permeability and local intestinal inflammation. Prism 5.02 for Windows (GraphPad Software, San Diego, CA) was used for computations.

\section{Results}

\section{Rapid increase of ileal permeability following hemorrhagic shock is prevented by lipid-rich nutrition}

As soon as 30 minutes following shock, a significant increase of HRP leakage was observed compared with pre-shock conditions ( $P<0.01$, Figure 5.2$)$. Gut permeability further increased at 60 minutes $(P<0.01)$. Lipid-rich nutrition reduced ileal leakage of HRP in comparison with low-lipid nutrition $(P<0.01)$ and fasted animals $(P<0.001)$ at 30 minutes post-shock. Also low-lipid nutrition reduced ileal barrier loss compared with fasting $(P<0.05)$. In all intervention groups, gut wall permeability further increased at 60 minutes after shock. Also at this time point, gut permeability to HRP was decreased in lipid-rich treated animals compared with low-lipid $(P<0.01)$ and fasted controls $(P<0.001)$.

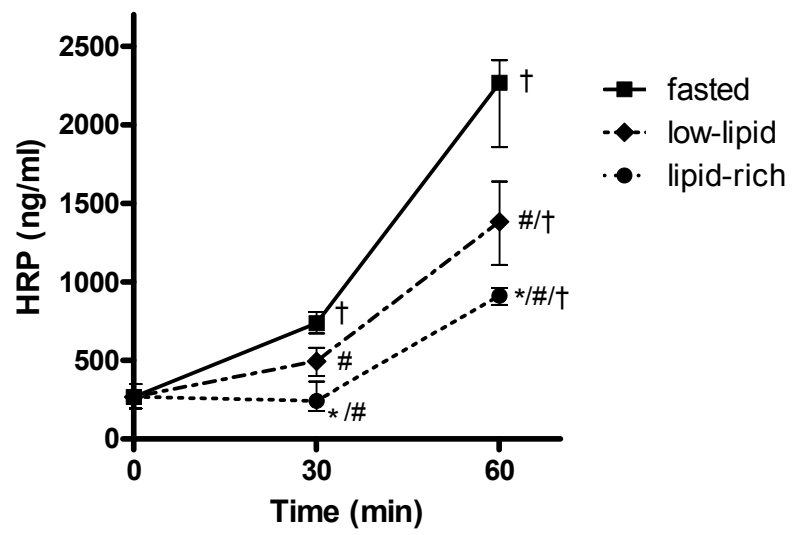

Figure 5.2 Intestinal barrier dysfunction develops rapidly following shock and is prevented by lipid-rich feeding. At 30 and 60 minutes post-shock, ileal permeability to horseradish peroxidase was significantly elevated compared to pre-shock values. Pre-treatment with lipid-rich nutrition significantly reduced horseradish peroxidase leakage compared to low-lipid and fasted animals at both time points. $+P<0.01$ vs. pre-shock, $* P<0.01$ vs. with low-lipid feeding, $\# P<0.05$ vs. fasting. 


\section{Lipid-rich nutrition reduces shock-induced enterocyte damage}

A specific marker for ileal cell damage in man is ILBP ${ }^{23}$. Here, we investigated the expression of ILBP in digestive tract, liver, spleen, kidneys, heart and lungs of healthy rats. Western blot analysis showed selective presence of ILBP in ileum, while the protein was not detected in the other organs (Figure 5.3A). The specific localization of ILBP in ileum was confirmed by immunohistochemistry (Figure 5.3C; other organs not shown). The presence of ILBP was restricted to the upper part of the villi, no expression was observed in crypts and muscular layers. These findings identify ILBP as a specific marker of differentiated ileal enterocytes in rats.

After onset of shock, ILBP plasma concentrations remained close to pre-shock levels at 30 minutes (Figure 5.3B). A significant increase of ILBP in plasma was observed at 60 minutes versus pre-shock values $(P<0.01)$. Elevated plasma ILBP levels coincided with a decreased ILBP expression in rat ileal enterocytes (Figure 5.3B and 5.3C).

Enterocyte damage was significantly reduced by lipid-rich nutrition at 60 minutes postshock compared with fasted animals $(P<0.05)$ and a protective trend was seen in comparison with low-lipid feeding ( $P=0.07$, Figure 5.3B). Immunohistochemistry showed that decreased ILBP plasma values in lipid-rich treated rats paralleled the prevention of ILBP loss in ileal enterocytes in comparison with fasted controls (Figure 5.3C).

\section{Early progress of local inflammation is reduced by lipid-rich nutrition}

Mast cell-derived RMCP II, a protease abundantly expressed in intestinal mucosal mast cells $^{24}$, is undetectable in plasma under physiological circumstances. As early as 30 minutes following shock, enhanced RMCP II levels were detected in fasted animals (Figure 5.4A). Treatment with lipid-rich feeding decreased RMCP II levels significantly $(P<0.01)$. Also low-lipid nutrition lowered mast cell degranulation compared with fasting $(P<0.05)$. At 60 minutes, circulating RMCP II values of all groups had returned to pre-shock concentrations (data not shown).

lleal tissue levels of MPO were used as a measure for neutrophilic granulocyte infiltration. Although traces of MPO can also be found in monocytes and specific resident macrophages ${ }^{25}$, an increase of tissue MPO levels is considered representative of neutrophil influx ${ }^{26}$. MPO concentrations were undetectable in healthy animals and at 30 minutes (data not shown). At 60 minutes, a strong increase of ileal MPO was observed in fasted animals (Figure 5.4B). Treatment with lipid-rich feeding significantly reduced MPO levels compared with fasted animals $(P<0.05)$. 

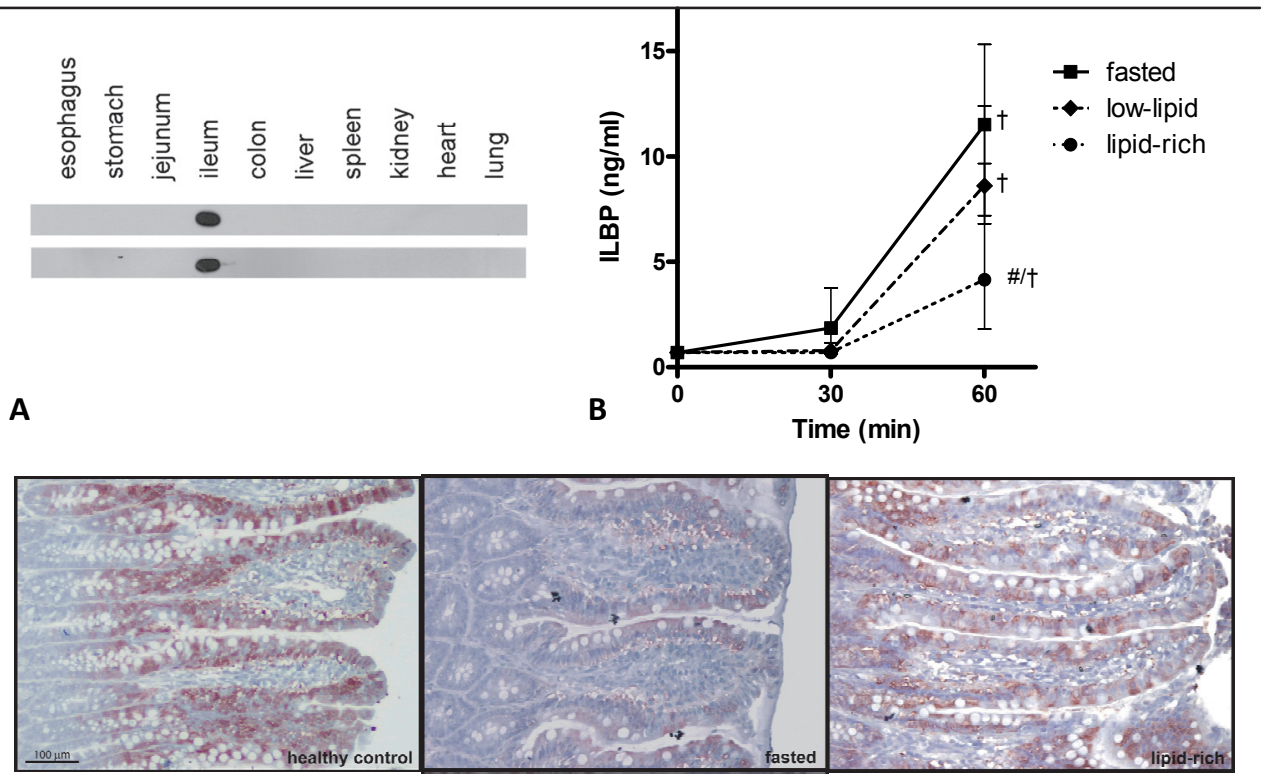

C

Figure 5.3 Early ileal cell damage is prevented by lipid-rich nutrition. A. Western blot revealed presence of ileal lipid binding protein (ILBP) in ileum and absence in other segments of the gastrointestinal tract. Moreover, ILBP was not detected in liver, spleen, kidney, heart and lung. B. Plasma ILBP levels representing epithelial damage in ileum were strongly increased at 60 minutes after shock compared to pre-shock. Lipid-rich feeding significantly reduced circulatory ILBP levels compared to low-lipid feeding and fasting. $+P<0.01$ compared with preshock and \# $P<0.05$ vs. fasting. C. Staining of ILBP (red) in ileum of healthy animals indicated presence specifically at the location of maturated enterocytes, whereas ILBP was not observed in crypts and submucosa. Nuclei were stained with haematoxylin (blue). Preserved enterocyte ILBP expression was observed in terminal ileum of lipid-rich treated animals compared to fasted animals at 60 minutes.

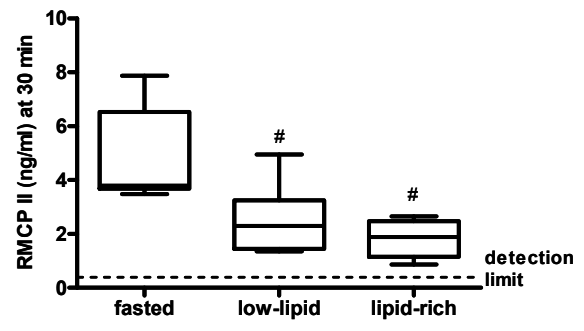

A

Figure 5.4 Mast cell degranulation and neutrophil influx occur early post-shock and are suppressed by lipid-rich nutrition. A. Administration of lipid-rich feeding reduced mast cell degranulation assessed as plasma rat mast cell protease II at 30 minutes compared with fasting. Also low-lipid feeding significantly reduced mast cell degranulation. B. Tissue myeloperoxidase levels in ileum were significantly decreased at 60 minutes following shock in lipid-rich treated animals compared to fasted controls. \# $P<0.05$ vs. fasting. 


\section{Gut barrier loss early after shock is related to the development of local intestinal inflammation}

The crosstalk between loss of barrier integrity resulting in penetration of luminal contents and the early local inflammatory response is considered to contribute cumulatively to the development of systemic inflammation ${ }^{5}$. Here, we studied the relation between gut wall permeability to HRP and markers of local inflammation. At 30 minutes, HRP leakage and RMCP II plasma levels correlated positively $\left(r_{s}=0.67\right.$, $P<0.001$, Figure 5.5A). In addition, a correlation was found between ileal permeability and MPO levels in ileum at 60 minutes $\left(r_{s}=0.58, P<0.05\right.$, Figure 5.5B).
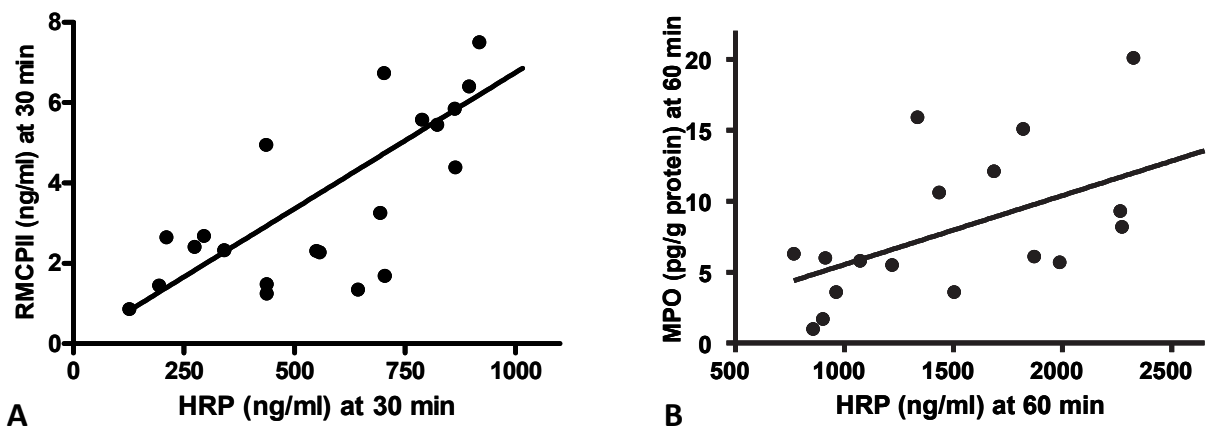

Figure 5.5 Early loss of gut barrier function correlates with development of local inflammation. A. Horseradish peroxidase leakage through ileal wall and rat mast cell protease II levels in plasma correlate positively at 30 minutes after shock $\left(r_{s}=0.67, P<0.001\right)$. B. At 60 minutes after hemorrhage, gut wall permeability correlates with myeloperoxidase concentrations in ileum $\left(r_{s}=0.58, P<0.05\right)$.

\section{Systemic inflammation develops at later stage}

TNF $\alpha$ and IL- 6 were measured to confirm that early loss of intestinal compromise precedes the development of systemic inflammation. Whereas TNF $\alpha$ and II-6 could not be detected at 30 minutes, concentrations surpassed the detection limit in $17 \%(4 / 18)$ and $56 \%(10 / 18)$ of the animals at 60 minutes. Conform previous findings, at 90 minutes lipid-rich nutrition significantly reduced inflammation compared with lowlipid $(66$ [49-72] pg/ml vs. 101 [83-124] pg/ml, $P<0.05)$ and fasted animals $(272 \text { [214-315] pg/ml, } P<0.01)^{15}$. Similar data were obtained with IL-6 (lipid-rich: 43 [32-54] pg/ml vs. low-lipid: 104 [89-119] pg/ml, $P<0.05$ and fasted: $164[139-176] \mathrm{pg} / \mathrm{ml}, P<0.01)$. 


\section{Cholecystokinin receptors mediate the early gut-preserving effects of lipid-rich nutrition}

Antagonists to CCK-r were administered to investigate the involvement of the vagal anti-inflammatory pathway in the preservation of gut homeostasis in the early phase following shock. The protective effects of lipid-rich nutrition on intestinal permeability to HRP at 30 minutes were abrogated by CCK-r antagonists $(P<0.05$, Figure 5.6A). In line, CCK-r blockage prevented the decrease of mast cell degranulation observed in lipid-rich treated animals $(P<0.05$, Figure 5.6B).
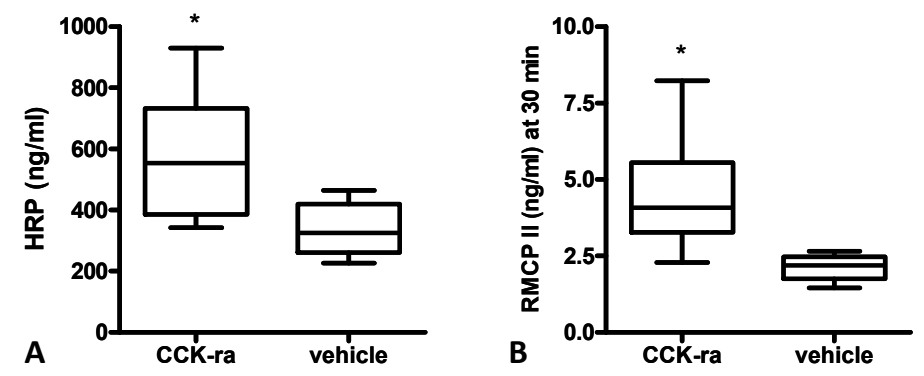

Figure 5.6 Cholecystokinin receptors mediate the protective effects of lipid-rich nutrtition on early gut wall integrity and local inflammation. A. The prevention of intestinal barrier loss by lipid-rich nutrition at 30 minutes was abrogated by cholecystokinin receptor antagonists. B. Blockage of cholecystokinin-receptors blunted the decreased mast cell degranulation observed in lipid-rich treated animals. $* P<0.05$ vs. vehicle.

\section{Discussion}

Experimental and clinical findings identified preservation of intestinal integrity as a potential target for interventions directed at control of excessive inflammation and improvement of clinical outcome following major surgery or severe trauma ${ }^{1-4,13,14}$. Here, we provide evidence that lipid-rich enteral nutrition limits the development of enterocyte damage, ameliorates gut barrier function and reduces local intestinal inflammation shortly following shock.

Splanchnic hypoperfusion is considered to be crucial in the development of intestinal compromise ${ }^{11,13,27}$. Therefore, in the current study a model of hemorrhagic shock was selected in which perfusion of mesenteric organs is known to be severely restricted ${ }^{27,28}$. Previously, in this model early disruption of the enterocyte cytoskeleton and interconnecting tight junctions was shown ${ }^{20}$. Since an intact epithelial lining is vital for gut barrier maintenance ${ }^{29}$, gut wall integrity loss and intestinal inflammation were assumed to develop early following shock. 
In line with clinical studies showing rapid development of intestinal cell damage following severe trauma and non-abdominal surgery ${ }^{13,14}$, in the current study ileal cell damage was detected within an hour after shock. Enterocyte damage was defined as increased plasma levels of ILBP, an ileum-specific bile acid transporter confined to mature enterocytes ${ }^{22,23,30}$. Next to epithelial cell damage, also gut wall permeability increased rapidly following shock. Loss of intestinal integrity may result in an increased exposure of the immune apparatus to endogenous and exogenous pro-inflammatory signals, thus contributing to a local inflammatory response ${ }^{1,29}$. In accordance, here we demonstrate a correlation between intestinal barrier dysfunction and increased levels of local inflammatory markers before systemic inflammation developed.

Lipid-rich nutrition significantly prevented the development of barrier dysfunction and enterocyte damage. Previously, lipid-rich nutrition was identified as a potent stimulator of the autonomic nervous system via activation of CCK receptors ${ }^{15}$. In accordance, the protective impact of lipid-rich nutrition can be mimicked by administration of pegylated CCK (Lubbers et al, Ann Surg; in press). Here we show, using CCK-r antagonists, that the vagus-mediated pathway underlies the effects of lipid-rich nutrition on early gut compromise before systemic inflammation develops. The current study indicates that the intestine may be an early and vital target organ for activation of the vagal pathway with lipid-rich nutrition.

Enhanced plasma levels of mast cell degranulation marker RMCP II were shown rapidly following shock. An important consequence of intestinal mucosal mast cell activation is increased gut wall permeability ${ }^{24,31-33}$. Vice versa, the influx of microbes and toxins as a result of increased intestinal permeability may induce mast cell activation ${ }^{32}$. In line, the current study shows that plasma RMCP II levels correlate with early dysfunction of the intestinal barrier. Another important effect of mast cell degranulation is enhanced influx of neutrophils in damaged tissue by vascular leakage ${ }^{34}$. In this study neutrophil influx in ileum was observed at one hour after shock. Administration of lipid-rich nutrition strongly decreased mast cell activation and ileal levels of MPO. Although mast cells are important regulators of neutrophil influx, in the current study it could not be excluded that lipid-rich nutrition reduced neutrophil influx also in a non-mast cell dependent manner. Apart from being a marker for neutrophil influx, MPO is a potent initiator and modulator of the local inflammatory response itself ${ }^{25,35}$. Local intestinal inflammation and gut barrier integrity are supposed to be interrelated ${ }^{1,5,29}$, which is conform the correlation between ileal MPO levels and gut wall permeability observed in this study.

Lipid-rich nutrition inhibited early shock-induced mast cell activation via CCK-r activation, implicating an important role for the vagal anti-inflammatory pathway. This finding is supported by a previous study that showed CCK-r involvement in the protective effects of lipid-rich nutrition on postoperative ileus, a mast cell dependent 
phenomenon $^{26}$. Several lines of evidence indicate that mast cell degranulation is regulated by the vagus nerve, including a close anatomical relation that was shown between vagal nerve endings and intestinal mucosal mast cells ${ }^{36}$. A functional link between the vagus nerve and mast cells was provided by Stead and colleagues, who demonstrated profound alterations in mast cell function following vagus stimulation or vagotomy ${ }^{37}$. Moreover, it was shown that nicotine and acetylcholine reduce degranulation of bonemarrow derived mast cells ${ }^{38}$. Taken together, these studies support activation of the CCK-r dependent vagal pathway as the underlying mechanism of the decreased mast cell activation reported here.

In the current study, nutritional intervention was installed before induction of shock. Previously, also post-shock administration of lipid-rich nutrition was demonstrated to attenuate inflammation and preserve intestinal integrity ${ }^{18}$, indicating that patients with ongoing inflammation or a compromised gut may benefit from intervention with enriched nutrition. Together, these data fit in the current tendency towards more liberal fasting guidelines pre-operatively and rapid installation of enteral nutrition post-operatively ${ }^{39-41}$. Since prevention of inflammation with lipid-rich nutrition yields stronger protective effects than post-treatment, in clinical setting nutritional interventions should preferably be oriented towards a pre-treatment approach.

\section{Conclusions}

The present study demonstrates rapid development of gut barrier loss, enterocyte damage and local intestinal inflammation following hemorrhagic shock. A small quantity of lipid-rich enteral nutrition strongly prevents early intestinal compromise before systemic inflammation develops in a CCK-r dependent manner. This study identifies nutritional activation of the vagal anti-inflammatory pathway with lipid-rich feeding as a potential therapy in patients prone to develop a compromised gut. 


\section{References}

1. Fink MP, Delude RL. Epithelial barrier dysfunction: a unifying theme to explain the pathogenesis of multiple organ dysfunction at the cellular level. Crit Care Clin 2005; 21:177-196.

2. Deitch EA, Xu D, Kaise VL. Role of the gut in the development of injury- and shock induced SIRS and MODS: the gut-lymph hypothesis, a review. Front Biosci 2006; 11:520-528.

3. Clark JA, Gan H, Samocha AJ, et al. Enterocyte-specific epidermal growth factor prevents barrier dysfunction and improves mortality in murine peritonitis. Am J Physiol Gastrointest Liver Physiol 2009; 297:G471-479.

4. Su L, Shen L, Clayburgh DR, et al. Targeted epithelial tight junction dysfunction causes immune activation and contributes to development of experimental colitis. Gastroenterology 2009; 136: 551-563.

5. Clark JA, Coopersmith CM. Intestinal crosstalk: a new paradigm for understanding the gut as the "motor" of critical illness. Shock 2007; 28:384-393.

6. Messick WJ, Koruda M, Meyer A, et al. Differential changes in intestinal permeability following burn injury. J Trauma 1994; 36:306-311.

7. Bjarnason I, MacPherson A, Hollander D, et al. Intestinal permeability: an overview. Gastroenterology 1995; 108:1566-1581.

8. Ascione R, Talpahewa S, Rajakaruna C, et al. Splanchnic organ injury during coronary surgery with or without cardiopulmonary bypass: a randomized, controlled trial. Ann Thorac Surg 2006; 81:97-103.

9. Hietbrink F, Besselink MG, Renooij W, et al. Systemic inflammation increases intestinal permeability during experimental human endotoxemia. Shock 2009; 32:374-378.

10. Besselink MG, van Santvoort HC, Renooij W, et al. Intestinal barrier dysfunction in a randomized trial of a specific probiotic composition in acute pancreatitis. Ann Surg 2009; 250:712-719.

11. Derikx JP, Poeze M, van Bijnen AA, et al. Evidence for intestinal and liver epithelial cell injury in the early phase of sepsis. Shock 2007; 28:544-548.

12. Derikx JP, Bijker EM, Vos GD, et al. Gut mucosal cell damage in meningococcal sepsis in children: Relation with clinical outcome. Crit Care Med 2009; 38:133-137.

13. Derikx JP, van Waardenburg DA, Thuijls G, et al. New Insight in Loss of Gut Barrier during Major NonAbdominal Surgery. PLoS One 2008; 3:e3954.

14. de Haan JJ, Lubbers T, Derikx JP, et al. Rapid development of intestinal cell damage following severe trauma: a prospective observational cohort study. Crit Care 2009; 13:R86.

15. Luyer MD, Greve JW, Hadfoune M, et al. Nutritional stimulation of cholecystokinin receptors inhibits inflammation via the vagus nerve. J Exp Med 2005; 202:1023-1029.

16. Borovikova LV, Ivanova $\mathrm{S}$, Zhang $\mathrm{M}$, et al. Vagus nerve stimulation attenuates the systemic inflammatory response to endotoxin. Nature 2000; 405:458-462.

17. Wang $H, \mathrm{Yu} M$, Ochani $M$, et al. Nicotinic acetylcholine receptor alpha7 subunit is an essential regulator of inflammation. Nature 2003; 421:384-388.

18. de Haan JJ, Lubbers $T$, Hadfoune $M$, et al. Postshock intervention with high-lipid enteral nutrition reduces inflammation and tissue damage. Ann Surg 2008; 248:842-848.

19. Luyer MD, Derikx JP, Beyaert R, et al. High-fat nutrition reduces hepatic damage following exposure to bacterial DNA and hemorrhagic shock. J Hepatol 2009; 50:342-350.

20. Thuijls G, de Haan JJ, Derikx JP, et al. Intestinal cytoskeleton degradation precedes tight junction loss following hemorrhagic shock. Shock 2009; 31:164-169.

21. Luyer MD, Jacobs JA, Vreugdenhil AC, et al. Enteral administration of high-fat nutrition before and directly after hemorrhagic shock reduces endotoxemia and bacterial translocation. Ann Surg 2004; 239:257-264.

22. Derikx JP, Blijlevens NM, Donnelly JP, et al. Loss of enterocyte mass is accompanied by diminished turnover of enterocytes after myeloablative therapy in haematopoietic stem-cell transplant recipients. Ann Oncol 2009; 20:337-342.

23. Watanabe K, Hoshi N, Tsuura Y, et al. Immunohistochemical distribution of intestinal $15 \mathrm{kDa}$ protein in human tissues. Arch Histol Cytol 1995; 58:303-306. 
24. Scudamore CL, Thornton EM, McMillan L, et al. Release of the mucosal mast cell granule chymase, rat mast cell protease-II, during anaphylaxis is associated with the rapid development of paracellular permeability to macromolecules in rat jejunum. J Exp Med 1995; 182:1871-1881.

25. Klebanoff SJ. Myeloperoxidase: friend and foe. J Leukoc Biol 2005; 77:598-625.

26. Lubbers T, Luyer MD, de Haan JJ, et al. Lipid-rich enteral nutrition reduces postoperative ileus in rats via activation of cholecystokinin-receptors. Ann Surg 2009; 249:481-487.

27. Tamion F, Richard V, Sauger F, et al. Gastric mucosal acidosis and cytokine release in patients with septic shock. Crit Care Med 2003; 31:2137-2143.

28. Ceppa EP, Fuh KC, Bulkley GB. Mesenteric hemodynamic response to circulatory shock. Curr Opin Crit Care 2003; 9:127-132.

29. Turner JR. Intestinal mucosal barrier function in health and disease. Nat Rev Immunol 2009; 9:799-809.

30. Furuhashi M, Hotamisligil GS: Fatty acid-binding proteins: role in metabolic diseases and potential as drug targets. Nat Rev Drug Discov 2008; 7:489-503.

31. Jacob C, Yang PC, Darmoul D, et al. Mast cell tryptase controls paracellular permeability of the intestine. Role of protease-activated receptor 2 and beta-arrestins. J Biol Chem 2005; 280: 31936-31948.

32. Theoharides TC, Kempuraj D, Tagen $M$, et al. Differential release of mast cell mediators and the pathogenesis of inflammation. Immunol Rev 2007; 217:65-78.

33. Dawicki W, Marshall JS. New and emerging roles for mast cells in host defence. Curr Opin Immunol 2007; 19:31-38.

34. Malaviya R, Ikeda T, Ross E, et al. Mast cell modulation of neutrophil influx and bacterial clearance at sites of infection through TNF-alpha. Nature 1996; 381:77-80.

35. Veen BV, Winther MD, Heeringa P, et al. Myeloperoxidase: Molecular mechanisms of action and their relevance to human health and disease. Antioxid Redox Signal 2009; 11:2899-2937.

36. Stead RH, Dixon MF, Bramwell NH, et al. Mast cells are closely apposed to nerves in the human gastrointestinal mucosa. Gastroenterology 1989; 97:575-585.

37. Stead RH, Colley EC, Wang B, et al. Vagal influences over mast cells. Auton Neurosci 2006; 125:53-61.

38. Kageyama-Yahara N, Suehiro Y, Yamamoto T, et al. IgE-induced degranulation of mucosal mast cells is negatively regulated via nicotinic acetylcholine receptors. Biochem Biophys Res Commun 2008; 377:321-325.

39. Weimann A, Braga M, Harsanyi L, et al. ESPEN Guidelines on Enteral Nutrition: Surgery including organ transplantation. Clin Nutr 2006: 25:224-244.

40. Soreide E, Eriksson LI, Hirlekar G, et al. Pre-operative fasting guidelines: an update. Acta Anaesthesiol Scand 2005; 49:1041-1047.

41. Carr CS, Ling KD, Boulos $P$, et al. Randomised trial of safety and efficacy of immediate postoperative enteral feeding in patients undergoing gastrointestinal resection. BMJ 1996; 312:869-871. 


\section{CHAPTER 6}

Lipid-rich enteral nutrition regulates mucosal mast cell activation via the vagal anti-inflammatory reflex

Jacco J. de Haan, M'hamed Hadfoune, Tim Lubbers, Caroline Hodin, Akihiko Ito, Isabelle Verbaeys, Wouter J. de Jonge, Michael Skynner, Jan-Willem M. Greve, Wim A. Buurman 


\section{Abstract}

Introduction: Recent studies identified nutritional stimulation of the cholecystokinin-1 receptor (CCK-1R) and nicotinic acetylcholine receptor (nAChR)-mediated vagal reflex as a potent and physiological means to reduce inflammation and preserve intestinal integrity. Mast cells are important early regulators of the innate immune reaction, therefore modulation of mucosal mast cells is a potential therapeutic target to control the acute inflammatory response in the intestine. The present study investigates intestinal mast cell responsiveness upon nutritional activation of the vagal antiinflammatory reflex in a setting of acute inflammation.

Methods en results: Mucosal mast cell degranulation was induced in C57/BI6 mice by administration of Salmonella enterica LPS. Lipid-rich enteral feeding prior to LPS significantly decreased circulatory levels of mouse mast cell protease at 30 minutes post-LPS compared with isocaloric low-lipid nutrition $(P<0.05)$ or fasting $(P<0.001)$. CCK-1R blockage reversed the inhibitory effects of lipid-rich feeding $(P<0.05)$, whereas stimulation of the peripheral CCK-1R mimicked nutritional mast cell inhibition $(P<0.05)$. The effects of lipid-rich nutrition were negated by $\mathrm{nAChR}$ blockers chlorisondamine and $\alpha$-bungarotoxin (both $P<0.05$ ). These in vivo findings were substantiated by in vitro data showing that release of $\beta$-hexosaminidase by $\mathrm{MC} / 9$ mast cells following LPS or IgE-OVA complexes is dose-dependently inhibited by acetylcholine $(P<0.01)$ or nicotine $(P<0.05)$. Furthermore, application of GSK1345038A, a specific agonist of the nAChR $\alpha 7$ in bone marrow derived mast cells from nAChR $32-/-$ and wild types showed that cholinergic inhibition of mast cells is mediated by the $\mathrm{nAChR} \alpha 7$ and is independent of the $\beta 2$ containing $n A C h R s$.

Conclusions: the current study reveals mucosal mast cell inhibition as a previously unknown target of the nutritional anti-inflammatory vagal reflex. 


\section{Introduction}

The majority of mast cells resides in the gut wall. Here, they function as an important part of the immunological barrier between the internal milieu and luminal content ${ }^{1,2}$. Mucosal mast cell degranulation is associated with gut barrier dysfunction, an event that has been implicated in the development of excessive systemic inflammation and distant organ injury in settings of surgery and sepsis ${ }^{3-5}$. Further support for a pivotal role of intestinal mast cells in the development of inflammation was derived in an intestinal ischemia and reperfusion model, in which the antihistaminic and mast cell stabilizing drug ketotifen was shown to inhibit local leukocyte adhesion and reduce both local and remote tissue injury ${ }^{6}$. Therefore, regulation of early mucosal mast cell activity is a potential strategy to attenuate the acute immune response and prevent the development of inflammatory complications ${ }^{7,8}$.

Nutritional activation of a hard-wired vagal anti-inflammatory reflex is a novel approach to modulate the acute inflammatory response and preserve intestinal integrity in a physiological manner, ${ }^{9,10}$. The protective effects are mediated by stimulating cholecystokinin-1 receptors (CCK-1R) on afferent vagal fibers ${ }^{10}$. This vagal input is relayed to the brain and then passed to the efferent branch, leading to decreased cytokine production by immune cells via release of cholinergic neurotransmitters ${ }^{9,11}$. The $\alpha 7$ subunit of the nicotinic acetylcholine receptor ( $\mathrm{AAChR} \alpha 7$ ) was demonstrated to be pivotal in the cholinergic inhibition of proinflammatory cytokine production, whereas vagal inhibition of specific macrophage functions including phagocytosis and endocytosis was mediated by the $\beta 2$ subunit $^{12,13}$. Compelling evidence of improved outcome by nutritional, pharmacological and electrical stimulation of this neuroimmune axis, designated the cholinergic antiinflammatory pathway, has been provided in diverse settings ${ }^{14-16}$.

Recently, in a rodent model of postoperative ileus, reduced levels of mucosal mast cell protease were observed following treatment with enteral nutrition, which raised the question whether mast cell activation can be modulated by the CCK-1R dependent anti-inflammatory reflex ${ }^{17}$. The current study investigates the effects of vagal stimulation with lipid-rich nutrition on mast cell responsiveness during acute inflammation. For this, a murine LPS model is used. The importance of mast cells in this model is tested by administration of ketotifen. In addition, in vitro studies are performed in which vagal signaling is simulated by nAChR agonists and involvement of $\alpha 7$ and $\beta 2$ subunits is investigated. The current study identifies mucosal mast cells as early targets of the nutrition-induced vagal anti-inflammatory reflex during acute inflammation. 


\section{Materials and methods}

\section{Animals}

Male C57/BI6 mice, aged 10-12 weeks, were purchased from Charles River Laboratories (Maastricht, the Netherlands). Mice were housed under controlled conditions of temperature and humidity in groups of 3-4 per cage. Prior to the experiments, mice were drug- and test-naïve and had ad libitum access to standard rodent chow and water. Mice were randomly assigned to 21 study groups. In 3 groups of 8 animals (fasted or fed with lipid-rich or low-lipid nutrition), the nutritional effects on LPS-induced mast cell activation were investigated. In 16 groups of 6 animals, the role of the vagal anti-inflammatory reflex in the nutritional impact on mast cell reactivity was studied using diverse agonists and antagonists. Group sizes were based on previously reported effects of enriched nutrition on circulatory mast cell markers and earlier experiments in which agonists and antagonists of the vagal pathway were applied $^{10,16}$. Finally, in 2 groups of 6 animals (ketotifen and vehicle), the importance of mast cells in the development of LPS-induced inflammation and intestinal barrier loss was studied. The experimental protocols were carried out following institutional guidelines and approved by the Animal Ethics Committee of Maastricht University Medical Centre+. This study is reported in accordance with the ARRIVE guidelines.

\section{Experimental design of the animal studies}

Mice received an intraperitoneal dose of LPS $(2 \mathrm{mg} / \mathrm{kg}$ ) from Salmonella enterica serotype minnesota Re 595 (Sigma, St Louis, MO), dissolved in sterile saline $(200 \mu \mathrm{g} / \mathrm{ml} ; \mathrm{pH}$ 7.4). Animals displayed sickness behavior shortly following LPS. All animals were fasted from 4 hours prior to LPS administration until sacrifice. To investigate the nutritional impact on mast cell activation, liquid lipid-rich or liquid control low-lipid nutrition was given at 2 hours $(0.2 \mathrm{ml})$ and 45 minutes $(0.2 \mathrm{ml})$ before LPS via oral gavage. To assess early mucosal mast cell activity, animals were sacrificed at 30 minutes following LPS injection. The involvement of mast cells in the response to LPS was investigated by administration of ketotifen $(1 \mathrm{mg} / \mathrm{kg}$; Novartis Pharma, Arnhem, the Netherlands) or vehicle (sterile saline) i.p. at 48, 24 and 4 hours before LPS injection. These animals were sacrificed at 90 minutes post-LPS by vena cava puncture following anesthesia using pentobarbital (200 mg/kg i.p.). Samples were coded to ensure blinded analysis and stored at $-80^{\circ} \mathrm{C}$.

\section{Nutritional composition}

Lipid-rich nutrition contained 50.4 energy percent (en\%) fat, $8.7 e n \%$ protein, and 40.9 en $\%$ carbohydrates. The fat fraction contained $30 \%$ phospholipids. The low-lipid control nutrition contained $16.0 \mathrm{en} \%$ fat, $8.7 \mathrm{en} \%$ proteins, and $75.3 \mathrm{en} \%$ carbohydrates. 
The protein and carbohydrate composition of the two feedings were identical. The amount of fat in the control nutrition was similar to that present in standard rodent chow and the lipid-rich nutrition was isocaloric and isonitrogenous to the control nutrition. The total energy provided by the two enteral feedings approximated $4 \%$ of the total daily energy expenditure.

\section{Receptor antagonists and agonists}

All antagonists and agonists were dissolved and administered i.p. (10 $\mu \mathrm{l} / \mathrm{g}$ body weight) at 30 minutes prior to LPS. To investigate the role of the peripheral CCK-1R in the nutritional effects on mast cell reactivity, mice that were fasted or treated with lipidrich nutrition received A70104, also known as A65186 $(100 \mu \mathrm{g} / \mathrm{kg}$, kindly provided by Abbott Laboratories, Abbott Park, IL), a CCK-1R antagonist that does not cross the blood-brain barrier ${ }^{18}$. A70104 was dissolved in sterile saline with 1\% DMSO.

Stimulation of the afferent vagus nerve in fasted animals was assessed by administration of $6 \mu \mathrm{g} / \mathrm{kg}$ pegylated-CCK9 (produced by Dr Verbaeys, Kortrijk, Belgium) dissolved in sterile saline. Pegylated-CCK9 specifically binds to CCK-1R and does not cross the blood brain barrier ${ }^{19}$. To investigate the effects of afferent vagus stimulation via the transient receptor potential vanilloid 1 (TRPV1), the specific agonist SA13353 (12 mg/kg; kindly provided by $\operatorname{Dr}$ Tsuji, Osaka, Japan) or vehicle (saline with $1 \%$ Cremophor EL, Sigma) was employed ${ }^{20}$. Conform the recommendations of the producers, $0.1 \mathrm{mg} / \mathrm{kg}$ terbutaline and $10 \mathrm{mg} / \mathrm{kg}$ theophylline were administered s.c. at 15 minutes prior to SA13353 to counteract its acute respiratory and cardiovascular effects.

The role of peripherally localized $\mathrm{nAChR}$ was studied by administration of chlorisondamine diiodide ( $125 \mu \mathrm{g} / \mathrm{kg}$; Tocris Bioscience, Bristol, UK) or vehicle (saline). Next, the nAChR $\alpha 7$ antagonist $\alpha$-bungarotoxin ( $2 \mu \mathrm{g} / \mathrm{kg}$; Sigma), which does not pass the blood-brain barrier, or its vehicle (PBS) was applied. Whereas $\alpha$-bungarotoxin is widely used as a blocker of the nAChR $\alpha 7$, affinity has also been reported for other nAChR subunits, including $\alpha 1, \alpha 9$ and $\alpha 10^{21}$.

\section{Mast cell protease and IL- 6 assays}

Mouse mast cell protease I (MMCP I), the primary outcome parameter of this study, was measured in plasma using two standard ELISAs for mice MMCP I from Moredun (Midlothian, UK) and Thermo Fischer Scientific (Rockford, II). Repeated measurements demonstrated that values differed $<5 \%$ between both assays. The detection limit of MMCP I was $50 \mathrm{pg} / \mathrm{ml}$. Systemic inflammation was assessed by determination of plasma IL-6 concentrations using a standard ELISA for mouse IL-6 (R\&D Systems, Minneapolis, MN; detection limit $10 \mathrm{pg} / \mathrm{ml}$ ). 


\section{Intestinal permeability}

Gut wall permeability was assessed in $5 \mathrm{~cm}$ segments of terminal ileum, of which the distal end was located at $5 \mathrm{~cm}$ of the ileocecal valve. Segments were gently flushed and filled with $0.4 \mathrm{ml}$ of Tris buffer (125 mM NaCl, $10 \mathrm{mM}$ fructose, $30 \mathrm{mM}$ Tris; $\mathrm{pH}$ 7.5) containing $40 \mu \mathrm{g} / \mathrm{ml}$ of the $44 \mathrm{kD}$ enzyme HRP (Sigma). After ligation of both ends, the filled segments were incubated in $1 \mathrm{ml}$ Tris buffer at room temperature for 45 minutes. Next, the ileal segment was carefully removed and HRP activity in the buffer was measured spectrophotometrically at $450 \mathrm{~nm}$ after addition of TMB as a substrate ${ }^{16}$.

\section{Culture and stimulation of $\mathrm{MC} / 9$ and bone marrow derived mast cells}

$\mathrm{MC} / 9$ (provided by Dr Ito, Kobe, Japan), a murine cell line with a mast cell phenotype, was cultured at $37^{\circ} \mathrm{C}$ with $5.0 \% \mathrm{CO}_{2}$ in RPMI-1640 (Life Technologies, Carlsbad, CA), supplemented with $10 \% \mathrm{FCS}, 100 \mathrm{IU} / \mathrm{ml}$ penicillin, $100 \mu \mathrm{g} / \mathrm{ml}$ streptomycin and $2 \mathrm{mM}$ L-glutamine ${ }^{22}$. In addition, $1 \%$ of $\mathrm{MC} / 9$ medium constituted of the supernatant of IL-3 producing transfected $\mathrm{CHO}$ cells (a kind gift of Dr Renauld, Brussels, Belgium). $\mathrm{CHO}$ cells were cultured in GMEM enriched with $10 \%$ FCS, $0.1 \mathrm{mM}$ nonessential amino acids, $1.0 \mathrm{mM}$ sodium pyruvate, nucleoside mix (adenosine, guanosine, cytidine, uridine, thymidine; $7 \mathrm{\mu g} / \mathrm{ml}$ each), $100 \mathrm{IU} / \mathrm{ml}$ penicillin and $100 \mu \mathrm{g} / \mathrm{ml}$ streptomycin $^{23}$. $\mathrm{MC} / 9$ cultures were split when $80 \%$ confluence was reached. Under these conditions, cell populations duplicated in 10 hours.

Bone marrow mast cells were cultured from nAChR $32-/-$ mice (kindly provided by $\mathrm{Dr}$ Maskos, Paris, France) or C57/BI6 wild-type mice as described earlier ${ }^{24}$. In brief, femoral bone marrow cells were maintained in vitro for 4 weeks in RPMI 1640 complete medium (Life Technologies Inc.) supplemented with $10 \%$ fetal calf serum, in the presence of stem cell factor (50 ng/ml; Pepro Tech, Rocky Hill, NJ), interleukin-3 ( $1 \mathrm{ng} / \mathrm{ml}$; Pepro Tech) and 6\% bone marrow mast cell supplement (containing $20 \%$ MEM non-essential amino acids, 1\% L-glutamine, 0.22\% Sodium Pyruvate, $0.005 \%$ $\beta$-mercapto-ethanol). During culture, medium was refreshed once weekly. After this culture period, mast cells represented more than $95 \%$ of the total cells as determined by Toluidine blue staining on cytospin preparations. All cells were cultured in plates and flasks from Greiner Bio-One (Alphen a/d Rijn, the Netherlands).

Before stimulation, mast cells were washed, resuspended in Tyrode's buffer (10 mM HEPES, $130 \mathrm{mM}$ saline, $6.2 \mathrm{mM}$ D-glucose, $3.0 \mathrm{mM} \mathrm{KCl}, 1.4 \mathrm{mM} \mathrm{CaCl}, 1.0 \mathrm{mM} \mathrm{MgCl}$ and $0.1 \% \mathrm{BSA})$ and plated in triplicate in 96-well flat bottom microplates $\left(1.5 \times 10^{5} /\right.$ well; Corning Incorporated, Lowell, MA). To study the mast cell response to LPS, MC/9 cells were incubated for 2 hours with $100 \mu \mathrm{g} / \mathrm{ml}$ LPS of Salmonella enterica ${ }^{25}$. IgE-mediated degranulation of $\mathrm{MC} / 9$ cells was induced by incubation of the cells for 2 hours with murine monoclonal anti-OVA IgE $(5 \mu \mathrm{g} / \mathrm{ml}$, kindly provided by Dr Kiniwa, 
Taiho Pharmaceutical, Tokushima, Japan) followed by 1 hour incubation with $100 \mu \mathrm{g} / \mathrm{ml}$ OVA (Sigma) (26). Bone marrow derived mast cells were stimulated with compound $48 / 80(1 \mathrm{mg} / \mathrm{ml})$, LPS $(100 \mathrm{ng} / \mathrm{ml})$ or peptidoglycan $(10 \mathrm{ng} / \mathrm{ml})$ for 3 hours. Cell cultures were centrifuged and supernatants were collected. Cell pellets were lyzed in Tyrode's buffer containing $1 \%$ Triton X-100. Stimulation experiments were performed at least twice. Throughout the experiments, cells were kept at $37^{\circ} \mathrm{C}$.

To simulate neuronal activity, MC/9 cells and bone marrow derived mast cells were pre-incubated with a serial dilution of vagal neurotransmitter acetylcholine or nAChR agonist nicotine (both Sigma, dissolved in Tyrode's buffer) at 1 hour prior to LPS, IgE, peptidoglycan or compound 48/80. Acetylcholine was applied in presence of $2 \mathrm{mM}$ cholinesterase inhibitor pyridostigmine bromide (Sigma). Bone marrow derived mast cells were also stimulated with GSK1345038A (supplied by GlaxoSmithKline, Stevenage, UK) at the indicated concentrations.

\section{Beta-hexosaminidase assay}

The enzymatic activities of $\beta$-hexosaminidase in $\mathrm{MC} / 9$ cell supernatants and lysates were measured using $2 \mathrm{mM}$ 4-nitrophenol-N-acetyl- $\beta$-D-glucosaminide (Sigma) dissolved in $0.2 \mathrm{M}$ citrate buffer $(\mathrm{pH} 4.5)$ at $37^{\circ} \mathrm{C}$ for 2 hours in a $5 \% \mathrm{CO}_{2}$ humidified atmosphere. The reaction was quenched by addition of Tris $(\mathrm{pH} 9.0)$. Production of $p$-nitrophenol was detected by absorbance at $405 \mathrm{~nm}^{27}$. The activity of bone marrow derived mast cells was assessed using a 4-methylumbelliferyl glucosaminide (4-MUG) substrate solution (3.79 $\mathrm{mg} \mathrm{MUG/mI} \mathrm{DMSO}$ ) in $0.1 \mathrm{M}$ citrate buffer ( $\mathrm{pH} \mathrm{4.5).} \mathrm{The}$ reaction was stopped by adding $0.2 \mathrm{M}$ glycine buffer $(\mathrm{pH} 10.7)$. Fluorescence was measured using a multiwell plate reader at an emission wavelength of $360 \mathrm{~nm}$ and excitation wavelength of $460 \mathrm{~nm}$. The percentage of degranulation is calculated as follows: $((a-b) /(t-b)) \times 100$, where $a$ is the amount of $\beta$-hexosaminidase released from stimulated cells that are pretreated with cholinergic agents, $b$ is the amount released from unstimulated cells (basal release by cells incubated with Tyrode's buffer only), and $t$ is $\beta$-hexosaminidase release by stimulated cells without cholinergic agents.

\section{Flow-cytometric analysis}

To confirm the mast cell characteristics of MC/9 cells, the mast cell-specific CD200R3binding rat anti-mouse antibody Ba91 (kindly provided by $\mathrm{Dr}$ Karasuyama, Tokyo, Japan) was used for flow cytometry ${ }^{28}$. Cells were washed, resuspended in FACS buffer (PBS with 2\% BSA) and incubated for 30 minutes with Ba91 or appropriate isotype control (Hycult Biotech, Uden, the Netherlands). Next, after washing twice, cells were incubated for 30 minutes with a FITC-conjugated goat anti-rat IgG (HP1101, Hycult Biotech). After washing again, cells were resuspended in FACS buffer and analyzed on a 
FACSsort cytometer (BD, Franklin Lakes, NJ). For each measurement, 10.000 cells were acquired.

\section{Statistical analysis}

All animals were included in the analysis. The Kruskal-Wallis test with Dunn's post-test was applied to perform multiple comparisons between groups (Figure 6.1, 6.2A, 6.3, 6.5C, 6.6). A two-tailed Mann-Whitney $U$ test was used for comparisons between two groups (Figure 6.2B, 6.4). All data are displayed as mean \pm SEM. P-values smaller than or equal to 0.05 were considered statistically significant. Prism 5.02 for Windows (GraphPad Software Inc., San Diego, CA) was used for computations.

\section{Results}

\section{Lipid-rich enteral nutrition reduces LPS-induced mast cell degranulation in mice}

Circulatory MMCP I levels were measured to assess mucosal mast cell activation following in vivo LPS exposure. Whereas MMCP I levels were undetectable in healthy animals (not shown), a strong MMCP I increase was observed at 30 minutes following LPS (Figure 6.1). Lipid-rich nutrition significantly decreased MMCP I levels compared with fasted $(P<0.001)$ and low-lipid treated controls $(P<0.05)$. MMCP I levels in lowlipid treated animals were not statistically different from the fasted group.

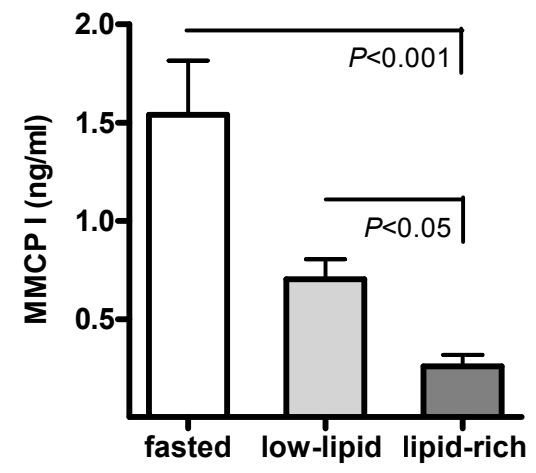

Figure 6.1 Lipid-rich enteral nutrition reduces mast cell degranulation following LPS exposure. Plasma levels of mouse mast cell protease I (MMCP I) were increased at 30 minutes following LPS. Lipid-rich nutrition significantly reduced MMCP । levels compared with low-lipid and fasted controls. $n=8$ for all groups. 


\section{Stimulation of peripheral cholecystokinin-1 receptors inhibits mast cell degranulation}

To investigate involvement of the CCK-1R dependent vagal pathway in the observed mast cell inhibition by lipid-rich nutrition, A70104 was employed, an antagonist of peripheral CCK-1 $\mathrm{R}^{18}$. Administration of A70104 prior to LPS abolished the effects of lipid-rich nutrition on MMCP I release (Figure 6.2A; $P<0.05$ ), while in vehicle treated lipid-rich fed animals, MMCP I levels were significantly reduced compared with fasted controls receiving vehicle $(P<0.01)$. No effect of $A 70104$ was seen in fasted animals. In addition, no statistical differences were observed between the fasted and lipid-rich fed animals that received $A 70104$.

The effects of peripheral CCK-1R signaling on mast cell reactivity were further explored by administration of pegylated-CCK9. Previously, pegylated-CCK9 was shown to inhibit the acute inflammatory response via CCK-1 $\mathrm{R}^{10}$. Here, pegylated-CCK9 significantly reduced MMCP I levels compared with vehicle in fasted animals (Figure 6.2B; $P<0.05$ ). To assess whether mast cell inhibition could also be obtained by CCK-R independent stimulation of the afferent vagus nerve, we employed SA13353, a specific agonist of the vanilloid receptor TRPV1 that is abundantly expressed on the afferent vagus nerve $^{20}$. A trend towards decreased MMCP I levels following administration of SA13353 was observed, however no statistical differences were obtained (Figure 6.2B).

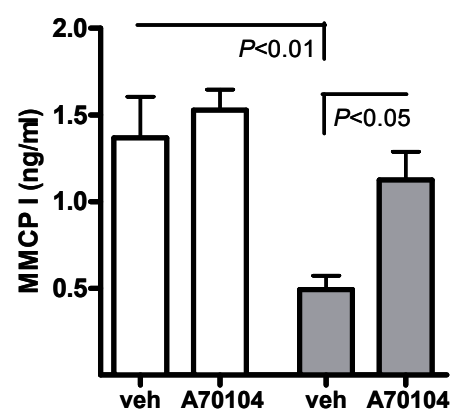

A

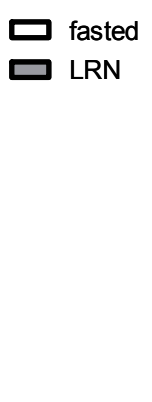

B

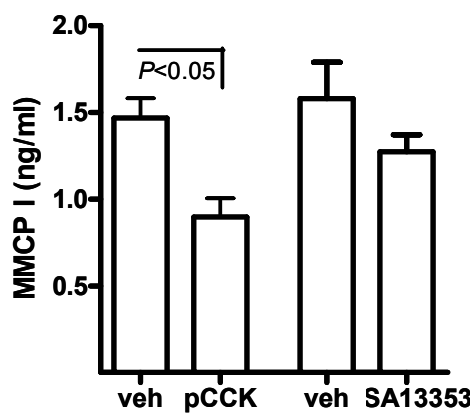

Figure 6.2 Activation of cholecystokinin-1 receptors mediates nutritional mast cell inhibition. A. A70104, an antagonist to peripheral CCK-1R, abolished the reduction of LPS-induced mast cell degranulation that was observed in lipid-rich treated mice receiving vehicle (veh) compared with fasted mice receiving vehicle. B. Pegylated-CCK9 (pCCK) but not transient receptor potential vanilloid 1 agonist SA13353 reduced MMCP I levels following LPS in fasted animals compared with vehicle. $L R N=$ lipid-rich nutrition; $n=6$ for all groups. 


\section{Nicotinic acetylcholine receptors are crucial in the inhibition of LPS- induced mast cell degranulation by lipid-rich nutrition}

Previously, nAChR activation was shown to be pivotal in the anti-inflammatory effects of vagus nerve signaling ${ }^{9,11}$. First, we investigated the involvement of $n A C h R$ in the nutritional inhibition of LPS-induced mast cell responsiveness using chlorisondamine, a non-specific peripheral nAChR antagonist. Chlorisondamine prevented the decrease of MMCP I that was observed in lipid-rich treated animals (Figure $6.3 A ; P<0.05$ ) in comparison with fasted controls $(P<0.05)$.

In particular the $\alpha 7$ subunit of the $n A C h R$ was reported to mediate cholinergic inhibition of cytokine release in macrophages, therefore we evaluated the effects of a nAChR $\alpha 7$ antagonist, $\alpha$-bungarotoxin, on nutritional mast cell inhibition ${ }^{12}$. Administration of $\alpha$-bungarotoxin abrogated the effects of lipid-rich nutrition (Figure 6.3B; $P<0.05$ ), implicating involvement of the $n A C h R ~ \alpha 7$ in the vagal inhibition of mast cell activity by lipid-rich nutrition. Neither chlorisondamine nor $\alpha$-bungarotoxin significantly affected MMCP I levels in fasted animals, indicating that these compounds lack an intrinsic mast cell-stimulatory effect.
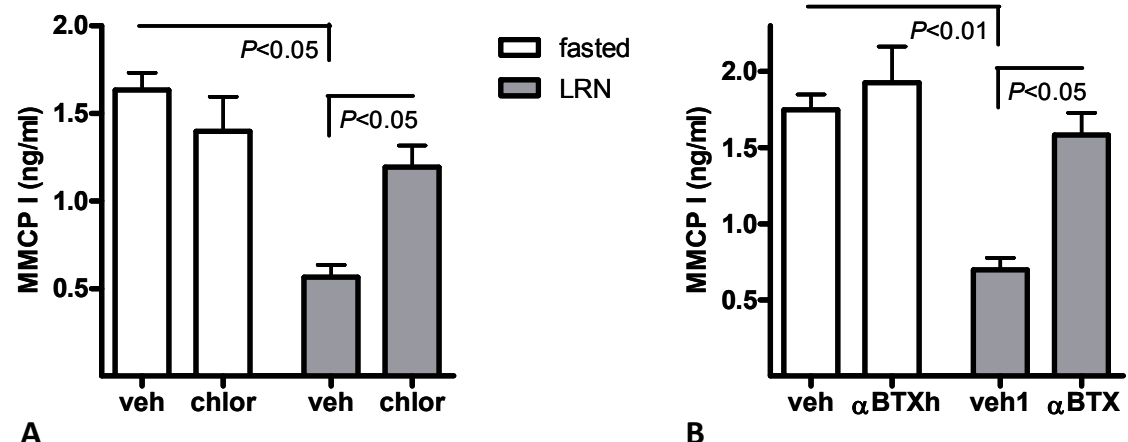

Figure 6.3 Nicotinic acetylcholine receptors mediate mast cell inhibition by lipid-rich nutrition. A. Chlorisondamine (chlor), a non-specific antagonist to peripheral nicotinic acetylcholine receptors ( $\mathrm{nAChR}$ ), abolished the effects of lipid-rich nutrition on LPS-induced mast cell degranulation. B. The $\mathrm{nAChR} \alpha 7$ antagonist $\alpha$-bungarotoxin ( $\alpha \mathrm{BTX}$ ) blocked the nutritional inhibition of mast cells. LRN = lipid-rich nutrition; veh = vehicle; $n=6$ for all groups.

\section{The antihistaminic drug ketotifen reduces cytokine release and preserves intestinal integrity following LPS}

Earlier studies implicated a prominent role for mast cells in the development of the general inflammatory response and intestinal barrier dysfunction ${ }^{1,2,4}$. To assess whether mucosal mast cells are involved in cytokine release and loss of gut wall 
integrity following LPS exposure, fasted animals were pre-treated with ketotifen. Ketotifen, which possesses histamine-1 receptor antagonizing as well as mast cell stabilizing properties, significantly decreased plasma levels of pro-inflammatory cytokine IL-6 following LPS compared with animals receiving vehicle (Figure 6.4A; $P<0.05)$. In addition, ketotifen reduced ileal permeability to HRP compared with vehicle-treated controls (Figure 6.4B; $P<0.05$ ). Ketotifen did not significantly alter circulatory levels of MMCP I (data not shown).
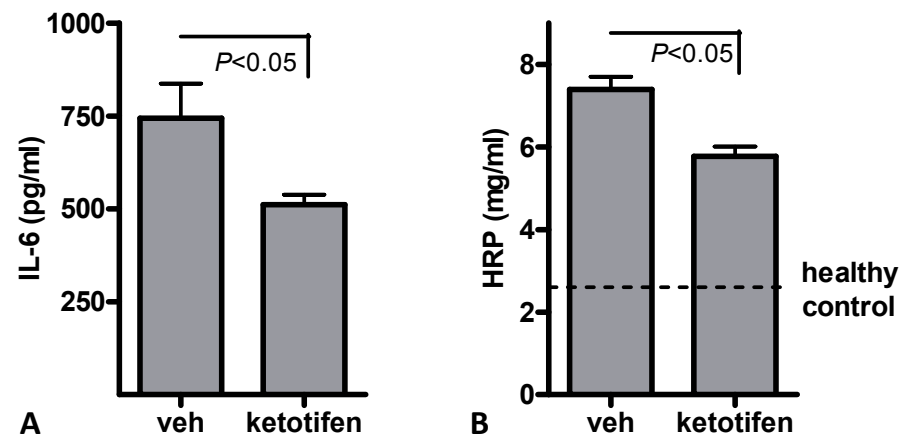

Figure 6.4 Mast cells contribute to cytokine release and intestinal compromise following LPS exposure. Administration of histaminic receptor antagonist ketotifen before LPS decreased IL- 6 concentrations in plasma (A) and reduced leakage of HRP through the intestinal wall (B) in fasted animals compared with animals that received vehicle (veh). $n=6$ for all groups.

\section{Acetylcholine and nicotine reduce mast cell degranulation following LPS and IgE exposure}

Cultured MC/9 cells were employed to further assess the effects of cholinergic signaling on mast cell activation. The affinity of Ba91, an antibody that specifically binds to the CD200R3 located on murine mast cells, for MC/9 cells confirmed the mast cell characteristics of the cell line (Figure $6.5 \mathrm{~A})^{28}$. First, $\mathrm{MC} / 9$ cells were activated by exposure to Salmonella enterica LPS. Both acetylcholine and nicotine dosedependently decreased LPS-induced mast cell degranulation as assessed by quantification of $\beta$-hexosaminidase release (Figure 6.5B). Acetylcholine was demonstrated to be a stronger inhibitor of $\mathrm{MC} / 9$ activity compared with nicotine.

To confirm the inhibitory effects of acetylcholine and nicotine on mast cell activation with a mast cell specific stimulus, sensitization of $\mathrm{MC} / 9$ cells with anti-OVA IgE and subsequent exposure to OVA was applied. Whereas anti-OVA IgE and OVA independently did not affect mast cell activity (data not shown), the combination led to strongly enhanced degranulation, which was set as $100 \%$ (Figure $6.5 \mathrm{C}$ ). Cholinergic 
control of the IgE-induced response was assessed by pre-incubation with $1 \mu \mathrm{M}$ of acetylcholine or nicotine. This concentration was based on the abovementioned experiments using LPS. IgE-mediated mast cell activation was significantly reduced by acetylcholine as well as nicotine (Figure 6.5C; $P<0.01$ and $P<0.05$ respectively).
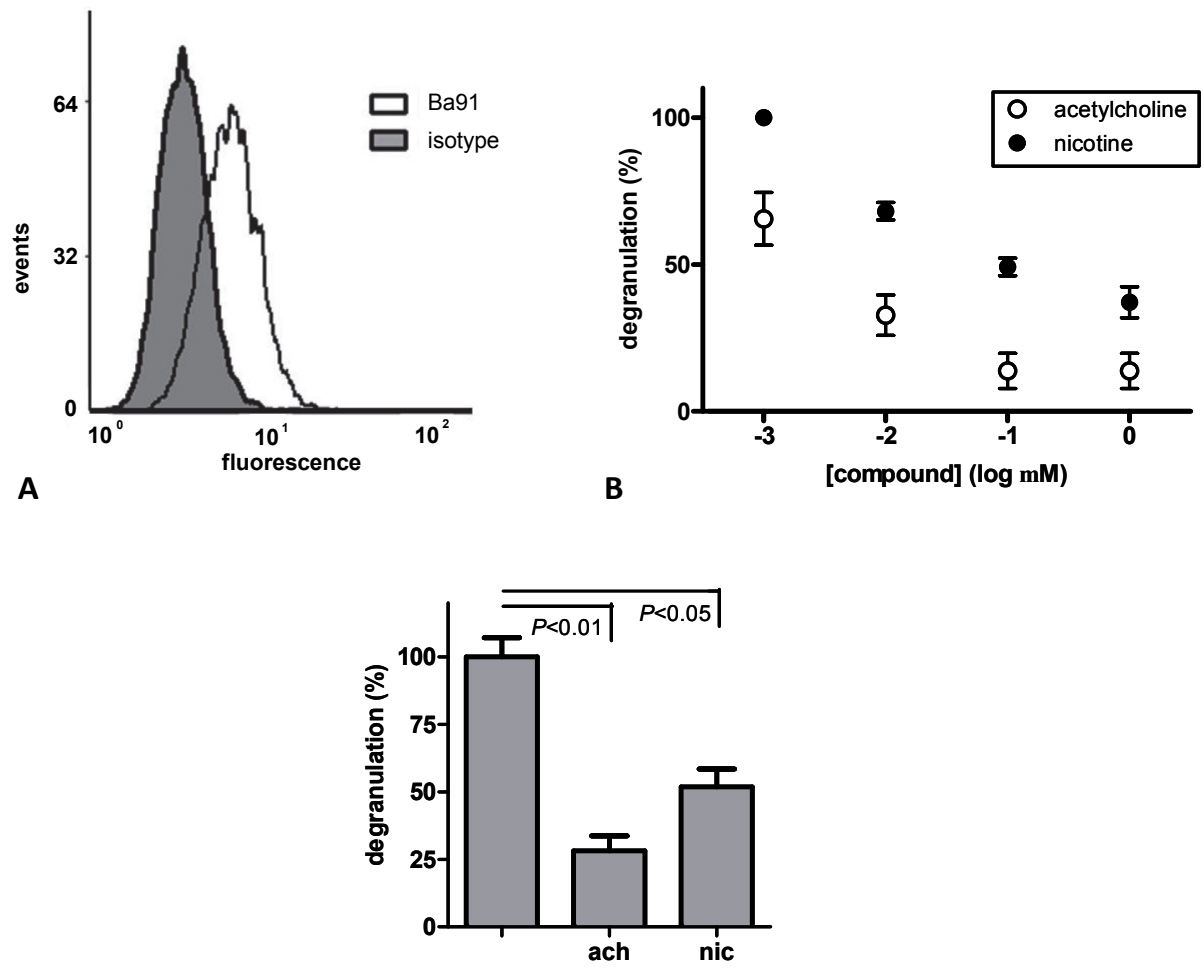

C

Figure 6.5 Cholinergic agents inhibit LPS and IgE-induced mast cell degranulation. A. Flowcytometric analysis shows affinity of MC/9 cells for mast cell-specific murine CD200R3 antibody Ba91, confirming the mast cell characteristics of the cell line. B. Acetylcholine and nicotine dosedependently inhibited $\mathrm{MC} / 9$ mast cell degranulation, as determined by $\beta$-hexosaminidase release after 2 hours of stimulation with LPS. C. OVA exposure followed by anti-OVA IgE resulted in increased $\mathrm{MC} / 9$ degranulation (set as $100 \%$ and no stimulation as $0 \%$ ). Administration of $1 \mu \mathrm{M}$ of either acetylcholine (ach) or nicotine (nic) significantly reduced $\mathrm{MC} / 9$ degranulation. All experiments were performed at least twice.

\section{The alpha7 subunit mediates the cholinergic inhibition of mast cells independently of the beta2 subunit}

$\mathrm{MC} / 9$ cells possess a mast cell phenotype, however the nAChR subtypes that are expressed by these cells have not been determined so far. Therefore, the involvement 
of the reportedly important $\alpha 7$ and $\beta 2$ subunits was investigated in bone marrow derived mast cells. Stimulation with peptidoglycan resulted in enhanced $\beta$-hexosaminidase release (i.e. $34.4 \%$ of the release following compound 48/80) compared with LPS, confirming Ikeda et al. ${ }^{29}$. Conform the observations in $\mathrm{MC} / 9$ cells, both acetylcholine and nicotine reduced bone marrow derived mast cell activity following peptidoglycan stimulation $(P<0.05$ for $0.1 \mathrm{mM}$ nicotine and $P<0.05$ for $0.1 \mathrm{mM}$ acetylcholine; Figure 6.6A). A highly specific agonist of the nAChR $\alpha 7$, GSK1345038A, reduced mast cell activity to a similar extent compared to nicotine and acetylcholine. Next, the involvement of the $\beta 2$ subunit was investigated. In mast cells derived from $\beta 2$-/- mice bone marrow, a dose-dependent reduction of mast cell activity was observed following administration of acetylcholine $(10 \mu \mathrm{M}: P<0.01$ and $100 \mu \mathrm{M}: \mathrm{P}<0.001)$, nicotine $(10 \mu \mathrm{M}$ and $100 \mu \mathrm{M}$ : both $\mathrm{P}<0.001)$ and $\mathrm{GSK} 1345038 \mathrm{~A}$ (10 $\mu \mathrm{M}: \mathrm{P}<0.05$ and $100 \mu \mathrm{M}: \mathrm{P}<0.01$; Figure 6.6B).

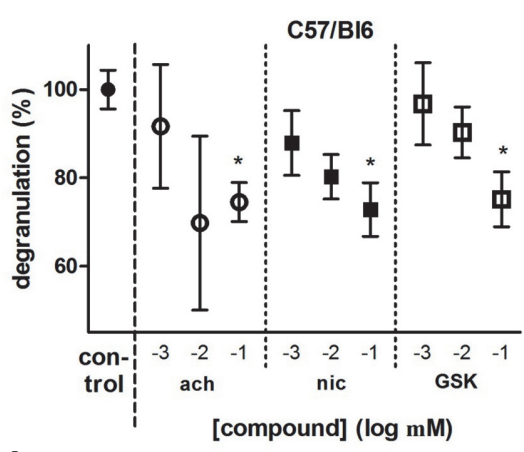

A

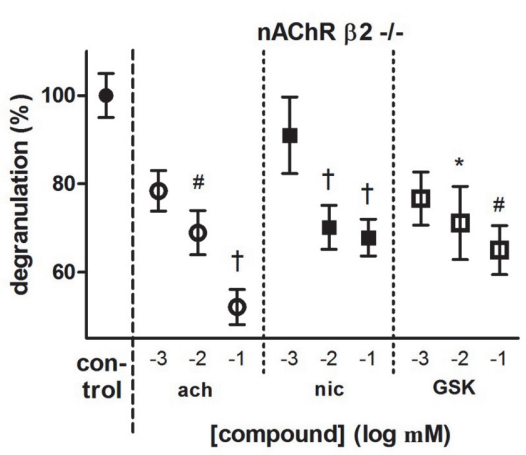

B

Figure 6.6 Alpha7 subunits but not beta2 subunits of the nicotinic acetylcholine receptor mediate cholinergic mast cell regulation. A. Nicotine, acetylcholine and nAChR $\alpha 7$ agonist GSK1345038A (GSK) dose-dependently reduced degranulation of bone marrow derived mast cells from C57/BI6 mice. B. In B2-/- mice, degranulation of bone marrow derived mast cells was significantly decreased by nicotine, acetylcholine and GSK1345038A. All experiments were performed at least twice. ${ }^{*} p<.05$ vs control, $\# p<.01$ vs control, $+p<0.001$ vs control.

\section{Discussion}

The present study identifies stimulation of the hard-wired vagal anti-inflammatory reflex by enteral lipid-rich nutrition as a strong inhibitor of mucosal mast cell reactivity. Since mast cells are recognized as early and pivotal regulators of the innate immune response, these findings support nutritional intervention in patients prone to develop an excessive inflammatory response. 
In the current study, LPS exposure to mice resulted in increased levels of MMCP I, a protein secreted by mucosal mast cells in the gastrointestinal tract $^{30}$. The detection of MMCP I as soon as 30 minutes following LPS may represent a direct mast cellstimulatory effect of LPS, since mast cells express TLR4, the LPS signaling receptor ${ }^{31}$. In particular LPS derived from Salmonella enterica, as used in the present study, was reported to exert a strong activation of mast cells ${ }^{25}$. Here, the in vivo findings were reflected by enhanced release of protease $\beta$-hexosaminidase in $\mathrm{MC} / 9$ cultures following exposure to LPS from the same origin. Also in bone marrow derived mast cells, LPS resulted in enhanced $\beta$-hexosaminidase release, although stronger activation was obtained by administration of TLR2 agonist peptidoglycan.

In settings of splanchnic hypoperfusion, as frequently observed in surgical and critical care settings, early local intestinal inflammation develops in parallel with enterocyte damage and intestinal permeability loss ${ }^{5}$. Evidence has been provided that these local intestinal events contribute to the development of systemic inflammatory complications ${ }^{5,32,33}$. Following recognition of pathogens or endogenous danger signals, mucosal mast cells are among the first immune cells to become activated in the intestine during the innate immune response ${ }^{2,34}$. Via instant release of biologically active chemokines, cytokines, vasoactive amines and proteases, mucosal mast cell activity plays a pivotal role in the recruitment of neutrophils, increase of vascular and mucosal permeability and the development of local intestinal damage in the early phase of intestinal inflammation ${ }^{2-4,35}$. In addition, mast cells were recently shown to be crucial in the chemoexcitation of mesenteric afferent vagus fibers in the early phase of intestinal ischemia ${ }^{36}$. Mast cell signaling to remote lymphoid tissues is facilitated by the release of cytokine-containing particles into lymphatic vessels ${ }^{37}$. Together, mast cell regulation is currently appreciated and tested as a potential therapeutic strategy in several intestinal diseases ${ }^{6,8,38}$. In the present study, the contributory role of mast cells in the development of inflammation and loss of gut wall integrity is confirmed by the observation that administration of histamine-1 receptor antagonist ketotifen prior to LPS resulted in decreased IL- 6 concentrations and improvement of gut barrier function. Whereas ketotifen has also been reported to exert mast cell stabilizing properties, next to histamine receptor-1 antagonism and weak inhibition of leukotrienes and phosphodiesterases ${ }^{39}$, it did not affect circulatory MMCP I concentrations, which is in accordance with a recent clinical study of Klooker et al. ${ }^{38}$.

Here, lipid-rich nutrition is identified as a strong inhibitor of mucosal mast cell degranulation. In addition, peripheral CCK-1R are demonstrated to be crucial in the nutritional modulation of mast cells. These data are supported by earlier reports that demonstrated a critical role for stimulation of CCK-1R that are located on the afferent vagus nerve in the immunomodulatory effects of lipid-rich nutrition ${ }^{10}$. The observation that CCK-1R antagonists did not affect MMCP I levels in fasted animals confirmed that 
the observed CCK-1R-dependent inhibition of mast cell responsiveness depends on nutritional intake. In line with our findings, Vergara et al. reported on mast cell inhibition by infusion of high doses of $\mathrm{CCK}^{40}$. Since CCK release in the proximal intestine is enhanced by dietary lipids and proteins, in the current study lipid-rich and isocaloric low-lipid feedings were applied that proved to be effective in previous studies $^{15,16}$. Enrichment of the feeding with lipids resulted in strongest mast cell inhibition, thus stressing the importance of carefully designed nutritional compositions in order to obtain optimal anti-inflammatory effects in the intestine.

CCK released in the gut wall can activate the central nervous system via the afferent vagus nerve but also via the humoral route ${ }^{41}$. In the current model we employed pegylated-CCK9, a well-characterized activator of the afferent vagus nerve that solely acts peripherally ${ }^{19}$. Pegylated-CCK9 was shown to reduce MMCP I levels, thus mimicking the nutritional inhibition of mast cells and confirming the importance of the neural route in this context. It should be noted that the vagus nerve consists of several types of neurons that respond to different stimuli ${ }^{42}$. To investigate whether afferent vagus stimulation attenuates mast cell responsiveness also in a non-CCK mediated fashion, the vanilloid receptor TRPV1 was stimulated. The TRPV1 is abundantly expressed on afferent nerve endings in the gastrointestinal tract with diverse functions including the transmission of nociception ${ }^{43}$. Although TRPV1 agonist SA13353 was previously reported to reduce inflammation in models of endotoxemia and arthritis ${ }^{20}$, in the current study SA13353 did not significantly reduce MMCP I levels. This observation suggests that stimulation of the afferent vagus nerve needs to be specific, e.g. via nutrition and CCK-1R, to inhibit mast cell activity. In theory, our data do not exclude the possibility that CCK binds to mast cells directly. Indeed, evidence has been provided that mouse fetal skin-derived mast cells possess CCK-receptors, however to our knowledge these observations have not been replicated in intestinal mast cells (44). In addition, the finding that $n A C h R$ antagonists abrogate the nutritional effects on mucosal mast cells indicates that direct actions of CCK do not play a major role in vivo.

Nutritional effects on mucosal mast cell reactivity were inhibited by chlorisondamine and $\alpha$-bungarotoxin, pointing at a crucial role for nAChR activation. Alphabungarotoxin is commonly used as a specific $n A C h R ~ \alpha 7$ agonist, although affinity has been reported also for other subunits ${ }^{21}$. The current study is first to establish a direct link between nutritional stimulation of the vagal anti-inflammatory pathway and involvement of the $n A C h R \alpha 7^{12,45}$. Cholinergic inhibition of mast cells was further investigated in a in vitro setting. First, inhibition of $\mathrm{MC} / 9$ by acetylcholine and nicotine was shown following LPS. Acetylcholine was demonstrated to be a stronger mast cell inhibitor compared with nicotine, which is in accordance with previous macrophages studies $^{11}$. As the range of $\mathrm{nAChR}$ subtypes that are expressed by MC/ 9 cells has not been determined, the role of the $\mathrm{nAChR} \alpha 7$ and $\beta 2$ subunit was investigated in bone 
marrow derived mast cells. In these cells, stimulation of the $\mathrm{nAChR} \alpha 7$ was shown to inhibit mast cells to a similar extent compared with nicotine and acetylcholine. Interestingly, the $\beta 2$ subtype, that was previously shown to mediate the cholinergic stimulation of phagocytosis, was not involved in the mast cell inhibitory effects of nicotine and acetylcholine.

In this study, cholinergic agents were shown to inhibit mast cell activation after a mast cell-specific anti-OVA IgE combined with an OVA trigger. These data are in congruence with studies of Kageyama and Mishra that showed cholinergic inhibition of bone marrow derived mast cells and the rat mast cell / basophil cell line RBL-2H3 and involvement of the $\mathrm{nAChR} \alpha 7^{45,46}$. The current data on cholinergic modulation of mast cells fit in the growing body of literature concerning the extensive and complex interactions between intestinal mast cells and neurons ${ }^{43,47,48}$. Also a micro-anatomic basis for communications between nerves and mast cells in the intestinal wall has been provided by Stead et al, showing that the majority of intestinal mast cells is apposed to nerve fibers ${ }^{49}$. The findings of the present study do not exclude an additional direct inhibitory effect of $n-3$ and $n-6$ polyunsaturated fatty acids (PUFA) on mast cell activation, as shown previously in vitro ${ }^{50}$. However, since CCK-1R and $\alpha 7 n A C h R$ antagonists blunted the nutritional effects, a direct mast cell inhibitory effect of small quantities of enteral lipids as used in the current study appears not to be of substantial importance.

Taken together, regulation of mast cell activity is a promising approach that could be therapeutic in various clinical settings of intestinal and systemic inflammation. The present study provides evidence that early mucosal mast cell activity during a general inflammatory response is inhibited by nutritional stimulation of the CCK-1R and nAChR $\alpha 7-$ mediated vagal anti-inflammatory reflex. These findings, providing novel insight in neuroimmune interactions triggered by enriched enteral nutrition, may contribute to more goal-directed clinical interventions. 


\section{References}

1. Dawicki W, Marshall JS. New and emerging roles for mast cells in host defence. Curr Opin Immunol 2007;19:31-38.

2. Abraham SN, St John AL. Mast cell-orchestrated immunity to pathogens. Nat Rev Immunol 2010;10:440-452.

3. Scudamore CL, Thornton EM, McMillan L, Newlands GF, Miller HR. Release of the mucosal mast cell granule chymase, rat mast cell protease-II, during anaphylaxis is associated with the rapid development of paracellular permeability to macromolecules in rat jejunum. J Exp Med 1995;182:1871-1881.

4. Moriez R, Leveque M, Salvador-Cartier C, Barreau F, Theodorou V, Fioramonti J, Bueno L, Eutamene $\mathrm{H}$. Mucosal mast cell proteases are involved in colonic permeability alterations and subsequent bacterial translocation in endotoxemic rats. Shock 2007;28:118-124.

5. Clark JA, Coopersmith CM. Intestinal crosstalk: a new paradigm for understanding the gut as the "motor" of critical illness. Shock 2007;28:384-393.

6. Kalia N, Brown NJ, Wood RF, Pockley AG. Ketotifen abrogates local and systemic consequences of rat intestinal ischemia-reperfusion injury. J Gastroenterol Hepatol 2005;20:1032-1038.

7. The FO, Buist MR, Lei A, Bennink RJ, Hofland J, van den Wijngaard RM, de Jonge WJ, Boeckxstaens GE. The role of mast cell stabilization in treatment of postoperative ileus: a pilot study. Am J Gastroenterol 2009;104:2257-2266.

8. Karra L, Berent-Maoz B, Ben-Zimra M, Levi-Schaffer F. Are we ready to downregulate mast cells? Curr Opin Immunol 2009;21:708-714.

9. Luyer MD, Greve JW, Hadfoune M, Jacobs JA, Dejong $\mathrm{CH}$, Buurman WA. Nutritional stimulation of cholecystokinin receptors inhibits inflammation via the vagus nerve. J Exp Med 2005;202:1023-1029.

10. Lubbers T, de Haan JJ, Luyer MD, Verbaeys I, Hadfoune M, Dejong CH, Buurman WA, Greve JW. Cholecystokinin/Cholecystokinin-1 receptor-mediated peripheral activation of the afferent vagus by enteral nutrients attenuates inflammation in rats. Ann Surg 2010;252:376-382.

11. Borovikova LV, Ivanova S, Zhang M, Yang H, Botchkina GI, Watkins LR, Wang H, Abumrad N, Eaton JW, Tracey KJ. Vagus nerve stimulation attenuates the systemic inflammatory response to endotoxin. Nature 2000;405:458-462.

12. Wang H, Yu M, Ochani M, Amella CA, Tanovic M, Susarla S, Li JH, Yang H, Ulloa L, Al-Abed Y, et al. Nicotinic acetylcholine receptor alpha7 subunit is an essential regulator of inflammation. Nature 2003;421:384-388.

13. van der Zanden EP, Snoek SA, Heinsbroek SE, Stanisor OI, Verseijden C, Boeckxstaens GE, Peppelenbosch MP, Greaves DR, Gordon S, De Jonge WJ. Vagus nerve activity augments intestinal macrophage phagocytosis via nicotinic acetylcholine receptor alpha4beta2. Gastroenterology 2009;137:1029-1039.

14. Tracey KJ. Reflex control of immunity. Nat Rev Immunol 2009;9:418-428.

15. Lubbers T, De Haan JJ, Hadfoune M, Zhang Y, Luyer MD, Grundy D, Buurman WA, Greve JW. Lipidenriched enteral nutrition controls the inflammatory response in murine Gram-negative sepsis. Crit Care Med 2010;38:1996-2002.

16. de Haan JJ, Thuijls G, Lubbers T, Hadfoune M, Reisinger K, Heineman E, Greve JW, Buurman WA. Protection against early intestinal compromise by lipid-rich enteral nutrition through cholecystokinin receptors. Crit Care Med 2010;38:1592-1597.

17. Lubbers T, Luyer MD, de Haan JJ, Hadfoune M, Buurman WA, Greve JW. Lipid-rich enteral nutrition reduces postoperative ileus in rats via activation of cholecystokinin-receptors. Ann Surg 2009;249: 481-487.

18. Ebenezer IS, Parrott RF. A70104 and food intake in pigs: implication for the CCK 'satiety' hypothesis. Neuroreport 1993;4:495-498.

19. Verbaeys I, Leon-Tamariz F, Buyse J, De Cuyper M, Pottel H, Van Boven M, Cokelaere M. PEGylated cholecystokinin prolongs satiation in rats: dose dependency and receptor involvement. $\mathrm{Br} J$ Pharmacol 2007;152:396-403. 
20. Murai M, Tsuji F, Nose M, Seki I, Oki K, Setoguchi C, Suhara H, Sasano M, Aono H. SA13353 (1-[2-(1Adamantyl)ethyl]-1-pentyl-3-[3-(4-pyridyl)propyl]urea) inhibits TNF-alpha production through the activation of capsaicin-sensitive afferent neurons mediated via transient receptor potential vanilloid 1 in vivo. Eur J Pharmacol 2008;588:309-315.

21. Whiteaker P, Marks MJ, Christensen S, Dowell C, Collins AC, Mclntosh JM. Synthesis and characterization of 125I-alpha-conotoxin ArIB[V11L;V16A], a selective alpha7 nicotinic acetylcholine receptor antagonist. J Pharmacol Exp Ther 2008;325:910-919.

22. Koma Y, Ito A, Watabe K, Hirata T, Mizuki M, Yokozaki H, Kitamura T, Kanakura Y, Kitamura Y. Distinct role for c-kit receptor tyrosine kinase and SgIGSF adhesion molecule in attachment of mast cells to fibroblasts. Lab Invest 2005;85:426-435.

23. Knoops L, Hornakova T, Royer Y, Constantinescu SN, Renauld JC. JAK kinases overexpression promotes in vitro cell transformation. Oncogene 2008;27:1511-1519.

24. de Jonge WJ, The FO, van der Coelen D, Bennink RJ, Reitsma PH, van Deventer SJ, van den Wijngaard RM, Boeckxstaens GE. Mast cell degranulation during abdominal surgery initiates postoperative ileus in mice. Gastroenterology 2004;127:535-545.

25. Dietrich N, Rohde M, Geffers R, Kroger A, Hauser H, Weiss S, Gekara NO. Mast cells elicit proinflammatory but not type I interferon responses upon activation of TLRs by bacteria. Proc Natl Acad Sci U S A 2010;107:8748-8753.

26. Sawada K, Nagai H, Basaki Y, Yamaya H, Ikizawa K, Watanabe M, Kojima M, Matsuura N, Kiniwa M. The expression of murine cutaneous late phase reaction requires both IgE antibodies and CD4 T cells. Clin Exp Allergy 1997;27:225-231.

27. Ali K, Bilancio A, Thomas M, Pearce W, Gilfillan AM, Tkaczyk C, Kuehn N, Gray A, Giddings J, Peskett E, et al. Essential role for the p110delta phosphoinositide 3-kinase in the allergic response. Nature 2004;431:1007-1011.

28. Kojima T, Obata K, Mukai K, Sato S, Takai T, Minegishi Y, Karasuyama H. Mast cells and basophils are selectively activated in vitro and in vivo through CD200R3 in an IgE-independent manner. J Immunol 2007;179:7093-7100.

29. Ikeda T, Funaba M. Altered function of murine mast cells in response to lipopolysaccharide and peptidoglycan. Immunol Lett 2003;88:21-26.

30. Andersson MK, Pemberton AD, Miller HR, Hellman L. Extended cleavage specificity of mMCP-1, the major mucosal mast cell protease in mouse-high specificity indicates high substrate selectivity. Mol Immunol 2008;45:2548-2558.

31. McCurdy JD, Lin TJ, Marshall JS. Toll-like receptor 4-mediated activation of murine mast cells. J Leukoc Biol 2001;70:977-984.

32. Kirton OC, Windsor J, Wedderburn R, Hudson-Civetta J, Shatz DV, Mataragas NR, Civetta JM. Failure of splanchnic resuscitation in the acutely injured trauma patient correlates with multiple organ system failure and length of stay in the ICU. Chest 1998;113:1064-1069.

33. Deitch EA. Gut lymph and lymphatics: a source of factors leading to organ injury and dysfunction. Ann NY Acad Sci 2010;1207 Suppl 1:E103-111.

34. Enoksson M, Lyberg K, Moller-Westerberg C, Fallon PG, Nilsson G, Lunderius-Andersson C. Mast cells as sensors of cell injury through IL-33 recognition. J Immunol 2011;186:2523-2528.

35. Galli SJ, Grimbaldeston M, Tsai M. Immunomodulatory mast cells: negative, as well as positive, regulators of immunity. Nat Rev Immunol 2008;8:478-486.

36. Jiang W, Kirkup AJ, Grundy D. Mast cells drive mesenteric afferent signalling during acute intestinal ischemia. J Physiol 2011;589:3867-3882.

37. Kunder CA, St John AL, Li G, Leong KW, Berwin B, Staats HF, Abraham SN. Mast cell-derived particles deliver peripheral signals to remote lymph nodes. J Exp Med 2009;206:2455-2467.

38. Klooker TK, Braak B, Koopman KE, Welting O, Wouters MM, van der Heide S, Schemann M, Bischoff SC, van den Wijngaard RM, Boeckxstaens GE. The mast cell stabiliser ketotifen decreases visceral hypersensitivity and improves intestinal symptoms in patients with irritable bowel syndrome. Gut 2010;59:1213-1221.

39. Grant SM, Goa KL, Fitton A, Sorkin EM. Ketotifen. A review of its pharmacodynamic and pharmacokinetic properties, and therapeutic use in asthma and allergic disorders. Drugs 1990;40: $412-448$ 
40. Vergara $P$, Saavedra $Y$, Juanola C. Neuroendocrine control of intestinal mucosal mast cells under physiological conditions. Neurogastroenterol Motil 2002;14:35-42.

41. Berthoud HR. Vagal and hormonal gut-brain communication: from satiation to satisfaction. Neurogastroenterol Motil 2008;20 Suppl 1:64-72.

42. Verberne AJ, Saita M, Sartor DM. Chemical stimulation of vagal afferent neurons and sympathetic vasomotor tone. Brain Res Brain Res Rev 2003;41:288-305.

43. van Diest SA, Stanisor OI, Boeckxstaens GE, de Jonge WJ, van den Wijngaard RM. Relevance of mast cell-nerve interactions in intestinal nociception. Biochim Biophys Acta 2012;1822:74-84.

44. Fukamachi S, Mori T, Sakabe J, Shiraishi N, Kuroda E, Kobayashi M, Bito T, Kabashima K, Nakamura M, Tokura Y. Topical cholecystokinin depresses itch-associated scratching behavior in mice. J Invest Dermatol 2011;131:956-961.

45. Kageyama-Yahara N, Suehiro Y, Yamamoto T, Kadowaki M. IgE-induced degranulation of mucosal mast cells is negatively regulated via nicotinic acetylcholine receptors. Biochem Biophys Res Commun 2008;377:321-325.

46. Mishra NC, Rir-sima-ah J, Boyd RT, Singh SP, Gundavarapu S, Langley RJ, Razani-Boroujerdi S, Sopori ML. Nicotine inhibits Fc epsilon RI-induced cysteinyl leukotrienes and cytokine production without affecting mast cell degranulation through alpha 7/alpha 9/alpha 10-nicotinic receptors. J Immunol 2010;185:588-596.

47. Stead RH, Colley EC, Wang B, Partosoedarso E, Lin J, Stanisz A, Hillsley K. Vagal influences over mast cells. Auton Neurosci 2006;125:53-61.

48. Tore F, Tuncel N. Mast cells: target and source of neuropeptides. Curr Pharm Des 2009;15:3433-3445.

49. Stead RH, Dixon MF, Bramwell NH, Riddell RH, Bienenstock J. Mast cells are closely apposed to nerves in the human gastrointestinal mucosa. Gastroenterology 1989;97:575-585.

50. Ishihara K, Murata M, Kaneniwa M, Saito H, Shinohara K, Maeda-Yamamoto M, Kawasaki K, Ooizumi T. Effect of tetracosahexaenoic acid on the content and release of histamine, and eicosanoid production in MC/9 mouse mast cell. Lipids 1998;33:1107-1114. 


\section{Part III}

Explorations on the applicability of the nutritional anti-inflammatory reflex in surgical, trauma and critical care settings 


\title{
CHAPTER 7
}

\section{Post-shock intervention with high-lipid enteral nutrition reduces inflammation}

\author{
and tissue damage
}

Jacco J. de Haan, Tim Lubbers, M'hamed Hadfoune, Misha D. Luyer, Cornelis H. Dejong, Wim A. Buurman, Jan-Willem M. Greve 


\section{Abstract}

Introduction: An excessive inflammatory response following severe trauma is associated with poor clinical outcome. Currently, therapies directed at attenuation of an ongoing inflammatory cascade are lacking. Administration of high-lipid enteral nutrition prior to hemorrhagic shock has been shown to effectively inhibit early and late proinflammatory cytokines by activation of the autonomic nervous system via cholecystokinin (CCK)-receptors. This study investigates the effects of high-lipid enteral nutrition in a setting of developing inflammation and tissue damage.

Methods: A rat model of hemorrhagic shock was used in which animals were either fasted or treated with high-lipid or control low-lipid enteral nutrition. CCK-receptor antagonists were administered before feeding. Tissues and plasma were collected to assess inflammation and intestinal integrity.

Results: Administration of high-lipid enteral nutrition after shock significantly reduced plasma interferon-gamma (IFN- $\gamma$ ) compared with low-lipid treated and fasted animals $(P<0.01$ and $P<0.001$ resp.). Also IL-10 levels in plasma were decreased in comparison with fasted animals $(P<0.001)$. Enterocyte damage, expressed as circulating ileal lipid binding protein (ILBP), was prevented by early high-lipid nutrition compared with lowlipid treated and fasted animals ( $P=0.05$ and $P<0.001$ resp.). Furthermore, high-lipid feeding preserved intestinal integrity in comparison with low-lipid treated and fasted animals, as assessed by bacterial translocation (BT) to distant organs $(P<0.05$ and $P<0.001$ resp.) and ileal permeability to horseradish peroxidase (HRP) $(P=0.05$ and $P<0.001$ resp.). The protective effects of high-lipid intervention were taken away by CCK-receptor antagonists (IFN- $\gamma$; IL-10; BT; and HRP; $P<0.05$ ).

Conclusions: High-lipid enteral nutrition given post-shock reduces inflammation and preserves tissue integrity via a CCK-receptor dependent mechanism. These findings implicate that intervention with high-lipid enteral nutrition following events such as severe trauma is a potential therapy to attenuate the developing inflammatory response. 


\section{Introduction}

An uncontrolled inflammatory response as result of severe trauma followed by a second hit such as surgery or infection is associated with poor clinical outcome ${ }^{1-4}$. Despite important improvements in the treatment of trauma patients over the last decades, morbidity and mortality remain high $^{5-7}$. Our understanding of the inflammatory cascade triggered by severe trauma has advanced rapidly, however, until now there is no effective clinical therapy that controls excessive inflammation ${ }^{8}$. Consequently, current treatment of patients with severe trauma is aimed at rapid hemodynamic stabilization, damage control and sustained support of organ and endocrine systems ${ }^{9,10}$.

Improved insight into the complex inflammatory response following trauma has led to the development of diverse anti-inflammatory strategies, usually directed at single inflammatory mediators. Although such strategies were highly promising in various experimental models of trauma and sepsis, most interventions lacked effectiveness in clinical trials ${ }^{8}$. The intervention applied in the current study might overcome this problem by activating a potent endogenous pathway that modulates the immune system.

In recent studies, our group demonstrated that high-lipid enteral nutrition strongly attenuated the inflammatory response and preserved tissue integrity in a model of hemorrhagic shock ${ }^{11,12}$. The protective effects of lipid-enriched enteral feeding are based on nutritional activation of the autonomic nervous system via cholecystokinin (CCK)-receptors leading to activation of nicotinic receptors located on inflammatory cells ${ }^{13-15}$.

In previous studies high-lipid enteral nutrition was administered prior to shock. However, in many clinical settings as trauma, the inflammatory response is already developing before treatment can be initiated. Therefore, the aim of this study was to investigate the protective effects of lipid-enriched enteral nutrition administered in a setting in which the inflammatory cascade is unfolding.

\section{Methods}

\section{Animals}

Male Sprague-Dawley rats, weighing 300-350 g were purchased from Charles River Laboratories (Maastricht, the Netherlands). Animals were housed under standardized conditions of temperature and humidity and had free access to standard chow and water. The study was approved by the Animal Ethics Committee of Maastricht University Medical Center. 


\section{Experimental design}

Non-lethal hemorrhagic shock was induced as previously described ${ }^{11,12,16}$. In short, rats were anesthetized with isoflurane (induction $4 \%$, maintenance $1.5 \%$ ). The femoral artery was dissected and cannulated with a polyethylene tubing (PE-10) containing heparinized saline $(10 \mathrm{lU} / \mathrm{ml})$. At time of shock $(\mathrm{t}=0), 2.1 \mathrm{ml}$ blood per $100 \mathrm{~g}$ body weight (representing $30-40 \%$ of circulating volume) was withdrawn at a rate of $1 \mathrm{ml} /$ minute. Anesthesia was stopped at 60 minutes after shock. Prior to shock, all rats were fasted for 18 hours. Following shock, rats were fasted or submitted to either an early or a delayed intervention with high-lipid or control low-lipid enteral nutrition. In the early feeding regime, animals received $1.5 \mathrm{ml}$ nutrition at 30 minutes after shock by way of orogastric tube (PE-50) and $0.75 \mathrm{ml}$ at 3 hours post-shock by way of oral gavage ( $n=8$ for each group). Animals in the early feeding protocol were sacrificed at 4 hours after shock. In the delayed feeding regime, animals received nutrition at 80 minutes $(1.5 \mathrm{ml}), 3$ and 6 hours (both $0.75 \mathrm{ml}$ ) following shock. After the last feeding moment, they were given free access to standard chow and sacrificed at 24 hours after shock ( $n=10$ for each group, Figure 7.1). CCK-A and -B receptor antagonists (Devazepide and L365, 260 resp.; kind gifts from ML Laboratories PLC, Nottingham, United Kingdom) (both $500 \mu \mathrm{g} / \mathrm{kg}$ ) were given 10 minutes before the first and second high-lipid feeding intravenously resp. intraperitoneally $(n=6)$. A control group received high-lipid nutrition and vehicle ( $90 \% \mathrm{NaCl}, 5 \%$ Tween $20,5 \% \mathrm{DMSO})$.

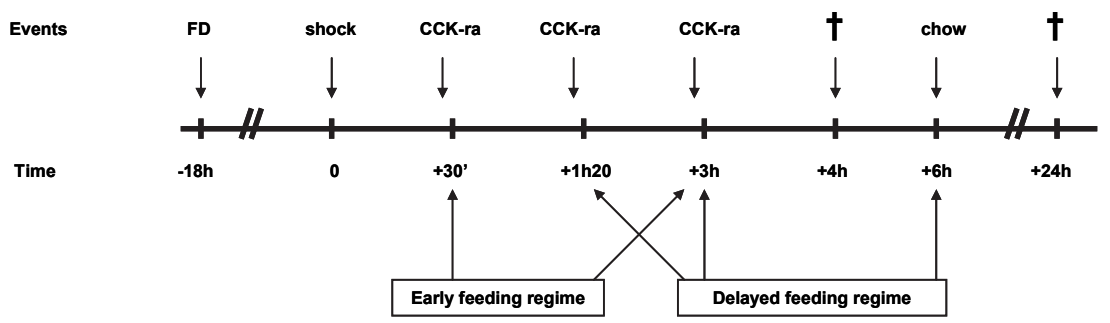

Figure 7.1 Experimental design of post-shock intervention with high-lipid enteral nutrition. Rats were deprived of food (FD) 18 hours prior to shock. At $t=0$, shock was induced. Subsequently, rats were fasted or received a liquid high-lipid or control low-lipid enteral nutrition in either an early or a delayed feeding regime. In the early feeding regime, nutrition was administered at 30 minutes by gastric tube and at 3 hours by oral gavage $(1.5$ and $0.75 \mathrm{ml}$ resp.) and rats were sacrificed after 4 hours $\left({ }^{+}\right)$. In the delayed feeding protocol, nutrition was given at 80 minutes, 3 and 6 hours following shock $(1.5 \mathrm{ml}, 0.75 \mathrm{ml}$ and $0.75 \mathrm{ml}$ respectively) by oral gavage. Next, rats were given free access to standard chow (chow) and sacrificed after 24 hours $(+)$ ). In both feeding protocols, CCK-receptor antagonists were administered 10 minutes prior to the first and second high-lipid feeding (CCKra). 


\section{Composition of nutrition}

The lipid-enriched liquid enteral diet contained 50.4 energy percent (en\%) fat, of which $30 \%$ constituted of phospholipids, $8.7 \mathrm{en} \%$ protein and $40.9 \mathrm{en} \%$ carbohydrates. The low-lipid nutrition contained $16.0 \mathrm{en} \%$ fat, $8.7 \mathrm{en} \%$ proteins and $75.3 \mathrm{en} \%$ carbohydrates. The high-lipid nutrition was isocaloric and isonitrogenous to the lowlipid nutrition and the amount of fat in the low-lipid diet was isocaloric to that present in standard rodent chow. The types of carbohydrates, proteins and fat used in both diets were identical. The lipid source was lecithin. Omega 3 and 6 fatty acids constituted $<5 \%$ in both feedings. Proteins were derived from lean milk powder, containing $80 \%$ casein and $20 \%$ whey protein. The carbohydrate source was a mixture of sucrose and maltodextrins (Glucidex 19DE).

\section{Blood analysis}

Interferon-gamma (IFN- $\gamma$ ), ileal lipid binding protein (ILBP) and IL-10 concentrations in arterial blood were determined using standard ELISA for rat IFN- $\gamma$ and rat-ILBP (both kindly provided by Hycult Biotechnology ( $\mathrm{Hbt})$, Uden, the Netherlands) and rat IL-10 (Biosource, Camarillo, CA).

\section{Myeloperoxidase quantification}

Per rat, sacrificed at 4 hours after shock, three segments of ileum were snap frozen in liquid nitrogen. Segments were homogenized in lysisbuffer $(300 \mathrm{mM} \mathrm{NaCl}, 30 \mathrm{mM}$ Tris, $2 \mathrm{mM} \mathrm{MgCl}_{2}, 2 \mathrm{mM} \mathrm{CaCl}, 1 \%$ Triton X-100, en Pepstatin A, Leupeptin, Aprotinin (all $20 \mathrm{ng} / \mathrm{ml}$ ); $\mathrm{pH} 7.4$ ), centrifuged and supernatants stored at $-20^{\circ} \mathrm{C}$ until analysis. Myeloperoxidase (MPO) was quantified using ELISA. In brief, a microtiter plate was coated with mAb 8F4, cross reactive with rat MPO ( $\mathrm{Hbt}$, Uden, the Netherlands) overnight at $4^{\circ} \mathrm{C}$ and blocked with $1 \%$ BSA in PBS. Binding was detected with biotinylated rabbit- $\alpha$-human MPO (DAKO, Glostrup, Denmark) and visualized with 3,3',5,5'-Tetramethylbenzidine (TMB). The results were recorded using an ELISA plate reader at $450 \mathrm{~nm}$. MPO content per sample was calculated, after correction for total extracted protein per sample.

\section{Microbiological methods}

Bacterial translocation to distant organs was assessed as described ${ }^{11-13}$. In short, mesenteric lymph nodes, the mid-section of the spleen and liver-segment IV were collected aseptically in preweighed thioglycolate broth tubes (Becton Dickinson, Franklin Lakes, NJ) in all rats. Tissue-fragments were weighed and homogenized and subsequently, the suspension was transferred to agar plates (Columbia III blood agar base supplemented with $5 \% \mathrm{vol} / \mathrm{vol}$ sheep blood (BBL, Franklin Lakes, NJ) (duplicate 
plates) and Chocolate PolyviteX agar (BioMérieux, Marcy L'Etoile, France)). After 48 hours of incubation, the number of colonies were counted and determined using conventional techniques. Subsequently, the numbers were adjusted to tissue weight, and expressed as number of colony forming units (CFU) per gram of tissue.

\section{Intestinal permeability}

Intestinal permeability was assessed by measuring permeability to horseradish peroxidase (HRP) in isolated segments of ileum as previously described ${ }^{11,17}$. In short, $8-\mathrm{cm}$ segments of the distal ileum were washed, everted, and filled with $1 \mathrm{ml}$ of Tris buffer (125 mmol// NaCl, $10 \mathrm{mmol} / \mathrm{I}$ fructose, $30 \mathrm{mmol} / \mathrm{l}$ Tris; $\mathrm{pH} \mathrm{7.5)}$ and ligated at both ends. The filled segment was incubated in Tris buffer containing $40 \mu \mathrm{g} / \mathrm{ml}$ of HRP (Sigma, St. Louis, MO). After incubation at room temperature for 45 minutes, segments of ileum were removed from the buffer and the content was carefully collected in a 1-ml syringe. HRP activity was measured spectrophotometrically at $405 \mathrm{~nm}$ after addition of TMB as substrate for HRP.

\section{Immunohistochemistry}

lleum sections $(4 \mu \mathrm{m})$ of rats sacrificed 4 hours after hemorrhagic shock and healthy controls were stained for tight junction protein Zonula Occludens protein 1 (ZO-1). After a 1 hour incubation with Rabbit anti-ZO-1 (61-7300, Zymed Laboratories, San Francisco, CA), the sections were incubated for 1 hour with Texas red conjugated goat anti-rabbit antibody (Jackson, West Grove, PA). This was followed by 2 minutes incubation with 4',6-diamino-2-phenyl indole (DAPI), mounted in Fluorescence Mounting Solution (Dakocytomation). The distribution of tight junctions was recorded at a magnification of 200x using the Metasystems Image Pro System (black and white charge-couple device camera; Metasystems, Sandhausen, Germany) mounted on a Leica DM-RE fluorescence microscope (Leica, Wetzler, Germany). All images were taken at equal time-exposures after being normalized to negative control sections without primary antibody, to exclude for non-specific binding of the secondary antibody or autofluorescence. At least 25 microscopic fields for each tissue section were examined.

\section{Statistical analysis}

All data are expressed as mean \pm SEM. A Mann-Whitney $U$ test was used for betweengroup comparisons. Differences were considered statistically significant at $P \leq 0.05$. 


\section{Results}

\section{Lipid-enriched enteral nutrition following hemorrhagic shock reduces inflammation}

Early intervention with high-lipid enteral feeding after shock significantly decreased circulating IFN- $\gamma$ compared with low-lipid treated and fasted animals $(0.4 \pm 0.1 \mathrm{ng} / \mathrm{ml}$ vs. $0.8 \pm 0.1 \mathrm{ng} / \mathrm{ml} ; P<0.01$ and $1.4 \pm 0.1 \mathrm{ng} / \mathrm{ml} ; P<0.001)$. Also low-lipid nutrition resulted in lower IFN- $\gamma$ levels compared with fasted animals $(P<0.01)$. CCK-receptor antagonists (CCK-ra) were administered 10 minutes before treatment with high-lipid nutrition to assess the role of CCK-receptor mediated activation of the autonomic nervous system. CCK-ra inhibited the effects of high-lipid nutrition on plasma IFN- $\gamma$ $(1.2 \pm 0.2 \mathrm{ng} / \mathrm{ml}$ vs. vehicle: $0.6 \pm 0.1 \mathrm{ng} / \mathrm{ml} ; P<0.05$, Figure $7.2 \mathrm{~A})$.

Also plasma levels of the anti-inflammatory cytokine IL-10 were markedly decreased by treatment post shock with high-lipid enteral nutrition in the early feeding regime compared with animals that were fasted after shock (109 $\pm 7 \mathrm{pg} / \mathrm{ml}$ vs. $156 \pm 4 \mathrm{pg} / \mathrm{ml}$; $P<0.001)$. A protective trend was seen in high-lipid treated animals compared to lowlipid controls (129 $\pm 7 \mathrm{pg} / \mathrm{ml}, P=0.06)$. Moreover, low-lipid nutrition reduced IL-10 levels compared to fasted animals $(P<0.01)$. Administration of CCK-ra blocked the effects of high-lipid feeding on IL-10 plasma levels compared with vehicle treated animals (150 $\pm 9 \mathrm{pg} / \mathrm{ml}$ vs. $107 \pm 10 \mathrm{pg} / \mathrm{ml} ; P<0.05$, Figure $7.2 \mathrm{~B})$.

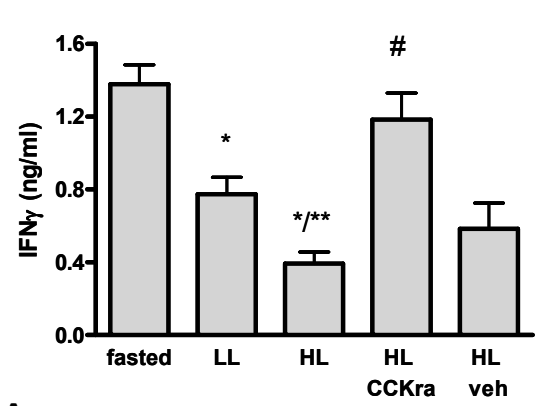

A

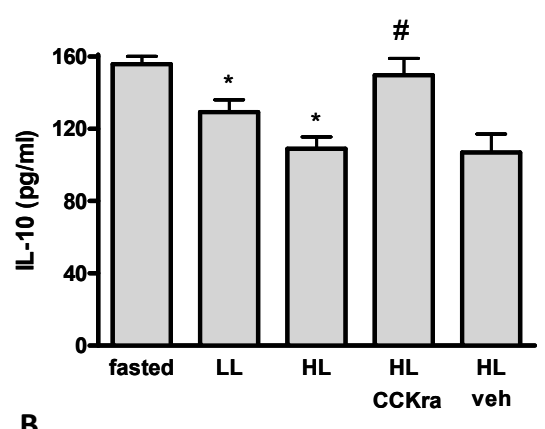

Figure 7.2 High-lipid enteral nutrition in the early feeding regime reduces plasma IFN- $\gamma$ and IL-10. A. Highlipid $(\mathrm{HL})$ enteral diet after shock significantly reduced plasma IFN- $\gamma$ concentrations at 4 hours after shock compared with low-lipid (LL) treated or fasted animals ( ${ }^{*} P<0.01$ and ${ }^{* *} P<0.01$ resp.). Administration of low-lipid nutrition resulted in decreased IFN- $\gamma$ levels compared with fasted animals $\left({ }^{*} P<0.01\right)$. Administration of CCK-receptor antagonists (CCKra) abrogated the anti-inflammatory effects of high-lipid nutrition on IFN- $\gamma$ ( $\# P<0.05$ to high-lipid + vehicle). B. High-lipid enteral feeding following shock significantly decreased plasma levels of IL-10 compared with fasted controls $(* P<0.01)$ and a trend of IL-10 reduction was observed of highlipid feeding compared with low-lipid treated controls. Next, low-lipid treated animals resulted in lower IL-10 levels compared with fasted animals ( $\left.{ }^{*} P<0.01\right)$. CCKra blunted the effect of high-lipid nutrition on IL-10 (\# $P<0.05$ to high-lipid + vehicle). 
Local intestinal inflammation was assessed by detection of myeloperoxidase (MPO) levels in ileum. In line with systemic inflammatory parameters, a protective trend towards reduced tissue MPO concentrations were observed in rats treated with highlipid enteral feeding compared with low-lipid feeding $(1.5 \pm 0.3 \mathrm{ng} / \mathrm{\mu g}$ protein vs. $2.3 \pm 1.0 \mathrm{ng} / \mu \mathrm{g}$ protein; $P=0.06$ ). Post-shock treatment with low-lipid nutrition did not sort any effect on MPO tissue levels in comparison with animals that were fasted $(2.5 \pm 1.2 \mathrm{ng} / \mu \mathrm{g}$ protein; $P=1.0$, Figure 7.3$)$.

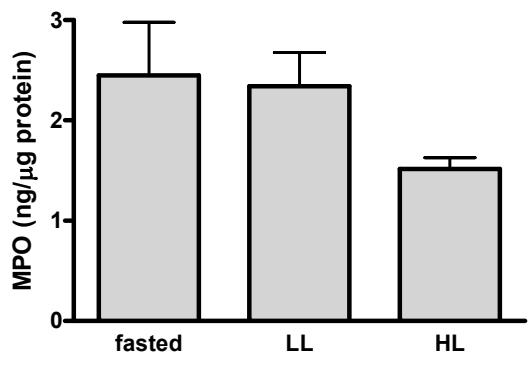

Figure 7.3 Effects of high-lipid enteral nutrition on local inflammation. A protective trend towards decreased myeloperoxidase (MPO) concentrations in ileum was seen in high-lipid (HL) treated animals compared with low-lipid (LL) control groups $(P=0.06)$. Low-lipid feeding did not exert any effect on tissue MPO levels compared with fasted animals.

\section{Administration of high-lipid enteral nutrition after shock reduces intestinal epithelial cell damage}

Hemorrhagic shock resulted in an elevation of plasma ileal lipid binding protein (ILBP), a $14 \mathrm{kD}$ cytosolic protein expressed by mature enterocytes that is rapidly released following cellular damage. Both the early and delayed feeding regimes with a high-lipid enteral diet significantly lowered ILBP-levels in plasma compared with fasted animals (early feeding: $3.7 \pm 0.3 \mathrm{ng} / \mathrm{ml}$ vs. $8.0 \pm 1.1 \mathrm{ng} / \mathrm{ml} ; P<0.001$ and delayed feeding: $1.3 \pm 0.2 \mathrm{ng} / \mathrm{ml}$ vs. $6.3 \pm 0.7 \mathrm{ng} / \mathrm{ml} ; P<0.001$, Figure $7.4 \mathrm{~A}$ and B). Moreover, ILBP levels were significantly reduced in high-lipid treated animals compared with the low-lipid group in the early feeding regime $(4.9 \pm 0.5 \mathrm{ng} / \mathrm{ml} ; P=0.05)$. Low-lipid feeding resulted in decreased ILBP levels compared with fasted animals (early and delayed feeding; $P<0.05)$.

\section{Enteral high-lipid feeding prevents loss of intestinal tight junction integrity}

Disruption of tight junctions was visualized by staining for ZO-1. In healthy controls ZO-1 showed a regular distribution along the villi of the terminal ileum, in association 
with the luminal surface of gut epithelium (Figure 7.5A). Hemorrhagic shock induced a major loss of ZO-1 in ileum of rats that were fasted for 4 hours after shock as we have observed before (Figure $7.5 \mathrm{~B})^{11,18}$. In contrast, tight junction integrity was largely preserved by nutrition given in the early feeding regime, as represented by a relatively undisturbed regular distribution of ZO-1 (low-lipid: Figure $7.5 \mathrm{C}$ and high lipid: Figure 7.5D). The protective effects on ZO-1 expression were most prominent following intervention with high-lipid nutrition.

Early feeding protocol

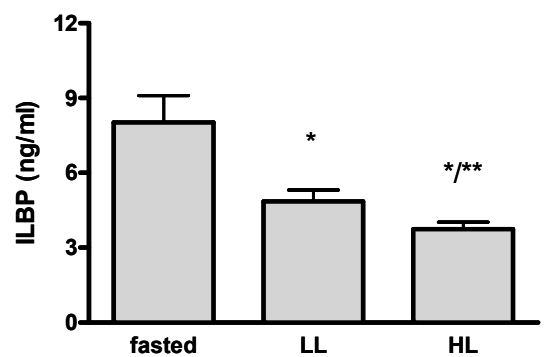

A
Delayed feeding protocol

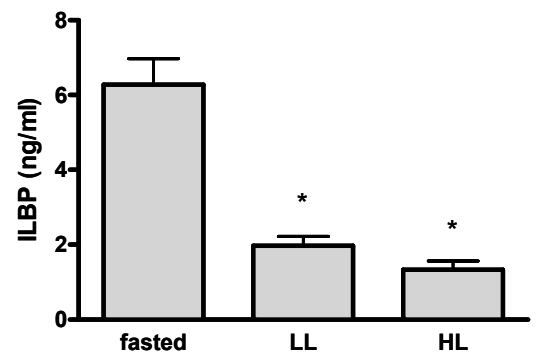

B

Figure 7.4 Administration of high-lipid enteral nutrition after shock decreases intestinal damage. A. Early high-lipid (HL) enteral feeding resulted in lower plasma ileal lipid binding protein (ILBP) levels compared with low-lipid (LL) feeding (** $P<0.05)$. ILBP concentrations in plasma after early nutritional intervention were significantly reduced in high-lipid and low-lipid treated animals compared with fasted controls $(* P \leq 0.05)$. B. Also the delayed feeding regime with either highlipid or low-lipid nutrition decreased circulating ILBP levels compared with fasted groups $(* P<0.05)$.

\section{Improved intestinal barrier function}

Bacterial translocation to distant organs and leakage of HRP in ileum were determined as parameters for loss of intestinal integrity following hemorrhagic shock. An early enteral regime of high-lipid feeding after shock resulted in a significantly reduced number of colony forming bacteria in distant organs compared with fasted animals (69.7 \pm 6.4 CFU/gr tissue vs. $237.6 \pm 16.4 \mathrm{CFU} / \mathrm{gr}$ tissue; $P<0.001)$ and to animals on a low-lipid diet $(100.9 \pm 9.2 \mathrm{CFU} / \mathrm{gr}$ tissue; $P<0.05)$. Also low-lipid feeding reduced bacterial translocation compared to fasted animals $(P<0.01$, Figure 7.6A). Furthermore, early intervention after shock with lipid-enriched enteral feeding significantly reduced leakage of HRP compared with fasted animals $(9.0 \pm 0.8 \mu \mathrm{g} / \mathrm{ml}$ vs. $26.4 \pm 2.1 \mu \mathrm{g} / \mathrm{ml}$; $P<0.001)$. Moreover, low-lipid feeding reduced ileal permeability to HRP in comparison with fasted animals $(11.8 \pm 1.1 \mu \mathrm{g} / \mathrm{ml} ; P<0.05$, Figure $7.6 \mathrm{~B})$. 
The delayed feeding regime resulted in a significant reduction of bacterial translocation at 24 hours after shock in animals given high-lipid feeding ( $43.0 \pm 3.6 \mathrm{CFU} / \mathrm{g}$ tissue vs. fasted: $133.1 \pm 16.8 \mathrm{CFU} / \mathrm{g}$ tissue; $P<0.001$ and vs. low-lipid: $69.0 \pm 4.9 \mathrm{CFU} / \mathrm{g}$ tissue; $P<0.01$, Figure 7.6C). Furthermore, low-lipid feeding reduced bacterial translocation compared to fasted animals $(P<0.001)$. Also HRP leakage was reduced after the delayed feeding regime with high-lipid intervention compared with low-lipid treated and fasted controls $(6.6 \pm 0.2 \mu \mathrm{g} / \mathrm{ml}$ vs. $7.3 \pm 0.3 \mu \mathrm{g} / \mathrm{ml} ; P<0.05$ and $9.1 \pm 0.3 \mu \mathrm{g} / \mathrm{ml} ; P<0.001$, Figure 7.6D). Next, low-lipid feeding reduced HRP permeability compared with fasted animals $(P<0.05)$.

Administration of CCK-receptor antagonists (CCKra) abrogated the protective effects of high-lipid nutrition on intestinal integrity. CCKra inhibited the reduction of bacterial translocation in high-lipid treated animals compared to high-lipid treated animals given vehicle in both feeding regimes (early feeding: $173.3 \pm 12.6 \mathrm{CFU} / \mathrm{g}$ tissue vs. $110.3 \pm 14.0 \mathrm{CFU} / \mathrm{g}$ tissue; $P<0.05$, Figure 7.6A and delayed feeding: $165.5 \pm 14.4 \mathrm{CFU} / \mathrm{g}$ tissue vs. $54.2 \pm 11.8 \mathrm{CFU} / \mathrm{g}$ tissue; $P<0.05$, Figure $7.6 \mathrm{~B})$. Blockage of CCK-receptors also abrogated the reduction of HRP leakage by high-lipid nutrition compared with vehicle treated animals (early feeding: $25.2 \pm 2.5 \mu \mathrm{g} / \mathrm{ml}$ vs. $11.7 \pm 1.0 \mu \mathrm{g} / \mathrm{ml} ; P<0.05$ and delayed feeding: $9.1 \pm 0.2 \mu \mathrm{g} / \mathrm{ml}$ vs. $6.5 \pm 0.2 \mu \mathrm{g} / \mathrm{ml} ; P<0.05)$.
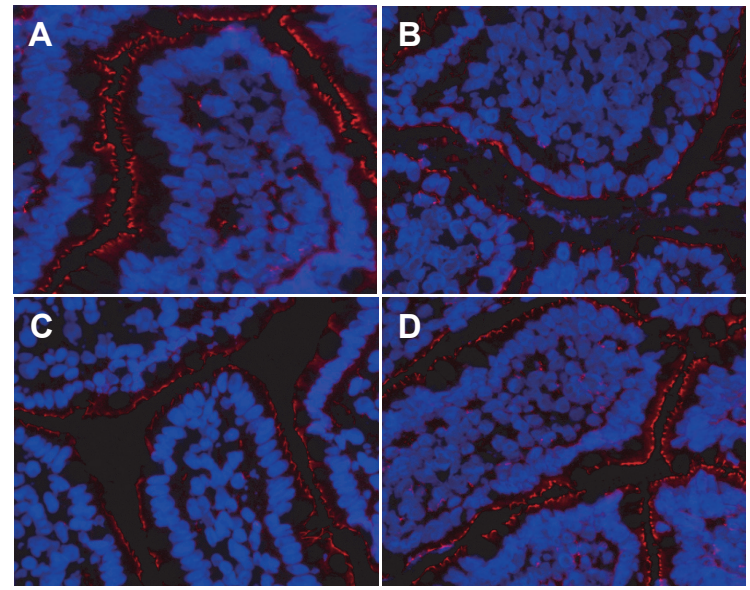

Figure 7.5 High-lipid feeding prevents deterioration of tight junction integrity in the intestine. A. In healthy control animals, ZO-1 expression on ileal villi at 200x magnification was intact and regular. B. Fasting after shock resulted in ZO-1 villus lining in animals that was irregular and discontinuous. C, D. In animals receiving high-lipid nutrition following shock, ZO-1 expression was largely preserved, although small irregularities were observed. The protective effects were present to a lesser extent following treatment with low-lipid nutrition. The histology shown is representative for all tissue samples studied. 


\section{Early feeding protocol}

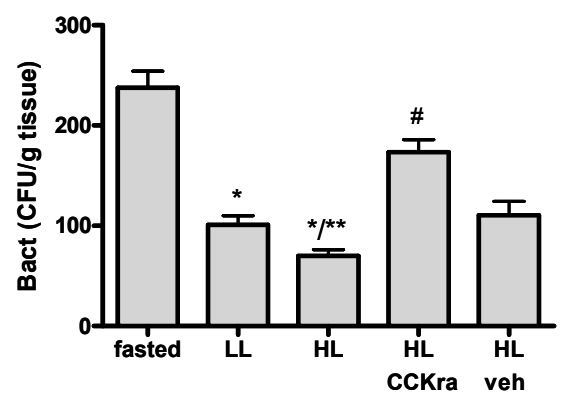

A

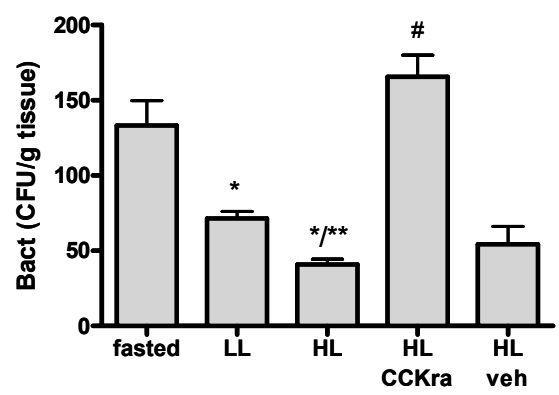

C

\section{Early feeding protocol}

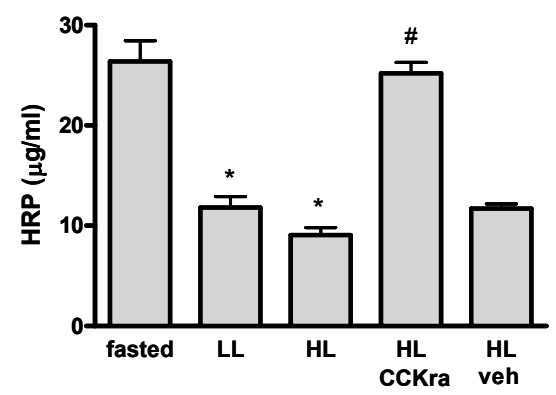

B

Delayed feeding protocol

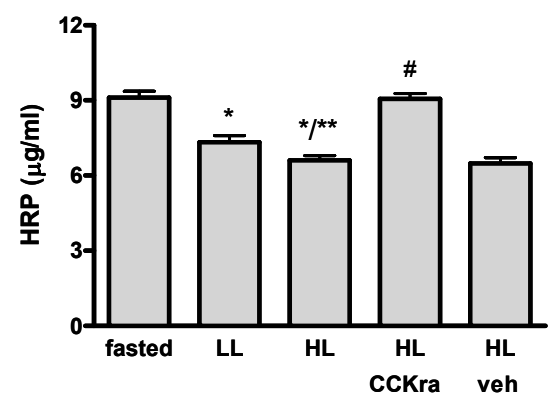

D

Figure 7.6 High-lipid enteral feeding after shock improves intestinal barrier function. A. Bacterial translocation to distant organs was significantly reduced in animals on an early high-lipid (HL) regime compared to low-lipid (LL) treated and fasted controls ( ${ }^{*} P<0.05$ and ${ }^{* *} P<0.01$ resp.). Furthermore, low-lipid enteral feeding decreased bacterial translocation compared to fasted animals $(* P<0.01)$. B. Early intervention with lipid-enriched feeding after shock significantly reduced leakage of horseradish peroxidase (HRP) in comparison to fasted animals $(* P<0.05)$. Also low-lipid feeding resulted in a significant reduction of HRP permeability compared to fasted animals $(* P<0.05)$. C. Delayed intervention with high-lipid nutrition reduced bacterial translocation significantly ( $* P<0.01$ vs. fasted and $* * P<0.001$ vs. low-lipid). Moreover, bacterial translocation was reduced in low-lipid animals compared to the fasted group $\left({ }^{*} P<0.01\right)$. D. A significant decrease of permeability to HRP was seen after delayed enteral feeding with high-lipid nutrition compared to low-lipid treated $(* * P=0.05)$ and fasted animals (* $P<0.05)$. Also low-lipid feeding resulted in a significant reduction of HRP permeability compared to fasted animals $(* P<0.05)$. In both feeding protocols CCK receptor antagonists abrogated the effects of high-lipid nutrition on bacterial translocation (early and delayed feeding: \# $P<0.05$ compared with $\mathrm{HL}+$ vehicle). Administration of CCK receptor antagonists blunted the protective effects of high-lipid feeding on ileal permeability to HRP in both the early and the delayed feeding regime (\# $P<0.05$ compared with $\mathrm{HL}+$ vehicle) 


\section{Discussion}

The inflammatory response to trauma has to be regulated carefully ${ }^{19}$. Uncontrolled inflammation occurring after severe trauma may result in a systemic inflammatory response syndrome (SIRS) or sepsis that are associated with poor clinical outcome $^{2,8,20-22}$. Therefore, control of the inflammatory cascade following trauma is considered pivotal to prevent the development of detrimental inflammatory syndromes $^{3,8,23,24}$. To mimic the clinical setting of trauma in which the inflammatory response is unfolding and only a post-treatment approach is feasible, the intervention in this study was started after induction of hemorrhagic shock. In this study the shortterm effects (within 24 hours) of inhibition of inflammation by nutritional intervention were investigated.

This is the first study to show that post-shock treatment with high-lipid enteral feeding reduces the shock-induced developing inflammatory response in a CCK-receptor dependent mechanism. Hemorrhagic shock resulted in significantly increased though moderately high circulating IFN- $\gamma$ levels $(1.4 \mathrm{ng} / \mathrm{ml})$. Early administration of lipidenriched feeding following shock strongly decreased these plasma levels of interferongamma (IFN- $\gamma$ ), a potent late inflammatory mediator with multiple actions on both innate and adaptive immune system ${ }^{25}$. In various experimental models including hemorrhagic shock elevated IFN- $\gamma$ levels have been implicated in the development of inflammation, tissue injury and gut barrier dysfunction ${ }^{26-29}$. Also clinical studies demonstrated a crucial role of IFN- $\gamma$ in the post-traumatic immune response ${ }^{30,31}$. Recent experimental studies indicated that reduction of late inflammatory mediators such as IFN- $\gamma$ is essential to attenuate an ongoing inflammatory response induced by major trauma, ${ }^{28,32}$. The reduced levels of plasma IFN- $\gamma$ following post-shock high-lipid feeding were accompanied by reduced circulating levels of anti-inflammatory cytokine IL-10. Elevated plasma levels of IL-10 indicate a hyper inflammatory state and are associated with an increased risk to develop septic complications. In the current study, the reduction of both pro- and anti-inflammatory cytokines (IFN- $\gamma$ and IL-10 resp.) indicate a broad inhibiting effect on developing inflammation by post-shock treatment with high-lipid enteral feeding.

Next, post-shock high-lipid enteral intervention strongly improved intestinal integrity. Translocation of bacteria and permeability to horseradish peroxidase (HRP) in highlipid treated animals were significantly reduced compared to low-lipid and fasted controls. These effects are in line with the effects of nutritional intervention given prior to shock ${ }^{11,12,18}$. Intestinal barrier dysfunction is widely postulated to play an important role in the development of inflammatory complications following surgery or trauma ${ }^{33-39}$. On the other hand, inflammatory cytokines such as IFN- $\gamma$ impair intestinal barrier function by disruption of epithelial tight junctions ${ }^{25,29}$. In accordance, our study 
shows that a reduction of systemic (IFN- $\gamma$ and IL-10) and local inflammation (MPO) by high-lipid intervention parallels a preserved expression of tight junction protein ZO-1. Furthermore, the findings that elevated ileal lipid binding protein (ILBP) plasma levels following shock were reduced by lipid-enriched nutrition indicate a protective effect on intestinal epithelial cell damage as well ${ }^{40-43}$. These protective effects on intestinal integrity were observed in two feeding protocols. The early feeding regime started at 30 minutes following shock, a time point at which the first signs of shock-induced intestinal tight junction loss are present (data submitted for publication). The delayed feeding protocol was initiated at 80 minutes post-shock at which time point systemic inflammation is already detectable ${ }^{13}$. This study demonstrates that, next to an extensive anti-inflammatory effect, post treatment with high-lipid enteral feeding results in a strong preservation of intestinal integrity.

The results show that the protective effects of high-lipid enteral nutrition given postshock are mediated by CCK-receptors. These findings are in accordance with our previous study which unraveled a neuro-endocrine pathway underlying the antiinflammatory actions of high-lipid nutrition ${ }^{13}$. In this mechanism, CCK-receptor dependent stimulation of the autonomic nervous system inhibits inflammation via binding of acetylcholine to alpha-7-nicotinergic receptors on macrophages ${ }^{13-15}$. The current study is the first to show that high-lipid nutritional stimulation of the autonomic nervous system strongly reduces the development of inflammation and intestinal barrier dysfunction in a setting of inflammation induced by hemorrhagic shock.

Severe trauma followed by a second hit such as surgery or infection provokes an excessive systemic inflammation that may result in organ dysfunction. Therefore, therapies are needed that reduce the inflammatory response of the primed immune system $^{1,3,4}$. The findings of this study that post-shock high-lipid enteral nutrition has strong anti-inflammatory effects are supported by previous studies demonstrating that activation of nicotinic receptors on immune cells is protective in settings of an ongoing inflammation. Nicotinic receptor activation via electrical vagus stimulation or administration of the alpha7nicotinergic agonist GST21 increased survival rates when applied after induction of septic peritonitis in mice ${ }^{44,45}$. The current study demonstrates that nutritional activation of the anti-inflammatory vagus-cholinergic pathway via CCK-receptor stimulation is a simple and physiological alternative. Moreover, feeding with a high lipid content was shown to be more effective than lowlipid feeding intervention. 


\section{Conclusions}

Administration of enteral high-lipid nutrition attenuates a developing inflammatory response and preserves intestinal integrity via a CCK-receptor dependent mechanism. This study implicates early enteral administration of high-lipid nutrition as a novel approach to attenuate the complex inflammatory cascade that unfolds in clinical settings such as severe trauma. 


\section{References}

1. Meldrum DR, Cleveland JC, Jr., Moore EE, et al. Adaptive and maladaptive mechanisms of cellular priming. Ann Surg. 1997;226:587-598.

2. Nast-Kolb D, Waydhas C, Gippner-Steppert C, et al. Indicators of the posttraumatic inflammatory response correlate with organ failure in patients with multiple injuries. J Trauma. 1997;42:446-454.

3. Lenz A, Franklin GA, Cheadle WG. Systemic inflammation after trauma. Injury. 2007;38:1336-1345.

4. Tschoeke SK, Hellmuth M, Hostmann A, et al. The early second hit in trauma management augments the proinflammatory immune response to multiple injuries. J Trauma. 2007;62:1396-1403.

5. Osborn TM, Tracy JK, Dunne JR, et al. Epidemiology of sepsis in patients with traumatic injury. Crit Care Med. 2004;32:2234-2240.

6. MacKenzie EJ. Epidemiology of injuries: current trends and future challenges. Epidemiol Rev. 2000;22:112-119.

7. Papa L, Langland-Orban B, Kallenborn C, et al. Assessing effectiveness of a mature trauma system: Association of trauma center presence with lower injury mortality rate. J Trauma. 2006;61:261-266.

8. Keel M, Trentz O. Pathophysiology of polytrauma. Injury. 2005;36:691-709.

9. Collicott PE, Hughes I. Training in advanced trauma life support. JAMA. 1980;243:1156-1159.

10. Bose D, Tejwani NC. Evolving trends in the care of polytrauma patients. Injury. 2006;37:20-28.

11. Luyer MD, Buurman WA, Hadfoune $M$, et al. Pretreatment with high-fat enteral nutrition reduces endotoxin and tumor necrosis factor-alpha and preserves gut barrier function early after hemorrhagic shock. Shock. 2004;21:65-71.

12. Luyer MD, Jacobs JA, Vreugdenhil AC, et al. Enteral administration of high-fat nutrition before and directly after hemorrhagic shock reduces endotoxemia and bacterial translocation. Ann Surg. 2004;239:257-264.

13. Luyer MD, Greve JW, Hadfoune M, et al. Nutritional stimulation of cholecystokinin receptors inhibits inflammation via the vagus nerve. J Exp Med. 2005;202:1023-1029.

14. Wang $\mathrm{H}, \mathrm{Yu} \mathrm{M}$, Ochani $\mathrm{M}$, et al. Nicotinic acetylcholine receptor alpha7 subunit is an essential regulator of inflammation. Nature. 2003;421:384-388.

15. Borovikova LV, Ivanova $\mathrm{S}$, Zhang $\mathrm{M}$, et al. Vagus nerve stimulation attenuates the systemic inflammatory response to endotoxin. Nature. 2000;405:458-462.

16. Bark T, Katouli M, Ljungqvist $O$, et al. Bacterial translocation after non-lethal hemorrhage in the rat. Circ Shock. 1993;41:60-65.

17. Carter EA, Harmatz PR, Udall JN, Walker WA. Barrier defense function of the small intestine: effect of ethanol and acute burn trauma. Adv Exp Med Biol. 1987;216A:829-833.

18. Luyer MD, Buurman WA, Hadfoune $M$, et al. High-fat enteral nutrition reduces endotoxin, tumor necrosis factor-alpha and gut permeability in bile duct-ligated rats subjected to hemorrhagic shock. $J$ Hepatol. 2004;41:377-383.

19. Nathan C. Points of control in inflammation. Nature. 2002;420:846-852.

20. Biffl WL, Moore EE, Moore FA, Peterson VM. Interleukin-6 in the injured patient. Marker of injury or mediator of inflammation? Ann Surg. 1996;224:647-664.

21. Moore FA, Sauaia A, Moore EE, et al. Postinjury multiple organ failure: a bimodal phenomenon. $J$ Trauma. 1996;40:501-510.

22. Lin E, Calvano SE, Lowry SF. Inflammatory cytokines and cell response in surgery. Surgery. 2000;127:117-126.

23. Bengmark S. Aggressive management of surgical emergencies. Ann R Coll Surg Engl. 2006;88:624-629.

24. Peitzman AB, Billiar TR, Harbrecht BG, et al. Hemorrhagic shock. Curr Prob/ Surg. 1995;32:925-1002.

25. Schoenborn JR, Wilson CB. Regulation of Interferon-gamma During Innate and Adaptive Immune Responses. Adv Immunol. 2007;96:41-101.

26. Madihally SV, Toner M, Yarmush ML et al. Interferon gamma modulates trauma-induced muscle wasting and immune dysfunction. Ann Surg. 2002;236:649-657.

27. Yin K, Gribbin E, Wang H. Interferon-gamma inhibition attenuates lethality after cecal ligation and puncture in rats: implication of high mobility group box-1. Shock. 2005;24:396-401. 
28. Luyer MD, Buurman WA, Hadfoune M, et al. Exposure to bacterial DNA before hemorrhagic shock strongly aggravates systemic inflammation and gut barrier loss via an IFN-gamma-dependent route. Ann Surg. 2007;245:795-802.

29. Li Q, Zhang $Q$, Wang $M$, et al. Interferon-gamma and tumor necrosis factor-alpha disrupt epithelial barrier function by altering lipid composition in membrane microdomains of tight junction. Clin Immunol. 2008;126:67-80.

30. Ertel W, Morrison $\mathrm{MH}$, Ayala A, et al. Interferon-gamma attenuates hemorrhage-induced suppression of macrophage and splenocyte functions and decreases susceptibility to sepsis. Surgery. 1992;111: 177-187.

31. Meldrum DR, Ayala A, Perrin MM, et al. Diltiazem restores IL-2, IL-3, IL-6, and IFN-gamma synthesis and decreases host susceptibility to sepsis following hemorrhage. J Surg Res. 1991;51:158-164.

32. Wang $\mathrm{H}$, Liao $\mathrm{H}$, Ochani $\mathrm{M}$, et al. Cholinergic agonists inhibit HMGB1 release and improve survival in experimental sepsis. Nat Med. 2004;10:1216-1221.

33. Clark JA, Coopersmith CM. Intestinal crosstalk: a new paradigm for understanding the gut as the "motor" of critical illness. Shock. 2007;28:384-393.

34. Deitch EA, Xu D, Kaise VL. Role of the gut in the development of injury- and shock induced SIRS and MODS: the gut-lymph hypothesis, a review. Front Biosci. 2006;11:520-528.

35. Fink MP, Delude RL. Epithelial barrier dysfunction: a unifying theme to explain the pathogenesis of multiple organ dysfunction at the cellular level. Crit Care Clin. 2005;21:177-196.

36. Alverdy JC, Laughlin RS, Wu L. Influence of the critically ill state on host-pathogen interactions within the intestine: gut-derived sepsis redefined. Crit Care Med. 2003;31:598-607.

37. Hassoun HT, Kone BC, Mercer DW, et al. Post-injury multiple organ failure: the role of the gut. Shock. 2001;15:1-10.

38. Souza DG, Vieira AT, Soares AC, et al. The essential role of the intestinal microbiota in facilitating acute inflammatory responses. J Immunol. 2004;173:4137-4146.

39. Coopersmith CM, Stromberg PE, Dunne WM, et al. Inhibition of intestinal epithelial apoptosis and survival in a murine model of pneumonia-induced sepsis. JAMA. 2002;287:1716-1721.

40. Barber AE, Shires GT. Cell damage after shock. New Horiz. 1996;4:161-167.

41. Derikx JP, Poeze M, van Bijnen AA, et al. Evidence for Intestinal and Liver Epithelial Cell Injury in the Early Phase of Sepsis. Shock. 2007;28:544-548.

42. Pelsers MM, Hermens WT, Glatz JF. Fatty acid-binding proteins as plasma markers of tissue injury. Clin Chim Acta. 2005;352:15-35.

43. Lieberman JM, Sacchettini J, Marks C, et al. Human intestinal fatty acid binding protein: report of an assay with studies in normal volunteers and intestinal ischemia. Surgery. 1997;121:335-342.

44. Pavlov VA, Ochani M, Yang LH, et al. Selective alpha7-nicotinic acetylcholine receptor agonist GTS-21 improves survival in murine endotoxemia and severe sepsis. Crit Care Med. 2007;35:1139-1144.

45. Huston JM, Puerta MG, Ochani M, et al. Transcutaneous vagus nerve stimulation reduces serum high mobility group box 1 levels and improves survival in murine sepsis. Crit Care Med. 2007;35:2762-2768. 


\title{
CHAPTER 8
}

\section{Prevention of hemolysis-induced organ damage by}

\section{nutritional activation of the vagal}

\author{
anti-inflammatory reflex
}

Jacco J. de Haan, Iris Vermeulen Windsant, Tim Lubbers, Sebiastiaan J. Hanssen, M'hamed Hadfoune, Frits W. Prinzen, Jan-Willem M. Greve, Wim A. Buurman

Submitted 


\section{Abstract}

Introduction: Acute hemolysis is associated with organ damage, inflammation and impaired vascular function in diverse critical care settings. Stimulation of the cholecystokinin-1 receptor (CCK-1R)-dependent vagal anti-inflammatory reflex with lipid-rich enteral nutrition was demonstrated to prevent tissue damage and attenuate inflammation. This study investigates the effects of nutritional activation of the vagal anti-inflammatory reflex on organ integrity, systemic inflammation and microcirculation during acute hemolysis.

Methods: Intravascular hemolysis was simulated by continuous infusion of pre-lysed erythrocytes in male Sprague-Dawley rats. Prior to the experiments, animals were fasted or received lipid-rich enteral nutrition. A CCK-1R antagonist and a nicotinic acetylcholine receptor ( $\mathrm{AAChR}$ ) antagonist were applied to investigate involvement of the vagal reflex. The role of CCK-1R was further studied by administration of pegylated (PEG)-CCK9.

Results: Induction of clinically relevant cell-free hemoglobin concentrations in the circulation resulted in organ damage and systemic inflammation. Nutritional intervention reduced renal tubular cell damage, hepatocyte damage, ileal leakage of horseradish peroxidase and bacterial translocation compared to food-deprivation (all $P<0.05)$. Also circulating IL-6 levels were decreased by enteral nutrition $(P<0.05)$. Blockage of the CCK-1R or the $n A C h R$ reversed the protective nutritional effects compared with vehicle $(P<0.05)$, whereas PEG-CCK9 mimicked the impact of enteral feeding in fasted animals $(P<0.05)$. Moreover, nutritional intervention increased renal, hepatic and intestinal blood flow compared with fasted controls (all $P<0.05$ ), as evaluated using fluorescent microspheres.

Conclusions: Nutritional activation of the vagal anti-inflammatory reflex preserves tissue integrity and attenuates systemic inflammation in a rodent model of acute hemolysis. In addition, lipid-rich nutrition improves renal, hepatic and intestinal microcirculation during infusion of pre-lysed erythrocytes. These findings implicate stimulation of the autonomic nervous system by nutritional means as a potential therapy to prevent complications of acute hemolysis. 


\section{Introduction}

Nutritional activation of the vagal anti-inflammatory reflex is a promising approach to counteract excessive inflammation and reduce organ damage ${ }^{1,2}$. Lipid-rich enteral nutrition activates the autonomic nervous system via cholecystokinin-1 receptors (CCK-1R) on afferent vagal fibers ${ }^{2}$. In turn, parasympathetic outflow suppresses cytokine release via binding of cholinergic neurotransmitters to nicotinic acetylcholine receptors ( $\mathrm{nAChR}$ ) on inflammatory cells ${ }^{1,3,4}$. The efferent limb of this neuro-immune pathway has been designated the cholinergic anti-inflammatory pathway ${ }^{4}$.

Intravascular hemolysis is a common event in several surgical and critical clinical settings, e.g. during extracorporeal circulation with membrane oxygenation, sickle cell crisis and malaria infections, that is associated with endothelial dysfunction and organ injury $^{5-8}$. The development of tissue damage may contribute to the inflammatory state observed in hemolytic disease ${ }^{9}$. In this context we studied whether vagus nerve activation by lipid-rich nutrition reduces the detrimental sequelae of hemolysis ${ }^{10-12}$.

An important factor of the toxic effects of hemolysis is the scavenging of nitric oxide (NO) by cell-free hemoglobin $(\mathrm{fHb})^{9}$. The subsequent deficit of vasodilator NO results in an impaired endothelial function and decreased organ perfusion ${ }^{5,9,13-15}$. Interestingly, the sensibility for NO-independent vasoactive mechanisms increases during hemolysis $^{16}$. As acetylcholine is a potent vasodilator acting largely independent of $\mathrm{NO}^{17-19}$, we hypothesized that release of acetylcholine by nutritional vagus stimulation counteracts the vasoconstrictive effects of NO depletion during hemolysis, thus preventing the occurrence of organ damage and inflammation.

The current study investigates the effects of lipid-rich enteral nutrition on renal, hepatic and intestinal integrity and the development of systemic inflammation during acute hemolysis. Also the nutritional effects on regional blood flow are assessed. Involvement of the vagal anti-inflammatory reflex is determined using CCK-1R agonists and antagonists and nAChR antagonists. Ongoing hemolysis is mimicked in rodents by continuous infusion of non-membranous constituents of pre-lysed erythrocytes (LE). Together, using a physiological and straightforward nutritional approach, this study may contribute to the development of novel means to decrease hemolysis-related complications.

\section{Materials and methods}

\section{Animals}

Male Sprague-Dawley rats, weighing 380-430 g, were purchased from Charles River Laboratories (Maastricht, the Netherlands). Rats were housed in groups of 2-3 per cage under controlled conditions of temperature and humidity. Prior to the experiments, 
the rats had ad libitum access to standard rodent chow and water. Rats were randomly assigned to 11 study groups. In 3 groups, the role of NO scavenging in the development of organ damage during hemolysis was studied. In 8 groups, the effects of nutritional vagus stimulation on tissue integrity, inflammation and microcirculation during hemolysis were investigated. All groups consisted of 6 animals; the group size was based on previously reported effects of enriched nutrition on tissue integrity and inflammation ${ }^{1,2,20}$. The experimental protocols were carried out following institutional guidelines and approved by the Animal Ethics Committee of the Maastricht University Medical Centre+. This study is reported in accordance with the ARRIVE guidelines.

\section{Acute hemolysis model}

The hemolysis model in rodents was based on a canine model described by Minneci et al. ${ }^{5}$. After induction with $4 \%$ isoflurane, anesthesia was maintained at $2 \%$ until sacrifice. Acute hemolysis was simulated by administration of a bolus of lysed erythrocytes (LE; bolus ( $300 \mu \mathrm{M} ; 6.5 \mathrm{ml} / \mathrm{kg}$ ) followed by continuous intravenous LE infusion for 1 hour (300 $\mu \mathrm{M} ; 13 \mathrm{ml} / \mathrm{kg} /$ hour). Sham animals received sterile saline instead of LE. Animals were sacrificed at 2 hours after start of LE administration (Figure 8.1). Tissue and blood samples were coded and stored at $-80^{\circ} \mathrm{C}$.

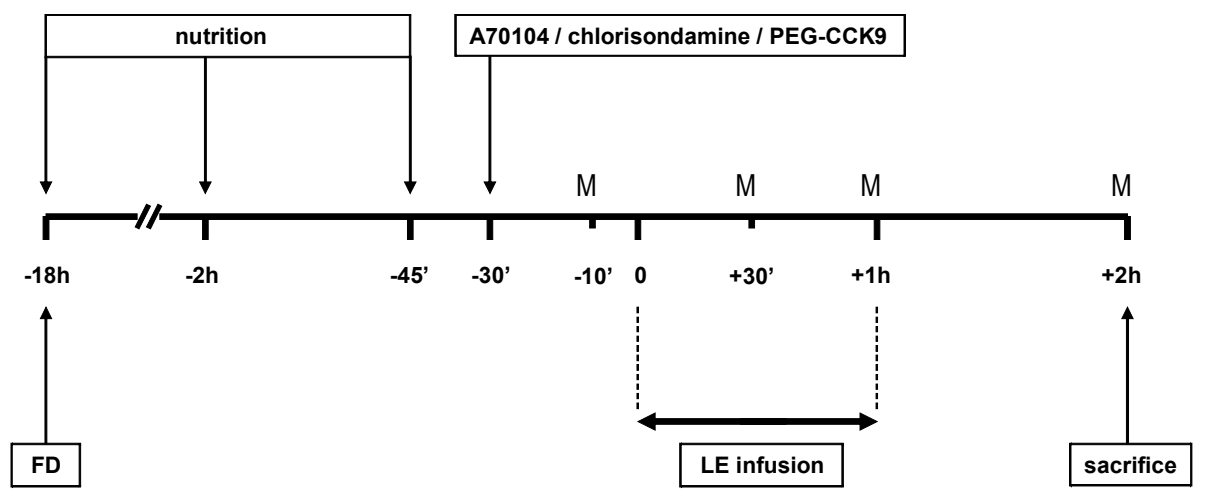

Figure 8.1 Experimental design. Rats were food deprived (FD) 18 hours before infusion of lysed erythrocytes (LE) or received enteral nutrition at -18 hours, -2 hours and $-45 \mathrm{~min}$. At $30 \mathrm{~min}$ before LE administration, A70104, chlorisondamine, PEG-CCK9, or corresponding vehicles were administered. Animals received LE infusion for 1 hour and were sacrificed at +2 hours. Microspheres (M) were administered at four time points. 


\section{Erythrocyte lysis and measurement of cell-free hemoglobin concentrations}

To generate LE for infusion, fresh blood samples were obtained from healthy male Sprague Dawley rats through aortic puncture. After diluting whole blood 1:2 in saline containing $10 \mathrm{IU} / \mathrm{mL}$ heparin, erythrocytes were isolated by centrifugation $(2,750 \mathrm{~g}$, $15 \mathrm{~min}, 4^{\circ} \mathrm{C}$ ). Plasma and buffy coat were carefully discarded and the remaining erythrocytes were washed three times with saline $(1: 3 \mathrm{v} / \mathrm{v})$ in sterile tubes (Greiner Bio-One, Alphen a/d Rijn, Netherlands) to remove plasma components. To induce hemolysis, the erythrocytes underwent three freeze-thaw cycles after the final washing step. Erythrocyte membranes were removed by ultra-centrifugation $(20,000 \mathrm{~g}$, $\left.30 \mathrm{~min}, 4^{\circ} \mathrm{C}\right)$. Next, the supernatant was passed through a micropore filter $(0.22 \mu \mathrm{m}$, Millipore, Billerica, MA). The final concentration was adjusted with sterile saline to 300 $\mu \mathrm{M}$ hemoglobin. A batch of LE was pre-saturated with NO gas (Linde Gas, Dieren, the Netherlands) using a hollow fiber oxygenator (CAPIOX RX, Terumo, Somerset, NJ). Routine spectrophotometry was used to assess the percentages of oxygenated hemoglobin and methemoglobin of total $\mathrm{fHb}$. The $\mathrm{fHb}$ concentrations in plasma and infusate were measured by derivative spectrophotometry ${ }^{21}$.

\section{Interventions}

Before LE infusion, rats were fasted overnight (18 hours) or were treated with liquid nutrition given per oral gavage at three time points (Figure 8.1) as described previously $^{1,2}$. The feeding contained 50.4 energy percent (en\%; i.e. percentage of total calories) lipid, 8.7 en $\%$ protein, and 40.9 en\% carbohydrates. The fat fraction contained $30 \%$ phospholipids. The lipid source was lecithin. Omega 3 and omega 6 fatty acids constituted less than $5 \mathrm{wt} \%(<50 \mathrm{~g} / \mathrm{l})$. Proteins were derived from lean milk powder, containing $80 \%$ casein and $20 \%$ whey protein. The carbohydrate source was a mixture of sucrose and maltodextrins (Glucidex 19DE). The total nutrition provided constituted 10.0 en\% of normal daily rat intake.

To investigate the role of peripheral CCK-1R in the nutritional effects on hemolytic damage, fed rats received A70104, also known as $A 65186(100 \mu \mathrm{g} / \mathrm{kg}$, kindly provided by Abbott Laboratories, Abbott Park, IL), a highly-sensitive CCK-1R antagonist that does not cross the blood-brain barrier ${ }^{22}$. A70104 was dissolved in sterile saline with $1 \%$ dimethyl sulfoxide. Involvement of peripherally localized $\mathrm{nAChR}$ was studied by administration of nAChR antagonist chlorisondamine diiodide $(125 \mu \mathrm{g} / \mathrm{kg}$; Sigma, St. Louis, MO), dissolved in saline. Due to its vasoactive effects, chlorisondamine could not be used to assess nAChR involvement in the nutritional effects on microcirculation during hemolysis ${ }^{23}$. The role of CCK-1R activation was further assessed in fasted animals by administration of $6 \mu \mathrm{g} / \mathrm{kg}$ pegylated cholecystokinin-9 (PEG-CCK9; kindly 
provided by Dr Verbaeys, Interdisciplinary Research Center, Campus Kortrijk, Katholieke Universiteit Leuven, Kortrijk, Belgium) dissolved in sterile saline. PEG-CCK9 specifically binds to peripheral CCK-1R and does not cross the blood brain barrier ${ }^{24}$. Antagonists and agonists were administered intravenously in a volume of $1 \mathrm{ml} / \mathrm{kg}$ at 30 min before LE infusion (Figure 8.1).

\section{Parameters of organ integrity and systemic inflammation}

To assess renal tubular damage, urinary $N$-acetyl- $\beta$-D-glucosaminidase (NAG) was measured by an enzyme colorimetric assay according to the manufacturer's instructions (HaemoScan, Groningen, the Netherlands). NAG, excreted predominantly by proximal tubular cells, is a relatively large molecule (130 kDa), which precludes glomerular filtration. Furthermore, NAG is not reabsorbed by the tubules. High levels of urinary NAG therefore indicate renal tubular damage ${ }^{25}$. Results were normalized to urinary creatinine values and expressed as Units/mmol creatinine.

Liver fatty acid binding protein (L-FABP) concentrations in plasma were assessed as a marker of liver damage. L-FABP is an abundant cytosolic protein in hepatocytes. Lower concentrations are expressed in the stomach, intestine, kidney and lung ${ }^{26,27}$. L-FABP was determined using a standard ELISA for rat L-FABP (Hycult Biotech, Uden, the Netherlands).

Intestinal permeability for macromolecules was assessed by measuring translocation of the $44 \mathrm{kD}$ enzyme horseradish peroxidase (HRP) through the ileal wall ${ }^{20}$. Segments of distal ileum $(8 \mathrm{~cm}$ ) were washed, everted, filled with $1 \mathrm{ml}$ of Tris buffer $(125 \mathrm{mmol} / \mathrm{l}$ $\mathrm{NaCl}, 10 \mathrm{mmol} / \mathrm{l}$ fructose, $30 \mathrm{mmol} / \mathrm{l}$ Tris; $\mathrm{pH} \mathrm{7.5)}$ and ligated at both ends. The filled segments were incubated in Tris buffer containing $40 \mu \mathrm{g} / \mathrm{ml}$ of HRP (Sigma). After incubation at room temperature for $45 \mathrm{~min}$, ileal content was carefully collected. HRP activity was measured spectrophotometrically at $405 \mathrm{~nm}$ after addition of tetramethylbenzidine as a substrate.

Bacterial translocation to mesenteric lymph nodes, liver and spleen, expressed as colony forming units (CFU) per gram tissue, was determined as described previously ${ }^{28}$. Systemic inflammation was assessed by detection of IL- 6 concentrations in arterial blood using a standard ELISA for rat IL-6 (R\&D Systems, Minneapolis, MN). The detection limit of IL-6 was $10 \mathrm{pg} / \mathrm{ml}$.

\section{Microcirculatory blood flow}

Assessment of microcirculation was performed using fluorescent microspheres (diameter $15 \mu \mathrm{m}$ ) with different colors (lemon, persimmon, orange and yellow) as described before ${ }^{29,30}$. The microspheres $\left(2.5 \times 10^{5}\right.$, Dye-Trak, Triton Technology, San Diego, CA) were infused $10 \mathrm{~min}$ before LE administration and $30 \mathrm{~min}$ and 1 and 2 hours after start of LE infusion (Figure 8.1) via a PE-10 cannula inserted in the right femoral 
artery that was transferred into the aortic arch. A reference blood sample from the left femoral artery was taken at every time point. After sacrifice, between 1.5 and 2 gram of kidney, liver and small intestine was harvested for microsphere retrieval. Following organ lysis in potassium hydroxide, the fluorescent dye was dissolved in diethylene glycol monoethyl ether acetate (Sigma). Fluorescence was measured using an automated fluorospectrometer (PerkinElmer LS 50B, Perkin Elmer, Waltham, MA). The blood flow to each individual organ was calculated as $\mathrm{mL} / \mathrm{min} / \mathrm{g}$ body weight. The pre$\mathrm{fHb}$ flow was set at $100 \%$ and flow changes at organ level during the experiments were determined for each individual subject.

\section{Statistical analysis}

The Kruskal-Wallis test with Dunn's post-hoc multiple comparison was applied to compare groups receiving LE or NO-saturated LE and sham controls (Figure 8.2). A twotailed Mann-Whitney $U$ test was used to compare fed with fasted animals and agonists or antagonists with corresponding vehicles (Figure 8.3 and 8.4). Microcirculatory differences were tested using a two-way ANOVA with Bonferroni post-test (Figure 8.5). All animals were included in the analyses. Differences were considered statistically significant at $P \leq 0.05$. Data are displayed as mean \pm SEM. Prism 5.02 for Windows (GraphPad Software Inc., San Diego, CA) was used for computations.

\section{Results}

\section{Administration of lysed erythrocytes results in loss of organ integrity via impairment of nitric oxide bioavailability}

Continuous administration of LE resulted in plasma fHb levels of $40 \pm 3 \mu \mathrm{M}$ at $30 \mathrm{~min}$ that remained stable until termination of LE infusion at 1 hour ( $43 \pm 4 \mu \mathrm{M})$. At 2 hours, $\mathrm{fHb}$ concentrations dropped to $16 \pm 1 \mu \mathrm{M}$, indicating a half time of $\mathrm{fHb}$ of approximately $40 \mathrm{~min}$. These $\mathrm{fHb}$ levels are comparable to the concentrations in patients undergoing a cardiopulmonary bypass or patients suffering from a sickle cell crisis or paroxysmal nocturnal hemoglobinuria ${ }^{6,31,32}$. Furthermore, these $\mathrm{fHb}$ concentrations surpass the thresholds of $6 \mu \mathrm{M} \mathrm{fHb}$, reported to produce vasoconstriction $^{33}$, and $10 \mu \mathrm{M} \mathrm{fHb}$, associated with renal damage ${ }^{6}$. Accordingly, infusion of LE resulted in renal tubular cell damage at 2 hours, as indicated by increased urinary NAG levels compared to sham $(P<0.01$; Figure 8.2A). Next, enhanced plasma levels of L-FABP following LE infusion indicated hepatocyte damage $(P<0.05$; Figure 8.2B). Loss of intestinal wall integrity after LE administration was demonstrated 
by increased ileal leakage of HRP ( $P<0.05$; Figure $8.2 \mathrm{C})$ and augmented translocation of luminal bacteria to mesenteric lymph nodes, liver and spleen $(P<0.01$; Figure 8.2D).

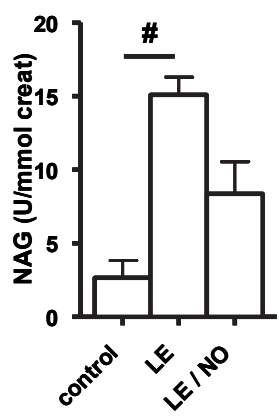

A

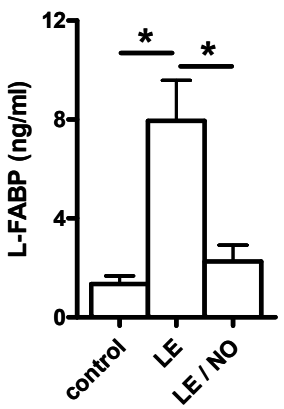

B

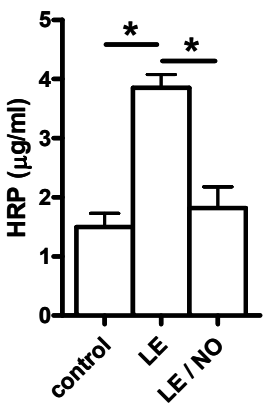

C

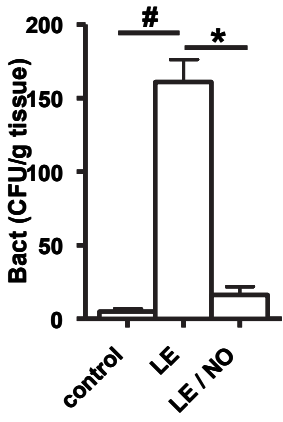

D

Figure 8.2 Infusion of lysed erythrocytes induces loss of organ integrity via nitric oxide scavenging. Following LE administration, renal (A) and hepatic (B) cell damage and increased translocation of HRP (C) and bacteria (D) through the intestinal wall were observed. Infusion of LE that was pre-saturated with NO (LE / NO) prevented hepatic injury (B) and improved the intestinal barrier function (C-D) compared with animals that were infused with unsaturated LE. ${ }^{*} P<0.05$, $\# P<0.01$.

Subsequently, the role of $\mathrm{NO}$ scavenging by $\mathrm{fHb}$ in the development of organ damage in our hemolysis model was investigated. In concordance with previous work of Minneci and colleagues, we assumed that exposure of $\mathrm{fHb}$ to NO before infusion, resulting in the irreversible formation of methemoglobin, would subsequently reduce organ damage by limiting the ability of $\mathrm{fHb}$ to scavenge $\mathrm{NO}$ in vivo ${ }^{5}$. Spectrophotometrical analysis demonstrated that $\mathrm{fHb}$ in freshly generated $\mathrm{LE}$ was oxygenated for $75 \%$. Pre-saturation with $\mathrm{NO}$ gas reduced the $\mathrm{fHb}$ oxygenation level to $51 \%$ and increased methemoglobin levels from $0.3 \%$ to $49 \%$. In line with expectations, administration of LE pre-saturated with NO resulted in a significant improvement of hepatic and intestinal integrity compared with administration of LE that was not saturated with NO (L-FABP: $P<0.05$, HRP: $P<0.05$, bacterial translocation: $P<0.05$; Figure 8.2B-C-D). Furthermore, a trend towards lower urinary NAG levels was observed in animals receiving NO-saturated LE compared with non-saturated LE $(P=0.08)$. No significant differences in organ integrity were observed between animals receiving NOpresaturated LE and sham controls. Together, these data confirm in our model the important role for NO scavenging in the development of organ damage during hemolysis. 


\section{Protective effects on organ integrity during acute hemolysis of nutrition are mediated by peripheral cholecystokinin-1 receptors and nicotinic acetylcholine receptors}

Enteral lipid-rich nutrition significantly decreased renal cell damage following LE infusion compared with fasted controls $(P<0.05$; Figure 8.3A). Also hepatocyte damage was strongly reduced by nutritional intervention $(P<0.05$; Figure $8.3 \mathrm{~B})$. Previous studies identified the intestine as an early target organ of nutritional vagus activation ${ }^{34}$. Here, pre-treatment with lipid-rich nutrition preserved the intestinal integrity, as shown by a reduced gut permeability to HRP $(P<0.01$; Figure $8.3 \mathrm{C})$ and bacterial translocation $(P<0.05$; Figure 8.3D) following LE infusion.

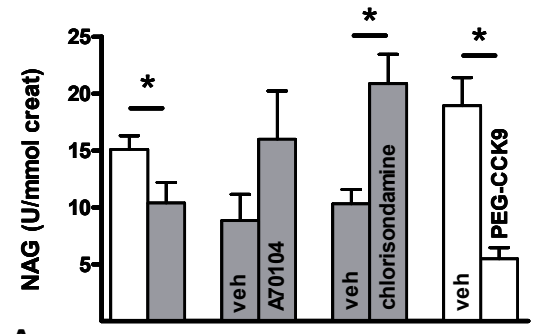

A

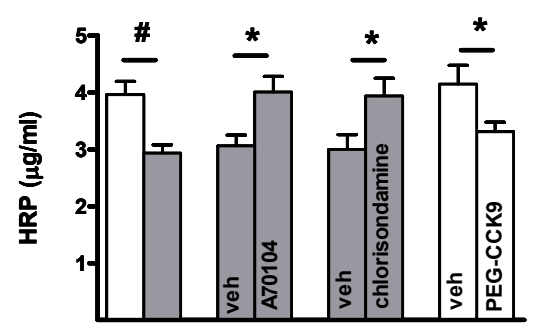

C

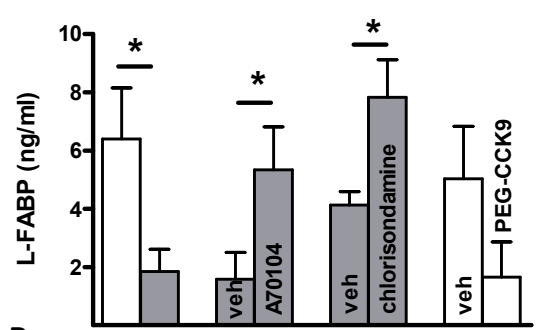

B

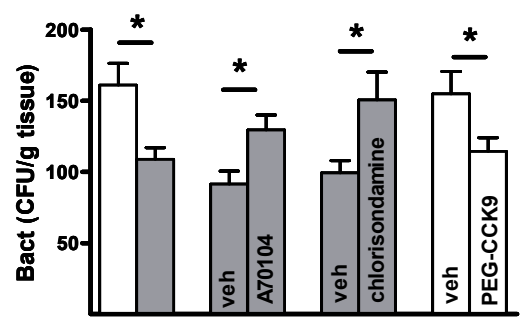

D LRN

Figure 8.3 Enteral lipid-rich nutrition improves organ integrity during hemolysis via activation of peripheral cholecystokinin-1 receptors and nicotinic acetylcholine receptors. Renal $(\mathbf{A})$ and hepatic (B) cell injury and gut wall permeability to HRP (C) and bacterial translocation (D) were significantly reduced by lipid-rich nutrition compared with fasted controls. The tissuepreserving effects of lipid-rich nutrition were abrogated by A70104, an antagonist of peripheral CCK-1R, and chlorisondamine, a nAChR antagonist. The nutritional impact on hemolysisinduced organ damage was mimicked by CCK-1R agonist PEG-CCK9. ${ }^{*} P<0.05, \# P<0.01$.

To investigate the involvement of the CCK-1R-dependent vagal pathway in the nutritional impact on hemolysis-induced loss of organ integrity, A70104, an antagonist 
to peripheral CCK-1R, was applied. Compared to vehicle, blockage of the CCK-1R abrogated the protective effects of lipid-rich nutrition on hepatic and intestinal integrity (all $P<0.05$; Figure 8.3B-C-D). The role of the vagal anti-inflammatory pathway was further assessed by administration of chlorisondamine, an antagonist of peripheral nAChR. Chlorisondamine administered prior to LE infusion blocked the protective effects of enteral nutrition on renal, hepatic and intestinal organ integrity compared to vehicle (all $P<0.05$; Figure 8.3), pointing at a crucial role for $\mathrm{nAChR}$ in the protective effects of nutritional intervention during hemolysis. Next, in fasted animals CCK-1R were stimulated with PEG-CCK9, a highly specific agonist of peripheral CCK-1R. PEG-CCK9 decreased renal cell damage and prevented gut barrier dysfunction in fasted animals compared with vehicle (all $P<0.05$; Figure $8.3 \mathrm{~A}-\mathrm{C}-\mathrm{D}$ ). In addition, a trend towards reduced L-FABP concentrations was observed in fasted animals receiving PEG-CCK9 ( $P=0.08$; Figure 8.3B). In summary, lipid-rich nutrition prevented the loss of organ integrity during acute hemolysis via CCK-1R and nAChR.

\section{Nutritional intervention improves renal, hepatic and intestinal microcirculation during acute hemolysis}

Since impaired perfusion as a consequence of NO scavenging is considered critical in the development of organ injury during hemolysis, we assessed the effects of nutritional intervention on regional blood flow. In fasted animals, hepatic and ileal blood flow during infusion of lysed erythrocytes decreased compared with pre-LE values ( $-48 \%$ and $-35 \%$ respectively at 1 hour), whereas renal blood flow was not reduced (Figure 8.4). These findings are conform the notion that in settings of a disrupted hemodynamic homeostasis, the mesenteric flow is disproportionally restricted in order to maintain systemic blood flow and flow to vital organs including the brain and kidneys ${ }^{35}$. Interestingly, enteral nutrition significantly improved the blood flow of the kidneys $(P<0.01)$, liver $(P<0.05)$ and ileum $(P<0.01)$ at $30 \mathrm{~min}$ and 1 hour. In LE treated animals, administration of CCK-1R antagonist A70104 blocked the nutritional impact on organ blood flow at $30 \mathrm{~min}$ and 1 hour (kidneys: $P<0.001$ and $P<0.01$ respectively and liver and ileum: $P<0.01$ at both time points). At 2 hours, no differences in renal, hepatic and ileal microcirculation were observed between groups (all $P>0.05$ ). 


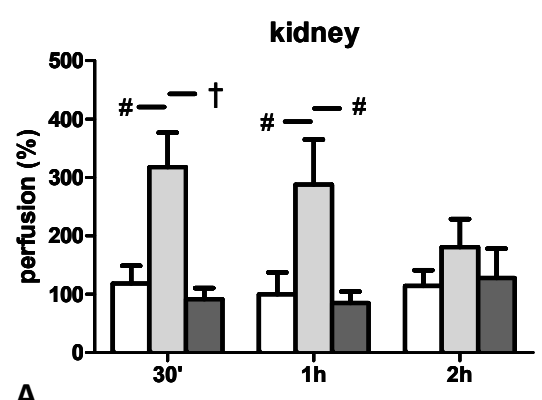

A

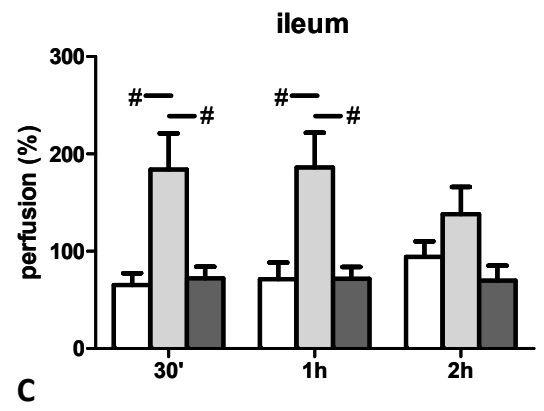

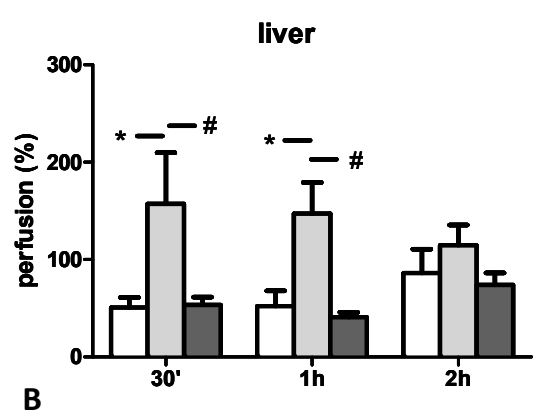

B

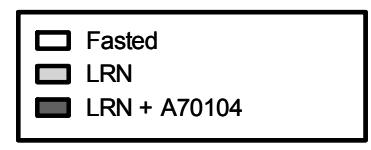

Figure 8.4 Enteral nutrition improves renal and splanchnic blood flow during hemolysis. Lipid-rich nutrition (LRN) improved microcirculation in kidney $(A)$, liver $(B)$ and ileum $(C)$ at 30 min and 1 hour compared with fasting. CCK-1R antagonist A70104 abrogated the nutritional effects on renal, hepatic and intestinal blood flow. ${ }^{*} P<0.05, \# P<0.01,+P<0.001$.

\section{Lipid-rich nutrition decreases circulatory interleukin-6 levels during acute hemolysis}

Infusion of LE resulted in a marked increase of IL- 6 plasma levels at 2 hours. Enteral nutrition significantly reduced IL-6 concentrations (Figure $8.5 ; P<0.05$ ). Next, the importance of the CCK-1R mediated vagal reflex in the nutritional inhibition of hemolysis-induced inflammation was investigated. Compared to vehicle, blockage of the CCK-1R significantly reduced the anti-inflammatory effects of enriched nutrition $(P<0.05)$. Also the $\mathrm{nAChR}$ was shown to be involved in the nutritional modulation of the inflammatory response during hemolysis, as $\mathrm{nAChR}$ antagonist chlorisondamine inhibited the IL-6 reduction by lipid-rich nutrition $(P<0.01)$. The role of CCK-1R activation was further studied by administration of PEG-CCK9 to fasted animals. Compared to controls that received vehicle, PEG-CCK9 significantly reduced IL-6 levels $(P<0.05)$. Together, these data implicate that the CCK-1R dependent vagal pathway mediates the nutritional anti-inflammatory effects during acute hemolysis. 


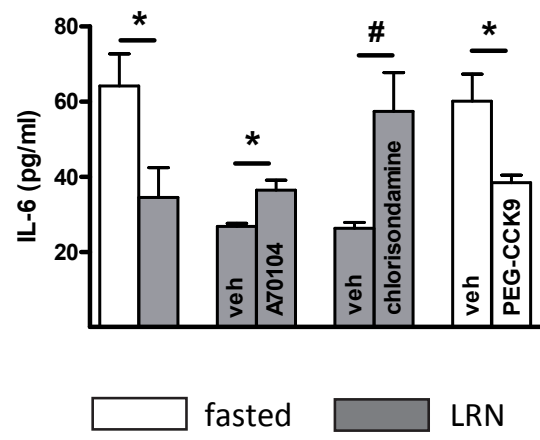

Figure 8.5 Systemic inflammation following infusion of lysed erythrocytes is reduced by nutritional intervention. Circulatory IL-6 concentrations are decreased by enteral lipid-rich nutrition. CCK-1R antagonist A70104 and nAChR antagonist chlorisondamine abrogated the nutritional effects, whereas CCK-1R agonist PEG-CCK9 reduced IL-6 levels in fasted animals. ${ }^{*} P<0.05$, $\# P<0.01$.

\section{Discussion}

A range of interventions aimed at reducing hemolysis-related organ damage is currently under investigation ${ }^{9,36}$. The present study indicates that stimulation of the vagal anti-inflammatory reflex with limited quantities of enteral nutrition, being a physiological approach, is of additional value to prevent the complications of hemolysis.

Current guidelines recommend an early start of enteral feeding in critical care and surgical patients ${ }^{37-39}$. In several patient groups, the supplemental use of omega-3 fatty acids is advocated ${ }^{39,40}$. The immune-modulating effects of omega- 3 polyunsaturated fatty acids are attributed to a direct inhibition of NFKB-mediated pro-inflammatory signaling and through modification of the pattern of lipid mediators ${ }^{41,42}$. A different mechanism via which enteral nutrition regulates the immune response was previously described by our group. Short-term intervention with limited amounts of lipid-rich nutrition, containing low amounts of omega-3 fatty acids, was demonstrated to reduce inflammation and preserve organ integrity by activation of the autonomic nervous system via peripheral CCK-1 $\mathrm{R}^{1,2,28}$.

Pretreatment with a lipid-rich nutritional composition was demonstrated to reduce renal and hepatic cell damage and preserve gut barrier function during acute hemolysis. In addition, nutritional intervention significantly reduced hemolysis-induced systemic inflammation, assessed as circulatory IL-6 concentrations. As also posttreatment with lipid-rich nutrition was previously shown to attenuate inflammation and preserve organ integrity, further studies are needed to investigate nutritional 
intervention at the time hemolysis is already manifest ${ }^{28}$. Here, administration of a CCK-1R antagonist significantly reduced the effects of lipid-rich nutrition on renal, hepatic and intestinal integrity and moreover abrogated the anti-inflammatory effects, thus providing evidence for a crucial role of peripheral CCK-1R. In earlier reports, CCK$1 R$-mediated effects on organ integrity and inflammation in models of hemorrhagic shock, endotoxemia and postoperative ileus were shown to run via a vagovagal pathway ${ }^{1,10,12}$. In line, the present study shows that also in settings of acute hemolysis, administration of a nAChR antagonist abrogates the effects of nutrition on organ integrity and systemic inflammation. In addition to stimulation of the autonomic nervous system with enteral nutrition, electrical vagus nerve stimulation and pharmacological activation of $\mathrm{nAChR}$ have been successfully applied in various experimental settings ${ }^{11}$.

Blockage of the peripheral CCK-1R strongly reduced the nutritional effects on hemolysis-induced organ damage, however only produced in a modest though significant effect on the nutritional lowering of IL-6 levels. These data are seemingly in discrepancy with a previous report in which the cytokine levels in lipid-rich fed animals with CCK-1R blockage were similar to fasted animals ${ }^{2}$. Therefore, the role of peripheral CCK-1R was further investigated using a pegylated form of CCK9. In a model of hemorrhagic shock, PEG-CCK9 was previously reported to attenuate TNF $\alpha$ and IL-6 levels and improve intestinal integrity ${ }^{2}$. Here, PEG-CCK9 reduced organ damage and inflammation in fasted animals following hemolysis, thus mimicking the impact of enriched nutrition and supporting the activation of CCK-1R as a potential therapeutic target to prevent the complications of hemolysis.

The ability of oxygenated $\mathrm{fHb}$ to irreversibly react with $\mathrm{NO}$, leading to the formation of methemoglobin and nitrate, is considered to be of major importance in the detrimental effects of hemolysis ${ }^{9}$. NO is a pivotal signalling molecule in the regulation of smooth muscle relaxation, endothelial adhesion molecule expression and platelet activation $^{13}$. Massive NO scavenging results in an impaired vascular function, decreased organ perfusion and eventually to tissue damage $\mathrm{e}^{5,9,14,15}$. In addition, in hemolytic patients a decreased availability of L-arginine is observed, the principal NO donor $^{9,43}$. In the current model, the importance of NO scavenging in the detrimental consequences of acute hemolysis is confirmed ${ }^{5,9}$. Pre-saturation of the infusate with NO gas, resulting in decreased oxygenated hemoglobin levels and enhanced methemoglobin levels, considerably reduced organ damage compared with animals that received non-saturated LE. In line, it was shown that saturation of circulatory $\mathrm{fHb}$ with inhaled NO improves tissue perfusion in a canine hemolysis model ${ }^{5}$. It should be noted however that next to hemoglobin, also other erythrocyte constituents may contribute to the loss of organ integrity during hemolysis. For instance cell-free arginase-1 has been postulated to hamper NO formation by converting NO-donor 
arginine into ornithine ${ }^{43,44}$. Since the level of organ damage in animals receiving LE that were presaturated with NO was not significantly increased compared with healthy controls, in this model cell-free hemoglobin appears to be the main cause of the perturbations observed.

During hemolytic disease, the sensibility for NO-independent vasodilators such as acetylcholine is increased ${ }^{16-19}$. Therefore, we investigated whether the microcirculation is improved by nutritional stimulation of the vagal anti-inflammatory reflex, which results in release of acetylcholine. Conform the notion that the mesenteric flow is disproportionally restricted in settings of a disrupted hemodynamic homeostasis, here we showed that during hemolysis the intestinal and hepatic blood flow were reduced, whereas the renal flow was relatively preserved ${ }^{35}$. Pretreatment with lipid-rich nutrition improved renal, hepatic and intestinal microcirculation during hemolysis, which is in line with a report of Gatt and coworkers that showed an increase of superior mesenteric artery flow following enteral nutrition in ICU patients ${ }^{45}$. The effects of lipid-rich nutrition on renal, hepatic and intestinal blood flow were significantly reduced by a CCK-1R antagonist. The vasoactive effects of chlorisondamine prevent its use in the assessment of $\mathrm{nAChR}$ involvement in the effects of lipid-rich nutrition on microcirculation ${ }^{23}$. Therefore, it remains to be clarified whether in settings of acute hemolysis, CCK-mediated modulation of organ microcirculation is mediated by parasympathetic signalling or via non-neural pathways $^{46,47}$.

\section{Conclusions}

Lipid-rich nutrition preserves renal, hepatic and intestinal organ integrity and reduces systemic inflammation in the CCK-1R and nAChR-dependent neuro-immune axis in a rodent model of acute hemolysis. In addition, nutritional intervention significantly improves the microcirculation of these organs during hemolysis. This study implicates activation of the vagal anti-inflammatory reflex with enriched enteral nutrition as a potential therapy in patients prone to develop hemolysis. 


\section{References}

1. Luyer MD, Greve JW, Hadfoune M, et al. Nutritional stimulation of cholecystokinin receptors inhibits inflammation via the vagus nerve. J Exp Med 2005; 202:1023-1029.

2. Lubbers T, de Haan JJ, Luyer MD, et al. Cholecystokinin/Cholecystokinin-1 receptor-mediated peripheral activation of the afferent vagus by enteral nutrients attenuates inflammation in rats. Ann Surg 2010; 252:376-382.

3. Borovikova LV, Ivanova $\mathrm{S}$, Zhang $\mathrm{M}$, et al. Vagus nerve stimulation attenuates the systemic inflammatory response to endotoxin. Nature 2000; 405:458-462.

4. Wang $\mathrm{H}, \mathrm{Yu}$ M, Ochani $\mathrm{M}$, et al. Nicotinic acetylcholine receptor alpha7 subunit is an essential regulator of inflammation. Nature 2003; 421:384-388.

5. Minneci PC, Deans KJ, Zhi H, et al. Hemolysis-associated endothelial dysfunction mediated by accelerated NO inactivation by decompartmentalized oxyhemoglobin. J Clin Invest 2005; 115: 3409-3417.

6. Vermeulen Windsant IC, Snoeijs MG, Hanssen SJ, et al. Hemolysis is associated with acute kidney injury during major aortic surgery. Kidney Int 2010; 77:913-920.

7. Meyer $C$, Heiss $C$, Drexhage $C$, et al. Hemodialysis-induced release of hemoglobin limits nitric oxide bioavailability and impairs vascular function. J Am Coll Cardiol 2010; 55:454-459.

8. Hanssen SJ, Lubbers T, Hodin CM, et al. Hemolysis results in impaired intestinal microcirculation and intestinal epithelial cell injury. World J Gastroenterol 2011; 17:213-218.

9. Rother RP, Bell L, Hillmen P, et al. The clinical sequelae of intravascular hemolysis and extracellular plasma hemoglobin: a novel mechanism of human disease. JAMA 2005; 293:1653-1662.

10. Lubbers T, Luyer MD, de Haan JJ, et al. Lipid-rich enteral nutrition reduces postoperative ileus in rats via activation of cholecystokinin-receptors. Ann Surg 2009; 249:481-487.

11. Tracey KJ. Reflex control of immunity. Nat Rev Immunol 2009; 9:418-428.

12. Lubbers $T$, De Haan JJ, Hadfoune $M$, et al. Lipid-enriched enteral nutrition controls the inflammatory response in murine Gram-negative sepsis. Crit Care Med 2010; 38:1996-2002.

13. McMahon TJ, Moon RE, Luschinger BP, et al. Nitric oxide in the human respiratory cycle. Nat Med 2002, 8:711-717.

14. Hsu LL, Champion HC, Campbell-Lee SA, et al. Hemolysis in sickle cell mice causes pulmonary hypertension due to global impairment in nitric oxide bioavailability. Blood 2007; 109:3088-3098.

15. Yeo TW, Lampah DA, Tjitra E, et al. Relationship of cell-free hemoglobin to impaired endothelial nitric oxide bioavailability and perfusion in severe falciparum malaria. J Infect Dis 2009; 200:1522-1529.

16. Gladwin MT, Schechter AN, Ognibene FP, et al. Divergent nitric oxide bioavailability in men and women with sickle cell disease. Circulation 2003; 107:271-278.

17. Baile EM, McKay K, Wang L, et al. NO does not mediate inhibitory neural responses in sheep airway and bronchial vascular smooth muscle. J Appl Physiol 1998; 84:809-814.

18. Imaeda $\mathrm{K}$, Yamamoto $\mathrm{Y}$, Fukuta $\mathrm{H}$, et al. Hyperpolarization-induced dilatation of submucosal arterioles in the guinea-pig ileum. Br J Pharmacol 2000; 131:1121-1128.

19. Eguchi S, Miyashita S, Kitamura $Y$, et al. Alpha3beta4-nicotinic receptors mediate adrenergic nerveand peptidergic (CGRP) nerve-dependent vasodilation induced by nicotine in rat mesenteric arteries. Br J Pharmacol 2007; 151:1216-1223.

20. de Haan JJ, Thuijls G, Lubbers T, et al. Protection against early intestinal compromise by lipid-rich enteral nutrition through cholecystokinin receptors. Crit Care Med 2010; 38:1592-1597.

21. Cruz-Landeira A, Bal MJ, Quintela O, et al. Determination of methemoglobin and total hemoglobin in toxicological studies by derivative spectrophotometry. J Anal Toxicol 2002; 26:67-72.

22. Ebenezer IS, Parrott RF. A70104 and food intake in pigs: implication for the CCK 'satiety' hypothesis. Neuroreport 1993; 4:495-498.

23. Chadman KK, Woods JH. Cardiovascular effects of nicotine, chlorisondamine, and mecamylamine in the pigeon. J Pharmacol Exp Ther 2004; 308:73-78.

24. Verbaeys I, Leon-Tamariz F, Buyse J, et al. PEGylated cholecystokinin prolongs satiation in rats: dose dependency and receptor involvement. Br J Pharmacol 2007; 152:396-403.

25. Dittrich S, Kurschat K, Dahnert I, et al. Renal function after cardiopulmonary bypass surgery in cyanotic congenital heart disease. Int J Cardiol 2000; 73:173-179. 
26. Pelsers MM, Hermens WT, Glatz JF. Fatty acid-binding proteins as plasma markers of tissue injury. Clin Chim Acta 2005; 352:15-35.

27. Furuhashi M, Hotamisligil GS. Fatty acid-binding proteins: role in metabolic diseases and potential as drug targets. Nat Rev Drug Discov 2008; 7:489-503.

28. de Haan JJ, Lubbers $T$, Hadfoune $M$, et al. Postshock intervention with high-lipid enteral nutrition reduces inflammation and tissue damage. Ann Surg 2008; 248:842-848.

29. Raab S, Thein E, Harris AG, et al. A new sample-processing unit for the fluorescent microsphere method. Am J Physiol 1999; 276:H1801-1806.

30. Prinzen FW, Bassingthwaighte JB. Blood flow distributions by microsphere deposition methods. Cardiovasc Res 2000; 45:13-21.

31. Davis CL, Kausz AT, Zager RA, et al. Acute renal failure after cardiopulmonary bypass in related to decreased serum ferritin levels. J Am Soc Nephrol 1999; 10:2396-2402.

32. Ergul S, Brunson CY, Hutchinson J, et al. Vasoactive factors in sickle cell disease: in vitro evidence for endothelin-1-mediated vasoconstriction. Am J Hematol 2004; 76:245-251.

33. Reiter CD, Wang $\mathrm{X}$, Tanus-Santos JE, et al. Cell-free hemoglobin limits nitric oxide bioavailability in sickle-cell disease. Nat Med 2002; 8:1383-1389.

34. de Haan JJ, Thuijls G, Lubbers T, et al. Protection against early intestinal compromise by lipid-rich enteral nutrition through cholecystokinin receptors. Crit Care Med 2010; 38:1592-1597.

35. Ceppa EP, Fuh KC, Bulkley GB. Mesenteric hemodynamic response to circulatory shock. Curr Opin Crit Care 2003; 9:127-132.

36. Vermeulen Windsant IC, Hanssen SJ, Buurman WA, et al. Cardiovascular surgery and organ damage: Time to reconsider the role of hemolysis. J Thorac Cardiovasc Surg 2011; 142:1-11.

37. Guidelines for the use of parenteral and enteral nutrition in adult and pediatric patients. JPEN $J$ Parenter Enteral Nutr 2002; 26:1SA-138SA.

38. Kreymann KG, Berger MM, Deutz NE, et al. ESPEN Guidelines on Enteral Nutrition: Intensive care. Clin Nutr 2006; 25:210-223.

39. Martindale RG, McClave SA, Vanek VW, et al. Guidelines for the provision and assessment of nutrition support therapy in the adult critically ill patient: Society of Critical Care Medicine and American Society for Parenteral and Enteral Nutrition: Executive Summary. Crit Care Med 2009; 37:1757-1761.

40. Marik PE, Zaloga GP. Immunonutrition in critically ill patients: a systematic review and analysis of the literature. Intensive Care Med 2008; 34:1980-1990.

41. Wendel M, Paul R, Heller AR. Lipoproteins in inflammation and sepsis. II. Clinical aspects. Intensive Care Med 2007; 33:25-35.

42. Pontes-Arruda A, Martins LF, de Lima SM, et al. Enteral nutrition with eicosapentaenoic acid, gammalinolenic acid and antioxidants in the early treatment of sepsis: results from a multicenter, prospective, randomized, double-blinded, controlled study: the INTERSEPT study. Crit Care 2011; 15:R144.

43. Morris CR, Kato GJ, Poljakovic M, et al. Dysregulated arginine metabolism, hemolysis-associated pulmonary hypertension, and mortality in sickle cell disease. JAMA 2005; 294:81-90.

44. Hanssen SJ, van de Poll MC, Houben AJ, et al. Hemolysis Compromises Nitric Oxide-Dependent Vasodilatory Responses in Patients Undergoing Major Cardiovascular Surgery. Thorac Cardiovasc Surg 2012;60:255-261.

45. Gatt M, MacFie J, Anderson AD, et al. Changes in superior mesenteric artery blood flow after oral, enteral, and parenteral feeding in humans. Crit Care Med 2009; 37:171-176.

46. Sanchez-Fernandez C, Gonzalez MC, Beart PM, et al. A novel role for cholecystokinin: regulation of mesenteric vascular resistance. Regul Pept 2004; 121:145-153.

47. Yamada $\mathrm{Y}$, Iwasaki $\mathrm{M}$, Usui $\mathrm{H}$, et al. Rapakinin, an anti-hypertensive peptide derived from rapeseed protein, dilates mesenteric artery of spontaneously hypertensive rats via the prostaglandin IP receptor followed by CCK(1) receptor. Peptides 2010; 31:909-914. 


\title{
CHAPTER 9
}

\section{Lipid-enriched enteral nutrition controls}

\section{the inflammatory response in murine}

\author{
gram-negative sepsis
}

Tim Lubbers, Jacco J. de Haan, M'Hamed Hadfoune, Yiren Zhang, Misha D. Luyer, David Grundy, Wim A. Buurman, Jan-Willem M. Greve 


\section{Abstract}

Introduction: Controlling the inflammatory cascade during sepsis remains a major clinical challenge. Recently, it has become evident that the autonomic nervous system reduces inflammation via the vagus nerve. The current study investigates whether nutritional stimulation of the autonomic nervous system effectively attenuates the inflammatory response in murine gram-negative sepsis.

Methods: Male C57bl6 mice were intraperitoneally challenged with lipopolysaccharide (LPS) derived from Escherichia Coli. Prior to LPS administration, mice were fasted or enterally fed either lipid-rich nutrition or low-lipid nutrition. Antagonists to cholecystokinin receptors or nicotinic receptors were administered before LPS administration. Blood and tissue samples were collected at 90 minutes. Mesenteric afferent discharge was determined in ex vivo preparations in response to both nutritional compositions.

Results: Both lipid-rich and low-lipid nutrition dose-dependently reduced LPS-induced TNF- $\alpha$ release (high dose: both $1.4 \pm 0.4 \mathrm{ng} / \mathrm{ml}$ ) compared with fasted mice $(3.7 \pm 0.8$ $\mathrm{ng} / \mathrm{ml} ; P<0.01)$. The anti-inflammatory effect of both nutritional compositions was mediated via cholecystokinin receptors $(P<0.01)$, activation of mesenteric vagal afferents $(P<0.05)$ and peripheral nicotinic receptors $(P<0.05)$. Lipid-rich nutrition attenuated the inflammatory response at lower dosages than low-lipid nutrition, indicating that enrichment of enteral nutrition with lipid augments the antiinflammatory potential. Administration of lipid-rich nutrition prevented endotoxininduced small intestinal epithelium damage and reduced inflammation in liver and spleen compared with fasted (all $P<0.01$ ) and low-lipid nutrition controls (all $P<0.05$ ).

Conclusions: The current study demonstrates that lipid-rich nutrition attenuates intestinal damage and systemic as well as organ-specific inflammation in murine gramnegative sepsis via the nutritional vagal anti-inflammatory pathway. These findings implicate enteral administration of lipid-enriched nutrition as a promising intervention to modulate the inflammatory response during septic conditions. 


\section{Introduction}

An exaggerated inflammatory response following surgery, trauma and burns is a dreaded complication, that can ultimately lead to sepsis and septic shock ${ }^{1,2}$. A key characteristic in sepsis is the fierce systemic inflammatory response to bacterial toxins, which is mediated by excessive release of numerous pro-inflammatory mediators ${ }^{3,4}$. The subsequent hyper-inflammatory response results in multiple organ dysfunction and correlates with adverse outcome ${ }^{5,6}$. Despite recent advances in medical care, sepsis remains life-threatening in the intensive care unit $^{7}$. Although experimental studies demonstrated promising results of anti-inflammatory strategies aimed at inhibition of single pro-inflammatory mediators, clinical implementation has largely failed to improve survival ${ }^{8}$. Enhanced insight in disease pathology and development of novel treatments, which broadly affect the inflammatory response, are critical to reduce sepsis-induced mortality ${ }^{9}$.

Recent experimental evidence has revealed an important neuroimmune pathway ${ }^{9}$. Circulating cytokines are sensed by afferent vagal fibers, resulting in fever and an antiinflammatory response via the hypothalamic-pituitary-adrenal axis ${ }^{10,11}$. Moreover, electric stimulation of the vagus nerve attenuates inflammation via activation of nicotinic acetylcholine receptors on inflammatory cells ${ }^{12,13}$. Activation of this so-called "cholinergic anti-inflammatory pathway" improved outcome in several systemic inflammatory models ${ }^{14,15}$.

Recently, our group demonstrated in rat models of postoperative ileus and non-lethal hemorrhagic shock that nutritional activation of the autonomic nervous system modulates the inflammatory response ${ }^{16-18}$. Enteral administration of lipid-rich nutrition activates the autonomic nervous system via cholecystokinin (CCK)-receptors. Cytokine release is subsequently inhibited via a vagally-mediated stimulation of nicotinic receptors on inflammatory cells ${ }^{19}$. These findings implicate lipid-rich nutrition as a physiologic anti-inflammatory intervention in settings of controlled inflammation. The current study aims to investigate the anti-inflammatory potential of lipid-rich nutrition in murine endotoxemia. Additionally, involvement of the vagal pathway in the immune-modulating effect of enteral nutrition was studied.

\section{Materials and methods}

\section{Animals}

Male C57bl6 mice, aged 8-12 weeks were purchased from Charles River Laboratories (Maastricht, the Netherlands) or bred at the University of Sheffield and housed under controlled conditions of temperature and humidity with ad libitum access to standard rodent chow and water. The experimental protocols were approved by the Animal 
Ethics Committee of the Maastricht University Medical Center and University of Sheffield.

\section{Experimental design and procedure}

Mice received an intraperitoneal dose of lipopolysaccharide (LPS from Escherichia coli 055;B5, Sigma-Aldrich, Zwijndrecht, the Netherlands) $2 \mathrm{mg} / \mathrm{kg}$ in sterile phosphatebuffered saline (PBS; pH 7.4) to induce gram-negative sepsis. Prior to LPS, mice were randomly assigned to a fasted group or one of the nutritional intervention groups. The fasted group was starved 18 hours prior to LPS administration, whereas all nutritional groups were fed per oral gavage at 18 hours, 2 hours and 45 minutes prior to LPS administration. The nutritional groups were fed lipid-rich or control low-lipid nutrition in three different dosage regimens (see Figure 9.1A-B). The liquid lipid-rich diet contained 50.4 energy percent (en\%) fat, of which $30 \%$ were phospholipids, 8.7 en\% protein and 40.9 en\% carbohydrates. The low-lipid nutrition contained 16.0 en\% fat, 8.7 en\% proteins and 75.3 en\% carbohydrates. The carbohydrate and protein composition of both diets were identical. The lipid source was soy lecithin. Omega 3 and omega 6 fatty acids constituted $<5 \%$ in both feedings ${ }^{16}$. The high-lipid nutrition was isocaloric and isonitrogenous to low-lipid nutrition and the amount of fat in the control diet was isocaloric to that present in standard rodent chow. Proteins were derived from lean milk powder, containing $80 \%$ casein and $20 \%$ whey protein. The carbohydrate source was a mixture of sucrose and maltodextrins (Glucidex 19DE). To investigate the role of gastrointestinal distention in activation of the nutritional antiinflammatory pathway, mice were fed a non-caloric 30\% Polyethylene Glycol (PEG) 20.000 solution in PBS (Sigma-Aldrich; see Figure 9.1). All animals, subjected to endotoxin, displayed reduced locomotor activity, pilo-erection, and developed diarrhea.

\section{Receptor antagonists}

Mice received an intraperitoneal injection with antagonists to the CCK-1 receptor, Devazepide and the CCK-2 receptor, L365,260 or chlorisondamine diiodide 30 minutes before induction of endotoxemia. Devazepide and L365, 260 (both $500 \mu \mathrm{g} / \mathrm{kg}$; kind gifts from ML Laboratories PLC, Nottingham, UK) were dissolved in $90 \%$ saline, $5 \%$ Tween 20, 5\% DMSO. Chlorisondamine diiodide (125 $\mu \mathrm{g} / \mathrm{kg}$; Tocris Bioscience, Bristol, UK) was dissolved in saline. 


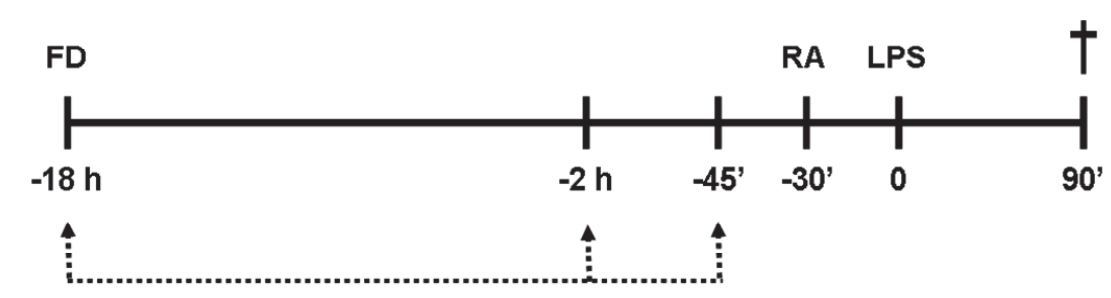

A

Enteral nutrition

\begin{tabular}{|l|c|c|c|c|}
\hline & $\mathbf{- 1 8}$ hours & $\mathbf{- 2}$ hours & $\mathbf{- 4 5}$ minutes & Number of animals \\
\hline Low dose & $0.3 \mathrm{ml}$ & $0.1 \mathrm{ml}$ & $0.1 \mathrm{ml}$ & 8 \\
\hline Intermediate dose & $0.3 \mathrm{ml}$ & $0.2 \mathrm{ml}$ & $0.2 \mathrm{ml}$ & 8 \\
\hline High dose & $0.4 \mathrm{ml}$ & $0.3 \mathrm{ml}$ & $0.3 \mathrm{ml}$ & 8 \\
\hline CCK- or nicotinic RA & $0.4 \mathrm{ml}$ & $0.3 \mathrm{ml}$ & $0.3 \mathrm{ml}$ & 6 \\
\hline PEG-solution & $0.4 \mathrm{ml}$ & $0.3 \mathrm{ml}$ & $0.3 \mathrm{ml}$ & 6 \\
\hline
\end{tabular}

B

Figure 9.1 Experimental protocol and groups. A. Mice were deprived of food (FD) 18 hours prior to LPS administration. In the nutritional intervention groups, mice were fed lipid-rich or low-lipid nutrition per oral gavage at three time points ( -18 hours, -2 hours and -45 minutes) prior to LPS. Antagonists to the CCK or peripheral nicotinic receptor (RA) were administered 30 minutes before induction of endotoxemia. Mice were killed at 90 minutes. B. The feedings were given in three dosage regimes, namely the low-dose ( $5 \%$ of normal daily intake (NDI)), the intermediate dose ( $7 \%$ NDI) and the high dose (10\% NDI). Animals that received RA were fed the high dose. Polyethylene glycol (PEG) solution was administered in the high dose to fasted rats.

\section{Mesenteric afferent discharge}

Mice were killed by cervical dislocation in accordance with the UK Animals Scientific Procedures Act (1986). Intestinal tissue was prepared for nerve recording as previously described $^{20}$. In short, proximal jejunal segments $(2-3 \mathrm{~cm})$ were dissected so that a nonbifurcating mesenteric bundle could be identified. The isolated segments were placed in oxygenated Krebs solution at $34^{\circ} \mathrm{C}$. A single nerve bundle was drawn into a suction electrode for afferent recording. The jejunum was cannulated at each end and intraluminal pressure was recorded via a pressure recorder. The lumen was perfused with saline at $0.2 \mathrm{ml} / \mathrm{min}$ except during distension, when the outlet tap was closed allowing pressure to rise up to $55 \mathrm{mmHg}$ and released by opening the tap.

Following a 60 minute stabilization period, intestinal segments were distended at 15 minutes intervals and mean afferent firing rate (spikes/s) was displayed as peristimulus rate histogram. Once reproducible responses were obtained, the effect of nutrition was tested by switching luminal perfusion to either lipid-rich or low-lipid 
nutrition (both $1 \mathrm{ml}$ ) with free-drainage. The nutrition remaining within the lumen was trapped for 15 minutes following closure of the outlet port with termination of the saline perfusion. One period of distension was achieved by perfusion with saline, which also served to flush out luminal contents when the outlet tap was opened. Saline perfusion and repeat distensions at 15 minutes continued until the response had recovered to baseline.

\section{Cytokine analysis}

TNF- $\alpha$ levels were determined in plasma and tissue harvested at 90 minutes following LPS challenge. Hepatic and splenic tissues were snap frozen in liquid nitrogen, after which they were homogenized in lysisbuffer $(300 \mathrm{mM} \mathrm{NaCl}, 30 \mathrm{mM}$ Tris, $2 \mathrm{mM} \mathrm{MgCl}$, $2 \mathrm{mM} \mathrm{CaCl}_{2}, 1 \%$ Triton X-100, en Pepstatin A, Leupeptin, Aprotinin (all $20 \mathrm{ng} / \mathrm{ml}$ ); $\mathrm{pH} 7.4$ ), centrifuged and supernatants stored at $-20^{\circ} \mathrm{C}$ until analysis. TNF- $\alpha$ was measured using a standard enzyme-linked immunosorbent assay (ELISA) for mice TNF- $\alpha$ (R\&D systems Europe, Oxon, UK).

\section{Determination of intestinal epithelial cell damage}

Localization of ileum-lipid binding protein (I-LBP) was visualized by immunohistochemistry on $4 \mu \mathrm{m}$ cut paraffin sections of ileum. Sections were incubated for 50 minutes with rabbit anti-mouse I-LBP (Hycult Biotech, Uden, the Netherlands). Thereafter, sections were incubated for 30 minutes with biotin labeled swine anti-rabbit IgG conjugate (Dako, Glostrup, Denmark), followed by 30 minutes incubation with the AB-complex and AEC staining. Nuclear staining was performed using haematoxylin. Pictures were taken using the Metasystems Image Pro System (Metasystems, Sandhausen, Germany) mounted on a Leica DM-RE microscope (Leica, Wetzler, Germany). Magnifications of 200x were used to display I-LBP expression. I-LBP was quantified in plasma using a specific ELISA (Hycult Biotech).

\section{Statistical analysis}

Data are expressed as median, range and interquartile range, unless otherwise indicated. A two-tailed Mann-Whitney $U$ test was used for between-group comparisons of plasma TNF- $\alpha$ and I-LBP. Spearman's correlation was used to assess the association between plasma levels of I-LBP and TNF- $\alpha$. Whole nerve afferent discharge was calculated from the number of spikes crossing a pre-set threshold and expressed as spikes/s. Baseline discharge was calculated as the mean firing in the 1 minute period preceding distension. Discharge during distension was expressed as increase above baseline, calculated as the mean firing frequency in $5 \mathrm{sec}$ periods at each level of distending pressure. Depicted data represent the last saline distension prior to nutrient perfusion, distension with nutrient in the lumen and first distension after washout. 
Discharge data were compared statistically using repeated measure ANOVA with Dunnett post-test analysis. Prism 5.02 for Windows (GraphPad Software Inc., San Diego, CA) was used for computations. All experimental groups consisted of 8 animals, unless otherwise indicated.

\section{Results}

\section{Lipid-rich nutrition reduces systemic inflammation more efficiently than low-lipid nutrition}

In order to investigate the anti-inflammatory potential of lipid-rich nutrition in murine gram-negative sepsis, we administered lipid-rich and low-lipid nutrition to endotoxemic mice in three dosage regimens (Figure 9.1). Low dose administration of both feeds prior to LPS challenge did not affect circulating levels of TNF- $\alpha$ compared with fasted mice (Figure 9.2). Pretreatment with an intermediate dose of lipid-rich nutrition suppressed systemic inflammation compared with fasted mice $(P<0.01)$ and low-lipid nutrition $(P<0.05)$. Administration of a high dosage of both feeds effectively inhibited circulating TNF- $\alpha$ (both $P<0.001$ ), indicating that both feeds are capable of attenuating systemic inflammation. To explore a role for gastrointestinal distention in the anti-inflammatory effect of enteral nutrition, we administered a high dose PEG solution. This non-caloric volume load did not affect plasma TNF- $\alpha$ levels, signifying that enteral nutrition attenuates endotoxin-induced systemic inflammation in a dosedependent manner and that nutrition enriched with lipids is more efficient than lowlipid nutrition.

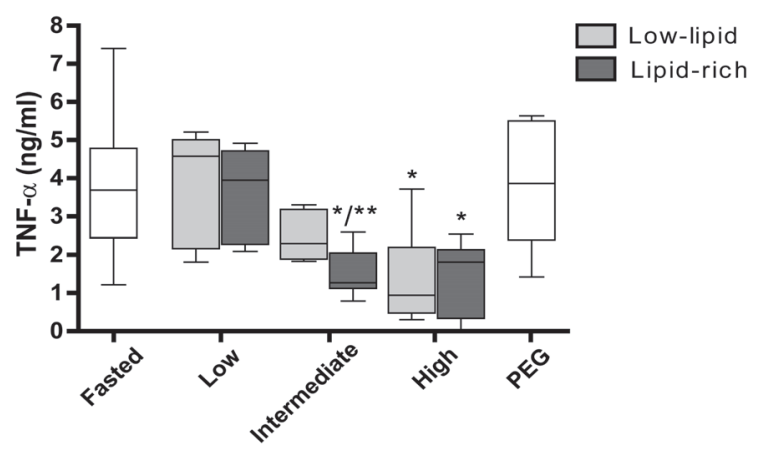

Figure 9.2 Enteral nutrition dose-dependently attenuates systemic inflammation in murine gram-negative sepsis. Intraperitoneal injection of endotoxin results in marked plasma levels of TNF- $\alpha$ in fasted mice. Pretreatment with lipid-rich nutrition attenuated systemic inflammation in the intermediate and high dose. Low-lipid nutrition reduced TNF- $\alpha$ levels only in the highest dose. Gastrointestinal distension using bolus administration of PEG-solution did not affect systemic inflammation $(\mathrm{n}=6) .{ }^{*} P<0.05$ compared with fasted. $* * P<0.05$ compared to intermediate dose of low-lipid. 


\section{The anti-inflammatory potential of enteral nutrition is mediated via the nutritional anti-inflammatory pathway}

To clarify whether the anti-inflammatory effects of both feeds were exerted via the vagal anti-inflammatory pathway, we first investigated whether a high dose of both lipid-rich and low-lipid nutrition triggered CCK-receptors. Pretreatment of mice with a combination of antagonists to the CCK-1 and CCK-2 receptor reduced the inhibitory effect of lipid-rich and low-lipid nutrition on plasma levels TNF- $\alpha$ compared with vehicle (both $P<0.01$. Figure $9.3 \mathrm{~A}$ ).

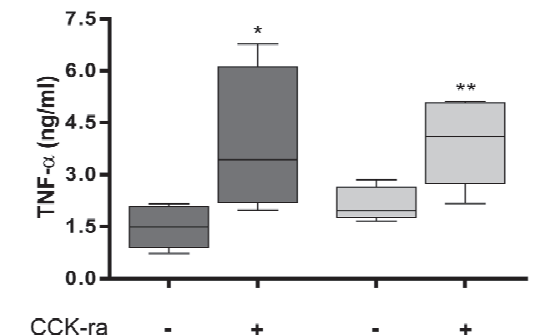

A

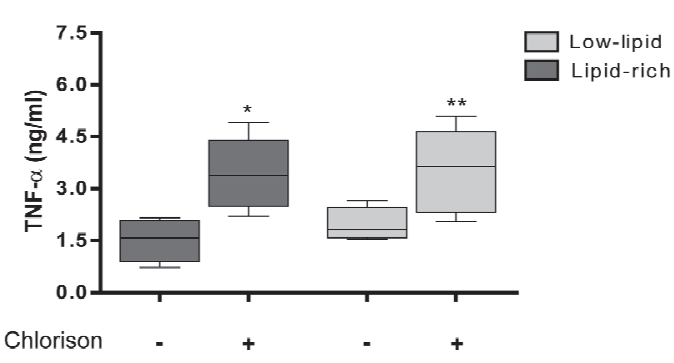

B

Figure 9.3 The anti-inflammatory effect of enteral nutrition is mediated via CCK-receptors and peripheral nicotinic receptors. A. Administration of CCK-receptor antagonists (ra) reversed the inhibitory effect of the highest dose of lipid-rich and low-lipid nutrition on circulating levels of TNF- $\alpha$. Pretreatment with the nicotinic ra. B. Counteracted the beneficial effect of lipid-rich and lowlipid nutrition treated mice. ${ }^{*} P<0.05$ compared with lipid-rich + vehicle, ${ }^{* *} \mathrm{P}<0.01$ compared with low-lipid + vehicle, $n=6$.

Next, we examined whether luminal presence of lipid-rich and low-lipid nutrition trigger firing of jejunal mechanosensitive afferents ex vivo. Since previous studies demonstrated that low-threshold afferents preferentially project via vagal pathways ${ }^{21}$, we quantified increase in afferent firing rate over the pressure range from 0 to 20 $\mathrm{mmHg}$. Lipid-rich nutrition (treatment $=\mathrm{T}$ ) enhanced afferent discharge to distension compared with discharge before treatment (BT) and after treatment (AT: $P<0.001$. Figure 9.4A). Likewise, administration of low-lipid nutrition increased afferent discharge compared with BT and AT ( $P<0.05$. Figure 9.4B). These differences were not related to changes in jejunal compliance and not mirrored in the firing of high threshold afferents at distension pressures $>20 \mathrm{mmHg}$, which project via spinal pathways (data not shown).

Lastly, we administered chlorisonamide diiodide, a peripheral nicotinic receptor antagonist. Chlorisondamine diiodide inhibited the anti-inflammatory effect of lipid- 
rich and low-lipid nutrition compared with vehicle (both; $P<0.05$. Figure 9.3B). These findings suggest that lipid-rich and low-lipid nutrition, at a sufficient dose, modulate endotoxemia-induced inflammation via the nutritional anti-inflammatory pathway.
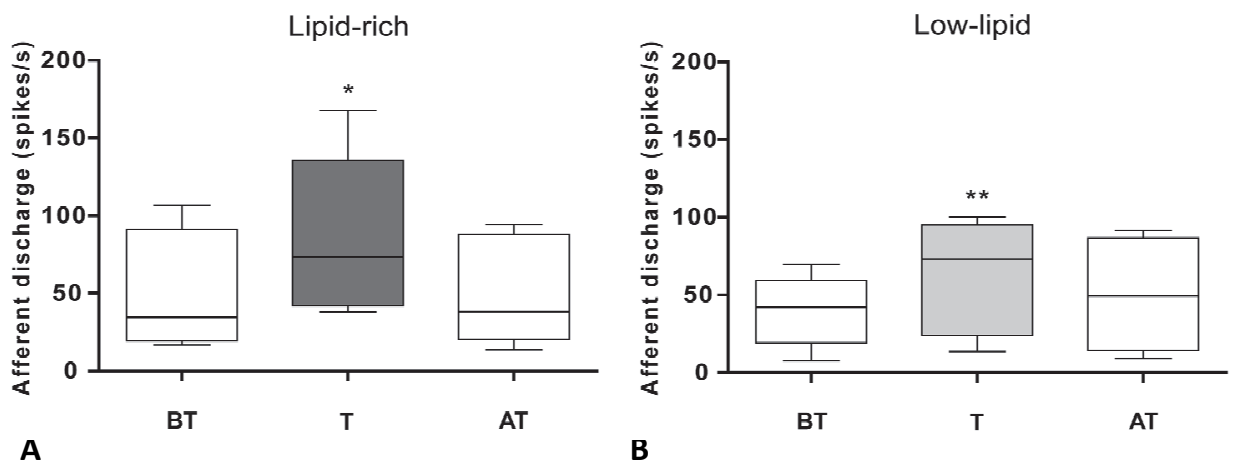

Figure 9.4 Enteral nutrition enhances afferent vagal discharge to distension. A. Intrajejunal administration ( $T$ ) of lipid-rich nutrition augments mesenteric afferent firing to luminal distension in the low-threshold range $(0-20 \mathrm{mmHg})$ compared with distension before treatment (BT) and after treatment (AT). Administration of low-lipid nutrition. B. resulted in a similar activation of the mesenteric afferent discharge. ${ }^{*} P<0.001$ for the lipid-rich treatment, ** $P<0.05$ for the low-lipid treatment, $\mathrm{n}=6$.

\section{Lipid-rich nutrition reduces intestinal epithelial cell damage during endotoxemia}

Gastrointestinal injury is implicated as a major component in the pathogenesis of sepsis and is linked with disease progression ${ }^{22,23}$. Lipid-rich nutrition was shown to attenuate systemic inflammation at lower quantities than low-lipid nutrition. Therefore, we investigated whether lipid-rich nutrition also attenuated intestinal epithelial cell damage more potently than low-lipid nutrition. Intestinal epithelial cell damage was assessed as plasma levels of I-LBP, a small cytosolic protein constitutively expressed in mature ileal enterocytes, which is rapidly released following cellular damage ${ }^{16}$. Endotoxemia in mice resulted in increased plasma levels of I-LBP compared with healthy control mice $(P<0.01$. Figure 9.5A). Endotoxemia-induced loss of I-LBP was immunohistochemically verified. Figure $9.5 \mathrm{C}$ represents the ileal distribution and localization of I-LBP in healthy controls. Figure 9.5D demonstrates endotoxin-induced loss of I-LBP from enterocytes and sludging of villus tips. Lipid-rich nutrition at an intermediate dose significantly reduced circulating levels of I-LBP compared with fasted mice $(P<0.01)$ and low-lipid nutrition $(P<0.05)$. Pretreatment with antagonists to CCK-receptors prevented the protective effects of lipid-rich nutrition on enterocyte damage $(P<0.05)$. TNF- $\alpha$ has been demonstrated to influence intestinal barrier function 
$(23,24)$. In the current model, we confirm that TNF- $\alpha$ is significantly correlated with I-LBP $\left(r^{2}=0.74, P<0.001\right.$. Figure 9.4B).
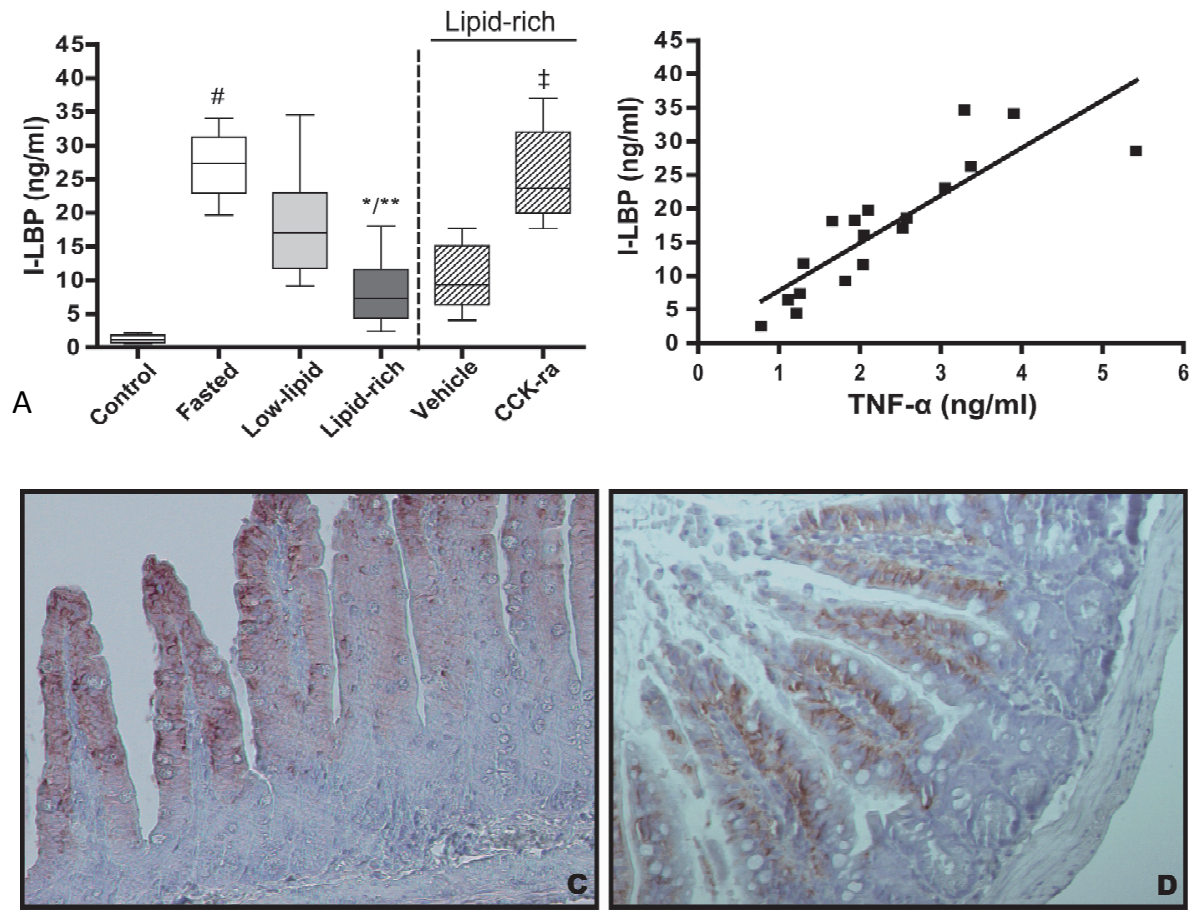

Figure 9.5 Lipid-rich nutrition reduces intestinal epithelial cell damage. Endotoxemia resulted in significant intestinal epithelial cell damage, measured as plasma levels of I-LBP (A) and visualized as loss of I-LBP from enterocytes (C, D). The nutritional intervention with lipid-rich nutrition in the intermediate dose prevented intestinal epithelial cell damage compared with fasted and low-lipid groups. CCK-receptor antagonist reduce the effect of lipid-rich nutrition on enterocyte damage. B. The plasma levels of I-LBP were significantly correlated with plasma TNF- $\alpha$ levels $\left(r^{2}: 0.74, P<0.001\right)$. Data represented as single dots (B). " $P<0.05$ compared with healthy control, ${ }^{*} P<0.05$ compared with fasted, ${ }^{*} P<0.05$ compared with low-lipid, ${ }^{\ddagger} P<0.05$ compared with vehicle.

\section{Lipid-rich nutrition attenuates hepatic and splenic inflammation}

The systemic inflammatory response of sepsis does not only lead to circulating cytokines, but also results in inflammation at organ level. To delineate the antiinflammatory potential of lipid-rich nutrition, we investigated the expression of TNF- $\alpha$ in tissue homogenates of liver and spleen. Intraperitoneal administration of LPS 
enhanced TNF- $\alpha$ protein levels in the liver (Figure 9.6A) and spleen (Figure 9.6B) compared with healthy controls (not detectable). Lipid-rich nutrition, administered at an intermediate dose reduced TNF- $\alpha$ content in the liver and spleen compared with fasted mice (both $P<0.01$ ) and low-lipid nutrition (both $P<0.05$ ). These observations indicate that lipid-rich nutrition decreases endotoxemia-induced organ-specific inflammation.
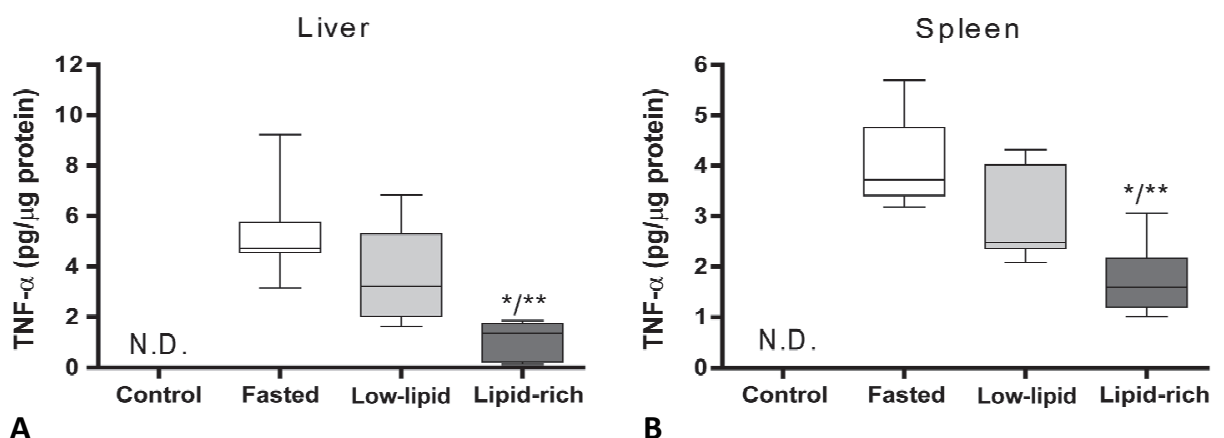

Figure 9.6 Lipid-rich nutrition attenuates organ-specific inflammation. Endotoxemia results in enhanced hepatic (A) and splenic (B) levels of TNF- $\alpha$ protein. Administration of an intermediate dose of lipid-rich nutrition attenuates the endotoxin-induced inflammation in the liver and spleen.

* $P<0.01$ compared with fasted, $* * P<0.01$ compared with low-lipid nutrition.

\section{Discussion}

Treatment of a dysregulated inflammatory response in critically-ill and surgical patients continues to be a clinical predicament. Anti-inflammatory therapies are needed that broadly affect the inflammatory response and can be safely used in these patients. The current study identifies lipid-rich nutrition as a promising intervention to treat inflammation during septic conditions.

Administration of lipid-rich nutrition has been shown to modulate inflammation in several rat models ${ }^{16-19}$. In the current murine model, a dose-dependent approach was used to investigate the anti-inflammatory effect of lipid-rich nutrition on gramnegative sepsis. Administration of a high dose of low-lipid and lipid-rich nutrition reduced endotoxemia-induced systemic TNF- $\alpha$ levels. In rats, the luminal presence of lipid-rich nutrition reduced inflammation via a vagus nerve-dependent neuroimmune pathway. Bilateral cervical vagotomy abrogated the protective effects of lipid-rich nutrition in rats $^{19}$. Here, we demonstrate for the first time that jejunal presence of lipid-rich or low-lipid nutrition augmented mesenteric afferent discharge of lowthreshold mechanoreceptors, indicating that both feeds activate vagal afferents ${ }^{21}$. 
Previous studies have demonstrated direct effects of CCK on mucosal afferents independent of mechanical sensitivity ${ }^{25}$. However, an interaction between responses to distension and CCK has been shown previously for gastric afferents ${ }^{26,27}$, suggesting that these endings encode both the presence and composition of luminal nutrients. The current finding suggest that the same may be true for jejunal mechanoreceptors, which appear to be sensitized by the presence of lipid.

The vagal pathway is activated via CCK-receptors and exerts its anti-inflammatory effect via peripheral nicotinic receptors ${ }^{16,18,19}$. Administration of antagonists to the CCK-receptor or peripheral nicotinic receptor both inhibited the anti-inflammatory effect of lipid-rich and low-lipid nutrition in mice, indicating that enteral nutrition activates two important receptor subtypes which are involved in the nutritional vagal anti-inflammatory pathway ${ }^{19}$.

Distension of the gastric wall has been shown to activate the vagus nerve in a CCKreceptor dependent manner ${ }^{28}$. Therefore, gastrointestinal distension, provoked by ingestion of a large amount of feeding, could play a role in the observed antiinflammatory effect. However, administration of a PEG-solution did not affect systemic inflammation, signifying that stimulation of CCK-receptors by luminal nutrients rather than gastrointestinal distension alone is essential.

In several experimental rat models, the anti-inflammatory potential of lipid-rich nutrition was superior to low-lipid nutrition ${ }^{18,19}$. These findings are confirmed in mice, since lipid-rich nutrition inhibited plasma TNF- $\alpha$ levels at lower quantities than lowlipid nutrition. In addition, the mesenteric afferent recordings demonstrated a greater discharge for lipid-rich than low-lipid nutrition. Increasing the lipid load results in higher CCK plasma levels and prolonged CCK-release ${ }^{29}$, leading to a sustained activation of CCK-receptors. Release of CCK and subsequent activation of mesenteric vagal afferents is triggered by intestinal application of protein as well as fatty acids $s^{30}$. However, the potency of lipid-rich nutrition to attenuate inflammation compared with low-lipid nutrition likely depends on the lipid fraction, since both feeds contain the same amount of protein and vary in the lipid composition.

Systemic inflammation following endotoxin administration has been demonstrated to result in intestinal damage ${ }^{22,31}$. TNF- $\alpha$ is one of the principal mediators of the pathophysiological changes during endotoxemia, including intestinal compromise ${ }^{3,32,33}$. Here, intraperitoneal administration of endotoxin resulted in marked intestinal epithelial cell damage. Accordingly, plasma levels of I-LBP showed a robust correlation with circulating TNF- $\alpha$. Preservation of intestinal enterocytes has been shown to improve survival in a cecal ligation and puncture model ${ }^{34}$. Moreover, release of intestinal-fatty acid binding protein (I-FABP), another member of the fatty acid binding protein family, is associated with disease severity, systemic inflammation and survival in clinical settings ${ }^{35-38}$. The enterocyte damage in the current model was significantly 
reduced by lipid-rich nutrition. In addition to the current data, we demonstrated that administration of lipid-rich nutrition prior to or following hemorrhagic shock in rats diminishes intestinal compromise ${ }^{16,17}$, emphasizing the use of lipid-rich nutrition to reduce intestinal damage during inflammatory conditions.

The liver and spleen are critically involved in the response to sepsis ${ }^{39,40}$. Administration of bacteria or endotoxin primarily activates macrophages in both organs, leading to organ damage and malfunction via a local cytokine response in which TNF- $\alpha$ plays a prominent role ${ }^{41-43}$. The marked elevation of TNF- $\alpha$ protein observed in the liver and spleen upon intraperitoneal administration of endotoxin was effectively reduced by lipid-rich nutrition. These findings are supported by studies demonstrating that stimulation of the vagal anti-inflammatory pathway attenuates inflammation in the liver and spleen during septic conditions ${ }^{55,56}$. Reduction of the primary inflammatory response in the liver has been shown to ameliorate hepatic injury ${ }^{39,46}$. In line with the observed anti-inflammatory effect on the liver, we previously demonstrated that lipidrich nutrition reduced liver damage in rats ${ }^{47}$. These findings indicate that stimulation of the nutritional anti-inflammatory pathway with lipid-rich nutrition has potent antiinflammatory effects in the liver and spleen under septic conditions.

Taken together, the current manuscript underlines that the autonomic nervous system plays a vital role in regulation of the inflammatory response. The data demonstrate that stimulation of the parasympathetic nervous system with lipid-rich nutrition is a promising intervention to control endotoxemia-induced hyper-inflammation. Interestingly, blockage of the sympathetic nervous system with beta-adrenergic receptor antagonists has been shown to improve immune competence and outcome in critical-illness $^{48,49}$. Administration of enteral lipid-rich nutrition combined with betaadrenergic blockade in critically-ill patients could be synergistic and deserves further investigation.

\section{Conclusions}

Nutritional regimens for critically-ill and surgical patients have changed significantly in the last two decades. Reduction of the preoperative fasting, preoperative enteral administration of nutrients and early nutritional support have positively influenced outcome $^{50}$. Enteral nutrition is preferred in critically-ill and surgical patients and has been shown to be well tolerated ${ }^{51-52}$. The current study supports the positive effects of enteral nutrition and reveals a potential mode of action. Our data demonstrate that enteral nutrition attenuates inflammation and intestinal damage during murine gramnegative sepsis via the nutritional anti-inflammatory pathway. These findings expand our current knowledge on the applicability of enteral nutrition to treat inflammatory conditions and indicate that enrichment of enteral nutrition with lipid potentiates the beneficial effects. 


\section{References}

1. Angus DC, Wax RS. Epidemiology of sepsis: an update. Crit Care Med 2001;29:S109-116.

2. Riedemann NC, Guo RF, Ward PA. Novel strategies for the treatment of sepsis. Nat Med 2003;9: 517-524.

3. Tracey KJ, Beutler B, Lowry SF, et al. Shock and tissue injury induced by recombinant human cachectin. Science $1986 ; 234: 470-474$.

4. Wang $\mathrm{H}$, Bloom $\mathrm{O}$, Zhang $\mathrm{M}$, et al. HMG-1 as a late mediator of endotoxin lethality in mice. Science 1999;285:248-251.

5. Barriere SL, Lowry SF. An overview of mortality risk prediction in sepsis. Crit Care Med 1995;23: 376-393.

6. Talmor M, Hydo L, Barie PS. Relationship of systemic inflammatory response syndrome to organ dysfunction, length of stay, and mortality in critical surgical illness: effect of intensive care unit resuscitation. Arch Surg 1999;134:81-87.

7. Rubulotta FM, Ramsay G, Parker MM, et al. An international survey: Public awareness and perception of sepsis. Crit Care Med 2009;37:167-170.

8. Abraham E, Laterre PF, Garbino J, et al. Lenercept (p55 tumor necrosis factor receptor fusion protein) in severe sepsis and early septic shock: a randomized, double-blind, placebo-controlled, multicenter phase III trial with 1,342 patients. Crit Care Med 2001;29:503-510.

9. Parrish WR, Gallowitsch-Puerta M, Czura CJ, et al. Experimental therapeutic strategies for severe sepsis: mediators and mechanisms. Ann N Y Acad Sci 2008;1144:210-236.

10. Pavlov VA, Wang $\mathrm{H}$, Czura $\mathrm{CJ}$, et al. The cholinergic anti-inflammatory pathway: a missing link in neuroimmunomodulation. Mol Med 2003;9:125-134.

11. Fleshner M, Goehler LE, Schwartz BA, et al. Thermogenic and corticosterone responses to intravenous cytokines (IL-1beta and TNF-alpha) are attenuated by subdiaphragmatic vagotomy. J Neuroimmunol 1998;86:134-141.

12. Wang $\mathrm{H}, \mathrm{Yu}$ M, Ochani $\mathrm{M}$, et al. Nicotinic acetylcholine receptor alpha7 subunit is an essential regulator of inflammation. Nature 2003;421:384-388.

13. Zanden EP, Snoek SA, Heinsbroek SE, et al. Vagus nerve activity augments intestinal macrophage phagocytosis via nicotinic acetylcholine receptor alpha4beta2. Gastroenterology 2009;137:1029-1039.

14. van Westerloo DJ, Giebelen IA, Florquin S, et al. The cholinergic anti-inflammatory pathway regulates the host response during septic peritonitis. J Infect Dis 2005;191:2138-2148.

15. Borovikova LV, Ivanova $\mathrm{S}$, Zhang $\mathrm{M}$, et al. Vagus nerve stimulation attenuates the systemic inflammatory response to endotoxin. Nature 2000;405:458-462.

16. de Haan JJ, Lubbers T, Hadfoune M, et al. Postshock Intervention With High-Lipid Enteral Nutrition Reduces Inflammation and Tissue Damage. Ann Surg 2008;248:842-848.

17. Luyer MD, Jacobs JA, Vreugdenhil AC, et al. Enteral administration of high-fat nutrition before and directly after hemorrhagic shock reduces endotoxemia and bacterial translocation. Ann Surg 2004;239:257-264.

18. Lubbers T, Luyer MD, de Haan JJ, et al. Lipid-Rich Enteral Nutrition Reduces Postoperative Ileus in Rats via Activation of Cholecystokinin-Receptors. Ann Surg 2009;249:481-487.

19. Luyer MD, Greve JW, Hadfoune M, et al. Nutritional stimulation of cholecystokinin receptors inhibits inflammation via the vagus nerve. J Exp Med 2005;202:1023-1029.

20. Rong W, Keating $C$, Sun B, et al. Purinergic contribution to small intestinal afferent hypersensitivity in a murine model of postinfectious bowel disease. Neurogastroenterol Motil 2009;21:665-671.

21. Booth CE, Kirkup AJ, Hicks GA, et al. Somatostatin sst(2) receptor-mediated inhibition of mesenteric afferent nerves of the jejunum in the anesthetized rat. Gastroenterology 2001;121:358-369.

22. Han X, Fink MP, Yang R, et al. Increased iNOS activity is essential for intestinal epithelial tight junction dysfunction in endotoxemic mice. Shock 2004;21:261-270.

23. Clark JA, Coopersmith CM. Intestinal crosstalk: a new paradigm for understanding the gut as the "motor" of critical illness. Shock 2007;28:384-393.

24. Han X, Fink MP, Delude RL. Proinflammatory cytokines cause NO*-dependent and -independent changes in expression and localization of tight junction proteins in intestinal epithelial cells. Shock 2003;19:229-237. 
25. Richards W, Hillsley K, Eastwood C, et al. Sensitivity of vagal mucosal afferents to cholecystokinin and its role in afferent signal transduction in the rat. J Physiol 1996;497:473-481.

26. Schwartz GJ, McHugh PR, Moran TH. Gastric loads and cholecystokinin synergistically stimulate rat gastric vagal afferents. Am J Physiol 1993;265:R872-876.

27. van de Wall EH, Duffy P, Ritter RC. CCK enhances response to gastric distension by acting on capsaicininsensitive vagal afferents. Am J Physiol Regul Integr Comp Physiol 2005;289:R695-703.

28. Bozkurt A, Oktar BK, Kurtel H, et al. Capsaicin-sensitive vagal fibres and 5-HT3-, gastrin releasing peptide- and cholecystokinin A-receptors are involved in distension-induced inhibition of gastric emptying in the rat. Regul Pept 1999;83:81-86.

29. Pilichiewicz AN, Papadopoulos P, Brennan IM, et al. Load-dependent effects of duodenal lipid on antropyloroduodenal motility, plasma CCK and PYY, and energy intake in healthy men. Am J Physiol Regul Integr Comp Physiol 2007;293:R2170-2178.

30. Eastwood C, Maubach K, Kirkup AJ, et al. The role of endogenous cholecystokinin in the sensory transduction of luminal nutrient signals in the rat jejunum. Neurosci Lett 1998;254:145-148.

31. Deitch EA, Berg R, Specian R. Endotoxin promotes the translocation of bacteria from the gut. Arch Surg $1987 ; 122: 185-190$.

32. Sun XM, Hsueh W. Bowel necrosis induced by tumor necrosis factor in rats is mediated by plateletactivating factor. J Clin Invest 1988;81:1328-1331.

33. Beutler B, Milsark IW, Cerami AC. Passive immunization against cachectin/tumor necrosis factor protects mice from lethal effect of endotoxin. Science 1985;229:869-871.

34. Clark JA, Gan H, Samocha AJ, et al. Enterocyte-specific epidermal growth factor prevents barrier dysfunction and improves mortality in murine peritonitis. Am J Physiol Gastrointest Liver Physiol 2009;297:G471-479.

35. de Haan JJ, Lubbers T, Derikx JP, et al. Rapid development of intestinal cell damage following severe trauma: a prospective observational cohort study. Crit Care 2009;13:R86.

36. Derikx JP, van Waardenburg DA, Thuijls G, et al: New Insight in Loss of Gut Barrier during Major NonAbdominal Surgery. PLoS One 2008;3:e3954.

37. Derikx JP, Bijker EM, Vos GD, et al. Gut mucosal cell damage in meningococcal sepsis in children: Relation with clinical outcome. Crit Care Med 2009;38:133-137.

38. Derikx JP, Poeze M, van Bijnen AA, et al. Evidence for intestinal and liver epithelial cell injury in the early phase of sepsis. Shock 2007;28:544-548.

39. Dhainaut JF, Marin N, Mignon A, et al. Hepatic response to sepsis: interaction between coagulation and inflammatory processes. Crit Care Med 2001;29:S42-47.

40. Altamura M, Caradonna L, Amati L, et al. Splenectomy and sepsis: the role of the spleen in the immune-mediated bacterial clearance. Immunopharmacol Immunotoxicol 2001;23:153-161.

41. Ge Y, Ezzell RM, Clark BD, et al. Relationship of tissue and cellular interleukin-1 and lipopolysaccharide after endotoxemia and bacteremia. J Infect Dis 1997;176:1313-1321.

42. Katagiri $\mathrm{H}$, Ito $\mathrm{Y}$, Ito $\mathrm{S}$, et al. TNF-alpha induces thromboxane receptor signaling-dependent microcirculatory dysfunction in mouse liver. Shock 2008;30:463-467.

43. Tracey KJ, Wei H, Manogue KR, et al. Cachectin/tumor necrosis factor induces cachexia, anemia, and inflammation. J Exp Med 1988;167:1211-1227.

44. Mabley JG, Pacher P, Szabo C. Activation of the cholinergic antiinflammatory pathway reduces ricininduced mortality and organ failure in mice. Mol Med 2009;15:166-172.

45. Rosas-Ballina $M$, Ochani $M$, Parrish $W R$, et al. Splenic nerve is required for cholinergic antiinflammatory pathway control of TNF in endotoxemia. Proc Natl Acad Sci USA 2008;105:1100811013.

46. Li B, Li YM, Li X, et al. COX-2 inhibition improves immune system homeostasis and decreases liver damage in septic rats. J Surg Res 2009;157:43-47.

47. Luyer MD, Derikx JP, Beyaert R, et al. High-fat nutrition reduces hepatic damage following exposure to bacterial DNA and hemorrhagic shock. J Hepatol 2009;50:342-350.

48. Herndon DN, Hart DW, Wolf SE, et al. Reversal of catabolism by beta-blockade after severe burns. $N$ Engl J Med 2001;345:1223-1229.

49. Ackland GL, Yao ST, Rudiger A, Dyson A, Stidwill R, Poputnikov D, Singer M, Gourine AV. Cardioprotection, attenuated systemic inflammation, and survival benefit of beta1-adrenoceptor blockade in severe sepsis in rats. Crit Care Med;38:388-394. 
50. Elke G, Schadler D, Engel C, et al. Current practice in nutritional support and its association with mortality in septic patients--results from a national, prospective, multicenter study. Crit Care Med 2008;36:1762-1767.

51. Bisgaard T, Kehlet $\mathrm{H}$. Early oral feeding after elective abdominal surgery--what are the issues? Nutrition 2002;18:944-948.

52. Bengmark S. Enteral nutrition in HPB surgery: past and future. J Hepatobiliary Pancreat Surg 2002;9:448-458. 


\title{
CHAPTER 10
}

\author{
Lipid-rich enteral nutrition
}

reduces immunosuppression

during polymicrobial sepsis

Jacco J. de Haan, Eva Pastille, Florian Wirsdörfer, Tim Lubbers, Jan-Willem M. Greve, Yang Zhang, Wim A. Buurman, Stefanie B. Flohé 


\section{Abstract}

Introduction: The development of an immunosuppressive state during the protracted course of sepsis is associated with opportunistic infections and is considered to correlate with the extent of the pro-inflammatory response during early sepsis. Stimulation of the autonomic nervous system with enteral lipid-rich nutrition was shown to attenuate the acute inflammatory response. This study investigates the effects of lipid-rich nutrition on the immunosuppression induced by polymicrobial sepsis.

Methods: Female BALB/c mice were either fasted or fed liquid lipid-rich nutrition or isocaloric control nutrition before and shortly after induction of polymicrobial sepsis through cecal ligation and puncture (CLP) or sham operation. After 4 days, mice were intranasally infected with Pseudomonas aeruginosa.

Results: Twenty-four hours after $P$. aeruginosa infection, fasted or control nutritionfed CLP mice displayed a significantly higher bacterial load in the lungs than corresponding sham operated mice $(P<0.001$ and $P<0.05$, respectively). Fasted CLP mice expressed reduced pulmonary levels of pro-inflammatory cytokines interleukin (IL)-12 and interferon (IFN) $-\gamma$ in comparison to sham mice (both $P<0.05$ ). Lipid-rich nutrition prevented the increase in bacteria, promoted the IL-12 and IFN- $\gamma$ production (IL-12 and IFN- $\gamma: P<0.05$ vs. fasted and IFN- $-P<0.05$ vs. control nutrition) and prevented the expression of the immunosuppressive cytokine IL-10 $(P<0.05$ vs. control nutrition) in lungs of CLP mice. The preserved immune defense during late sepsis in lipid-rich fed mice was preceded by attenuation of the early inflammatory response (IL-6; $P=0.05$ and IL-10; $P<0.01$ vs. fasted CLP mice) at six hours post-CLP.

Conclusions: Short-term treatment with lipid-rich enteral nutrition reduces immunosuppression during polymicrobial sepsis. 


\section{Introduction}

Immunosuppression is a feared consequence of septic disease that results in an inability to control infections and predisposes patients to secondary infections caused by opportunistic pathogens ${ }^{1,2}$. In particular, septic patients are susceptible to develop refractory pneumonias, with Pseudomonas aeruginosa as most prevalent causative organism at the $\mathrm{ICU}^{3,4}$. Despite optimal antibiotic and supportive care, such secondary infections are associated with high mortality rates ${ }^{5}$.

Typical for the state of immunosuppression during ongoing sepsis is the failure of the host to produce appropriate levels of interleukin (IL)-12 and interferon (IFN) $-\gamma$ in response to opportunistic pathogens including $P$. aeruginosa ${ }^{6,7}$. IL-12 triggers the release of IFN- $\gamma$ that in turn stimulates phagocytes like macrophages and neutrophils to efficiently eliminate the invading microorganisms. In contrast, the formation of IL-10, a potent suppressor of IL-12 and IFN- $\gamma$, is strongly increased during ongoing sepsis $^{8,9}$. Restoration of the IL-12 / IL-10 balance during sepsis was shown to improve the defence against opportunistic pathogens, which emphasizes the decisive role of these cytokines ${ }^{10}$. The development of immunosuppression is generally considered to compensate hyperinflammation during early sepsis, which is represented by strongly increased circulatory levels of pro- and anti-inflammatory mediators including IL-6 and $\mathrm{IL}-10^{11}$. Therefore, modulation of the acute inflammatory response forms a potential means to prevent later immunosuppression-related complications such as secondary infections ${ }^{2,12}$.

A novel and effective strategy to attenuate the acute inflammatory response is nutritional activation of the vagal anti-inflammatory reflex ${ }^{13,14}$. Enteral lipid-rich nutrition stimulates the autonomic nervous system via activation of cholecystokinin (CCK)-1 receptors on afferent vagal fibers ${ }^{14}$. In turn, parasympathetic outflow suppresses cytokine release via binding of cholinergic neurotransmitters to nicotinic acetylcholine receptors on inflammatory cells ${ }^{13,15}$. Next to attenuation of the acute inflammatory response, nutritional activation of the vagal reflex preserves organ integrity and promotes gastrointestinal motility in diverse models of acute inflammation including endotoxemia, hemorrhagic shock, exposure to bacterial DNA and postoperative ileus ${ }^{13,16-18}$. Considering these broad protective effects, we hypothesized that lipid-rich nutrition prevents the development of immunosuppression during sepsis through attenuation of the early inflammatory response.

This study investigates the capacity of short-term intervention with lipid-rich enteral nutrition to reduce cytokine levels during early polymicrobial sepsis. Next, the impact of nutrition on the pulmonary immune defense in the immunosuppressive state of 
sepsis is assessed. For this, cecal ligation and puncture (CLP) was applied as a model for immunosuppression induced by polymicrobial sepsis ${ }^{19}$.

\section{Materials and methods}

\section{Animals}

Female BALB/C mice, aged 8-10 weeks, were purchased from Harlan Winkelmann (Borchen, Germany). The mice were housed under controlled conditions of temperature and humidity and had ad libitum access to standard rodent chow and water. Prior to CLP, mice were randomly assigned to one of the study groups. The groups in the early sepsis experiments consisted of 8 animals each; the group size was based on the reduction of cytokine levels by lipid-rich nutrition in previous studies ${ }^{13,17}$. The groups of the late sepsis experiments included 17 animals each; the group size was based on earlier reported microbial counts in this model ${ }^{7}$. All animal procedures were carried out following institutional guidelines and approved by the regional ethics committee LANUV NRW, Recklinghausen, Germany.

\section{Cecal ligation and puncture model}

Polymicrobial sepsis was induced as described previously with minor modifications ${ }^{7}$. Briefly, mice were anesthetized using an i.m. application of $100 \mathrm{mg} / \mathrm{kg}$ Ketamin and $13 \mathrm{mg} / \mathrm{kg}$ Xylazin (both Ceva Sante Animale, Dusseldorf, Germany). After a midline laparotomy, the cecum was exposed and ligated by $50 \%$. A 27 -gauge needle was used to puncture the cecum once, and a small amount of cecum content was extruded. The cecum was then replaced into the abdominal cavity, and the incision was closed with two layers. Sham mice were treated identically except for the ligation and puncture of the cecum. All mice were resuscitated by an intraperitoneal injection of $1 \mathrm{ml}$ sterile saline. The mice did not receive antibiotics. In order to measure early cytokine levels in serum, mice were sacrificed at 6 hours after CLP by vena cava puncture. To investigate the responsiveness to secondary infections, mice were infected with $P$. aeruginosa on day 4 after CLP or sham treatment. These animals were sacrificed 24 hours later by cervical dislocation to determine the bacterial load and cytokine levels in the lung (Figure 10.1). Samples were stored at $-80^{\circ} \mathrm{C}$ until analysis.

All mice showed signs of severe illness within $24 \mathrm{~h}$ after induction of sepsis (including shaggy fur, shaking, apathy, reduced food intake) but recovered during the following 4 days. The death of mice occurred within the first 24 hours after CLP but not thereafter. The mortality rate following CLP was $17 \%$ in fasted, $17 \%$ in low-lipid and $24 \%$ in lipid-rich fed animals, which is in congruence with previous reports ${ }^{7}$. In 
addition, five animals died during anesthesia before CLP or sham operation (two mice in the acute sepsis experiments and three mice in the late sepsis experiments).

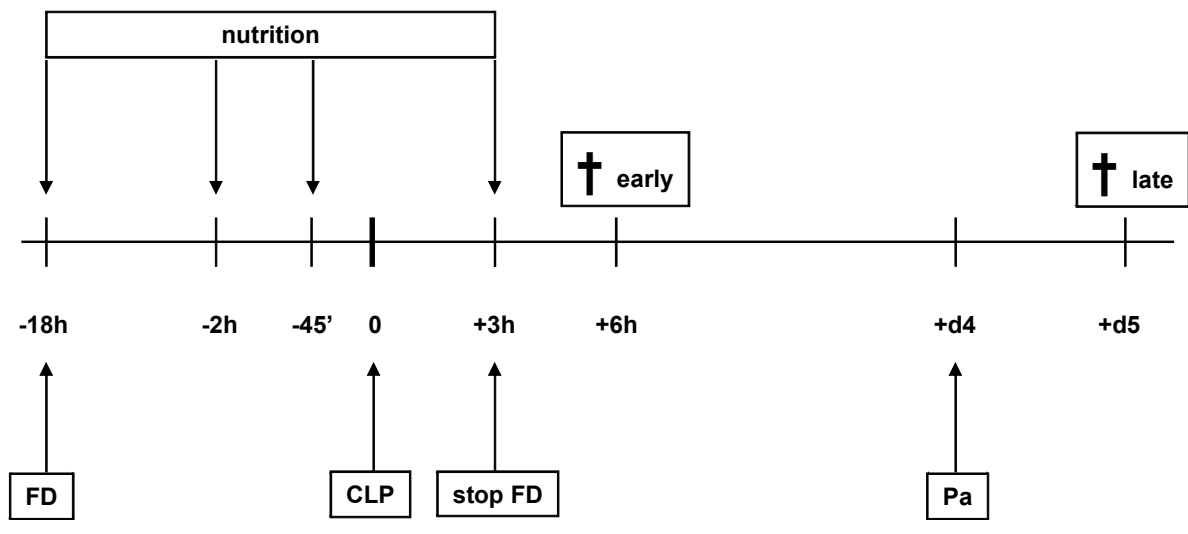

Figure 10.1 Study design. Polymicrobial sepsis in mice was induced by cecal ligation and puncture (CLP). Animals were either food-deprived (FD) for 18 hours before CLP until 3 hours post-CLP (stop FD) or received enteral lipid-rich or low-lipid nutrition at -18 hours, -2 hours, -45 minutes and +3 hours. Animals were sacrificed at 6 hours ( + early) or at day 5 after CLP ( + late). Animals sacrificed at day 5 received an intranasal bolus of Pseudomonas aeruginosa $(\mathrm{Pa})$ at day 4 following CLP.

\section{Nutritional intervention}

All animals were food-deprived between 18 hours prior to and 3 hours after CLP or sham operation. Nutritional groups were fed lipid-rich or control low-lipid nutrition via oral gavage 18 hours $(0.3 \mathrm{ml}), 2$ hours $(0.2 \mathrm{ml})$ and 45 minutes $(0.2 \mathrm{ml})$ before CLP and 3 hours after CLP $(0.2 \mathrm{ml})$ (Figure 10.1). To reduce the number of animals, in the current study the low-lipid control group was only included in the late sepsis experiments. The total energy provided by the 4 enteral feedings approximated $9 \%$ of the normal daily energy expenditure of mice. The feeding regimen, food quantities, and selected compositions were based on previous rodent studies ${ }^{13,17}$. From 3 hours post-CLP onwards, all animals regained access to standard chow.

The lipid-rich nutrition was isocaloric $(1.3 \mathrm{kcal} / \mathrm{ml})$ and isonitrogenous to the control nutrition. The amount of lipids in the control nutrition was isocaloric to that present in standard rodent chow. The liquid lipid-rich diet contained 50.4 energy percent (en\%, i.e. percentage of total calories) fat, 8.7 en\% protein, and 40.9 en\% carbohydrates. The fat fraction contained $30 \%$ phospholipids. The low-lipid control nutrition contained 16.0 en\% fat, 8.7 en\% proteins, and 75.3 en\% carbohydrates. The lipid source was lecithin. Omega-3 and omega- 6 fatty acids constituted less than 5 weight percent $(<5 \mathrm{~g} / 100 \mathrm{ml})$. Proteins were derived from lean milk powder, containing $80 \%$ casein 
and $20 \%$ whey protein. The carbohydrate source was a mixture of sucrose and maltodextrins (Glucidex 19DE). The protein and carbohydrate compositions of the two feedings were identical.

\section{Infection with Pseudomonas aeruginosa}

P. aeruginosa (strain ATCC 27853) was plated overnight on tryptic soy agar plates at $37^{\circ} \mathrm{C}$. After resuspension in tryptic soy broth, bacteria were grown for 1 hour. Bacteria were harvested during the logarithmic growth phase according to the optical density by pelleting and resuspension in fresh tryptic soy broth [20]. Prior to infection, bacteria were washed twice in RPMI 1640. Mice were intranasally infected with $5 \times 10^{8}$ CFU of $P$. aeruginosa in $20 \mu \mathrm{l}$. The experimental groups to which the mice belonged were concealed at the moment of microbe administration. After 24 hours, lungs were removed and homogenized in $1 \mathrm{ml}$ phosphate buffered saline using an Ultra-Turrax disperser (IKA, Staufen, Germany). For determination of the bacterial load, homogenates were lysed for $10 \mathrm{~min}$ with saponin $(5 \mathrm{mg} / \mathrm{ml}$; Sigma-Aldrich, Taufkirchen, Germany) to release intracellular bacteria ${ }^{20}$. Serial dilutions were cultured on tryptic soy agar plates for 18 hours, colonies were counted, and the number of colony-forming units (CFU) was calculated. Prior to the quantification of proteins, homogenates were centrifuged at $13000 \mathrm{~g}$ to clear from debris.

\section{ELISA}

Cytokine levels in serum were determined by standard enzyme-linked immunosorbent assays (ELISA) for murine IL-6 and IL-10 (R\&D Systems, Minneapolis, MN; detection limits both $20 \mathrm{pg} / \mathrm{ml}$ ). Concentrations of IFN- $\gamma, \mathrm{IL}-12$, and IL-10 in cleared lung tissue homogenates were detected using ELISA for murine IFN- $\gamma$ and IL-10 (R\&D Systems), and murine IL-12 (eBioscience, San Diego, CA). The concentration of total protein in lung tissue homogenates was quantified using the $D C^{T M}$ Protein Assay (Bio-Rad, Munchen, Germany). Cytokine levels in the lung were expressed as $\mathrm{pg} / \mathrm{mg}$ total protein.

\section{Statistical analysis}

Data are presented as median, interquartiles, and range. The Mann-Whitney U-test was used to compare the fasted and lipid-rich nutrition fed CLP groups in the acute sepsis experiments (Figure 10.2). The Kruskal-Wallis test with Dunn's post-test was applied to perform multiple comparisons between the state of fasting and different nutritions in CLP mice and sham mice in the late sepsis experiments (Figure 10.3 and 10.4). Differences were considered statistically significant at $P \leq 0.05$. Prism 5.02 for Windows (GraphPad Software Inc., San Diego, CA) was used for computations. 


\section{Results}

\section{Enteral lipid-rich nutrition reduces inflammatory parameters in the early phase of polymicrobial sepsis}

At 6 hours after CLP, elevated circulatory levels of the cytokines IL- 6 and IL-10 were observed in fasted CLP mice (Figure 10.2). CLP mice that were treated with lipid-rich nutrition showed significantly reduced serum levels of IL- 6 and IL-10 compared to fasted CLP mice ( $P=0.05$ and $P<0.01$, respectively).
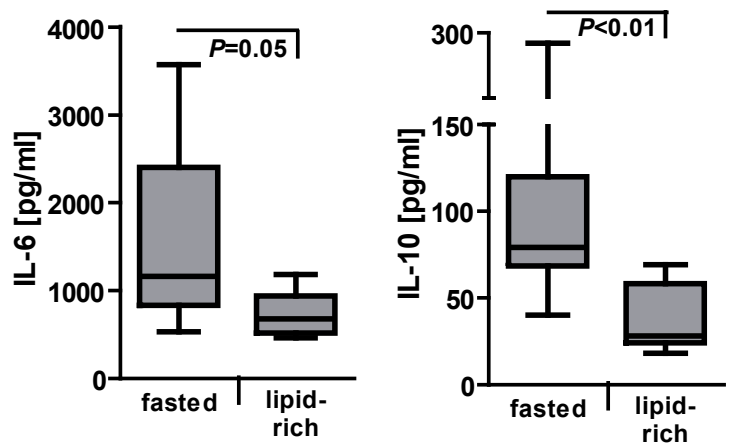

Figure 10.2 Lipid-rich nutrition attenuates the inflammatory response in the early phase of polymicrobial sepsis. Mice were fasted or received enteral lipid-rich nutrition before and shortly after CLP. At 6 hours following CLP, enteral lipid-rich nutrition significantly reduced the circulatory levels of both IL- 6 and IL-10 compared with fasted mice.

\section{Lipid-rich nutrition preserves the pulmonary cytokine secretion pattern in response to a secondary infection in the lung during the protracted phase of sepsis}

Fasted CLP mice that underwent a secondary $P$. aeruginosa infection showed significantly reduced pulmonary levels of IL-12 and IFN- $\gamma$ in comparison to sham mice (both $P<0.05$; Figure $10.3 \mathrm{~A}, \mathrm{~B}$ ). Intervention with the lipid-rich nutrition led to a significant increase of IL-12 and IFN- $\gamma$ in the lungs of CLP mice (both $P<0.05$ vs fasting). Likewise, lipid-rich nutrition caused higher pulmonary levels of IFN- $\gamma$ in CLP mice than the low-lipid nutrition $(P<0.05)$. The lungs of CLP mice that had received the lipid-rich nutrition contained concentrations of IL-12 and IFN- $\gamma$ that were comparable with concentrations found in the corresponding sham operated animals. In addition, no significant IL-12 and IFN- $\gamma$ differences were observed between CLP mice and sham mice that had received the low-lipid diet (Figure 10.3A,B). 
A trend towards increased pulmonary levels of immunosuppressive mediator IL-10 was observed in fasted CLP animals compared to fasted sham ( $P=0.10$; Figure $10.3 \mathrm{C}$ ), but did not reach statistical significance. In low-lipid nutrition-treated animals, the content of IL-10 in the lungs was significantly higher in CLP mice than in sham mice $(P<0.05)$. CLP animals that had received the lipid-rich nutrition showed reduced pulmonary IL-10 concentrations compared with control diet-treated CLP mice ( $P<0.05$; Figure $10.3 \mathrm{C})$. In mice receiving lipid-rich feeding, the levels of IL-10 in the lung did not differ between CLP and sham operation, indicating that lipid-rich nutrition prevents the increase of anti-inflammatory signaling during late sepsis.
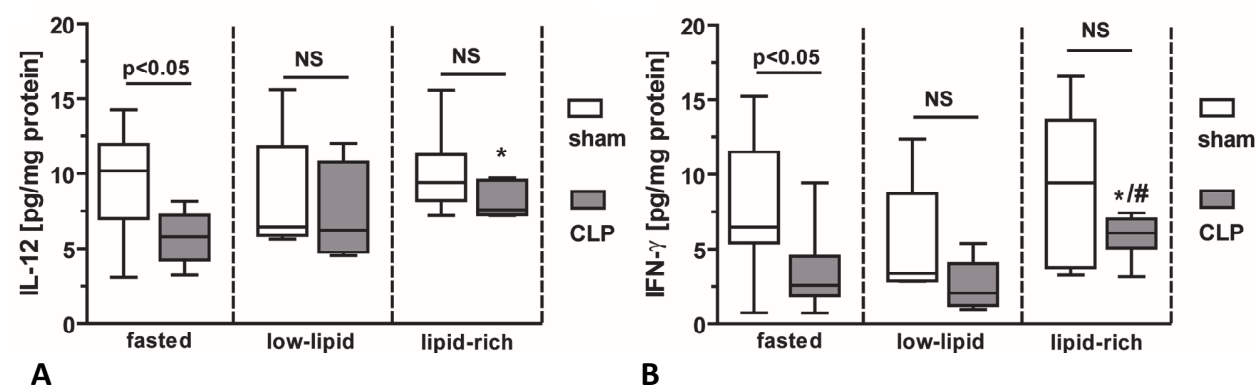

B

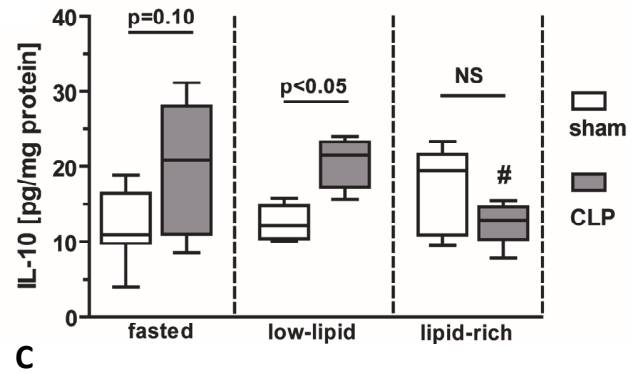

Figure 10.3 Treatment with lipid-rich nutrition increases pulmonary IL-12 and IFN- $\gamma$ concentrations and reduces the pulmonary anti-inflammatory response upon secondary infection during late sepsis. In fasted animals, CLP led to reduced pulmonary IL-12 (A) and IFN- $\gamma$ (B) levels after a secondary infection compared to sham treated controls, whereas no significant decrease of IL-12 and IFN- $\gamma$ was observed between CLP and sham treatment in lipid-rich and low-lipid fed animals. Pulmonary cytokine levels in septic animals that had received lipid-rich nutrition were significantly increased compared to septic mice that had fasted (IL-12 and IFN- $\gamma$ ) or had received low-lipid nutrition (IFN- $\gamma$ ). Compared with corresponding sham treated controls, IL-10 concentrations in the lungs following $P$. aeruginosa installation tended to be increased in fasted and low-lipid treated CLP mice (C), whereas in lipid-rich fed animals, IL-10 concentrations after CLP did not differ from sham operated animals. Furthermore, lungs from lipid-rich fed CLP mice contained decreased amounts of IL-10 in comparison to low-lipid fed CLP mice. ${ }^{*} P<0.05$ vs. CLP fasted. \# $P<0.05$ vs. CLP low-lipid. NS=not significant. 


\section{The defense against a secondary infection in the lungs of septic mice is improved by lipid-rich nutrition}

At 24 hours following intranasal installation of $P$. aeruginosa, a significantly increased number of microbes was detected in the lungs of fasted CLP mice compared with sham operated mice, indicating a state of immunosuppression $(P<0.001$; Figure 10.4). These findings are in line with previous reports on CLP that is complicated by a secondary infection $^{7,19}$. Also in animals that received low-lipid nutrition, an enhanced number of bacteria was observed in the lungs of CLP mice in comparison to the corresponding group of sham operated mice $(P<0.05)$. In contrast, after intervention with lipid-rich nutrition, the bacterial load in the lungs of mice undergoing CLP and secondary $P$. aeruginosa infection did not differ from the lungs of sham operated mice. These findings implicate that lipid-rich nutrition preserves the immune defense during polymicrobial sepsis.

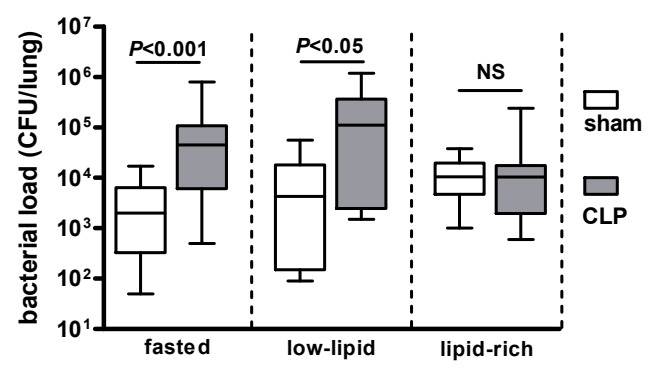

Figure 10.4 The bacterial clearance following secondary infection in septic mice is improved by lipid-rich nutrition. At 24 hours after secondary infection with $P$. aeruginosa, the bacterial load in the lungs of septic mice was determined. In fasted and low-lipid fed animals, the number of colony forming units (CFU) in the lungs was significantly increased in CLP mice compared to sham operated mice. Intervention with lipid-rich nutrition resulted in similar bacterial loads in CLP mice and sham operated controls. NS = not significant.

\section{Discussion}

The early delivery of nutritional support, preferably via the enteral route, is considered a proactive therapeutic strategy in critically ill patients to reduce disease severity, diminish complications and decrease the length of ICU stay ${ }^{21,22}$. In several patient groups, the supplemental use of omega- 3 fatty acids is advocated ${ }^{22,23}$. The immunemodulating effects of omega- 3 polyunsaturated fatty acids are attributed to a direct inhibition of NFKB-mediated pro-inflammatory signaling and through modification of the pattern of diverse lipid mediators ${ }^{24,25}$. A totally different mechanism via which 
enteral nutrition modulates the inflammatory response was previously described by our group. Intervention with limited amounts of enteral lipid-rich nutrition, containing less than 5 en\% omega- 3 fatty acids, was demonstrated to attenuate inflammation and preserve organ integrity in rodents by activation of the autonomic nervous system via peripheral CCK-1 receptors ${ }^{13,14}$.

Using the same nutritional composition and feeding schedule as before, in the current study we first investigated the effects of lipid-rich nutrition on the early inflammatory response after $C_{2}{ }^{13,17}$. Six hours post-CLP, markedly enhanced serum levels of the proinflammatory cytokine IL-6 and the anti-inflammatory regulator IL-10 were detected, which is characteristic for the early hyperinflammatory state of sepsis. Early measurement of both cytokines was reported to predict mortality in settings of trauma and sepsis ${ }^{26,27}$. The current data are the first to demonstrate that short-term enteral lipid-rich nutrition reduces both pro- and anti-inflammatory cytokine release during the first hours of polymicrobial sepsis. These findings are in line with previous studies showing a broad reduction of the early inflammatory response in models of endotoxemia, hemorrhagic shock and exposure to bacterial DNA ${ }^{17,18,28}$.

Patients who survive the initial hyperinflammatory phase of sepsis are at risk to develop secondary infections due to the state of sustained immunosuppression. In accordance with previous clinical and experimental findings, we observed that septic animals displayed an impaired microbial clearance in the lung upon secondary infection with $P$. aeruginosa ${ }^{7,19,29}$. The reduced ability to clear pulmonary microbes during sepsis has previously been attributed to impaired responsiveness of innate immune cells like alveolar macrophages, neutrophils and dendritic cells ${ }^{7,8,12}$. A disturbed production of pro-inflammatory cytokines such as IL-12 and an increased release of immunosuppressive mediators like IL-10 are considered to play a key role in the diminished defense against secondary infections ${ }^{9,10,30}$. In accordance, in the current study the decrease of microbial eradication was paralleled by a decreased formation of IL-12 and IFN- $\gamma$ and a concomitant increase of IL-10 levels in the lungs upon secondary $P$. aeruginosa infection.

Importantly, we provide evidence that enteral lipid-rich nutrition at the onset of polymicrobial sepsis reduces the pulmonary dissemination of bacteria upon a secondary $P$. aeruginosa infection in the lung. The improved defense of CLP animals fed lipid-rich nutrition against $P$. aeruginosa was associated with enhanced pulmonary IL-12 and IFN- $\gamma$ levels and maintained IL-10 concentrations, which resulted in a cytokine profile that was similar to that of sham operated mice. The preservation of immune competence by lipid-rich nutrition during the immunosuppressive phase of sepsis might be explained by the attenuation of the early inflammatory response ${ }^{2}$. In line with our findings, Takahashi et al. demonstrated that a mild initial immune reaction leads to an improved resistance to secondary infections, whereas a secondary 
bacterial infection following a severe insult results in enhanced mortality ${ }^{31}$. Also clinical studies report a close relation between excessive early inflammation and late mortality, thus supporting the modulation of the initial immune response as a potential therapeutic target to improve outcome $e^{2,32}$. However, the pathways that connect the lipid-mediated limitation of the initial inflammatory response during sepsis and the reduction of immunosuppression at several days thereafter remain to be defined. Further investigations are required to determine the role of nutrition-induced vagus nerve activation and subsequent binding of acetylcholine to nicotinic acetylcholine receptors on innate immune cells in the reversion of cellular dysfunction and attenuation of the concomitant immunosuppressed state $e^{33-35}$.

The reduction of both pro- and anti-inflammatory mediators during early sepsis by lipid-rich nutrition is unlike the effects of many other anti-inflammatory interventions. For instance, phosphodiesterase inhibitors piclamilast and pentoxifylline couple early inhibition of pro-inflammatory cytokines such as TNF- $\alpha$ to an increase of antiinflammatory mediators, including IL-10 ${ }^{36,37}$. The disappointing effects of inhibiting specific pro-inflammatory cytokines in settings of sepsis, e.g. through neutralizing antibodies against TNF- $\alpha$, have been attributed at least partly to increased immunosuppressive signaling and subsequent development of infections ${ }^{38}$. Interestingly, in comparison with single-hit models such as endotoxemia, inhibition of single inflammatory mediators including TNF- $\alpha$ was shown to be less effective in CLP models in which initial inflammation is followed by a state of immunosuppression ${ }^{39}$. Here, lipid-rich nutrition is shown to preserve immune competence also during ongoing polymicrobial sepsis. Conform earlier reports, enrichment of the feeding with lipids led to stronger protective effects compared to isocaloric low-lipid nutrition ${ }^{13,17}$. Implementation of international guidelines has improved sepsis survival considerably, nevertheless the need for better control of the immune response remains eminent ${ }^{40}$. Although observations in rodents should be extrapolated to clinical settings with caution, the present study suggests that administration of limited quantities of enriched enteral nutrition may be of additional value to prevent inflammatory complications of sepsis. With regard to its potential clinical implications, it should be noted that the current study is the first that demonstrates a protective effect of shortterm intervention with lipid-rich nutrition in female animals. Also post-treatment with lipid-rich feeding has been shown to reduce inflammation and preserve organ integrity, therefore further studies should clarify whether nutritional intervention is applicable when sepsis is already manifest ${ }^{28}$. 


\section{Conclusions}

The current study demonstrates that enteral lipid-rich nutrition attenuates the initial hyperinflammatory response during polymicrobial sepsis. In the prolonged phase of sepsis, lipid-rich nutrition sustains the immune function and prevents the state of immunosuppression. Of major clinical importance is the observation that short-term intervention with lipid-rich nutrition promotes microbial eradication during late sepsis. Together, the present study implicates early administration of enriched nutrition as a novel and physiological adjuvant therapy to preserve immune competence during ongoing sepsis. 


\section{References}

1. Hotchkiss RS, Karl IE. The pathophysiology and treatment of sepsis. N Engl J Med 2003;348:138-150.

2. Adib-Conquy M, Cavaillon JM. Compensatory anti-inflammatory response syndrome. Thromb Haemost 2009;101:36-47.

3. Neuhauser MM, Weinstein RA, Rydman R, Danziger LH, Karam G, Quinn JP. Antibiotic resistance among gram-negative bacilli in US intensive care units: implications for fluoroquinolone use. JAMA 2003;289:885-888.

4. Fujitani S, Sun HY, Yu VL, Weingarten JA. Pneumonia due to Pseudomonas aeruginosa: part I: epidemiology, clinical diagnosis, and source. Chest 2011;139:909-919.

5. Mustard RA, Bohnen JM, Rosati C, Schouten BD. Pneumonia complicating abdominal sepsis. An independent risk factor for mortality. Arch Surg 1991;126:170-175.

6. Murphey ED, Lin CY, McGuire RW, Toliver-Kinsky T, Herndon DN, Sherwood ER. Diminished bacterial clearance is associated with decreased IL-12 and interferon-gamma production but a sustained proinflammatory response in a murine model of postseptic immunosuppression. Shock 2004;21: 415-425.

7. Pastille E, Didovic S, Brauckmann D, Rani M, Agrawal H, Schade FU, Zhang Y, Flohe SB. Modulation of dendritic cell differentiation in the bone marrow mediates sustained immunosuppression after polymicrobial sepsis. J Immunol 2011;186:977-986.

8. Steinhauser ML, Hogaboam CM, Kunkel SL, Lukacs NW, Strieter RM, Standiford TJ. IL-10 is a major mediator of sepsis-induced impairment in lung antibacterial host defense. J Immunol 1999;162: 392-399.

9. Couper KN, Blount DG, Riley EM. IL-10 the master regulator of immunity to infection. J Immunol 2008;180:5771-5777.

10. Wen H, Hogaboam CM, Gauldie J, Kunkel SL. Severe sepsis exacerbates cell-mediated immunity in the lung due to an altered dendritic cell cytokine profile. Am J Pathol 2006;168:1940-1950.

11. Cohen J. The immunopathogenesis of sepsis. Nature 2002;420:885-891.

12. Delano MJ, Thayer T, Gabrilovich S, Kelly-Scumpia KM, Winfield RD, Scumpia PO et al. Sepsis induces early alterations in innate immunity that impact mortality to secondary infection. J Immunol 2011;186:195-202.

13. Luyer MD, Greve JW, Hadfoune M, Jacobs JA, Dejong $\mathrm{CH}$, Buurman WA. Nutritional stimulation of cholecystokinin receptors inhibits inflammation via the vagus nerve. J Exp Med 2005;202:1023-1029.

14. Lubbers T, de Haan JJ, Luyer MD, Verbaeys I, Hadfoune M, Dejong CH, Buurman WA, Greve JW. Cholecystokinin/Cholecystokinin-1 receptor-mediated peripheral activation of the afferent vagus by enteral nutrients attenuates inflammation in rats. Ann Surg 2010;252:376-382.

15. Wang H, Yu M, Ochani M, Amella CA, Tanovic M, Susarla S, Li JH, Yang H, Ulloa L, Al-Abed Y et al. Nicotinic acetylcholine receptor alpha7 subunit is an essential regulator of inflammation. Nature 2003;421:384-388.

16. Lubbers T, Luyer MD, de Haan JJ, Hadfoune M, Buurman WA, Greve JW. Lipid-rich enteral nutrition reduces postoperative ileus in rats via activation of cholecystokinin-receptors. Ann Surg 2009;249: 481-487.

17. Lubbers T, De Haan JJ, Hadfoune M, Zhang Y, Luyer MD, Grundy D, Buurman WA, Greve JW. Lipidenriched enteral nutrition controls the inflammatory response in murine Gram-negative sepsis. Crit Care Med 2010;38:1996-2002.

18. Luyer MD, Derikx JP, Beyaert R, Hadfoune $M$, van Kuppevelt $T H$, Dejong $C H$, Heineman $E$, Buurman WA, Greve JW. High-fat nutrition reduces hepatic damage following exposure to bacterial DNA and hemorrhagic shock. J Hepatol 2009;50:342-350.

19. Muenzer JT, Davis CG, Dunne BS, Unsinger J, Dunne WM, Hotchkiss RS. Pneumonia after cecal ligation and puncture: a clinically relevant "two-hit" model of sepsis. Shock 2006;26:565-570.

20. Zhang Y, Li X, Carpinteiro A, Goettel JA, Soddemann M, Gulbins E. Kinase suppressor of Ras-1 protects against pulmonary Pseudomonas aeruginosa infections. Nat Med 2011.17:341-346.

21. Kreymann KG, Berger MM, Deutz NE, Hiesmayr M, Jolliet P, Kazandjiev G, Nitenberg G, van den Berghe G, Wernerman J, Ebner C et al. ESPEN Guidelines on Enteral Nutrition: Intensive care. Clin Nutr 2006;25:210-223. 
22. Martindale RG, McClave SA, Vanek VW, McCarthy M, Roberts P, Taylor B, Ochoa JB, Napolitano L, Cresci G. Guidelines for the provision and assessment of nutrition support therapy in the adult critically ill patient: Society of Critical Care Medicine and American Society for Parenteral and Enteral Nutrition: Executive Summary. Crit Care Med 2009;37:1757-1761.

23. Marik PE, Zaloga GP. Immunonutrition in critically ill patients: a systematic review and analysis of the literature. Intensive Care Med 2008;34:1980-1990.

24. Pontes-Arruda A, Martins LF, de Lima SM, Isola AM, Toledo D, Rezende E, Maia M, Magnan GB. Enteral nutrition with eicosapentaenoic acid, gamma-linolenic acid and antioxidants in the early treatment of sepsis: results from a multicenter, prospective, randomized, double-blinded, controlled study: the INTERSEPT study. Crit Care 2011;15:R144.

25. Wendel M, Paul R, Heller AR. Lipoproteins in inflammation and sepsis. II. Clinical aspects. Intensive Care Med 2007;33:25-35.

26. Stensballe J, Christiansen M, Tonnesen E, Espersen K, Lippert FK, Rasmussen LS. The early IL-6 and IL10 response in trauma is correlated with injury severity and mortality. Acta Anaesthesiol Scand 2009;53:515-521.

27. Remick DG, Bolgos GR, Siddiqui J, Shin J, Nemzek JA. Six at six: interleukin- 6 measured $6 \mathrm{~h}$ after the initiation of sepsis predicts mortality over 3 days. Shock 2002;17:463-467.

28. de Haan JJ, Lubbers T, Hadfoune M, Luyer MD, Dejong CH, Buurman WA, Greve JW. Postshock intervention with high-lipid enteral nutrition reduces inflammation and tissue damage. Ann Surg 2008;248:842-848.

29. Richardson JD, DeCamp MM, Garrison RN, Fry DE. Pulmonary infection complicating intra-abdominal sepsis: clinical and experimental observations. Ann Surg 1982;195:732-738.

30. Ocuin LM, Bamboat ZM, Balachandran VP, Cavnar MJ, Obaid H, Plitas G, DeMatteo RP. Neutrophil IL10 suppresses peritoneal inflammatory monocytes during polymicrobial sepsis. J Leukoc Biol 2011;89:423-432.

31. Takahashi H, Tsuda Y, Takeuchi D, Kobayashi M, Herndon DN, Suzuki F. Influence of systemic inflammatory response syndrome on host resistance against bacterial infections. Crit Care Med 2004;32:1879-1885.

32. Quartin AA, Schein RM, Kett DH, Peduzzi PN. Magnitude and duration of the effect of sepsis on survival. Department of Veterans Affairs Systemic Sepsis Cooperative Studies Group. JAMA 1997;277:1058-1063.

33. Aicher A, Heeschen C, Mohaupt M, Cooke JP, Zeiher AM, Dimmeler S. Nicotine strongly activates dendritic cell-mediated adaptive immunity: potential role for progression of atherosclerotic lesions. Circulation 2003;107:604-611.

34. van der Zanden EP, Snoek SA, Heinsbroek SE, Stanisor OI, Verseijden C, Boeckxstaens GE, Peppelenbosch MP, Greaves DR, Gordon S, De Jonge WJ. Vagus nerve activity augments intestinal macrophage phagocytosis via nicotinic acetylcholine receptor alpha4beta2. Gastroenterology 2009;137:1029-1039.

35. Flohe SB, Agrawal H, Flohe S, Rani M, Bangen JM, Schade FU. Diversity of interferon gamma and granulocyte-macrophage colony-stimulating factor in restoring immune dysfunction of dendritic cells and macrophages during polymicrobial sepsis. Mol Med 2008;14:247-256.

36. Corbel M, Germain N, Lanchou J, Molet S, PM ReS, Martins MA, Boichot E, Lagente V. The selective phosphodiesterase 4 inhibitor RP 73-401 reduced matrix metalloproteinase 9 activity and transforming growth factor-beta release during acute lung injury in mice: the role of the balance between Tumor necrosis factor-alpha and interleukin-10. J Pharmacol Exp Ther 2002;301:258-265.

37. Fernandes JL, de Oliveira RT, Mamoni RL, Coelho OR, Nicolau JC, Blotta MH, Serrano CV, Jr. Pentoxifylline reduces pro-inflammatory and increases anti-inflammatory activity in patients with coronary artery disease--a randomized placebo-controlled study. Atherosclerosis 2008;196:434-442.

38. Fisher CJ, Jr., Agosti JM, Opal SM, Lowry SF, Balk RA, Sadoff JC, Abraham E, Schein RM, Benjamin E. Treatment of septic shock with the tumor necrosis factor receptor:Fc fusion protein. The Soluble TNF Receptor Sepsis Study Group. N Engl J Med 1996;334:1697-1702.

39. Lorente JA, Marshall JC. Neutralization of tumor necrosis factor in preclinical models of sepsis. Shock 2005;24 Suppl 1:107-119. 
40. Dellinger RP, Levy MM, Carlet JM, Bion J, Parker MM, Jaeschke R, Reinhart K, Angus DC, Brun-Buisson C, Beale R et al. Surviving Sepsis Campaign: international guidelines for management of severe sepsis and septic shock: 2008. Crit Care Med 2008;36:296-327. 


\section{Part IV}

The nutritional anti-inflammatory reflex: preclinical human studies 


\title{
CHAPTER 11
}

Application of vagus stimulation with enriched

enteral feeding in man: selection of an optimal

\author{
nutritional composition
}

Jacco J. de Haan, Tim Lubbers, Jan-Willem M. Greve, Wim A. Buurman 


\section{Abstract}

Introduction: Dysregulated inflammation in surgical and critical care patients is associated with increased morbidity and mortality. Previously, it was shown in rodents that stimulation of a cholecystokinin (CCK)-mediated vagal anti-inflammatory reflex with lipid-rich enteral nutrition attenuates inflammation and reduces organ damage. This study assesses means to select a nutritional intervention to be used as an antiinflammatory intervention in a future human proof-of-principle study.

Methods: After an overnight fast, healthy subjects $(\mathrm{n}=12)$ received a $200 \mathrm{ml}$ or $400 \mathrm{ml}$ bolus of lipid-rich nutrition Diasip and a $200 \mathrm{ml}$ or $400 \mathrm{ml}$ bolus of the low-lipid nutrition Respifor on 4 consecutive days. Both nutritional formulas are commercially available. Subsequently, 6 healthy subjects ingested a custom-made lipid- and proteinenriched (enriched) nutrition, designed to induce intestinal CCK release, at day 1 , followed by a standard tube feed on day 2. CCK levels were determined in blood that was withdrawn before ingestion of the feeding and at indicated time points thereafter. Finally, in 6 healthy subjects, vagus nerve activity following a $200 \mathrm{ml}$ bolus of Diasip or Respifor was assessed. The level of vagus nerve signaling was determined by measuring the high frequency domain of heart rate variability (HRV).

Results: Within 15 minutes after ingestion of $200 \mathrm{ml}$ Diasip or Respifor, peak CCK plasma levels were observed $(7.0 \pm 1.1 \mathrm{pmol} / \mathrm{l}$ and $8.2 \pm 2.0 \mathrm{pmol} / \mathrm{l}$, respectively). CCK plasma levels steadily decreased afterwards, approximating the detection level at 90 minutes. No differences in the CCK plasma response were observed between Diasip and Respifor $(P=0.44)$. Doubling of the nutritional dose of Diasip and Resipfor tended to protract the CCK plasma response compared with the single dose $P=0.05$ and $P=0.06$, respectively), but resulted in similar peak plasma levels compared with the lower dose (Diasip: $8.6 \pm 1.8 \mathrm{pmol} / \mathrm{l} ; P=0.77$ and Respifor: $7.8 \pm 1.7 \mathrm{pmol} / \mathrm{l} ; P=0.98$ ). The CCK plasma response following ingestion of the custom-made enriched nutrition was identical to the standard tube feed $(P=0.99)$. Furthermore, following intake of Diasip and Respifor, no differences in vagus nerve signaling were observed (area under the curve: $P=1.00)$.

Conclusions: This study indicates that determination of CCK plasma levels and heart rate variability are ineffective tools to select a suitable nutritional composition to be used in further human studies based on activation of the vagal anti-inflammatory reflex. The finding that increasing the ingested dose resulted in a protracted CCK plasma response implicates that the intestine should be continuously exposed to nutrients in order to activate the vagus nerve. 


\section{Introduction}

Excessive inflammation in surgical, trauma and ICU patients, defined as sepsis and related syndromes, results in strongly increased morbidity and mortality ${ }^{1,2}$. Until today, modulation of the immune response during these conditions has been proven to be extremely difficult. Promising experimental interventions, usually aimed to neutralize single inflammatory mediators, failed to improve outcome in clinical trials or even aggravated the course of disease ${ }^{3,4}$.

Enteral administration of lipid-rich nutrition was recently shown to effectively attenuate inflammation and reduce tissue injury in several inflammatory rodent models, including hemorrhagic shock, endotoxemia and postoperative ileus ${ }^{5-7}$. The beneficial effects of lipid-rich nutrition were also observed when the intervention was started following hemorrhagic shock, a setting similar to trauma where inflammation and tissue injury are already present ${ }^{8}$. Ingestion of lipid-rich nutrition triggers a novel gut-brain-immune axis. In this pathway, the luminal presence of lipid results in intestinal release of cholecystokinin (CCK), which activates afferent vagal fibers via peripheral CCK-1 receptors ${ }^{9}$. Subsequent activation of the efferent vagus nerve reduces release of pro-inflammatory mediators via activation of nicotinic receptors on inflammatory cells ${ }^{10-12}$. Nutritional stimulation of the CCK-mediated vagovagal antiinflammatory reflex provides a promising and physiological approach to modulate the immune response in clinical settings and improve outcome.

The current pre-clinical study aims to identify an optimal nutritional intervention to be used during a human proof-of-principle study and future clinical interventions. Based on rodent studies that elucidated the underlying mechanism, an enriched feeding should, in comparison to a standard feeding, induce 1) enhanced CCK release and 2) increased vagus nerve activity. First, plasma CCK responses following ingestion of a commercially available lipid-rich nutrition, Diasip, and a control low-lipid nutrition, Respifor, were determined in healthy subjects. In addition, the CCK plasma response was investigated following a twofold increase in the nutritional dose. We studied also the effects of a lipid- and protein-enriched (enriched) nutrition, developed to induce intestinal release of CCK, on circulatory levels of CCK. Finally, the impact of Diasip and Respifor on vagus nerve signaling was determined by assessment of heart rate variability.

\section{Materials and methods}

\section{Subjects}

This study consisted of 2 arms: measurement of CCK plasma level and vagus nerve activity. In the CCK arm, 6 healthy male and 6 healthy female subjects between the age 
of 45 and 60 years were included. Next, 6 healthy male subjects in the age of 18-25 years underwent vagus nerve recording. Subjects with diabetes, cardiovascular disease or previous head, neck or thoracic surgery were excluded. Subjects gave written informed consent to participate in the experiments in accordance with the Declaration of Helsinki 2008. This study was registered at ClinicalTrail.gov as NCT00468507 and approved by the local ethics committee of the Maastricht University Medical Centre+.

\section{Nutritional intervention}

The nutritional intervention was performed in both study arms in a double-blind randomized setting with cross-over design. In the first part of the CCK experiments, subjects received Diasip and Respifor in a dose of $200 \mathrm{ml}$ and $400 \mathrm{ml}$ on four separate days. Next, all subjects received $200 \mathrm{ml}$ of enriched nutrition and Nutrison Standard on two days. In the second part of the study in which vagus nerve activity was assessed, subjects received Diasip and Respifor in a dose of $200 \mathrm{ml}$ on three separate days. The first day was used to get the subjects accustomed to the heart rate variability measurements and was not used for statistical analysis. On the evening prior to all experiments, subjects were deprived of food from $24.00 \mathrm{hrs}$ onwards. At $t=0$, subjects ingested $200 \mathrm{ml}$ of the liquid nutrition within one minute. During the experiments in which a total of $400 \mathrm{ml}$ was administered, subjects were asked to drink a second bolus within 1 minute at 5 minutes following the first bolus (Figure 11.1).

\begin{tabular}{llllllllllll}
\hline Time $(\min )$ & -30 & 0 & +5 & +10 & +15 & +20 & +30 & +45 & +60 & +90 \\
\hline Arm I & $\times$ & B1 & B2 & $\times$ & $\times$ & $\times$ & $x$ & $x$ & $\times$ & $x$ \\
\hline
\end{tabular}

Arm II

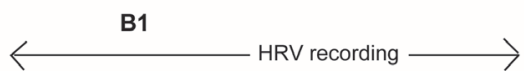

Figure 11.1 Experimental procedure. At $t=0$, subjects ingested $200 \mathrm{ml}$ (B1) of one of the nutritional compositions. In the experiments in which the effects of a double dose were assessed, subjects received a second bolus of $200 \mathrm{ml}(\mathrm{B} 2)$ at $\mathrm{t}=+5 \mathrm{~min}$. In arm I, blood samples were withdrawn at the indicated time points $(x)$ to measure CCK concentrations. In arm II, heart rate variability (HRV) was recorded from $t=-30$ min until $t=+30$ min.

\section{Feeding composition}

Table 11.1 shows the macronutrient composition of the commercially available products Diasip, Respifor and Nutrison Standard and the custom-made enriched nutrition. The fat fraction of the enriched feeding contained $10 \%$ phospholipids. The protein fraction consisted of intact casein, whey protein and soy protein hydrolysate. All nutritional compositions provided $1 \mathrm{kcal} / \mathrm{ml}$. 
Table 11.1 Macronutrient composition of the feedings

\begin{tabular}{lccc}
\hline & Fat (en\%) & Protein (en\%) & Carbohydrate (en\%) \\
\hline Diasip & 49 & 16 & 35 \\
Respifor & 20 & 20 & 60 \\
Nutrison Standard & 35 & 16 & 49 \\
Enriched & 44 & 25 & 31 \\
\hline
\end{tabular}

\section{Blood withdrawal and CCK determination}

In order to measure CCK concentrations, venous blood was withdrawn via an intravenous catheter before administration of the enteral nutrition and serially thereafter until 90 minutes (Figure 11.1). Blood was collected in pre-chilled glass tubes (BD Biosciences, Breda, the Netherlands), put on ice, centrifuged and stored at $-20^{\circ} \mathrm{C}$ until analysis. Systemic CCK levels were determined in plasma using a highly specific CCK-radioimmunoassay with a detection limit of $0.3 \mathrm{pmol} / \mathrm{I}$ (Eurodiagnostica, Malmö, Sweden). Collection tubes and micro plates were from Greiner Bio-One (Alphen a/d Rijn, the Netherlands).

\section{Heart rate variability}

Series of $R-R$ intervals were derived from continuous ECG measurement for the analysis of heart rate variability according to the guidelines of the Task Force of the European Society of Cardiology and the North American Society of Pacing and Electrophysiology ${ }^{13}$. Using the Task Force Monitor (CNSystems, Graz, Austria), frequency domain analysis of the HRV power (in ms2 or in normalized units) was computed in the high frequency (HF: $0.15-0.5 \mathrm{~Hz}$ ) and low frequency (LF: 0.04-0.15 Hz) bands based on the Welch's periodogram. The LF:HF ratio was computed as well ${ }^{13-15}$. Assessment of heart rate variability started $30 \mathrm{~min}$ before the intake of nutrition to assess baseline activity and terminated at $30 \mathrm{~min}$ post-feeding (Figure 11.1). Patients were instructed not talk or move throughout the experiments.

\section{Statistical analysis}

All values are depicted as mean \pm SEM. Two-way analysis of variance was used to detect differences between groups for serial data. Differences in serial data within groups were analyzed by one-way ANOVA with Bonferroni's post-hoc test. Heart rate variability in the HF domain is displayed as normalized units or as a percentage of baseline recordings. Prism 5.02 for Windows (GraphPad Software Inc., San Diego, CA) was used for computations. A $P$-value less than 0.05 was considered statistically significant. 


\section{Results}

\section{A bolus of a high-lipid and low-lipid commercially available nutrition result in comparable CCK plasma levels}

Circulating CCK was undetectable in all fasted subjects. Ingestion of $200 \mathrm{ml}$ of Diasip and Respifor resulted in a significant rise in CCK plasma levels over time (both $P<0.001$, Figure 11.2A). CCK levels peaked at 15 minutes following ingestion of high-lipid nutrition $(7.0 \pm 1.1 \mathrm{pmol} / \mathrm{l})$ and at 10 minutes in the low-lipid nutrition group $(8.2 \pm 2.0 \mathrm{pmol} / \mathrm{l})$. The CCK peak levels of both compositions were similar $(P=0.98)$. Following the plasma peak, circulating levels of CCK returned to baseline at 90 minutes. The plasma CCK response and area under the curve (AUC) did not differ between the two feedings ( $P=0.44$ and $P=0.84$, respectively; Figure $11.2 \mathrm{C}$ ).
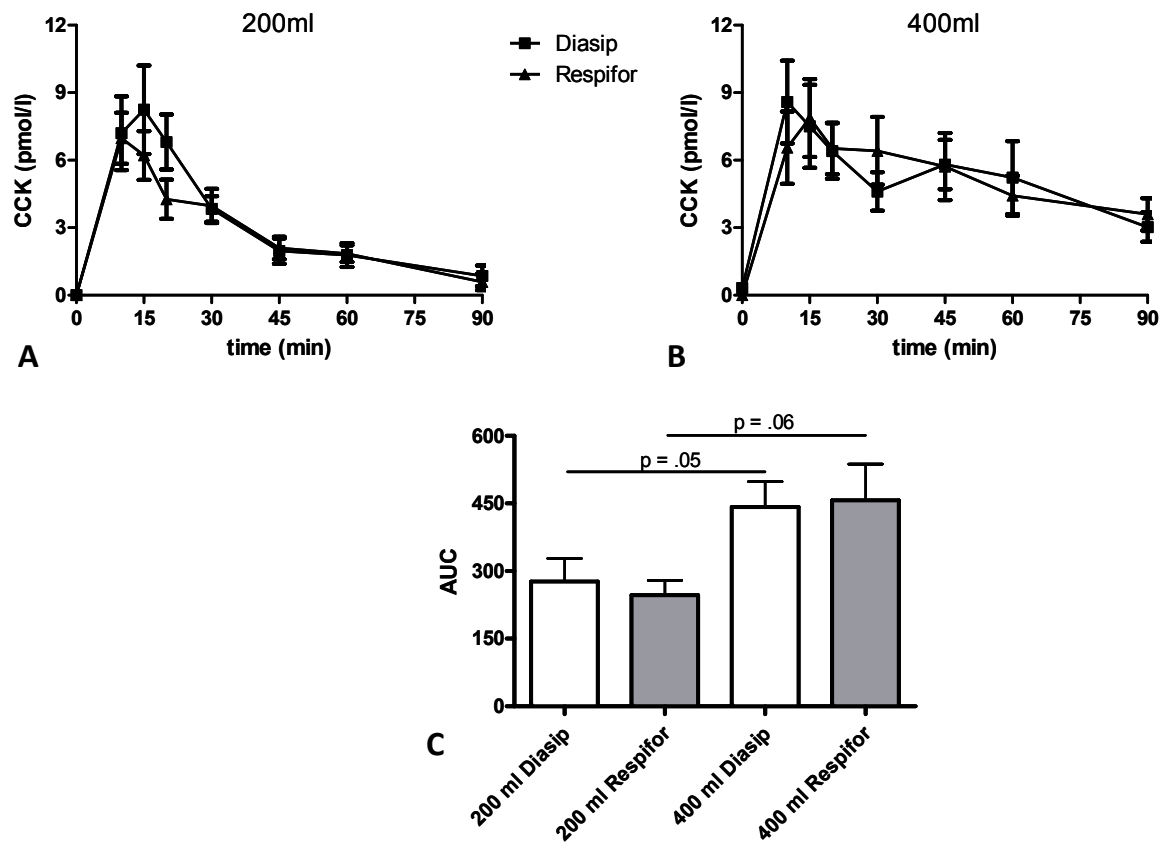

Figure 11.2 Diasip and Respifor demonstrate similar CCK plasma responses. A. CCK levels were undetectable in fasted subjects. Ingestion of $200 \mathrm{ml}$ Diasip and Respifor resulted in peak plasma levels within 15 minutes, after which the CCK levels gradually decreased. In the low volume group, CCK plasma levels approximated fasted levels at $t=90$ minutes $B$. During the high dose experiments, peak levels equaled those observed with the lower dose, while the CCK response tended to be protracted. C. No differences in plasma CCK response and AUC were observed between the lipid-rich and low-lipid nutrition, however the AUC tended to be increased in subjects receiving $400 \mathrm{ml}$ compared with $200 \mathrm{ml}$. 
Doubling the dose of both nutritional compositions did not affect peak plasma levels of CCK (Figure 11.2B). A $400 \mathrm{ml}$ dose of Diasip or Respifor resulted in similar peak plasma CCK levels compared with the $200 \mathrm{ml}$ dose of both compositions (Diasip: $8.6 \pm 1.8 \mathrm{pmol} / \mathrm{l} ; P=0.77$ and Respifor: $7.8 \pm 1.7 \mathrm{pmol} / \mathrm{l} ; P=0.98$ ). No differences in the plasma CCK response and AUC were observed between the higher dose of lipid-rich and the low-lipid nutrition ( $P=0.80$ and $P=0.78$, respectively). Increasing the dose of Diasip tended to enhance the AUC ( $P=0.05$; Figure $11.2 \mathrm{C})$. Doubling the dose of Respifor displayed a similar trend $(P=0.06)$. No gender differences in the plasma CCK response could be observed during the four different nutritional interventions (data not shown).

\section{Enriched nutrition and Nutrison Standard exhibit a similar CCK response}

As no gender difference was observed in the plasma CCK response in the first part of the study, 6 male subjects were included in a subsequent experiment. Peak CCK plasma levels of $7.1 \pm 1.6 \mathrm{pmol} / \mathrm{l}$ for the specifically designed enriched nutrition and $7.4 \pm 1.7 \mathrm{pmol} / \mathrm{l}$ for Nutrison Standard were observed at $10 \mathrm{~min}$ following administration $(P=0.82$; Figure 11.3A). Both feeding compositions displayed an identical plasma CCK response and AUC $(P=0.99$ and $P=0.42$, respectively; Figure 11.3B).
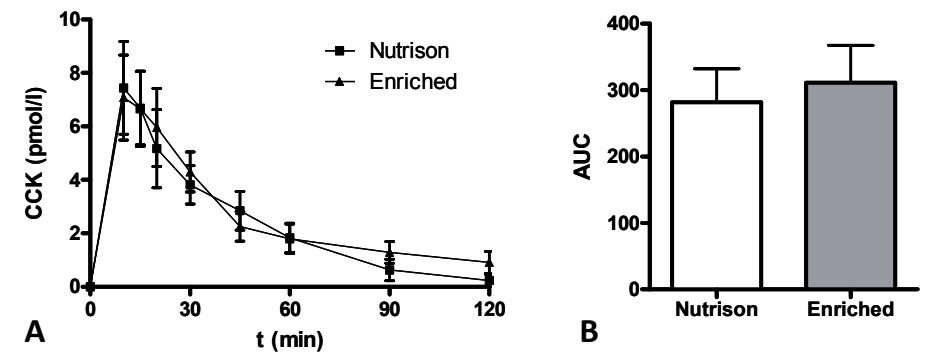

Figure 11.3 No differences are observed in the plasma CCK response following Nutrison Standard and Enriched nutrition. A. Ingestion of enriched nutrition and Nutrison Standard resulted in similar peak plasma CCK levels at 10 minutes. Next, CCK levels steadily dropped. No differences in CCK plasma response (A) and AUC (B) were demonstrated following ingestion of enriched nutrition and Nutrison Standard. 


\section{No differences in vagus nerve signaling are recorded following a high- lipid or a low-lipid nutrition}

Frequency domain measures of the heart rate variability were used to assess sympathetic and parasympathetic activity. Activity in the high frequency (HF) domain, indicating parasympathetic activity, was not significantly different following the intake of Diasip and Respifor (Figure 11.4A,B). Also the activity in the low frequency, representing both sympathetic and parasympathetic activity, and the HF: LF ratio did not differ between feedings (data not shown). Next, the post-nutritional activity in the HF domain was compared with pre-nutritional levels. Again, no differences were observed between Diasip and Respifor (Figure 11.4C).
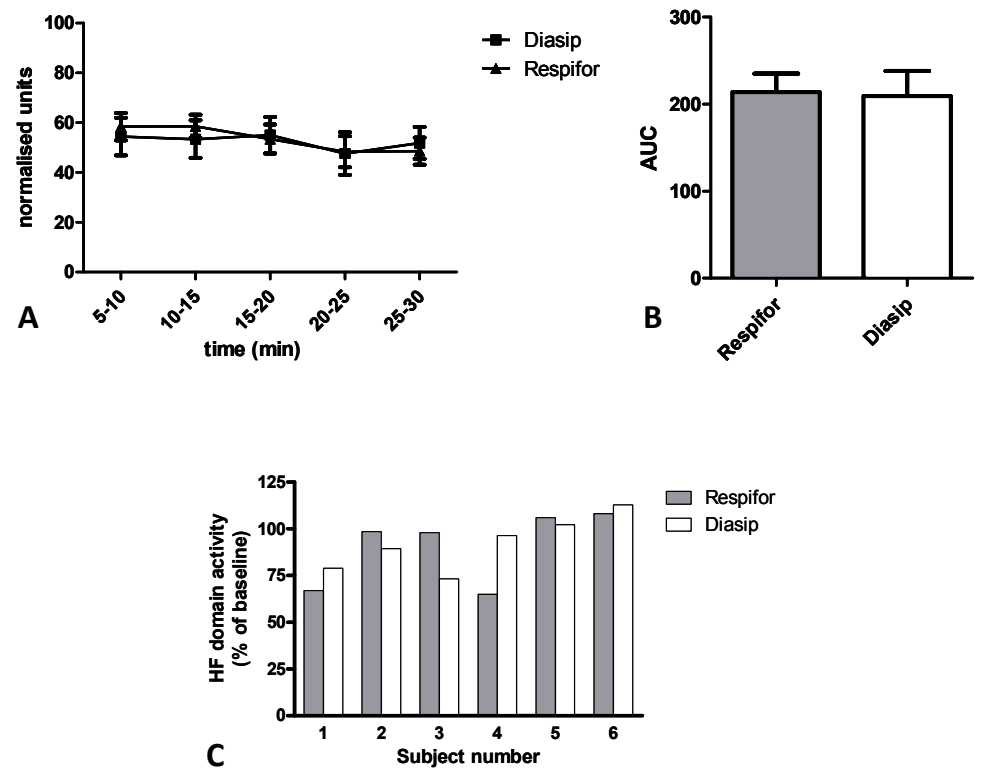

Figure 11.4 Parasympathetic activity following Diasip and Respifor is similar. A,B. No differences were observed in the high frequency domain of HRV variability, representing vagus nerve activity, between 6 and 30 min following the intake of either Diasip or Respifor. C. Also compared to pre-nutritional levels of activity in the high frequency domain, the parasympathetic activity between 6 and 30 min after intake of Diasip and Respifor did not differ.

\section{Discussion}

Rodent studies from our group demonstrated that the protective effects of lipid-rich nutrition are mediated by CCK-mediated stimulation of the vagus nerve ${ }^{8-10}$. This study aimed to select a nutritional intervention to be used in further studies in man by 
measuring CCK levels and vagus nerve activity following diverse nutritional interventions.

Unfortunately, local intestinal CCK levels cannot be analyzed in the human setting. Therefore, the CCK plasma response following ingestion of various nutritional compositions was determined as a surrogate marker for intestinal CCK release. Whereas plasma CCK levels are undetectable in rats and mice (unpublished data), plasma CCK levels in humans are known to be readily detectable following ingestion of nutrients ${ }^{16,17}$. In rodents, our group demonstrated that lipid-rich nutrition displayed a superior anti-inflammatory potential compared with low-lipid nutrition ${ }^{6}$. Therefore, in the first set of human experiments, the CCK plasma response was investigated following ingestion of Diasip and Respifor, as these nutritional compositions are akin to the high-lipid and low-lipid rodent feedings regarding fat, protein and carbohydrate content. In line with previous reports, plasma CCK levels peaked within 15 minutes following administration of Diasip and Respifor and returned to baseline within 90 minutes ${ }^{18-20}$. However, in our studies, no difference in circulating CCK levels was observed following ingestion of the two feedings. Remarkably, in a subsequent experiment, even the custom-made enriched nutrition displayed similar plasma CCK responses compared with Nutrison Standard. This enriched nutrition contained a high lipid content supplemented with phospholipids and a high protein content containing hydrolyzed protein and whey protein. This composition and these specific components are known to induce $C C K$ release in $\operatorname{man}^{21-23}$. The current data suggest that oral ingestion of isocaloric mixed meals with different macronutrient compositions likely results in comparable CCK plasma responses. In accordance with our findings, Maffeis et al. demonstrated that ingestion of a high-fat mixed meal of which $52 \%$ were lipids and a low-fat mixed meal of which $27 \%$ were lipids resulted in equivalent CCK plasma levels ${ }^{16}$. As all macronutrients induce CCK release to a certain extent in $\operatorname{man}^{17,24}$, we hypothesize that differences in macronutrient content in a mixed meal should be larger to induce differences in CCK plasma levels. In line, Pilichiewicz et al demonstrated that a threefold increase of lipid infusion significantly enhanced CCK plasma levels compared with the lower lipid concentration ${ }^{17,25}$. As the differences in lipid load between feedings in their experiment were comparable with the lipid load differences between Diasip and Respifor in our study, the absence of a statistical difference in the CCK response in our study may be attributed to the additional presence of proteins and carbohydrates in the investigated compositions.

In the current experimental approach, the plasma CCK response is also influenced by the phenomenon of gastric emptying. Gastric emptying, which is predominantly mediated via CCK, is the rate limiting step in the transport of nutrients from the stomach to the duodenum ${ }^{26-28}$. In our study, this is most likely visualized by the prolonged CCK plasma response following the $400 \mathrm{ml}$ dose of Diasip and Respifor. In 
these experiments, peak levels of CCK were similar compared with the lower dose, while the plasma CCK response was protracted. These data suggest that the amounts of nutrition that directly enter the duodenum is similar between the high and low dose, but the luminal exposure to nutrients is prolonged following the high dose. Moreover, these findings imply that the CCK-driven gastric emptying dictates CCK peak levels and subsequent plasma response following oral ingestion of nutrients. In accordance, it has been demonstrated that the duration of duodenal nutrient exposure determines the CCK plasma response ${ }^{17,25}$. Consequently, continuous intraduodenal administration of nutrients is an attractive means to bypass gastric emptying, maintain a high and protracted CCK plasma response and effectively stimulate the CCK/CCK-1 receptor mediated vagal anti-inflammatory pathway.

Based on CCK plasma levels, a suitable nutritional composition to be used in a human study could not be identified in the current study. However, circulating CCK levels might not reflect local intestinal CCK levels and subsequent activation of the nutritional pathway via vagal afferents, as the CCK peptide is rapidly inactivated in plasma ${ }^{29,30}$. Moreover, we have recently shown that activation of glucagon-like peptide-1 (GLP-1) receptors is also involved in the nutritional anti-inflammatory reflex ${ }^{31}$. In addition, other intestinal peptides might play a role $\mathrm{r}^{32,33}$.

Next to CCK concentration measurement, also heart rate variability was applied as a biomarker to identify a nutritional intervention that optimally stimulates the vagal anti-inflammatory reflex ${ }^{34}$. Heart rate variability analysis is a well-established and noninvasive means to assess autonomic nervous system functionality ${ }^{35}$. Heart rate variability has been related to inflammatory markers in health and disease ${ }^{36,37}$. Since age and BMI are inversely related to heart rate variability, this study was performed with young volunteers having a normal posture ${ }^{38,39}$. As also sex was shown to influence heart rate variability parameters in young people, only men were included ${ }^{38-41}$. The Task Force of the European Society of Cardiology and the North American Society of Pacing and Electrophysiology has stated that measurements should at least take 20 minutes in order to obtain reproducible data ${ }^{13}$. In our experiments, baseline recording lasted between 30 minutes before nutrition was given until 30 minutes after food intake. Since circulatory CCK was measured as soon as 10 minutes postprandially and the vagus nerve is stimulated as a direct response to locally released CCK, the supposed peak of vagus nerve signaling is likely to occur within $30 \mathrm{~min}$ after nutrient ingestion. The one hour period of vagus nerve measurement prevents the development of uncomfortable feelings that are reported during prolonged measurement that may affect the vago-sympathetic balance ${ }^{42}$. To avoid stress and get the subjects accustomed to the experimental setting of vagus nerve measurement, the first testing day was not used for analysis. Throughout the experiments, disturbance of the vagus nerve activity was reduced by instructing patients not to move or talk ${ }^{13,41}$. 
The pilot study described in the current thesis did not show significant differences following a bolus of Diasip or Respifor. Neither in the high frequency domain, representing parasympathetic activity, nor in the low frequency domain, representing both sympathetic and parasympathetic activity nor in the LF:HF ratio, a trend towards difference between feedings was observed. Apart from the possibility that the feedings in the doses given activate the vagal anti-inflammatory reflex to a similar extent, other factors may account for the lack of discrimination between feedings. The experimental setting was standardized as much as possible, however, in this study the respiration was not synchronized. Whereas many heart rate variability studies are performed in settings of uncontrolled normal breathing, some authors state that the respiration has to be standardized in order to improve the recording of parasympathetic activity ${ }^{42,43}$. Furthermore, it can not be ruled out that the branches that innervate the heart and modulate heart rate variability are different from the bundles that innervate the reticulo-endothelial system ${ }^{44}$. Indeed, vagal effects on the heart and anti-inflammatory effects were previously shown to be discernible ${ }^{34}$.

In conclusion, this study shows that measurement of circulatory CCK levels and heart rate variability can not be readily used to select nutritional interventions for human studies based on activation of the vagal anti-inflammatory reflex. Considering the finding that increasing the nutritional dose results in a protracted CCK response, postpyloric administration of a lipid- and protein-enriched nutrition is proposed as a feasible approach to induce prolonged stimulation of vagal signaling in humans. 


\section{References}

1. Riedemann NC, Guo RF, Ward PA. Novel strategies for the treatment of sepsis. Nat Med 2003;9: 517-524.

2. Angus DC, Linde-Zwirble WT, Lidicker J, Clermont G, Carcillo J, Pinsky MR. Epidemiology of severe sepsis in the United States: analysis of incidence, outcome, and associated costs of care. Crit Care Med 2001;29:1303-1310.

3. Fisher CJ, Jr., Dhainaut JF, Opal SM, Pribble JP, Balk RA, Slotman GJ, Iberti TJ, Rackow EC, Shapiro MJ, Greenman RL et al. Recombinant human interleukin 1 receptor antagonist in the treatment of patients with sepsis syndrome. Results from a randomized, double-blind, placebo-controlled trial. Phase III rhIL1ra Sepsis Syndrome Study Group. JAMA 1994;271:1836-1843.

4. Fisher CJ, Jr., Agosti JM, Opal SM, Lowry SF, Balk RA, Sadoff JC, Abraham E, Schein RM, Benjamin E. Treatment of septic shock with the tumor necrosis factor receptor:Fc fusion protein. The Soluble TNF Receptor Sepsis Study Group. N Engl J Med 1996;334:1697-1702.

5. Lubbers T, Luyer MD, de Haan JJ, Hadfoune M, Buurman WA, Greve JW. Lipid-rich enteral nutrition reduces postoperative ileus in rats via activation of cholecystokinin-receptors. Ann Surg 2009; 249:481-487.

6. Lubbers T, De Haan JJ, Hadfoune M, Zhang Y, Luyer MD, Grundy D, Buurman WA, Greve JW. Lipidenriched enteral nutrition controls the inflammatory response in murine Gram-negative sepsis. Crit Care Med 2010;38:1996-2002.

7. de Haan JJ, Thuijls G, Lubbers T, Hadfoune M, Reisinger K, Heineman E, Greve JW, Buurman WA. Protection against early intestinal compromise by lipid-rich enteral nutrition through cholecystokinin receptors. Crit Care Med 2010;38:1592-1597.

8. de Haan JJ, Lubbers T, Hadfoune M, Luyer MD, Dejong CH, Buurman WA, Greve JW. Postshock intervention with high-lipid enteral nutrition reduces inflammation and tissue damage. Ann Surg 2008; 248:842-848.

9. Lubbers T, de Haan JJ, Luyer MD, Verbaeys I, Hadfoune M, Dejong CH, Buurman WA, Greve JW. Cholecystokinin/Cholecystokinin-1 receptor-mediated peripheral activation of the afferent vagus by enteral nutrients attenuates inflammation in rats. Ann Surg 2010;252:376-382.

10. Luyer MD, Greve JW, Hadfoune M, Jacobs JA, Dejong CH, Buurman WA. Nutritional stimulation of cholecystokinin receptors inhibits inflammation via the vagus nerve. J Exp Med 2005;202:1023-1029.

11. Wang H, Yu M, Ochani M, Amella CA, Tanovic M, Susarla S, Li JH, Yang H, Ulloa L, Al-Abed Y et al. Nicotinic acetylcholine receptor alpha7 subunit is an essential regulator of inflammation. Nature 2003; 421:384-388.

12. Borovikova LV, Ivanova S, Zhang M, Yang H, Botchkina GI, Watkins LR, Wang H, Abumrad N, Eaton JW, Tracey KJ. Vagus nerve stimulation attenuates the systemic inflammatory response to endotoxin. Nature 2000;405:458-462.

13. Heart rate variability. Standards of measurement, physiological interpretation, and clinical use. Task Force of the European Society of Cardiology and the North American Society of Pacing and Electrophysiology. Eur Heart J 1996;17:354-381.

14. Hayano J, Sakakibara Y, Yamada A, Yamada M, Mukai S, Fujinami T, Yokoyama K, Watanabe Y, Takata K. Accuracy of assessment of cardiac vagal tone by heart rate variability in normal subjects. Am J Cardiol 1991;67:199-204.

15. Malliani A, Pagani M, Lombardi F, Cerutti S. Cardiovascular neural regulation explored in the frequency domain. Circulation 1991;84:482-492.

16. Maffeis C, Surano MG, Cordioli S, Gasperotti S, Corradi M, Pinelli L. A high-fat vs. a moderate-fat meal in obese boys: nutrient balance, appetite, and gastrointestinal hormone changes. Obesity (Silver Spring) 2010;18:449-455.

17. Pilichiewicz AN, Little TJ, Brennan IM, Meyer JH, Wishart JM, Otto B, Horowitz M, Feinle-Bisset C. Effects of load, and duration, of duodenal lipid on antropyloroduodenal motility, plasma CCK and PYY, and energy intake in healthy men. Am J Physiol Regul Integr Comp Physiol 2006;290:R668-677.

18. Niederau C, Schwarzendrube J, Luthen R, Niederau M, Strohmeyer G, Rovati L. Effects of cholecystokinin receptor blockade on circulating concentrations of glucose, insulin, C-peptide, and pancreatic polypeptide after various meals in healthy human volunteers. Pancreas 1992;7:1-10. 
19. Liddle RA, Goldfine ID, Rosen MS, Taplitz RA, Williams JA. Cholecystokinin bioactivity in human plasma. Molecular forms, responses to feeding, and relationship to gallbladder contraction. J Clin Invest 1985; 75:1144-1152.

20. Liddle RA, Morita ET, Conrad CK, Williams JA. Regulation of gastric emptying in humans by cholecystokinin. J Clin Invest 1986;77:992-996.

21. Hall WL, Millward DJ, Long SJ, Morgan LM. Casein and whey exert different effects on plasma amino acid profiles, gastrointestinal hormone secretion and appetite. Br J Nutr 2003;89:239-248.

22. Nishimukai $M$, Hara $H$, Aoyama $\mathrm{Y}$. The addition of soybean phosphatidylcholine to triglyceride increases suppressive effects on food intake and gastric emptying in rats. J Nutr 2003;133:1255-1258.

23. Foltz M, Ansems P, Schwarz J, Tasker MC, Lourbakos A, Gerhardt CC. Protein hydrolysates induce CCK release from enteroendocrine cells and act as partial agonists of the CCK1 receptor. J Agric Food Chem 2008;56:837-843.

24. Karhunen $L$, Juvonen KR, Huotari A, Purhonen AK, Herzig KH. Effect of protein, fat, carbohydrate and fibre on gastrointestinal peptide release in humans. Regul Pept 2008;149:70-78.

25. Pilichiewicz AN, Papadopoulos P, Brennan IM, Little TJ, Meyer JH, Wishart JM, Horowitz M, FeinleBisset C. Load-dependent effects of duodenal lipid on antropyloroduodenal motility, plasma CCK and PYY, and energy intake in healthy men. Am J Physiol Regul Integr Comp Physiol 2007;293:R2170-2178.

26. Edelbroek M, Horowitz M, Maddox A, Bellen J. Gastric emptying and intragastric distribution of oil in the presence of a liquid or a solid meal. J Nucl Med 1992;33:1283-1290.

27. Little TJ, Russo A, Meyer JH, Horowitz M, Smyth DR, Bellon M, Wishart JM, Jones KL, Feinle-Bisset C. Free fatty acids have more potent effects on gastric emptying, gut hormones, and appetite than triacylglycerides. Gastroenterology 2007;133:1124-1131.

28. Fried M, Erlacher U, Schwizer W, Lochner C, Koerfer J, Beglinger C, Jansen JB, Lamers CB, Harder F, Bischof-Delaloye $A$ et al. Role of cholecystokinin in the regulation of gastric emptying and pancreatic enzyme secretion in humans. Studies with the cholecystokinin-receptor antagonist loxiglumide. Gastroenterology 1991;101:503-511.

29. Koulischer D, Moroder L, Deschodt-Lanckman M. Degradation of cholecystokinin octapeptide, related fragments and analogs by human and rat plasma in vitro. Regul Pept 1982;4:127-139.

30. Greenberg D, Smith GP, Gibbs J: Infusion of CCK-8 into hepatic-portal vein fails to reduce food intake in rats. Am J Physiol 1987;252:R1015-1018.

31. Lubbers T, de Haan JJ, Hadfoune M, Zabeau L, Tavernier J, Zhang Y, Grundy D, Greve JW, Buurman WA. Chylomicron formation and glucagon-like peptide 1 receptor are involved in activation of the nutritional anti-inflammatory pathway. J Nutr Biochem 2011;22:1105-1111.

32. Dockray GJ. Cholecystokinin and gut-brain signalling. Regul Pept 2009;155:6-10.

33. Beglinger S, Drewe J, Schirra J, Goke B, D'Amato M, Beglinger C. Role of fat hydrolysis in regulating glucagon-like Peptide-1 secretion. J Clin Endocrinol Metab 2010;95:879-886.

34. Huston JM, Tracey KJ. The pulse of inflammation: heart rate variability, the cholinergic antiinflammatory pathway and implications for therapy. J Intern Med 2011;269:45-53.

35. Eckberg DL. Sympathovagal balance: a critical appraisal. Circulation 1997;96:3224-3232.

36. Sloan RP, McCreath H, Tracey KJ, Sidney S, Liu K, Seeman T. RR interval variability is inversely related to inflammatory markers: the CARDIA study. Mol Med 2007;13:178-184.

37. Thayer JF, Fischer JE. Heart rate variability, overnight urinary norepinephrine and C-reactive protein: evidence for the cholinergic anti-inflammatory pathway in healthy human adults. J Intern Med 2009; 265:439-447.

38. Bonnemeier H, Richardt G, Potratz J, Wiegand UK, Brandes A, Kluge N, Katus HA. Circadian profile of cardiac autonomic nervous modulation in healthy subjects: differing effects of aging and gender on heart rate variability. J Cardiovasc Electrophysiol 2003;14:791-799.

39. Ramaekers D, Ector H, Aubert AE, Rubens A, Van de Werf F. Heart rate variability and heart rate in healthy volunteers. Is the female autonomic nervous system cardioprotective? Eur Heart J 1998; 19:1334-1341.

40. Huikuri HV, Pikkujamsa SM, Airaksinen KE, Ikaheimo MJ, Rantala AO, Kauma H, Lilja M, Kesaniemi YA. Sex-related differences in autonomic modulation of heart rate in middle-aged subjects. Circulation 1996;94:122-125.

41. Zhang J. Effect of age and sex on heart rate variability in healthy subjects. J Manipulative Physiol Ther 2007;30:374-379. 
42. Flanagan DE, Vaile JC, Petley GW, Phillips DI, Godsland IF, Owens P, Moore VM, Cockington RA, Robinson JS. Gender differences in the relationship between leptin, insulin resistance and the autonomic nervous system. Regul Pept 2007;140:37-42.

43. Agelink MW, Malessa R, Baumann B, Majewski T, Akila F, Zeit T, Ziegler D. Standardized tests of heart rate variability: normal ranges obtained from 309 healthy humans, and effects of age, gender, and heart rate. Clin Auton Res 2001;11:99-108.

44. de Haan JJ, Lubbers T, Greve JW, Buurman WA. Exploring the link between inflammation and the vagus nerve. J Intern Med 2010;267:130-131. 


\title{
CHAPTER 12
}

\section{Exploring the link between inflammation}

\author{
and the vagus nerve
}

Jacco J. de Haan, Tim Lubbers, Jan-Willem M. Greve, Wim A. Buurman

J Intern Med. 2010;267:130-131 
With great interest we read the recent report of Thayer and Fischer in the November online edition of the Journal of Internal Medicine. They showed an inverse association between indices of vagally mediated heart rate variability and sub-clinical plasma levels of CRP, a predictor of cardiovascular morbidity and mortality ${ }^{1}$. This association was present also after controlling for confounders as sympathetic nervous activity. In contrast to previous studies on the relation between the vagus nerve and inflammation, Thayer and Fischer investigated a healthy population ${ }^{2-4}$. As a consequence, the current findings expand the potential applicability of vagus nerve modulation to pre-clinical settings.

A growing number of experimental studies identifies the efferent vagus nerve as a potent physiological modulator of the immune system. This signaling pathway may have direct clinical implications, as in various experimental studies electrical, pharmacological and nutritional activation of the so-called cholinergic antiinflammatory pathway attenuated the inflammatory response $e^{2,5,6}$. These findings fit in our expanding knowledge of the complex mechanisms by which the brain monitors and modulates diverse physiological processes ${ }^{7}$. However, communication between the central nervous system and peripheral organs is bidirectional. The brain is continuously fuelled with a plethora of signals from the whole body. Notably the peripheral presence of inflammatory mediators affects brain function ${ }^{8}$. Therefore, it may well be that processes that underlie elevated levels of circulatory inflammation markers are not merely a result but also a cause of a chronically altered sympathetic / parasympathetic balance.

Measurement of the heart rate variability is an interesting tool to assess vagal activity in man. However, we should bear in mind that the vagus nerve consists of a large number of nerve bundles with diverse effects on various organs. Therefore, it remains to be elucidated to which extent vagally mediated heart rate variability represents activation of the vagus bundles that control inflammation via the cholinergic pathway. Taken together, the study of Thayer and Fischer raises intriguing questions about vagal control over inflammation that ask for further exploration. Hopefully, increased insight in this field will lead to a clinically feasible application of vagus nerve modulation to control or prevent inflammatory diseases. 


\section{References}

1. Thayer JF, Fischer JE. Heart rate variability, overnight urinary norepinephrine and C-reactive protein: evidence for the cholinergic anti-inflammatory pathway in healthy human adults. J Intern Med 2009; 265:439-447.

2. Borovikova LV, Ivanova $\mathrm{S}$, Zhang $\mathrm{M}$ et al. Vagus nerve stimulation attenuates the systemic inflammatory response to endotoxin. Nature 2000;405:458-462.

3. Sloan RP, McCreath H, Tracey KJ, Sidney S, Liu K, Seeman T. RR interval variability is inversely related to inflammatory markers: the CARDIA study. Mol Med 2007;13:178-184.

4. Goldstein RS, Bruchfeld A, Yang L et al. Cholinergic anti-inflammatory pathway activity and High Mobility Group Box-1 (HMGB1) serum levels in patients with rheumatoid arthritis. Mol Med 2007;13: 210-215.

5. Pavlov VA, Ochani M, Yang LH et al. Selective alpha7-nicotinic acetylcholine receptor agonist GTS-21 improves survival in murine endotoxemia and severe sepsis. Crit Care Med 2007;35:1139-1144.

6. Luyer MD, Greve JW, Hadfoune M, Jacobs JA, Dejong $\mathrm{CH}$, Buurman WA. Nutritional stimulation of cholecystokinin receptors inhibits inflammation via the vagus nerve. J Exp Med 2005; 202: 1023-1029.

7. Sternberg EM. Neural regulation of innate immunity: a coordinated nonspecific host response to pathogens. Nat Rev Immunol 2006;6:318-328.

8. Watkins LR, Maier SF. Immune regulation of central nervous system functions: from sickness responses to pathological pain. J Intern Med 2005;257:139-155. 


\section{CHAPTER 13}

Continuous administration of enteral lipid-and protein-rich nutrition limits inflammation in a human endotoxemia model

Tim Lubbers, Matthijs Kox, Jacco J. de Haan, Jan-Willem Greve, Jan C. Pompe, Bart P. Ramakers, Peter Pickkers, Wim A. Buurman 


\section{Abstract}

Introduction: An overzealous inflammatory response is an important cause of morbidity and mortality in surgical, trauma and critically ill patients. Enteral administration of lipid-rich nutrition was previously shown to attenuate inflammation and reduce organ damage via a cholecystokinin-1 receptor mediated vagovagal reflex in animal studies. The current pre-clinical study investigates the immunomodulatory potential of a custom-made enteral nutrition during systemic inflammation in man.

Methods: After an overnight fast, 18 healthy male volunteers received an intravenous bolus of Escherichia coli lipopolysaccharide (LPS; $2 \mathrm{ng} / \mathrm{kg}$ ). Subjects in the fasted group $(n=6)$ were deprived of food throughout the study, while subjects in the intervention groups were fed either custom-made lipid- and protein-rich nutrition $(n=6)$ or isocaloric control nutrition $(n=6)$ via nasojejunal tube, starting 1 hour prior to LPS administration until 6 hours afterwards. This double-blind randomized controlled trial was performed at an intensive care research unit.

Results: Bolus LPS administration resulted in a marked inflammatory response. Continuous postpyloric administration of nutrition significantly increased plasma cholecystokinin levels throughout the LPS-induced inflammatory response. Lipid- and protein-rich nutrition attenuated circulating levels of the pro-inflammatory cytokines TNF- $\alpha$ and IL- 6 and the IL-1 receptor antagonist compared with control nutrition (all: $P<0.05$ ) and fasted subjects (all: $P<0.05$ ). Additionally, lipid- and protein-rich nutrition augmented the anti-inflammatory response, reflected by increased plasma levels of IL-10 compared with fasted subjects $(P<0.0001)$.

Conclusions: The current pre-clinical study expands the immunomodulating effects of enteral nutrition as previously observed in rodents to man. Continuous administration of enteral nutrition resulted in a rapid anti-inflammatory effect. Moreover, enrichment of the nutritional composition with lipid and protein was shown to enhance the antiinflammatory potential. Therefore, continuous enteral administration of lipid- and protein-rich nutrition is a promising intervention to modulate the immune response in the early course of systemic inflammation in man. 


\section{Introduction}

Despite diagnostic and therapeutic advances in medical care, a dysregulated systemic inflammatory response remains a major complication in surgical, trauma and critically ill patients, leading to increased morbidity and mortality ${ }^{1,2}$. Modulation of the early excessive inflammatory response represents a potential therapeutic option to improve outcome $^{3}$. Although experimental studies demonstrated promising results of interventions aimed at inhibition of single pro-inflammatory mediators, clinical implementation has failed to be successful ${ }^{4}$. Enhanced insight in disease pathology and development of novel treatment modalities which broadly affect the inflammatory response are warranted to reduce morbidity and mortality ${ }^{5-7}$.

Previously, our group demonstrated in rodents that enteral administration of lipid-rich nutrition attenuates inflammation and reduces organ damage via a hard-wired pathway $^{8}$. The luminal presence of lipid-rich nutrition triggers a vagal reflex via peripheral CCK-1 receptors, that reduces local and systemic inflammation and decreases organ damage through activation of peripheral nicotinic acetylcholine receptors on inflammatory cells ${ }^{8-11}$. Well-timed nutritional stimulation of this novel gut-brain-immune axis could be a promising intervention to prevent or even treat overzealous inflammation in the clinical setting, as lipid-rich nutrition was also shown to control the immune response and reduce organ damage when administered after the inflammatory trigger ${ }^{9}$. Therefore, the aim of the current pre-clinical study was to investigate the anti-inflammatory potential of a nutritional intervention, specifically designed to result in a marked and prolonged CCK-release, in man. Based on observations that predominantly enteral lipids and proteins trigger CCK release ${ }^{12}$, continuous postpyloric administration of a custom-made lipid- and protein-rich nutrition was compared to an isocaloric low-lipid and low-protein control nutrition and to fasted subjects. The effect of lipid- and protein-rich nutrition on acute inflammation was studied in a model of human endotoxemia ${ }^{13}$. Furthermore, the influence of lipidand protein-rich nutrition on endotoxin-induced sub-clinical intestinal damage was investigated.

\section{Materials and methods}

\section{Subjects}

This study was registered at ClinicalTrial.gov (NCT01100996). After approval of the ethics committee of the University Medical Centre Nijmegen, 12 healthy male subjects gave written informed consent to participate in the experiments in accordance with the Declaration of Helsinki. Samples of fasted subjects $(n=6)$ were obtained from the placebo-group that participated in another double-blind LPS study performed in 
parallel (NCT00513110). There were no differences in subject characteristics (Table 13.1). All subjects tested negative for HIV and hepatitis B. The subjects did not have any febrile illness or use any medications in the two weeks preceding the study.

Table 13.1 Subject characteristics

\begin{tabular}{lcccc}
\hline & Fasted & Enriched & Control & $P$-value between groups \\
\hline Age $(\mathrm{y})$ & $24 \pm 1$ & $23 \pm 1$ & $25 \pm 2$ & 0.30 \\
BMI $\left(\mathrm{kg} / \mathrm{cm}^{2}\right.$ ) & $22.0 \pm 0.7$ & $23.0 \pm 0.6$ & $23.1 \pm 0.9$ & 0.60 \\
BMR (kcal) & $2822 \pm 44$ & $2845 \pm 79$ & $3020 \pm 137$ & 0.22 \\
Rate of infusion (kcal/min) & NA & $2.0 \pm 0.1$ & $2.1 \pm 0.1$ & 0.31 \\
\hline
\end{tabular}

Data are represented as mean \pm SEM. NA, not applicable.

\section{Experimental human endotoxemia}

Subjects were prehydrated with $1.5 \mathrm{~L}$ glucose $2.5 \% / \mathrm{NaCl} 0.45 \%$ after which they received an intravenous bolus of $2 \mathrm{ng} / \mathrm{kg}$ body weight U.S. reference $E$. coli endotoxin (Escherichia coli 0:113, Clinical Center Reference Endotoxin, National Institute of Health, Bethesda, MD) within one minute ${ }^{14}$. The pre-hydration protocol was issued by the local ethics committee to reduce the risk of endotoxin-induced hypovolemia. LPSinduced symptoms were rated using grades ranging from 0 (no symptoms) to 5 (most severe ever experienced), resulting in a cumulative sickness score ${ }^{15}$. Blood was drawn before the start of postpyloric feeding and serially thereafter up to 24 hours after LPS administration (Figure 13.1). Routine hematology parameters were determined using flow cytometry (Sysmex XE-2100; Goffin Meyvis, Etten-Leur, the Netherlands).

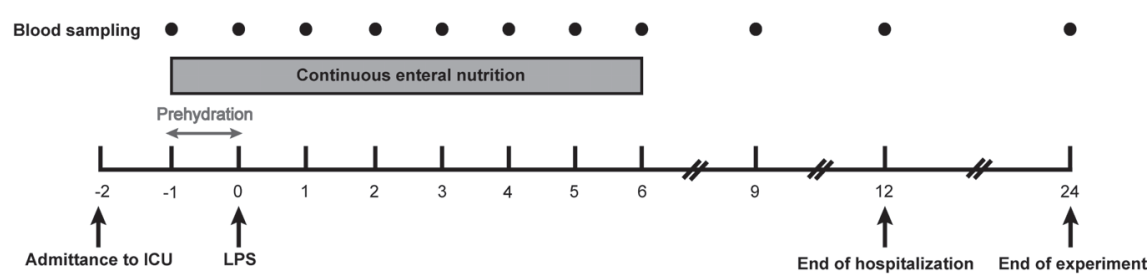

Figure 13.1 Experimental design. Subjects were admitted to the intensive care unit (ICU) after an overnight fast. One hour prior to LPS administration, subjects were pre-hydrated and the continuous administration of enteral nutrition commenced in the nutritional intervention groups, lasting until six hours after LPS administration. Blood was drawn at several time points during the experiment. Subjects left the hospital 12 hours after intravenous administration of LPS and returned the day after for final blood sampling. 


\section{Postpyloric feeding}

On the experimental day, two groups received a nutritional intervention in a doubleblind randomized fashion, while one group was fasted during the entire experiment (all groups: $n=6$ ). The nutritional intervention groups received continuous postpyloric infusion with a liquid, lipid- and protein-rich nutrition or an isocaloric control nutrition for 7 hours via a self-advancing nasojejunal feeding tube (Tiger 2, Cook Medical, Bloomington, IN). No feeding was aspirated via nasogastric tube or regurgitated throughout the experiment. The rate of feeding for each subject was based on their total energy requirement (TER). TER was calculated by multiplying basal metabolic rate of each subject with their activity level (1.55 times for all subjects) using the HarrisBenedict equation (Table 13.1).

\section{Feeding composition}

The lipid- and protein-rich nutrition contained 44 energy percent (en\%) fat, $25 e n \%$ protein and 31 en $\%$ carbohydrates. The protein fraction consisted of intact casein, whey protein and soy protein hydrolysate. The control nutrition contained $20 \mathrm{en} \%$ fat, 16 en\% protein and 64 en\% carbohydrates. The lipid fraction of both feedings contained less than 5 weight percent omega-3 fatty acids. Both the lipid- and protein-rich and control nutrition provided $1 \mathrm{kcal} / \mathrm{ml}$.

\section{Determination of plasma CCK, cytokines and sub-clinical intestinal damage}

During the experiment, EDTA anticoagulated blood was collected from the arterial line and immediately centrifuged at $4^{\circ} \mathrm{C}$ to obtain plasma. Samples were stored at $-80^{\circ} \mathrm{C}$ until analysis. TNF- $\alpha$, IL-6, IL-10, and IL-1 receptor antagonists (IL-1RA) were measured batch wise in duplicate using a multiplex Luminex Assay (Millipore, Billerica, MA). Intestinal-fatty acid binding protein (i-FABP), a marker of intestinal epithelial cell damage, was determined in plasma using an in-house developed, validated and standardized ELISA ${ }^{16,17}$. Systemic CCK levels were determined in plasma using a CCKradioimmunoassay (Eurodiagnostica, Malmö, Sweden).

\section{Statistical analysis}

All values are depicted as mean \pm SEM. Two-way analysis of variance was used to detect differences between groups for serial data. Differences in serial data within groups were analyzed by one-way ANOVA with Bonferroni's post-hoc test. Data were excluded from the analysis after being identified as significant outlier using the Grubb's test (extreme studentized deviate method). The TNF- $\alpha$ values of one subject in the lipid- and protein-rich nutrition group were removed from the analysis after being 
identified as significant outlier. A $P$-value less than 0.05 was considered statistically significant.

\section{Results}

\section{Hematologic and clinical response}

As summarized in Table 13.2, administration of endotoxin resulted in changes in hematologic and clinical parameters in the fasted and nutritional intervention groups. In all groups, mean arterial blood pressure decreased from 90 minutes after LPS administration onwards $(P<0.001)$, while a compensatory rise in heart rate was observed $(P<0.001)$. Also, endotoxemia resulted in a rise in core body temperature $(P<0.001)$ and white blood cell count $(P<0.001)$ in both the fasted and nutritional intervention groups. The LPS-induced changes in hemodynamic parameters, body temperature and white blood cell count were not affected by enteral nutrition. Administration of endotoxin resulted in flu-like symptoms such as headache, nausea, vomiting, shivering and myalgia, which were expressed as sickness score. The sickness score of all subjects peaked at 90 minutes following LPS administration. Administration of lipid- and protein-rich or control nutrition did not affect the sickness score compared with fasted subjects ( $P=0.43$ and $P=0.28$, respectively).

\section{Enteral feeding with lipid- and protein-rich nutrition attenuates pro- inflammatory and augments anti-inflammatory cytokines during experimental human endotoxemia}

Intravenous administration of LPS resulted in a marked pro-inflammatory response. Treatment with lipid- and protein-rich nutrition significantly attenuated TNF- $\alpha$ levels compared with fasted $(P<0.0001)$ and control nutrition $(P<0.05$; Figure 13.2A). Lipidand protein-rich nutrition lowered peak TNF- $\alpha$ levels with $40 \pm 8 \%$ compared with fasted subjects and $29 \pm 10 \%$ compared to control nutrition. The control nutrition demonstrated a trend towards lower TNF- $\alpha$ plasma levels compared with fasted subjects $(P=0.06)$. Lipid- and protein-rich nutrition also significantly reduced IL-6 plasma concentrations during the endotoxemia protocol compared with control nutrition $(P<0.001)$ and fasting $(P<0.05$; Figure 13.2B), while the control nutrition did not affect IL-6 compared with fasted subjects $(P=0.63)$. Administration of lipid- and protein-rich nutrition attenuated peak levels of IL- 6 with $41 \pm 9 \%$ compared to fasted subjects and $54 \pm 7 \%$ compared to control nutrition. 


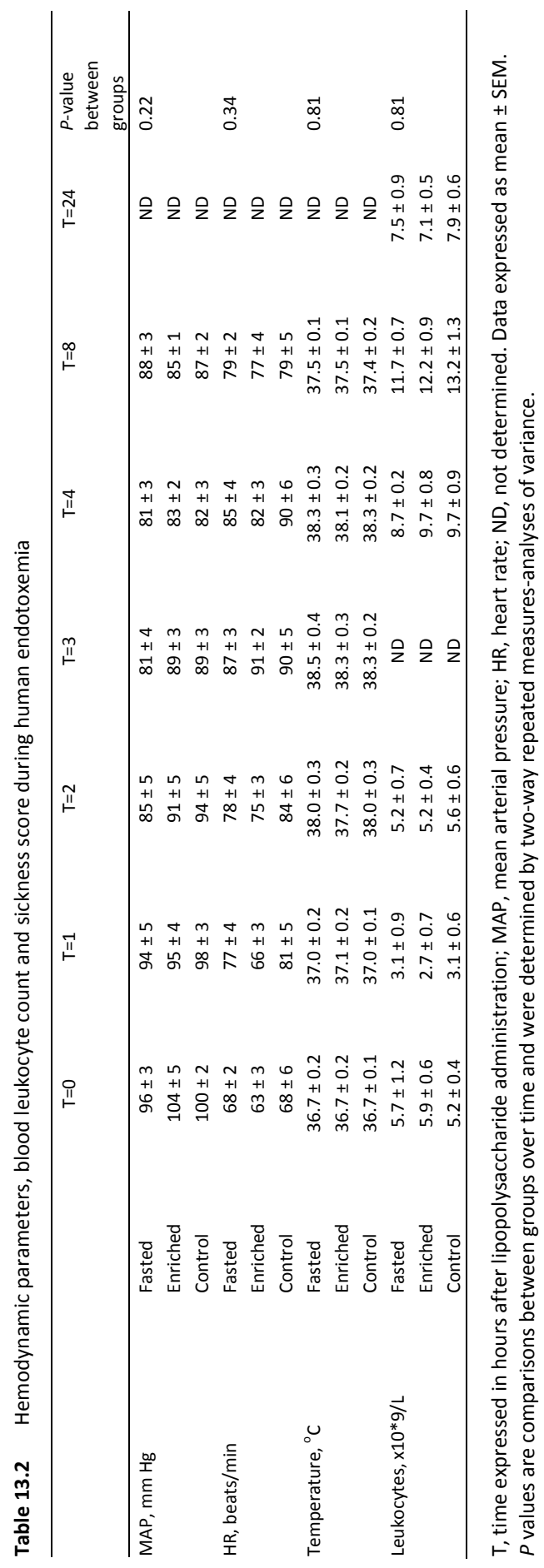


Intravenous injection of LPS is known to trigger a complex compensatory antiinflammatory response. Lipid- and protein-rich nutrition decreased circulating levels of the specific IL-1 receptor antagonist IL-1RA throughout the experiment compared with control nutrition $(P<0.0001)$ and fasting $(P<0.0001$; Figure $13.2 \mathrm{C})$. Peak levels of IL-1RA were $37 \pm 8 \%$ lower in the lipid- and protein-rich nutrition group compared with fasted subjects and $25 \pm 6 \%$ compared with control nutrition. The control nutrition did not affect IL-1 RA levels compared with fasted.

Continuous postpyloric infusion of lipid- and protein-rich nutrition resulted in elevated plasma concentrations of IL-10 over time compared with fasting $(P<0.0001)$, while the control nutrition demonstrated a trend towards higher IL-10 levels ( $P=0.07$; Figure 13.2D). Lipid- and protein-rich nutrition enhanced peak levels of IL-10 with $231 \pm 19 \%$ compared with fasted subjects and $130 \pm 12 \%$ with control nutrition.

$$
\rightarrow \text { Enriched } \quad \text { - }- \text { Control - }- \text { - Fasted }
$$
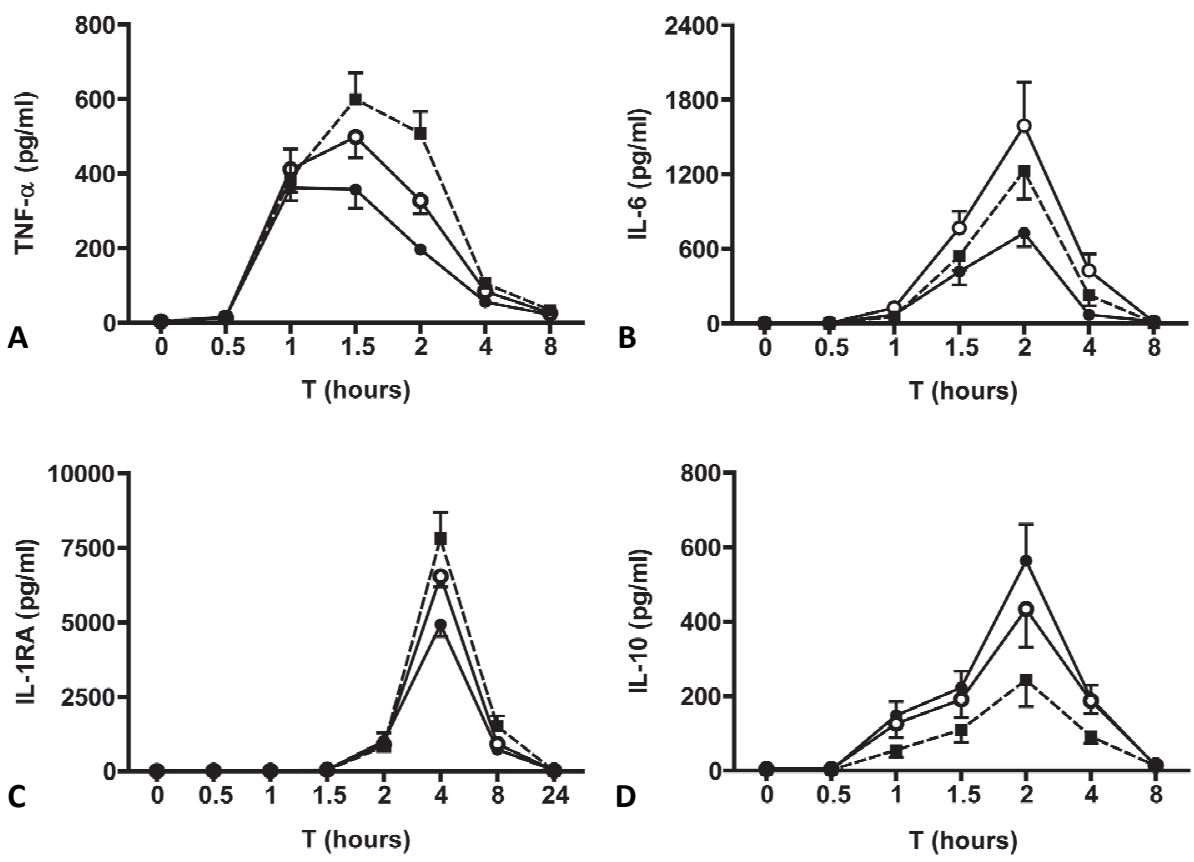

Figure 13.2 Enriched nutrition modulates the inflammatory response during endotoxemia. Mean plasma concentrations of TNF- $\alpha$ (A), IL-6 (B), IL-1RA (C) and IL-10 (D) following intravenous LPS administration. Enriched nutrition attenuated TNF- $\alpha$, IL- 6 and IL-1RA levels compared with control nutrition $(P<0.05)$ and fasting $(P<0.0001)$. Administration of the control product displayed a trend towards lower TNF- $\alpha$ levels $(P=0.06)$. The enriched nutrition enhanced IL-10 release $(P<0.0001$ vs fasted), while a trend was observed with control nutrition $(P=0.07$ vs. fasted). 


\section{Endotoxin-induced enterocyte damage}

In all subjects, administration of LPS resulted in a gradual increase in i-FABP plasma levels until 4 hours post-LPS, representing the occurrence of enterocyte damage (Figure 13.3A). From 4 hours post-LPS to 8 hours, levels of i-FABP in all groups returned to baseline. Fasted subjects and subjects receiving control nutrition displayed a more prominent increase in i-FABP levels during the experiment compared with subjects fed with lipid- and protein-rich nutrition. Total i-FABP release tended to be lower for the lipid- and protein-rich nutrition group compared with control nutrition and fasted subject, although this did not reach statistical significance (Figure 13.3B).
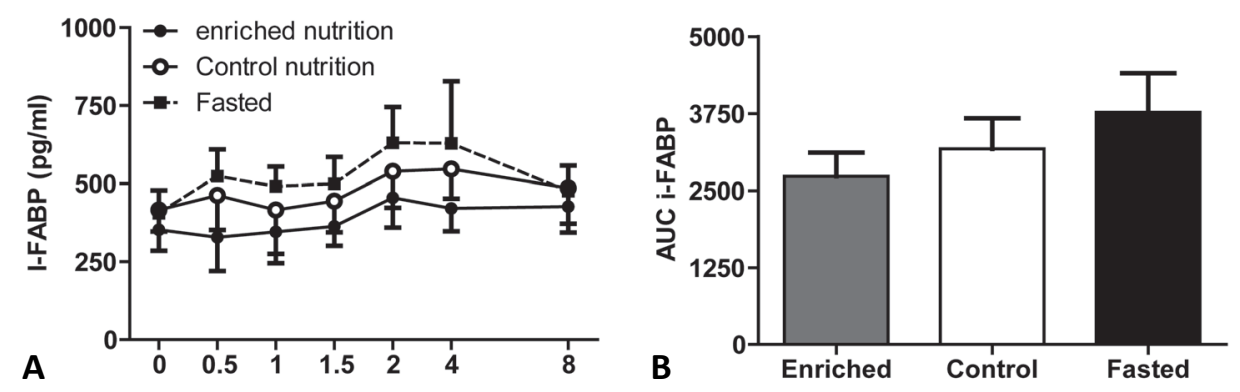

Figure 13.3 Administration of LPS results in sub-clinical intestinal damage. A. Intravenous administration of LPS resulted in a gradual increase of plasma i-FABP levels in all groups. A-B. Subjects fed enriched nutrition displayed a smaller increase in circulating i-FABP levels, although this did not reach statistical significance.

\section{Enteral nutrition increases plasma CCK levels during the inflammatory response}

In order to assess the effect of continuous duodenal infusion on CCK release, plasma CCK levels were measured on indicated time points (Figure 13.4A). CCK levels increased from non-detectable values $(<0.3 \mathrm{pmol} / \mathrm{l})$ before administration of enteral nutrition ( $\mathrm{T}=-1 \mathrm{hrs}$ ) to $2.3 \pm 0.5 \mathrm{pmol} / \mathrm{l}$ at 1 hour after onset of continuous administration of lipid- and protein-rich and control nutrition $(\mathrm{T}=0)$ at which time the bolus of endotoxin was administered. CCK plasma levels in the control group dropped four hours after intravenous LPS injection ( $0.7 \pm 0.2 \mathrm{pmol} / \mathrm{l} ; P<0.05)$ compared with the levels at $\mathrm{T}=0$ hours. The drop in CCK levels tended to be smaller in the lipid- and protein-rich group. There were no significant differences in total plasma CCK release between lipid- and protein-rich or control nutrition (Figure 13.4B). CCK levels dropped 
to non-detectable levels at 8 hours after cessation of the nutrient infusion. In fasted subjects, plasma CCK levels were below detection level throughout the protocol.

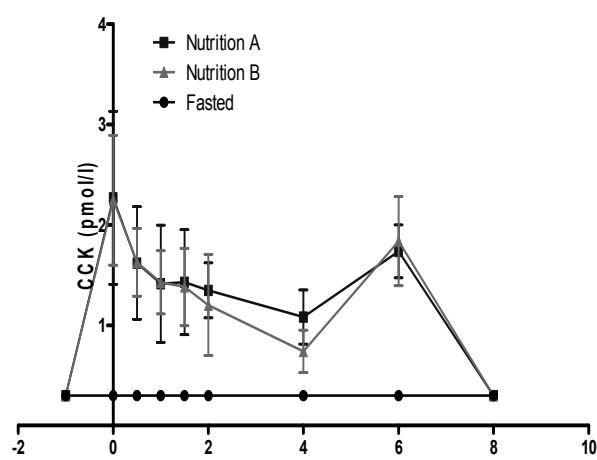

A

Figure 13.4 Postpyloric administration of control or enriched nutrition increases plasma levels of CCK. A. Continuous enteral administration of both the control and enriched nutrition resulted in an increase in CCK plasma levels compared with fasted subjects. Both nutritional interventions demonstrated a slight decrease in CCK plasma levels at 4 hours following LPS administration. After cessation of nutrient infusion, plasma CCK levels rapidly dropped below detection level. B. No differences in total plasma CCK release were observed between subjects fed enriched nutrition or control nutrition and fasted subjects.

\section{Discussion}

During the last decades, the catabolic state of surgical and critically ill patients increasingly gained interest ${ }^{18,19}$. The observed negative correlation between catabolism and clinical outcome resulted in more liberal nutritional regimes, such as reduced pre-operative fasting and early administration of enteral nutrition ${ }^{19}$. Implementation of these renewed nutritional support regimes reduced morbidity and length of hospital stay ${ }^{20,21}$. Although the exact mechanisms behind these beneficial effects are not well known, it is assumed that adequate nutritional support prevents immunodeficiency induced by caloric deficits ${ }^{22}$. Enteral nutrients are known to also activate digestive and metabolic feedback responses ${ }^{23,24}$. Previously, our group described a novel pathway via which enteral nutrition is able to modulate the inflammatory response in rodents. Short term administration of lipid-rich nutrition was shown to limit inflammation and reduce organ damage via CCK-1 receptor mediated activation of the so-called cholinergic anti-inflammatory pathway in several experimental models $s^{8,9,25-27}$. Herein, we present the first evidence that continuous 
postpyloric administration of enteral nutrition during the course of endotoxemia modulates inflammation in man.

Virtually every surgical, trauma and ICU patient suffers from systemic inflammation. The complex interplay between pro- and anti-inflammatory mechanisms during such a systemic inflammatory response is still incompletely understood ${ }^{28}$. Excess release of TNF- $\alpha$ is known to contribute to the development of systemic inflammatory response syndrome, organ damage and mortality in sepsis ${ }^{29}$. Furthermore, circulating levels of TNF- $\alpha$ and IL- 6 are correlated with the severity of sepsis in patients ${ }^{30}$. In line with these clinical observations, excessive release of pro-inflammatory mediators should be minimized in the early course of systemic inflammation to improve clinical outcome ${ }^{31}$. The current study demonstrates that lipid- and protein-rich nutrition limits systemic inflammation during human experimental endotoxemia by lowering circulating levels of TNF- $\alpha$ and IL-6. These findings are in line with rodent data from our group ${ }^{8,32}$. Moreover, the intervention with lipid- and protein-rich nutrition resulted in decreased IL-1RA plasma levels. These data are conform previous reports from others, demonstrating that TNF- $\alpha$ and IL- 6 enhance IL-1RA release during endotoxemia, while inhibition of these cytokines using epinephrine or glucocorticoids lowers circulating IL-1RA ${ }^{33-36}$. In parallel with these reports, our findings that lipid- and protein-rich nutrition not only decreases plasma levels of TNF- $\alpha$ and IL- 6 but also lowers circulating IL-1RA, reflect an overall reduced pro-inflammatory state. Interestingly, postpyloric administration of lipid- and protein-rich nutrition amplified the anti-inflammatory response to endotoxin as evidenced by a pronounced increase in circulating IL-10. Production of the cytokine IL-10 is considered to be part of the host-protective mechanism that counterbalances the pro-inflammatory response during acute infection and inflammation ${ }^{35}$. Furthermore, administration of IL-10 has been shown to reduce endotoxin-induced lethality in mice ${ }^{37}$. Together, these data indicate that pretreatment with lipid- and protein-rich enteral nutrition is a promising and above all physiological intervention to control acute systemic inflammation in man.

Intestinal epithelial cell damage often accompanies sepsis, trauma and major surgery and is related to the degree of gastrointestinal hypoperfusion ${ }^{16,38,39}$. Additionally, intestinal compromise has been implicated in the development of inflammatory complications following injury ${ }^{40}$. Here, intravenous administration of LPS resulted in increased i-FABP levels. i-FABP is a small cytosolic protein that is present in mature enterocytes and released into the circulation upon cell damage ${ }^{16}$. The rise in plasma iFABP levels was smaller in subjects treated with lipid- and protein-rich nutrition compared with control nutrition or fasted subjects, although this did not reach statistical significance. These data are supported by rodent studies demonstrating that lipid-rich nutrition preserves intestinal integrity in several models ${ }^{25,41}$. The small overall increase in i-FABP plasma levels is likely attributable to the relative low dose of LPS in 
combination with the prehydration protocol. It is to be expected that the prehydration protocol resulted in limited endotoxin-induced (splanchnic) hypoperfusion, thereby reducing enterocyte damage ${ }^{16}$. Future studies are needed to investigate a gutprotective effect of lipid- and protein-rich nutrition in man.

In rodents, activation of the nutritional anti-inflammatory pathway was shown to be mediated via peripheral CCK-1 receptors ${ }^{8}$. Intestinal release of CCK and subsequent activation of CCK-receptors are predominantly triggered by the luminal presence of lipid and protein ${ }^{12,42}$, while termination of nutrient exposure results in a rapid drop of CCK levels ${ }^{42}$. To this end, we continuously administered lipid- and protein-enriched nutrition in order to optimally stimulate peripheral CCK-1 receptors throughout the endotoxin-induced inflammatory response. Although the observed effects of enteral lipid- and protein-enriched nutrition on systemic inflammation were comparable to our rodent data, the human data do not support a clear role for CCK in the antiinflammatory potential of lipid- and protein-enriched nutrition. The differences in antiinflammatory potential between our nutritional compositions might be explained by the fact that circulating CCK levels do not reflect local intestinal concentrations and subsequent activation of afferent vagal fibers in the gut ${ }^{43}$. Moreover, it can also be explained by species differences between rodent and man combined with involvement of other neuropeptides, as the luminal presence of nutrients induces release of several neuropeptides resulting in a complex interplay of signals ${ }^{44}$. Therefore, it remains to be determined via which pathway enteral lipid- and protein-enriched nutrition modulates inflammation in man.

Together, the current study reveals a novel application of enteral nutrition to modulate inflammation in man. In contrast to the immunomodulating effects transferred by prolonged ingestion of omega- 3 fatty acids and glutamine ${ }^{45,46}$, our intervention demonstrated a rapid anti-inflammatory effect, which is suggestive for a direct feedback mechanism. This is underlined by the fact that the anti-inflammatory effect is achieved by continuous infusion of small amounts of nutrients, while bolus administration of enteral nutrition, delivering nearly twice the amount of lipid two hours prior to the induction of endotoxemia, did not affect the inflammatory response $^{47}$.

In conclusion, the current pre-clinical study demonstrates that: 1) short-term continuous administration of enteral nutrition starting prior to the inflammatory trigger modulates the acute systemic inflammatory response in humans, and 2) enrichment of the nutritional composition with lipid and protein reinforces this antiinflammatory potential. Taken together, our data implicate continuous administration of lipid- and protein-rich nutrition as a promising intervention to control an excessive inflammatory response in the clinical setting. 


\section{References}

1. Riedemann NC, Guo RF, Ward PA. Novel strategies for the treatment of sepsis. Nat Med 2003;9: 517-524.

2. Yende S, D'Angelo G, Kellum JA, Weissfeld L, Fine J, Welch RD, Kong L, Carter M, Angus DC. Inflammatory markers at hospital discharge predict subsequent mortality after pneumonia and sepsis. Am J Respir Crit Care Med 2008;177:1242-1247.

3. Osuchowski MF, Welch K, Siddiqui J, Remick DG. Circulating cytokine/inhibitor profiles reshape the understanding of the SIRS/CARS continuum in sepsis and predict mortality. J Immunol 2006;177: 1967-1974.

4. Rice TW, Wheeler AP, Bernard GR, Vincent JL, Angus DC, Aikawa N, Demeyer I, Sainati S, Amlot N, Cao $C$ et al. A randomized, double-blind, placebo-controlled trial of TAK-242 for the treatment of severe sepsis. Crit Care Med 2010;38:1685-1694.

5. Marshall JC, Charbonney E, Gonzalez PD. The immune system in critical illness. Clin Chest Med 2008; 29:605-616, vii.

6. Cinel I, Opal SM. Molecular biology of inflammation and sepsis: a primer. Crit Care Med 2009;37: 291-304.

7. Parrish WR, Gallowitsch-Puerta M, Czura CJ, Tracey KJ. Experimental therapeutic strategies for severe sepsis: mediators and mechanisms. Ann N Y Acad Sci 2008;1144:210-236.

8. Lubbers T, de Haan JJ, Luyer MD, Verbaeys I, Hadfoune M, Dejong CH, Buurman WA, Greve JW. Cholecystokinin/Cholecystokinin-1 receptor-mediated peripheral activation of the afferent vagus by enteral nutrients attenuates inflammation in rats. Ann Surg 2010;252:376-382.

9. de Haan JJ, Lubbers T, Hadfoune M, Luyer MD, Dejong CH, Buurman WA, Greve JW. Postshock Intervention With High-Lipid Enteral Nutrition Reduces Inflammation and Tissue Damage. Ann Surg 2008;248:842-848.

10. Zanden EP, Snoek SA, Heinsbroek SE, Stanisor OI, Verseijden C, Boeckxstaens GE, Peppelenbosch MP, Greaves DR, Gordon S, de Jonge WJ. Vagus nerve activity augments intestinal macrophage phagocytosis via nicotinic acetylcholine receptor alpha4beta2. Gastroenterology 2009;137:1029-1039,.

11. Wang H, Yu M, Ochani M, Amella CA, Tanovic M, Susarla S, Li JH, Wang H, Yang H, Ulloa L et al. Nicotinic acetylcholine receptor alpha7 subunit is an essential regulator of inflammation. Nature 2003; 421:384-388.

12. Karhunen LJ, Juvonen KR, Huotari A, Purhonen AK, Herzig KH. Effect of protein, fat, carbohydrate and fibre on gastrointestinal peptide release in humans. Regul Pept 2008;149:70-78.

13. Lowry SF. Human endotoxemia: a model for mechanistic insight and therapeutic targeting. Shock 2005; 24 Suppl 1:94-100.

14. Pickkers P, Dorresteijn MJ, Bouw MP, van der Hoeven JG, Smits P. In vivo evidence for nitric oxidemediated calcium-activated potassium-channel activation during human endotoxemia. Circulation 2006;114:414-421.

15. van Eijk LT, Dorresteijn MJ, Smits P, van der Hoeven JG, Netea MG, Pickkers P. Gender differences in the innate immune response and vascular reactivity following the administration of endotoxin to human volunteers. Crit Care Med 2007;35:1464-1469.

16. Derikx JP, van Waardenburg DA, Thuijls G, Willigers HM, Koenraads M, van Bijnen AA, Heineman E, Poeze M, Ambergen T, van Ooij A et al. New Insight in Loss of Gut Barrier during Major Non-Abdominal Surgery. PLoS One 2008;3:e3954.

17. van Wijck K, Lenaerts K, van Loon LJ, Peters WH, Buurman WA, Dejong CH. Exercise-induced splanchnic hypoperfusion results in gut dysfunction in healthy men. PLoS One 2011;6:e22366.

18. van Ginhoven TM, Mitchell JR, Verweij M, Hoeijmakers JH, ljzermans JN, de Bruin RW. The use of preoperative nutritional interventions to protect against hepatic ischemia-reperfusion injury. Liver Transp/ 2009;15:1183-1191.

19. Soreide E, Ljungqvist $O$. Modern preoperative fasting guidelines: a summary of the present recommendations and remaining questions. Best Pract Res Clin Anaesthesiol 2006;20:483-491.

20. Noblett SE, Watson DS, Huong H, Davison B, Hainsworth PJ, Horgan AF. Pre-operative oral carbohydrate loading in colorectal surgery: a randomized controlled trial. Colorectal Dis 2006;8: 563-569. 
21. El Nakeeb A, Fikry A, El Metwally T, Fouda E, Youssef M, Ghazy H, Badr S, Khafagy W, Farid M. Early oral feeding in patients undergoing elective colonic anastomosis. Int J Surg 2009;7:206-209.

22. Kreymann KG, Berger MM, Deutz NE, Hiesmayr M, Jolliet $P$, Kazandjiev G, Nitenberg G, van den Berghe G, Wernerman J, Ebner C et al. ESPEN Guidelines on Enteral Nutrition: Intensive care. Clin Nutr 2006; 25:210-223.

23. Wang PY, Caspi L, Lam CK, Chari M, Li X, Light PE, Gutierrez-Juarez R, Ang M, Schwartz GJ, Lam TK. Upper intestinal lipids trigger a gut-brain-liver axis to regulate glucose production. Nature 2008; 452:1012-1016.

24. Chandra R, Liddle RA. Cholecystokinin. Curr Opin Endocrinol Diabetes Obes 2007;14:63-67.

25. Lubbers T, de Haan JJ, Hadfoune M, Luyer MD, Zhang Y, Grundy D, Buurman WA, Greve JW. Lipidenriched enteral nutrition controls the inflammatory response in murine gram-negative sepsis Critical Care Medicine 2010;38:1996-2002.

26. Lubbers T, Luyer MD, de Haan JJ, Hadfoune M, Buurman WA, Greve JW. Lipid-Rich Enteral Nutrition Reduces Postoperative Ileus in Rats via Activation of Cholecystokinin-Receptors. Ann Surg 2009; 249:481-487.

27. Luyer MD, Greve JW, Hadfoune M, Jacobs JA, Dejong CH, Buurman WA. Nutritional stimulation of cholecystokinin receptors inhibits inflammation via the vagus nerve. J Exp Med 2005;202:1023-1029.

28. Flohe SB, Flohe S, Schade FU. Invited review: deterioration of the immune system after trauma: signals and cellular mechanisms. Innate Immun 2008;14:333-344.

29. Abraham E, Laterre PF, Garbino J, Pingleton S, Butler T, Dugernier T, Margolis B, Kudsk K, Zimmerli W, Anderson $\mathrm{P}$ et al. Lenercept (p55 tumor necrosis factor receptor fusion protein) in severe sepsis and early septic shock: a randomized, double-blind, placebo-controlled, multicenter phase III trial with 1,342 patients. Crit Care Med 2001;29:503-510.

30. Harbarth S, Holeckova K, Froidevaux C, Pittet D, Ricou B, Grau GE, Vadas L, Pugin J. Diagnostic value of procalcitonin, interleukin-6, and interleukin-8 in critically ill patients admitted with suspected sepsis. Am J Respir Crit Care Med 2001;164:396-402.

31. Hotchkiss RS, Coopersmith CM, McDunn JE, Ferguson TA. The sepsis seesaw: tilting toward immunosuppression. Nat Med 2009;15:496-497.

32. Lubbers T, De Haan JJ, Hadfoune M, Zhang Y, Luyer MD, Grundy D, Buurman WA, Greve JW. Lipidenriched enteral nutrition controls the inflammatory response in murine Gram-negative sepsis. Crit Care Med 2010;38:1996-2002.

33. van der Poll T, van Deventer SJ, ten Cate H, Levi M, ten Cate JW. Tumor necrosis factor is involved in the appearance of interleukin-1 receptor antagonist in endotoxemia. J Infect Dis 1994;169:665-667.

34. Gabay C, Smith MF, Eidlen D, Arend WP: Interleukin 1 receptor antagonist (IL-1Ra) is an acute-phase protein. J Clin Invest 1997;99:2930-2940.

35. van der Poll T, Coyle SM, Barbosa K, Braxton CC, Lowry SF. Epinephrine inhibits tumor necrosis factoralpha and potentiates interleukin 10 production during human endotoxemia. J Clin Invest 1996; 97:713-719.

36. Arzt E, Sauer J, Pollmacher T, Labeur M, Holsboer F, Reul JM, Stalla GK. Glucocorticoids suppress interleukin-1 receptor antagonist synthesis following induction by endotoxin. Endocrinology 1994; 134:672-677.

37. Howard M, Muchamuel T, Andrade S, Menon S. Interleukin 10 protects mice from lethal endotoxemia. J Exp Med 1993;177:1205-1208.

38. de Haan JJ, Lubbers T, Derikx JP, Relja B, Henrich D, Greve JW, Marzi I, Buurman WA. Rapid development of intestinal cell damage following severe trauma: a prospective observational cohort study. Crit Care 2009;13:R86.

39. Derikx JP, Poeze M, van Bijnen AA, Buurman WA, Heineman E. Evidence for intestinal and liver epithelial cell injury in the early phase of sepsis. Shock 2007;28:544-548.

40. Fink MP, Delude RL. Epithelial barrier dysfunction: a unifying theme to explain the pathogenesis of multiple organ dysfunction at the cellular level. Critical care clinics 2005;21:177-196.

41. de Haan JJ, Thuijls G, Lubbers T, Hadfoune M, Reisinger K, Heineman E, Greve JW, Buurman WA Protection against early intestinal compromise by lipid-rich enteral nutrition via cholecystokininreceptors. Crit Care Med 2010;38:1592-1597. 
42. Pilichiewicz AN, Little TJ, Brennan IM, Meyer JH, Wishart JM, Otto B, Horowitz M, Feinle-Bisset C. Effects of load, and duration, of duodenal lipid on antropyloroduodenal motility, plasma CCK and PYY, and energy intake in healthy men. Am J Physiol Regul Integr Comp Physiol 2006;290:R668-677.

43. Reidelberger RD, Kalogeris TJ, Solomon TE. Plasma CCK levels after food intake and infusion of CCK analogues that inhibit feeding in dogs. Am J Physiol 1989;256(5 Pt 2):R1148-1154.

44. Berthoud HR. Vagal and hormonal gut-brain communication: from satiation to satisfaction. Neurogastroenterol Motil 2008;20 Suppl 1:64-72.

45. Calder PC. n-3 polyunsaturated fatty acids, inflammation, and inflammatory diseases. Am J Clin Nutr 2006;83(6 Suppl):1505S-1519S.

46. Vermeulen MA, van de Poll MC, Ligthart-Melis GC, Dejong $\mathrm{CH}$, van den Tol MP, Boelens PG, van Leeuwen PA. Specific amino acids in the critically ill patient--exogenous glutamine/arginine: a common denominator? Crit Care Med 2007;35(9 Suppl):S568-576.

47. Harris HW, Johnson JA, Wigmore SJ. Endogenous lipoproteins impact the response to endotoxin in humans. Crit Care Med 2002;30:23-31. 


\section{CHAPTER 14}

Summary and discussion 
The immune system has developed a complex range of protective mechanisms during evolution to preserve homeostasis by detecting, controlling and eliminating pathogens and noxious substances. Usually, the immune response is adequate and proportional to the threats that are posed by a breach of tissue barriers ${ }^{1,2}$. Under certain circumstances, an excessive systemic spread may occur, causing collateral damage to the host and resulting in prolonged hospital stay, organ failure and even death. Particularly surgical, trauma and critically ill patients are prone to develop an uncontrolled inflammatory reaction, defined as systemic inflammatory response syndrome (SIRS), sepsis, and related syndromes ${ }^{3,4}$. Therefore, over the past decades substantial efforts have been made and resources have been spent worldwide to develop therapies that regulate and attenuate the immune response ${ }^{5}$. Unfortunately, most of the anti-inflammatory strategies aimed at neutralization of single inflammatory mediators did not improve clinical outcome. Referring to the long history of unsuccessful trials, Riedemann even described sepsis as the "graveyard for pharmaceutical companies" ${ }^{5}$. In the past years however, increasing insight in the immunological control by the central nervous system has opened a novel window for therapeutic opportunities. In particular the parasympathetic system was identified as a strong modulator of the inflammatory response. In addition to classical functions of regulating heart rate, hormone secretion, gastrointestinal peristalsis and nutrient digestion, the vagus nerve was demonstrated to attenuate inflammation, limit tissue damage and reduce mortality in several experimental models ${ }^{6,7}$.

Next to electrical stimulation and pharmacological simulation, a more physiological way to enhance vagus nerve signaling is administration of enteral nutrition. Via sensory fibers, enteral nutrients regulate satiety and processing of food on the short term and maintenance of energy homeostasis on the long term ${ }^{8,9}$. Importantly, our group previously showed that nutrition enriched with lipids attenuates the acute inflammatory response and promotes tissue integrity via CCK receptor-dependent stimulation of the vagus nerve ${ }^{10}$. These findings are supported by the work of Glatzle et al, showing that short-term exposure of the intestine to intraluminal lipids reduces macrophage activation and limits pulmonary dysfunction following LPS exposure ${ }^{11,12}$.

The studies described in this thesis can be considered as steps towards clinical application of the nutrition-induced neuro-immune axis. The first aim was to enhance the insight in the afferent and efferent arms of this anti-inflammatory pathway. The second aim was to explore the therapeutic window of intervention with lipid-rich nutrition in experimental models of hemorrhagic shock, acute hemolysis, endotoxemia, and polymicrobial sepsis. The third aim was to translate the experimental body of data to a human setting. In healthy volunteers, several nutritional formulas were tested in order to identify a suitable nutritional composition for further testing. Next, in a human model of endotoxemia, the effects of continuous 
administration of a custom-made lipid- and protein-rich feeding on the inflammatory response were investigated.

The development of safe and effective clinical treatment modalities based on enteral administration of enriched nutrition requires profound knowledge of the pathways that are activated. Whereas modulation of immune cell activity by efferent vagus nerve stimulation was extensively studied, the afferent pathway that transmits the nutritional anti-inflammatory signal to the central nervous system remained to be determined. The autonomic nervous system is informed about ingested nutrients either via sensory afferent nerves or via hormones that enter the brain via the circulation $^{8}$. First, the anti-inflammatory effects of lipid-rich nutrition were determined in animals lacking a functional afferent vagus nerve (chapter 2). Afferent neural signaling was disrupted using perivagal application of capsaicine, a procedure that preserves the efferent vagus fibers ${ }^{13}$. In deafferented animals, neither a reduction of TNF $\alpha$ and IL- 6 levels following lipid-rich nutrition was observed, nor a decrease in gut wall permeability ${ }^{14}$. These findings indicate that, combined with earlier reports that demonstrated the involvement of the efferent vagus nerve and release of cholinergic neurotransmitters, lipid-rich nutrition regulates the inflammatory response via a hardwired vagovagal reflex ${ }^{10,14}$.

Subsequently, the activation of sensory fibers by luminal nutrients was studied in more detail. Previously, the involvement of CCK receptors was demonstrated ${ }^{10}$. Using specific antagonists for CCK-1 receptor and CCK-2 receptor (devazepide and L365,260 respectively), both receptors were shown to be involved in the anti-inflammatory signaling, with strongest inhibition of the nutritional effects by blockage of the CCK-1 receptor. Interestingly, CCK receptors are found both in the central nervous system and in the periphery. To differentiate between a centrally and a peripherally mediated effect of CCK, a highly specific CCK-1 receptor antagonist, A70104, was applied that does not cross the blood-brain barrier ${ }^{15}$. The finding that the reduction of circulating cytokine levels by lipid-rich nutrition was taken away by A70104 points at a principal role for peripherally located CCK-1 receptors.

CCK-mediated activation of the nutritional anti-inflammatory reflex was further assessed by administration of CCK in fasted animals. Intravenous infusion of a physiological CCK subtype (sulphated CCK8) did not affect inflammatory parameters, which can be explained by the short half-time of $\mathrm{CCK}^{14}$. Previous reports indicate that, to generate local CCK levels that are sufficient to activate sensory vagus fibers, supraphysiological plasma levels need to be induced that however lead to severe sideeffects including anxiety and pancreatitis ${ }^{16}$. Therefore, a pegylated CCK construct (pegylated (CK9) with an enhanced bioavailability was applied that binds solely to peripheral CCK-1 receptors ${ }^{17}$. Pegylated CCK9 reduced inflammation in fasted animals, 
thus mimicking the CCK-mediated immunomodulation by lipid-rich nutrition. Taken together, these data indicate that the protective effects of lipid-rich nutrition are triggered via CCK dependent activation of peripheral CCK-1 receptors. This signaling cascade is similar to the pathways that mediate important digestive and metabolic responses following food ingestion ${ }^{14,18,19}$. The significance of CCK, which is released in particular upon exposure to hydrolyzed proteins and medium and long-chain fatty acids $^{20}$, is supported by repeated observations that nutrition enriched with phospholipids exerts stronger anti-inflammatory effects compared with isocalorical control nutrition.

The release of CCK by I-cells in the intestinal wall depends on the formation of chylomicrons, the principle lipid carriers in the circulation. Chylomicrons are known to attenuate gastric emptying via afferent sensory nerves ${ }^{21}$. Blocking the chylomicron formation without affecting lipid uptake abrogated the anti-inflammatory effects of lipid-rich nutrition, indicating that lipids need to be processed into chylomicrons in order to trigger the anti-inflammatory reflex ${ }^{22,23}$. Remarkably, our group previously demonstrated that bile-duct ligation, resulting in lower plasma triglyceride levels, did not affect the anti-inflammatory effects of lipid-rich nutrition ${ }^{24}$. This seemingly discrepancy could be explained by the fact that, in the absence of bile acids, the intestinal wall is still, to a certain degree, exposed to fatty acids, resulting in afferent vagus stimulation that is sufficient to modulate the immune response.

Next to CCK, a range of neuropeptides affects food intake by stimulation of the afferent vagus nerve ${ }^{9}$. In parallel studies, administration of a glucagon-like peptide 1-receptor antagonist, but not leptin or peptide $Y Y$ antagonists, suppressed the anti-inflammatory effects of lipid-rich nutrition. These findings point at a costimulatory role of the glucagon-like peptide 1-receptor. The fact that the antiinflammatory actions of lipid-rich nutrition were completely taken away by CCK receptor antagonists and mimicked by a CCK-1 receptor agonist is in accordance with previous reports showing that CCK strongly sensitizes vagal afferent neurons for stimulation by other gut peptides, thus acting as a gatekeeper ${ }^{22,25-27}$.

Representing the largest area of contact between the body and its environment, the gut wall has an important immunological function ${ }^{28}$. Various lines of experimental and clinical evidence point at a major role for early loss of intestinal integrity in the development of systemic inflammatory complications ${ }^{29-31}$. Penetration of microbes, toxins and digestive enzymes into the gut wall and beyond via the lymphatic system and circulation are considered to induce distant damage and systemic inflammation $^{32,33}$. Next to a weakened barrier function, also the presence of early enterocyte damage has been demonstrated in septic patients and patients undergoing non-abdominal surgery ${ }^{34,35}$. Furthermore, Derikx et al showed that the early 
occurrence of enterocyte damage is associated with poor clinical outcome. In diverse inflammatory settings including sepsis, interventions that specifically aim to improve intestinal integrity were reported to reduce distant organ damage and improve survival $^{33,36-39}$. Interestingly, the concept of selective gut decontamination as implemented in a growing number of intensive care units is based on the notion that translocation of intestinal microbes causes pulmonary infections ${ }^{40,41}$.

A major patient group prone to develop inflammatory complications are trauma patients. Although gut permeability is reportedly increased within 48 hours after trauma ${ }^{42}$, it remained to be clarified whether intestinal damage is present in the early hours post-trauma and forms a potential target of therapy. In this thesis, plasma concentrations of circulatory fatty acid binding proteins (FABP) are shown to be strongly increased already upon arrival at the Emergency Department in a cohort of polytrauma patients (chapter 3 ) $^{43}$. Whereas low levels of FABPs indicate enterocyte turnover, strongly increased serum concentrations point at intestinal cell damage ${ }^{44,45}$. The extent of enterocyte damage after trauma was related to the height of the Injury Severity Scale (ISS). Notably, I-FABP levels in the early phase after trauma correlated with the subsequent rise of inflammatory markers such as PCT, IL-6 and CRP in the days thereafter. These observations lend support to the body of literature on the causal relation between gut wall compromise and dysregulated inflammation / distant organ injury ${ }^{33,46}$. The findings indicate that early assessment of enterocyte damage may help to identify patients who are at risk to develop excessive inflammation in a later stage. In addition, this study implicates preservation of the intestinal barrier in trauma patients as a potential therapeutic target.

Before investigating the effects of lipid-rich nutrition on the breakdown of the intestinal barrier, the early structural and functional alterations in the intestinal wall were studied in a model of hemorrhagic shock. In this model, a third of circulating blood volume is withdrawn, resulting in systemic inflammation and intestinal barrier dysfunction ${ }^{47}$. Chapter 4 describes the disruption of the filamentous actin cytoskeleton of enterocytes via activation of actin-depolymerizing factor / cofilin as soon as 15 minutes post- shock ${ }^{48}$. This intracellular shift preceded the breakdown of the tight junctions that connect the enterocytes and thus form a vital part of the intestinal barrier. The structural changes were reflected in an increase of gut wall permeability, represented by bacterial translocation, and the development of an inflammatory response in the gut wall. These local intestinal events were followed by the occurrence of inflammatory markers in plasma.

After showing that early loss of the gut barrier develops following hemorrhagic shock, in a subsequent study the effects of nutritional vagus stimulation on the densely innervated intestinal wall were explored (chapter 5). The loss of gut barrier function early after shock was shown to be prevented by lipid-rich nutrition ${ }^{49}$. Furthermore, 
lipid-rich nutrition reduced the early increase of FABP levels in plasma. Considering the important contributory function of gut wall compromise to the development of inflammation, these findings may at least partially explain the modification of the systemic inflammatory response by lipid-rich nutrition. Interestingly, in settings of restraint stress in rodents, cholinergic signaling has been shown to decrease gut barrier function ${ }^{50,51}$. The finding that the increase of intestinal permeability was mediated by muscarinic receptors rather than nicotinic receptors indicates that vagus nerve signaling causes differential effects, the dominance of which may be dependent on the mode of vagus nerve activation.

Also local intestinal inflammation, represented by mucosal mast cell protease levels in circulation and intestinal myeloperoxidase concentrations, was significantly reduced by lipid-rich nutrition before systemic inflammation was detectable (chapter 5). The protective effects of lipid-rich nutrition were mediated by CCK receptor antagonists, which identified activation of the vagal anti-inflammatory reflex as a potential therapy to preserve intestinal integrity in the earliest phase of a systemic inflammatory response. However the extent to which intestinal barrier breakdown contributes to systemic inflammation remains to be determined ${ }^{29}$. It has been postulated, e.g. by Fink, that intestinal barrier breakdown represents a more generalized phenomenon that affects epithelial barrier function in a variety of organs, including the lungs, kidneys and liver ${ }^{52}$. In support of a multi-organ effect of lipid-rich nutrition, also local inflammation in liver and spleen was shown to be reduced by nutritional intervention (chapter 9). Furthermore, in a model of hemorrhage followed by bacterial DNA exposure, a reduction of hepatic cell damage was reported following intervention with lipid-rich nutrition ${ }^{53}$.

In this thesis, further investigations on the effects of nutritional vagus nerve activation on mast cell activity are described (chapter 6 ). Mast cells were activated using LPS as a common inflammatory trigger. Lipid-rich enteral feeding administered prior to LPS significantly decreased circulatory levels of mouse mast cell protease at 30 minutes post-LPS. Antagonists of the CCK-1 receptor reversed the inhibitory effects of lipid-rich feeding, whereas the peripheral CCK-1 receptor agonist pegylated-CCK9 mimicked nutritional mast cell inhibition. In line with earlier work in the hemorrhagic shock model, the mast cell inhibitory effects of lipid-rich nutrition were blocked by nicotinic receptor antagonists. Furthermore, using a specific blocker, mast cell activation was shown to be inhibited via the $\alpha 7$-subunit containing nACh receptor. In bone marrow derived maste cells, the involvement of $\alpha 7 n A C h$ receptors was confirmed by employment of a specific $\alpha 7 n A C h$ receptor agonist. These findings are first to directly connect vagal anti-inflammatory signaling by lipid-rich nutrition with the $\alpha 7 n A C h$ receptor-dependent mechanism described by Tracey $^{54}$. The importance of mast cell inhibition lies in the principle role of mast cells in the immunological barrier between 
the internal milieu and the environment. Whereas for decades mast cells were investigated solely in the context of allergy and asthma-like reactions, the role of mast cells in the orchestration of the innate immune reaction is increasingly acknowledged $^{55-57}$. In situations of a compromised intestinal barrier, mucosal mast cells are among the first immune cells to release inflammatory mediators. Mucosal mast cell degranulation is associated with gut barrier dysfunction and drives mesenteric afferent signaling during acute intestinal ischemia ${ }^{58-60}$. The finding that pretreatment with histaminic receptor-1 blocker and mast cell stabilizer ketotifen decreased plasma IL-6 and ileal leakage of HRP after LPS, emphasizes the role of mast cells activation in the development of inflammation and intestinal compromise.

The capacity of enriched nutrition to attenuate inflammation and reduce organ injury was further explored in animal models for clinical settings that are characterized by a dysregulated immune response. In patients with severe trauma, excessive inflammation is common and often leads to SIRS and sepsis, which are associated with high morbidity and mortality ${ }^{4}$. In contrast to patients undergoing elective surgery, interventions in trauma patients can only be initiated once tissue damage is already present and the immune response is unfolding. To test the effectiveness of posttreatment with lipid-rich nutrition, after shock nutritional intervention was started at 30 minutes when intestinal injury had developed, or at 80 minutes in presence of systemic inflammation (chapter 7 ) $^{61}$. Treatment with lipid-rich nutrition post-shock reduced plasma levels of IFNy, a potent late inflammatory mediator with multiple actions on both innate and adaptive immune systems ${ }^{62}$. Importantly, also concentrations of IL-10 were decreased, indicating that both pro- and antiinflammatory signaling is inhibited by nutritional intervention ${ }^{63}$. Furthermore, enterocyte damage and gut wall permeability were reduced in a CCK-receptor dependent manner, implicating vagus nerve stimulation as the underlying mechanism. Taken together, the effectiveness of nutritional activation of the vagal antiinflammatory reflex was demonstrated in a setting of manifest inflammation and tissue damage.

Intravascular hemolysis is a common event in diverse clinical situations, e.g. during major cardiovascular surgery, extracorporeal circulation with membrane oxygenation, sickle cell crisis or malaria infections. Hemolysis leads to organ damage and inflammation ${ }^{64,65}$. Endothelial dysfunction as a consequence of nitric oxide (NO) scavenging by sequestered cell-free hemoglobin is considered crucial in the detrimental sequelae of hemolysis ${ }^{66,67}$. NO is a pivotal signalling molecule in the regulation of smooth muscle relaxation, endothelial adhesion molecule expression and platelet activation. In hemolytic disease, the sensibility for NO-independent vasoactive mechanisms is increased ${ }^{68}$. Since acetylcholine is a potent vasodilator acting largely 
independent of NO, nutritional vagus stimulation, resulting in acetylcholine release, was hypothesized to counteract the vasoconstrictive effects of NO depletion and prevent the development of organ damage and inflammation ${ }^{69-71}$. The clinical scenario of ongoing hemolysis was mimicked in rodents by continuous infusion of lysed erythrocytes (chapter 8). Induction of clinically relevant cell-free hemoglobin concentrations in circulation resulted in rapid organ damage and systemic inflammation. Enteral lipid-rich nutrition significantly reduced the loss of renal, hepatic and intestinal integrity during hemolysis and decreased circulatory IL-6 levels. CCK-1 receptor antagonist $\mathrm{A70104}$ as well as $\mathrm{nACh}$ receptor antagonist chlorisondamine reversed the protective nutritional effects, whereas PEG-CCK9 mimicked the impact of enteral feeding in fasted animals. Moreover, nutritional intervention increased renal, hepatic and intestinal perfusion in a CCK-1 receptor dependent manner, as evaluated using fluorescent microspheres. These data implicate stimulation of the vagal antiinflammatory reflex by nutritional means as a potential therapy to prevent tissue injury and reduce inflammation in patients prone to develop hemolysis. Such intervention would be of additional value to existing and experimental therapeutic approaches to reduce hemolytic complications, such as inhalation of NO gas and administration of haptoglobin or nitrite ${ }^{66,72,73}$.

Before investigating the anti-inflammatory effects of lipid-rich enteral nutrition in a human model of endotoxemia as described in chapter 13, we first studied the effects of lipid-rich nutrition in a murine endotoxemia model in which mice received an intraperitoneal bolus of endotoxin (chapter 9). Endotoxin is a component of the outer cell wall of Gram-negative microbes that provokes a strong TLR-4 dependent immunologic response. Both lipid-rich and low-lipid nutrition dose-dependently reduced endotoxin-induced release of $\mathrm{TNF}^{74}$. Lipid-rich nutrition attenuated the inflammatory response at lower dosages than low-lipid nutrition, indicating that enrichment of enteral nutrition with specific nutrients augments the anti-inflammatory potential. In addition, administration of lipid-rich nutrition reduced endotoxin-induced enterocyte damage and decreased inflammation in the liver and spleen. The antiinflammatory impact of both lipid-rich and low-lipid nutrition was mediated through CCK receptors and peripheral nACh receptors. Moreover, lipid-rich nutrition enhanced firing of jejunal mechanosensitive afferents following gut wall distension compared with discharges before treatment and after treatment. These findings implicate vagus nerve signaling via enteral lipid-rich nutrition as a promising intervention to modulate the inflammatory response and prevent organ dysfunction during septic conditions. The protective effects of enriched nutrition in the endotoxemia model are comparable to the benefits obtained by electrical vagus nerve stimulation or pharmacological activation of $\mathrm{nACh}$ receptors ${ }^{75,76}$. 
Having established protective effects of lipid-rich nutrition in an acute setting of Gramnegative sepsis induced by a bolus of endotoxin, we further investigated the protective capacity of nutrition in a model of polymicrobial sepsis induced by cecal ligation and puncture (CLP) (chapter 10). This model is considered to represent a polymicrobial peritoneal infection that is complicated by a state of immunosuppression. In line with the anti-inflammatory effects in the endotoxemia model, lipid-rich nutrition reduced levels of circulatory cytokines in the early phase after CLP. Classically, the course of sepsis is divided in an early hyperinflammatory phase and a subsequent state of protracted immunosuppression. This inactivity of the immune system is a feared consequence of septic disease that results in an inability to control infections and a predisposition to secondary infections caused by opportunistic pathogens ${ }^{77-79}$. The severity of late immunosuppression is considered to correlate with the extent of inflammation during early sepsis ${ }^{80,81}$. Therefore, broad suppression of the acute inflammatory response may prevent later immunosuppression-related infections.

To replicate the clinical scenario of polymicrobial sepsis complicated by a secondary pneumonia, CLP was followed by intranasal application of $P$. aeruginosa 4 days later ${ }^{82}$. Compared to sham operated animals, in CLP animals the microbial count in the lungs was strongly enhanced following a secondary $P$. aeruginosa infection. Lipid-rich nutrition prevented the increase of the bacterial load in the lungs of mice undergoing CLP and secondary pneumonia. Next to enhancement of microbial clearance, a shift towards increased levels of pro-inflammatory cytokines IL-12 and IFN $\gamma$ was observed in the lungs whereas concentrations of anti-inflammatory cytokine IL-10 were decreased. These findings are in line with a study of Wen et al, showing that restoration of the IL-12/IL-10 balance during sepsis improves the defense against opportunistic pathogens ${ }^{83}$.

Together, early intervention with specifically enriched enteral nutrition may help to prevent secondary infections in the protracted immunosuppressive phase of sepsis, thus contributing to the solution of a major clinical problem. Notably, the CLP study described in chapter $\mathbf{1 0}$ is the first to describe protective effects of nutritional intervention in female animals. In previous studies, solely male animals were used. It is important that nutritional intervention is demonstrated to be effective in both sexes, considering the significant role of sex hormones in the immune response to trauma ${ }^{84}$.

By demonstrating 1) a reduction of the acute inflammatory response, 2) enforcement of immune competence during prolonged sepsis, 3) reduction of organ damage and 4) providing insight in the underlying neural pathway, the rodent studies form a solid base for the translation of nutritional intervention to the human setting.

The first preclinical studies with enriched nutrition are described in part IV. Since rodent studies repeatedly demonstrated a crucial role for CCK release in the anti- 
inflammatory effects of lipid-rich nutrition, nutritional intervention in man should logically induce a fierce CCK response. Therefore, CCK levels were assessed in healthy volunteers following ingestion of a commercially available lipid-rich nutrition (Diasip) or a low-lipid nutrition (Respifor) (chapter 11). The compositions of these feedings are comparable to the formulas applied in the rodent studies. Since local intestinal CCK cannot be measured in man, CCK concentrations in circulation were determined as a surrogate marker. No differences in CCK peak levels following intake of both feedings were found. Based on previous studies showing that in particular proteins and fatty acids with aliphatic tails of more than 12 carbons are potent triggers of CCK release, in a subsequent series of experiments a lipid- and protein-enriched nutrition was compared with standard tube feeding ${ }^{20}$. Again, no differences in CCK levels were observed between groups. These findings suggest that circulatory CCK is an ineffective tool to select a nutritional composition based on its capacity to activate the vagal antiinflammatory pathway. Circulatory CCK levels may represent an overflow that does not reflect the level of local CCK concentrations in the gut wall that are required to stimulate the sensory nerves ${ }^{85}$. However, it cannot be ruled out that the nutritional compositions and doses applied did indeed not lead to different CCK responses but rather to differences in other enteral mediators such as GLP-1. Interestingly, increasing the dose of nutrition did not increase the CCK peak levels but tended to protract the CCK response. This phenomenon could be explained by a prolonged period of gastric emptying that results in continuous exposure of the duodenal wall to nutrients and hence, to a prolonged release of CCK. In order to induce ongoing CCK release, feeding should either be orally given as a bolus with an intact passage to the duodenum or administered continuously beyond the pylorus.

A second measure that was hypothesized to indicate activation of the vagal antiinflammatory reflex by enteral nutrition is heart rate variability (HRV). Assessment of $\mathrm{HRV}$ is a well-characterized diagnostic tool to assess the functioning of the autonomic nervous system in humans. In a cross-over study, beat-to-beat variations were measured in healthy volunteers that received either Diasip or Respifor. Using standard methodology to discriminate sympathetic and parasympathetic input, no differences in parasympathetic activity were observed between feedings. Possibly, both lipid-rich and low-lipid feeding resulted in a comparable activation of the vagus nerve, and hence, to a similar activation of the anti-inflammatory pathway. An alternative explanation for the lack of discrimination between feedings could be that the parasympathetic output measured by HRV does not represent activation of the efferent vagus nerve bundles that transfer the anti-inflammatory signal. In support of the second possibility, the effects of vagus nerve activation on blood pressure and the immune system were shown to be dissociable ${ }^{86}$. This line of thought has also been followed in a letter that 
responded to a cohort study by Thayer et al in which decreased HRV was related to increased markers of inflammation (chapter 12$)^{87}$.

Finally, a proof of principle study was performed in a human setting of endotoxemia (chapter 13). In this well-established model, a homogenous group of healthy volunteers was exposed to an intravenous bolus of endotoxin in a highly standardized manner, resulting in symptoms of sickness and increased plasma levels of inflammatory markers ${ }^{88}$. In order to minimize the risk of aspiration and to induce a constant exposure of the proximal intestinal wall to nutrition, a custom-made lipidand protein-enriched nutrition or an isocaloric control nutrition were continuously administered via a duodenal tube. Since pre-treatment was previously shown to exert stronger anti-inflammatory effects compared with post-treatment, nutrition was initiated before the endotoxin bolus was administered ${ }^{10,61}$. Compared with volunteers that received control feeding or were fasted, enriched nutrition significantly reduced the pro-inflammatory parameters TNF $\alpha$, IL-6 and IL-1RA. Furthermore, lipid-rich nutrition increased the levels of anti-inflammatory marker IL-10. A trend towards lower plasma FABP levels was observed in the lipid-rich fed group. These findings are first to translate the anti-inflammatory effects of short-term intervention with enriched enteral nutrition to a human setting of acute inflammation. Future studies should delineate to what extent the vagal anti-inflammatory reflex mediates the observed anti-inflammatory effects of the enriched feeding.

It should be noted that in this proof-of-principle study, circulatory inflammatory mediators were used as surrogate parameters. The significant improvement of these secondary markers is an important indicator that the acute immune response is attenuated, including a reduction of phagocytosis and granulocyte recruitment. As early regulation of inflammation has been associated with benefits on primary clinical outcome parameters such as improvement of survival and a decreased hospital stay, future studies should be powered to demonstrate differences in such primary clinical parameters.

The present thesis describes a CCK / CCK-1 receptor mediated vagovagal reflex that underlies the immune-modulatory effects of enteral lipid-rich nutrition (part I). In addition, a protective nutritional impact that encompasses a reduction of the inflammatory response and maintenance of intestinal integrity is demonstrated in several rodent models representing diverse surgical and critical care settings (part II and III). Finally, in this thesis a proof-of-principle study performed in a human endotoxemia model is described, indicating that enteral enriched nutrition attenuates the inflammatory response also in man (part IV).

Under physiological circumstances, this previously unknown anti-inflammatory gutbrain-immune axis may prevent the development of an unnecessary and energy- 
consuming immune response following the intake of nutrients and the concomitant low-grade exposure of the body to antigens and microbes ${ }^{89,90}$. In non-physiologic settings of major surgery, severe trauma or critical illness, the activation of the vagal anti-inflammatory reflex by nutritional means may form a therapeutic option to regulate the immune response. Such nutritional approach fits with current guidelines that promote optimal nutritional support in surgical and critical care patients ${ }^{91,92}$.

Although so far many facets of the nutritionally induced neuro-immune axis have been elucidated, more questions remain to be answered. At a cellular level, the range of effector cells of vagal anti-inflammatory signaling, which encompasses macrophages, mast cells (chapter $\mathbf{6}$ ) and more, requires further definition. Since cholinergic receptors are expressed by all human cell types, both neural and non-neural, in theory all human cells are to some extent under cholinergic control ${ }^{93}$. Next, the effects of nutritional vagus signaling on several important inflammatory disease entities needs to be established. For example, administration of nACh receptor agonists decreased inflammation and reduced symptoms in models of colitis, arthritis and pancreatitis ${ }^{94-96}$, however whether nutritional activation of the vagal anti-inflammatory reflex exerts the same beneficial effects in these settings is unclear. With regard to the representativeness of animal models, it should be noted that, whereas hospitalized patients are mostly elderly, experimental animals are usually young. Although it remains controversial to what extent the immune response in 'old' animals reflect the immunological characteristics of elderly patients, in the members of both species agerelated changes of immune parameters take place ${ }^{97}$. Therefore, to gain insight in the potential applicability in elderly patients, it would be highly interesting to investigate the effects of enriched nutrition in older animals submitted to inflammation.

It is important to note that side effects or health hazards of nutritional intervention were observed neither in the rodent studies, nor in the human proof-of-principle study. Postpylorical feeding, as described in chapter $\mathbf{1 3}$ of this thesis, is an attractive option in future studies in order to avoid aspiration and deliver adequate amounts of feeding in the proximal intestinal segment that contains most CCK-releasing enteroendocrine cells. Duodenal feeding is regarded as a safe and well-tolerated means to administer nutrients. In theory, enteral nutrition may increase splanchnic metabolic demands, which in turn may lead to a mismatch between the need and supply of oxygen ${ }^{98,99}$. However, even in clinical patients with hemodynamic instability that are prone to develop ischemic injury, no complications of duodenal feeding have been observed. Complications of duodenal feeding were reported only in patients that received long-term duodenal feeding or in patients with a pre-existent compromised gut $^{100}$. The following step to be taken towards clinical implementation of enriched feeding is a phase I study to assess the safety and tolerability of nutritional intervention. Such phase I trial should determine whether it is safe to initiate 
consecutive studies on the nutritional effects on inflammation, organ integrity and primary clinical parameters such as the development of inflammatory complications and survival. Since pre-treatment was shown to result in more potent immunomodulation compared with post-treatment, future studies should preferably be performed in patients undergoing elective surgery.

In a meta-analysis performed by Cerantola and colleagues, immunonutrition significantly reduced overall complications when applied either before surgery, or both before and after surgery, or solely after surgery. In addition, immunonutrition led to a shorter hospital stay, however did not affect mortality. Omega-3 fatty acids, arginine, glutamine and RNA are the most common components of immunonutrition that are applied in various combinations and doses. These nutritional supplements are reported to exert direct effects on cell-mediated immune function, release of acutephase proteins, development of the post-traumatic inflammatory cascade, and release of hormones such as insulin ${ }^{101}$. Activation of the vagal neuro-immune axis as described in this thesis adds a novel dimension to the concept of immunonutrition. As a supplement to the current nutritional support of surgical and critically ill patients, activation of the vagal anti-inflammatory reflex with lipid- and protein-enriched nutrition may expand the treatment arsenal in patients that succumb to dysregulated inflammation. 


\section{References}

1. Beutler B, Poltorak A. Sepsis and evolution of the innate immune response. Crit Care Med 2001;29 (7 Suppl):S2-6; discussion S6-7.

2. Chaplin DD. 1. Overview of the immune response. J Allergy Clin Immunol 2003;111(2 Suppl):S442-459.

3. Dombrovskiy VY, Martin AA, Sunderram J, Paz HL. Rapid increase in hospitalization and mortality rates for severe sepsis in the United States: a trend analysis from 1993 to 2003. Crit Care Med 2007; 35:1244-1250.

4. Angus DC, Linde-Zwirble WT, Lidicker J, Clermont G, Carcillo J, Pinsky MR. Epidemiology of severe sepsis in the United States: analysis of incidence, outcome, and associated costs of care. Crit Care Med 2001;29:1303-1310.

5. Riedemann NC, Guo RF, Ward PA. The enigma of sepsis. J Clin Invest 2003;112:460-467.

6. Tracey KJ. Reflex control of immunity. Nat Rev Immunol 2009;9:418-428.

7. Van Der Zanden EP, Boeckxstaens GE, de Jonge WJ. The vagus nerve as a modulator of intestinal inflammation. Neurogastroenterol Motil 2009;21:6-17.

8. Woods SC. Gastrointestinal satiety signals I. An overview of gastrointestinal signals that influence food intake. Am J Physiol Gastrointest Liver Physiol 2004;286:G7-13.

9. Cummings DE, Overduin J. Gastrointestinal regulation of food intake. J Clin Invest 2007;117:13-23.

10. Luyer MD, Greve JW, Hadfoune M, Jacobs JA, Dejong $\mathrm{CH}$, Buurman WA. Nutritional stimulation of cholecystokinin receptors inhibits inflammation via the vagus nerve. J Exp Med 2005;202:1023-1029.

11. Glatzle J, Kasparek MS, Mueller MH, Binder F, Meile T, Kreis ME, Konigsrainer A, Steurer W. Enteral immunonutrition during sepsis prevents pulmonary dysfunction in a rat model. J Gastrointest Surg 2007;11:719-724.

12. Eisner F, Jacob P, Frick JS, Feilitzsch M, Geisel J, Mueller MH, Kuper MA, Raybould HE, Konigsrainer I, Glatzle J. Immunonutrition with long-chain fatty acids prevents activation of macrophages in the gut wall. J Gastrointest Surg 2011;15:853-859.

13. Raybould HE, Tache Y. Cholecystokinin inhibits gastric motility and emptying via a capsaicin-sensitive vagal pathway in rats. Am J Physiol 1988;255:G242-246.

14. Lubbers T, de Haan JJ, Luyer MD, Verbaeys I, Hadfoune M, Dejong CH, Buurman WA, Greve JW. Cholecystokinin/Cholecystokinin-1 receptor-mediated peripheral activation of the afferent vagus by enteral nutrients attenuates inflammation in rats. Ann Surg 2010;252:376-382.

15. Ebenezer IS, Parrott RF. A70104 and food intake in pigs: implication for the CCK 'satiety' hypothesis. Neuroreport 1993;4:495-498.

16. Niederau C, Liddle RA, Ferrell LD, Grendell JH. Beneficial effects of cholecystokinin-receptor blockade and inhibition of proteolytic enzyme activity in experimental acute hemorrhagic pancreatitis in mice. Evidence for cholecystokinin as a major factor in the development of acute pancreatitis. J Clin Invest 1986;78:1056-1063.

17. Verbaeys I, Leon-Tamariz F, Pottel H, Decuypere E, Swennen Q, Cokelaere M. PEGylated cholecystokinin is more potent in inducing anorexia than conditioned taste aversion in rats. $\mathrm{Br} J$ Pharmacol 2008;155:417-423.

18. Lal S, Kirkup AJ, Brunsden AM, Thompson DG, Grundy D. Vagal afferent responses to fatty acids of different chain length in the rat. Am J Physiol Gastrointest Liver Physiol 2001;281:G907-915.

19. Moran TH, Baldessarini AR, Salorio CF, Lowery T, Schwartz GJ. Vagal afferent and efferent contributions to the inhibition of food intake by cholecystokinin. Am J Physiol 1997;272:R1245-1251.

20. Karhunen L, Juvonen KR, Huotari A, Purhonen AK, Herzig KH. Effect of protein, fat, carbohydrate and fibre on gastrointestinal peptide release in humans. Regul Pept 2008;149:70-78.

21. Glatzle J, Wang Y, Adelson DW, Kalogeris TJ, Zittel TT, Tso P, Wei JY, Raybould HE. Chylomicron components activate duodenal vagal afferents via a cholecystokinin A receptor-mediated pathway to inhibit gastric motor function in the rat. J Physiol 2003;550:657-664.

22. Lubbers T, de Haan JJ, Hadfoune M, Zabeau L, Tavernier J, Zhang Y, Grundy D, Greve JW, Buurman WA. Chylomicron formation and glucagon-like peptide 1 receptor are involved in activation of the nutritional anti-inflammatory pathway. J Nutr Biochem 2011;22:1105-1111.

23. Tso P, Balint JA, Bishop MB, Rodgers JB. Acute inhibition of intestinal lipid transport by Pluronic L-81 in the rat. Am J Physiol 1981;241:G487-497. 
24. Luyer MD, Buurman WA, Hadfoune M, Jacobs JA, Dejong CH, Greve JW. High-fat enteral nutrition reduces endotoxin, tumor necrosis factor-alpha and gut permeability in bile duct-ligated rats subjected to hemorrhagic shock. J Hepatol 2004;41:377-383.

25. Dockray GJ. The versatility of the vagus. Physiol Behav 2009;97:531-536.

26. Beglinger S, Drewe J, Schirra J, Goke B, D'Amato M, Beglinger C. Role of fat hydrolysis in regulating glucagon-like Peptide-1 secretion. J Clin Endocrinol Metab 2010;95:879-886.

27. Degen L, Drewe J, Piccoli F, Grani K, Oesch S, Bunea R, D'Amato M, Beglinger C. Effect of CCK-1 receptor blockade on ghrelin and PYY secretion in men. Am J Physiol Regul Integr Comp Physiol 2007; 292:R1391-1399.

28. Garrett WS, Gordon JI, Glimcher LH. Homeostasis and inflammation in the intestine. Cell 2010; 140:859-870.

29. Carrico CJ, Meakins JL, Marshall JC, Fry D, Maier RV. Multiple-organ-failure syndrome. Arch Surg 1986; 121:196-208.

30. MacFie J, O'Boyle C, Mitchell CJ, Buckley PM, Johnstone D, Sudworth P. Gut origin of sepsis: a prospective study investigating associations between bacterial translocation, gastric microflora, and septic morbidity. Gut 1999;45:223-228.

31. Clark JA, Coopersmith CM. Intestinal crosstalk: a new paradigm for understanding the gut as the "motor" of critical illness. Shock 2007;28:384-393.

32. Deitch EA. Role of the gut lymphatic system in multiple organ failure. Curr Opin Crit Care 2001;7:92-98.

33. Chang M, Kistler EB, Schmid-Schonbein GW. Disruption of the mucosal barrier during gut ischemia allows entry of digestive enzymes into the intestinal wall. Shock 2012;37:297-305.

34. Derikx JP, van Waardenburg DA, Thuijls G, Willigers HM, Koenraads M, van Bijnen AA, Heineman E, Poeze M, Ambergen T, van Ooij A et al. New Insight in Loss of Gut Barrier during Major Non-Abdominal Surgery. PLoS One 2008;3:e3954.

35. Derikx JP, Poeze M, van Bijnen AA, Buurman WA, Heineman E. Evidence for intestinal and liver epithelial cell injury in the early phase of sepsis. Shock 2007;28:544-548.

36. Clark JA, Gan H, Samocha AJ, Fox AC, Buchman TG, Coopersmith CM. Enterocyte-specific epidermal growth factor prevents barrier dysfunction and improves mortality in murine peritonitis. Am J Physiol Gastrointest Liver Physiol 2009;297:G471-479.

37. Wu L, Zaborina O, Zaborin A, Chang EB, Musch M, Holbrook C, Shapiro J, Turner JR, Wu G, Lee KY et al. High-molecular-weight polyethylene glycol prevents lethal sepsis due to intestinal Pseudomonas aeruginosa. Gastroenterology 2004;126:488-498.

38. Ewaschuk J, Endersby R, Thiel D, Diaz H, Backer J, Ma M, Churchill T, Madsen K. Probiotic bacteria prevent hepatic damage and maintain colonic barrier function in a mouse model of sepsis. Hepatology 2007;46:841-850.

39. Su L, Shen L, Clayburgh DR, Nalle SC, Sullivan EA, Meddings JB, Abraham C, Turner JR. Targeted epithelial tight junction dysfunction causes immune activation and contributes to development of experimental colitis. Gastroenterology 2009;136:551-563.

40. Silvestri L, van Saene HK, Zandstra DF, Marshall JC, Gregori D, Gullo A. Impact of selective decontamination of the digestive tract on multiple organ dysfunction syndrome: systematic review of randomized controlled trials. Crit Care Med 2010;38:1370-1376.

41. Reed RL. Prevention of hospital-acquired infections by selective digestive decontamination. Surg Infect (Larchmt) 2011;12:221-229.

42. Langkamp-Henken B, Donovan TB, Pate LM, Maull CD, Kudsk KA. Increased intestinal permeability following blunt and penetrating trauma. Crit Care Med 1995;23:660-664.

43. de Haan JJ, Lubbers T, Derikx JP, Relja B, Henrich D, Greve JW, Marzi I, Buurman WA. Rapid development of intestinal cell damage following severe trauma: a prospective observational cohort study. Crit Care 2009;13:R86.

44. Pelsers MM, Namiot Z, Kisielewski W, Namiot A, Januszkiewicz M, Hermens WT, Glatz JF. Intestinaltype and liver-type fatty acid-binding protein in the intestine. Tissue distribution and clinical utility. Clin Biochem 2003;36:529-535.

45. Derikx JP, Matthijsen RA, de Bruine AP, van Bijnen AA, Heineman E, van Dam RM, Dejong CH, Buurman WA. Rapid reversal of human intestinal ischemia-reperfusion induced damage by shedding of injured enterocytes and reepithelialisation. PLoS One 2008;3:e3428. 
46. Deitch EA, Xu D, Kaise VL. Role of the gut in the development of injury- and shock induced SIRS and MODS: the gut-lymph hypothesis, a review. Front Biosci 2006;11:520-528.

47. Bark T, Katouli M, Ljungqvist O, Mollby R, Svenberg T. Bacterial translocation after non-lethal hemorrhage in the rat. Circ Shock 1993;41:60-65.

48. Thuijls G, de Haan JJ, Derikx JP, Daissormont I, Hadfoune M, Heineman E, Buurman WA. Intestinal cytoskeleton degradation precedes tight junction loss following hemorrhagic shock. Shock 2009; 31:164-169.

49. de Haan J, Thuijls, G., Lubbers T., Hadfoune M, Reisinger K, Heineman E, Greve J., Buurman W. Protection against early intestinal compromise by lipid-rich enteral nutrition via cholecystokininreceptors. Crit Care Med 2010;38:1592-1597.

50. Saunders PR, Hanssen NP, Perdue MH. Cholinergic nerves mediate stress-induced intestinal transport abnormalities in Wistar-Kyoto rats. Am J Physiol 1997;273:G486-490.

51. Cameron $\mathrm{HL}$, Perdue $\mathrm{MH}$. Muscarinic acetylcholine receptor activation increases transcellular transport of macromolecules across mouse and human intestinal epithelium in vitro. Neurogastroenterol Motil 2007;19:47-56.

52. Fink MP, Delude RL. Epithelial barrier dysfunction: a unifying theme to explain the pathogenesis of multiple organ dysfunction at the cellular level. Crit Care Clin 2005;21:177-196.

53. Luyer MD, Derikx JP, Beyaert R, Hadfoune M, van Kuppevelt TH, Dejong CH, Heineman E, Buurman WA, Greve JW. High-fat nutrition reduces hepatic damage following exposure to bacterial DNA and hemorrhagic shock. J Hepatol 2009;50:342-350.

54. Wang H, Yu M, Ochani M, Amella CA, Tanovic M, Susarla S, Li JH, Yang H, Ulloa L, Al-Abed Y et al. Nicotinic acetylcholine receptor alpha7 subunit is an essential regulator of inflammation. Nature 2003; 421:384-388.

55. Abraham SN, St John AL. Mast cell-orchestrated immunity to pathogens. Nat Rev Immunol 2010; 10:440-452.

56. Dawicki W, Marshall JS. New and emerging roles for mast cells in host defence. Curr Opin Immunol 2007;19:31-38.

57. Galli SJ, Grimbaldeston M, Tsai M. Immunomodulatory mast cells: negative, as well as positive, regulators of immunity. Nat Rev Immunol 2008;8:478-486.

58. Scudamore CL, Thornton EM, McMillan L, Newlands GF, Miller HR. Release of the mucosal mast cell granule chymase, rat mast cell protease-II, during anaphylaxis is associated with the rapid development of paracellular permeability to macromolecules in rat jejunum. J Exp Med 1995; 182:1871-1881.

59. Moriez R, Salvador-Cartier C, Theodorou V, Fioramonti J, Eutamene H, Bueno L. Myosin light chain kinase is involved in lipopolysaccharide-induced disruption of colonic epithelial barrier and bacterial translocation in rats. Am J Pathol 2005;167:1071-1079.

60. Jiang W, Kirkup AJ, Grundy D. Mast cells drive mesenteric afferent signalling during acute intestinal ischaemia. J Physiol 2011;589:3867-3882.

61. de Haan JJ, Lubbers T, Hadfoune M, Luyer MD, Dejong CH, Buurman WA, Greve JW. Postshock intervention with high-lipid enteral nutrition reduces inflammation and tissue damage. Ann Surg 2008; 248:842-848.

62. Schoenborn JR, Wilson CB. Regulation of interferon-gamma during innate and adaptive immune responses. Adv Immunol 2007;96:41-101.

63. Couper KN, Blount DG, Riley EM. IL-10: the master regulator of immunity to infection. J Immunol 2008; 180:5771-5777.

64. Vermeulen Windsant IC, Snoeijs MG, Hanssen SJ, Altintas S, Heijmans JH, Koeppel TA, Schurink GW, Buurman WA, Jacobs MJ. Hemolysis is associated with acute kidney injury during major aortic surgery. Kidney Int 2010;77:913-920.

65. Hanssen SJ, Lubbers T, Hodin CM, Prinzen FW, Buurman WA, Jacobs MJ. Hemolysis results in impaired intestinal microcirculation and intestinal epithelial cell injury. World J Gastroenterol 2011;17:213-218.

66. Minneci PC, Deans KJ, Zhi H, Yuen PS, Star RA, Banks SM, Schechter AN, Natanson C, Gladwin MT, Solomon SB. Hemolysis-associated endothelial dysfunction mediated by accelerated NO inactivation by decompartmentalized oxyhemoglobin. J Clin Invest 2005;115:3409-3417.

67. Rother RP, Bell L, Hillmen P, Gladwin MT. The clinical sequelae of intravascular hemolysis and extracellular plasma hemoglobin: a novel mechanism of human disease. JAMA 2005;293:1653-1662. 
68. Gladwin MT, Schechter AN, Ognibene FP, Coles WA, Reiter CD, Schenke WH, Csako G, Waclawiw MA, Panza JA, Cannon RO, 3rd. Divergent nitric oxide bioavailability in men and women with sickle cell disease. Circulation 2003;107:271-278.

69. Baile EM, McKay K, Wang L, Bai TR, Pare PD. NO does not mediate inhibitory neural responses in sheep airway and bronchial vascular smooth muscle. J Appl Physiol 1998;84:809-814.

70. Imaeda K, Yamamoto Y, Fukuta H, Koshita M, Suzuki H. Hyperpolarization-induced dilatation of submucosal arterioles in the guinea-pig ileum. Br J Pharmacol 2000;131:1121-1128.

71. Eguchi S, Miyashita S, Kitamura Y, Kawasaki H. Alpha3beta4-nicotinic receptors mediate adrenergic nerve- and peptidergic (CGRP) nerve-dependent vasodilation induced by nicotine in rat mesenteric arteries. Br J Pharmacol 2007;151:1216-1223.

72. Tanaka K, Kanamori Y, Sato T, Kondo C, Katayama Y, Yada I, Yuasa H, Kusagawa M. Administration of haptoglobin during cardiopulmonary bypass surgery. ASAIO Trans 1991;37:M482-483.

73. Bryan NS, Calvert JW, Elrod JW, Gundewar S, Ji SY, Lefer DJ. Dietary nitrite supplementation protects against myocardial ischemia-reperfusion injury. Proc Natl Acad Sci U S A 2007;104:19144-19149.

74. Lubbers T, De Haan JJ, Hadfoune M, Zhang Y, Luyer MD, Grundy D, Buurman WA, Greve JW. Lipidenriched enteral nutrition controls the inflammatory response in murine Gram-negative sepsis. Crit Care Med 2010;38:1996-2002.

75. Pavlov VA, Ochani M, Yang LH, Gallowitsch-Puerta M, Ochani K, Lin X, Levi J, Parrish WR, Rosas-Ballina $\mathrm{M}, \mathrm{Czura} \mathrm{CJ}$ et al. Selective alpha7-nicotinic acetylcholine receptor agonist GTS-21 improves survival in murine endotoxemia and severe sepsis. Crit Care Med 2007;35:1139-1144.

76. Borovikova LV, Ivanova S, Zhang M, Yang H, Botchkina GI, Watkins LR, Wang H, Abumrad N, Eaton JW, Tracey KJ. Vagus nerve stimulation attenuates the systemic inflammatory response to endotoxin. Nature 2000;405:458-462.

77. Reddy RC, Chen GH, Tekchandani PK, Standiford TJ. Sepsis-induced immunosuppression: from bad to worse. Immunol Res 2001;24:273-287.

78. Hotchkiss RS, Karl IE. The pathophysiology and treatment of sepsis. N Engl J Med 2003;348:138-150.

79. Richardson JD, DeCamp MM, Garrison RN, Fry DE. Pulmonary infection complicating intra-abdominal sepsis: clinical and experimental observations. Ann Surg 1982;195:732-738.

80. Adib-Conquy M, Cavaillon JM. Compensatory anti-inflammatory response syndrome. Thromb Haemost 2009;101:36-47.

81. Delano MJ, Thayer T, Gabrilovich S, Kelly-Scumpia KM, Winfield RD, Scumpia PO, Cuenca AG, Warner E, Wallet SM, Wallet MA et al. Sepsis induces early alterations in innate immunity that impact mortality to secondary infection. J Immunol 2011;186:195-202.

82. Pastille E, Didovic S, Brauckmann D, Rani M, Agrawal H, Schade FU, Zhang Y, Flohe SB. Modulation of dendritic cell differentiation in the bone marrow mediates sustained immunosuppression after polymicrobial sepsis. J Immunol 2011;186:977-986.

83. Wen H, Hogaboam CM, Gauldie J, Kunkel SL. Severe sepsis exacerbates cell-mediated immunity in the lung due to an altered dendritic cell cytokine profile. Am J Pathol 2006;168:1940-1950.

84. Choudhry MA, Bland KI, Chaudry IH. Trauma and immune response--effect of gender differences. Injury 2007;38:1382-1391.

85. Cheung GW, Kokorovic A, Lam CK, Chari M, Lam TK. Intestinal cholecystokinin controls glucose production through a neuronal network. Cell Metab 2009;10:99-109.

86. Huston JM, Gallowitsch-Puerta M, Ochani M, Ochani K, Yuan R, Rosas-Ballina M, Ashok M, Goldstein RS, Chavan S, Pavlov VA et al. Transcutaneous vagus nerve stimulation reduces serum high mobility group box 1 levels and improves survival in murine sepsis. Crit Care Med 2007;35:2762-2768.

87. Thayer JF, Fischer JE. Heart rate variability, overnight urinary norepinephrine and C-reactive protein: evidence for the cholinergic anti-inflammatory pathway in healthy human adults. J Intern Med 2009; 265:439-447.

88. Lowry SF. Human endotoxemia: a model for mechanistic insight and therapeutic targeting. Shock 2005; 24 Suppl 1:94-100.

89. Erridge C, Attina T, Spickett CM, Webb DJ. A high-fat meal induces low-grade endotoxemia: evidence of a novel mechanism of postprandial inflammation. Am J Clin Nutr 2007;86:1286-1292.

90. Aljada A, Mohanty P, Ghanim H, Abdo T, Tripathy D, Chaudhuri A, Dandona P. Increase in intranuclear nuclear factor kарраB and decrease in inhibitor kappaB in mononuclear cells after a mixed meal: evidence for a proinflammatory effect. Am J Clin Nutr 2004;79:682-690. 
91. Kreymann KG, Berger MM, Deutz NE, Hiesmayr M, Jolliet $P$, Kazandjiev G, Nitenberg $G$, van den Berghe G, Wernerman J, Ebner C et al. ESPEN Guidelines on Enteral Nutrition: Intensive care. Clin Nutr 2006; 25:210-223.

92. Martindale RG, McClave SA, Vanek VW, McCarthy M, Roberts P, Taylor B, Ochoa JB, Napolitano L, Cresci G. Guidelines for the provision and assessment of nutrition support therapy in the adult critically ill patient: Society of Critical Care Medicine and American Society for Parenteral and Enteral Nutrition: Executive Summary. Crit Care Med 2009;37:1757-1761.

93. Wessler I, Kirkpatrick CJ. Acetylcholine beyond neurons: the non-neuronal cholinergic system in humans. Br J Pharmacol 2008;154:1558-1571.

94. van Westerloo DJ, Giebelen IA, Florquin S, Bruno MJ, Larosa GJ, Ulloa L, Tracey KJ, van der Poll T. The vagus nerve and nicotinic receptors modulate experimental pancreatitis severity in mice. Gastroenterology 2006;130:1822-1830.

95. van Maanen MA, Lebre MC, van der Poll T, LaRosa GJ, Elbaum D, Vervoordeldonk MJ, Tak PP. Stimulation of nicotinic acetylcholine receptors attenuates collagen-induced arthritis in mice. Arthritis Rheum 2009;60:114-122.

96. Bai A, Guo Y, Lu N. The effect of the cholinergic anti-inflammatory pathway on experimental colitis. Scand J Immunol 2007;66:538-545.

97. De la Fuente M. Role of neuroimmunomodulation in aging. Neuroimmunomodulation 2008;15: 213-223.

98. Revelly JP, Tappy L, Berger MM, Gersbach P, Cayeux C, Chiolero R. Early metabolic and splanchnic responses to enteral nutrition in postoperative cardiac surgery patients with circulatory compromise. Intensive Care Med 2001;27:540-547.

99. Berger MM, Revelly JP, Cayeux MC, Chiolero RL. Enteral nutrition in critically ill patients with severe hemodynamic failure after cardiopulmonary bypass. Clin Nutr 2005;24:124-132.

100. Rokyta R, Jr., Matejovic M, Krouzecky A, Novak I. Enteral nutrition and hepatosplanchnic region in critically ill patients - friends or foes? Physiol Res 2003;52:31-37.

101. Cerantola $\mathrm{Y}$, Hubner M, Grass F, Demartines N, Schafer M. Immunonutrition in gastrointestinal surgery. Br J Surg 2011;98:37-48. 


\section{Samenvatting}


Verschillende barrières beschermen het lichaam tegen het binnendringen van pathogenen. Een beschadiging van deze barrières leidt tot een reactie van het immuunsysteem. Deze reactie wordt niet alleen worden veroorzaakt door binnendringende pathogenen, maar kan ook worden opgeroepen door lichaamseigen stoffen die bijvoorbeeld vrijkomen bij weefselschade. Een adequate en proportionele immuunrespons leidt tot neutralisatie van ziekteverwekkers en herstel van de geleden schade. Echter, vooral traumapatiënten, patiënten die een grote operatie krijgen of patiënten die een zware chemokuur ondergaan lopen risico op het ontwikkelen van excessieve ontstekingsreacties. Dergelijke buitensporige reacties van het immuunsysteem worden gedefinieerd als sepsis en sepsis-achtige syndromen. Hoewel de behandeling van sepsis in de laatste jaren is verbeterd, blijven de morbiditeit en mortaliteit van patiënten met deze ziektebeelden zeer hoog. Er bestaat daarom een grote behoefte aan nieuwe methoden om de immuunreactie onder controle te houden, zodat sepsis kan worden voorkomen of beter kan worden behandeld.

Een veelbelovende manier om de ontstekingsreactie te beïnvloeden is stimulering van het autonome zenuwstelsel, en in het bijzonder het parasympatisch zenuwstelsel. De ontstekingsremmende impulsen van het parasympatisch zenuwstelsel, die vooral via de nervus vagus worden voortgeleid, werden voor het eerst door dr. Tracey en collega's beschreven. In septische proefdieren toonden zij aan dat zowel elektrische prikkeling van de nervus vagus als farmacologische stimulering van nicotinerge acetylcholine ( $\mathrm{nACh}$ ) receptoren de afgifte van ontstekingsstoffen (bijvoorbeeld cytokines) remt. Ook leiden deze interventies tot minder orgaanschade en minder sterfte. Onze onderzoeksgroep liet eerder in een diermodel zien dat lipiderijke voeding via stimulatie van de nervus vagus de ontstekingsreactie remt en schade aan de darm en lever vermindert. Bij gezonde mensen zouden deze dempende effecten van enterale voeding een onnodige ontstekingsreactie kunnen voorkomen. Inname van voeding leidt namelijk tot een beperkte blootstelling van de darmwand aan microorganismen en antigenen die doorgaans geen sterke afweerreactie vereist. Bij patiënten bij wie de ontstekingsreactie te hevig is, zou activatie van deze ontstekingsremmende neuro-immuun-as door specifieke voeding kunnen bijdragen aan de behandeling. De in dit proefschrift beschreven studies kunnen worden beschouwd als stappen op de weg naar klinische toepassing van stimulering van het parasympatische zenuwstelsel door middel van enterale voeding.

Het eerste doel van dit proefschrift is het verder ontrafelen van het mechanisme dat aan de ontstekingsremmende werking van lipiderijke voeding ten grondslag ligt. Het tweede doel is de werkzaamheid van stimulatie van het autonome zenuwstelsel door voeding te onderzoeken. Hiervoor gebruiken we verschillende diermodellen voor belangrijke ziektebeelden in chirurgische en intensive care patiënten. Het derde doel is het vertalen van deze experimentele bevindingen naar de mens. Voor het eerst wordt 
aangetoond dat kortdurende interventie met verrijkte enterale voeding een acute ontstekingsrespons bij de mens remt.

Kennis van de mechanismen die de ontstekingsremmende werking van lipiderijke voeding verklaren is noodzakelijk om een optimale klinische behandeling te ontwikkelen en gezondheidsrisico's te beperken. In het eerste deel van dit proefschrift wordt onderzocht op welke manier voeding het centraal zenuwstelsel aanzet tot remming van de ontstekingsreactie. In eerdere studies bleek de communicatie tussen enterale voedingsstoffen en het brein te verlopen zowel via sensorische zenuwen als via de bloedbaan. Om de route te achterhalen waarlangs het ontstekingsremmende signaal wordt overgebracht, worden de sensorische zenuwen op cervicaal niveau uitgeschakeld door middel van capsaicine. Wanneer de signaaloverdracht via afferente vagusbundels op deze wijze wordt onderbroken, is lipiderijke voeding niet langer in staat om de ontstekingsreactie te dempen (hoofdstuk 2). Vervolgens wordt ingegaan op de activatie van de zenuwuiteinden in de darmwand. In eerdere studies werd aangetoond dat cholecystokinine (CCK) receptoren een essentiële schakel vormen in de ontstekingsremmende werking van lipiderijke voeding. CCK-receptoren komen onder meer voor op de perifere uiteinden van de afferente nervus vagus. Met behulp van specifieke antagonisten stellen we vast dat perifeer gelegen CCK-1 receptoren een cruciale schakel vormen in de gunstige effecten van lipiderijke voeding. In overeenstemming hiermee leidt toediening van een vorm van CCK die specifiek aan perifeer gelegen CCK-1 receptoren bindt, in gevaste dieren tot een zelfde mate van ontstekingsremming als lipiderijke voeding. Concluderend toont deze studie een voorheen onbekende darm-hersen-immuun reflex aan, berustend op activatie van perifeer gelegen CCK-1 receptoren en aanvoerende takken van de nervus vagus door nutriënten in het darmlumen.

In het tweede deel van dit proefschrift wordt de aantasting van de darmwand in de vroege fase van een systemische ontstekingsrespons bestudeerd, en de effecten van lipiderijke voeding hierop. Verschillende experimentele en klinische studies wijzen op een belangrijke rol van de darm in de ontwikkeling en ontsporing van de systemische ontstekingsreactie. Met behulp van de in het bloed gemeten biomarker I-FABP werd door dr. Derikx en collega's aangetoond dat schade aan enterocyten (darmepitheelcellen) plaatsvindt zowel in een vroeg stadium van sepsis als kort na niet-abdominale chirurgie. De mate van enterocytschade bleek samen te hangen met de prognose van deze patiënten en het ontstaan van complicaties. Een belangrijke patiëntengroep met een sterk verhoogd risico op het ontstaan van sepsis zijn mensen met een groot fysiek trauma. In hoofdstuk $\mathbf{3}$ wordt beschreven hoe met behulp van IFABP is vastgesteld dat enterocytschade na trauma al detecteerbaar is op het moment 
dat patiënten arriveren op de spoedeisende hulp. De mate van vroege enterocytschade is gerelateerd aan de omvang van het trauma, alsook aan de hoogte van ontstekingsparameters IL-6, CRP en procalcitonine, gemeten in de dagen na het trauma. Deze bevindingen impliceren dat vroege aantasting van de darmwand als een aangrijpingspunt kan worden beschouwd voor ontstekingsremmende interventies in traumapatiënten.

De veranderingen in de darmwand kort na activatie van het afweersysteem worden nader bestudeerd in een diermodel van hemorragische shock. In hoofdstuk 4 wordt beschreven dat afbraak van de actinefilamenten die de enterocyt structuur geven al een kwartier na shock plaatsvindt. De verstoring van de celstructuur wordt gevolgd door afbraak van de 'tight junctions' die de enterocyten onderling verbinden. Deze structurele veranderingen gaan gepaard met een toename van de permeabiliteit van de darmwand en het ontstaan van een lokale ontstekingsrespons. Deze processen in de darmwand gaan vooraf aan het verschijnen van ontstekingsstoffen in de circulatie. Vervolgens worden de effecten van lipiderijke voeding op de vroege aantasting van de darmwand bestudeerd. In hoofdstuk $\mathbf{5}$ wordt beschreven dat toediening van lipiderijke voeding de doorlaatbaarheid van de darmwand beperkt. Verder leidt voedingsinterventie tot een afname van enterocytschade en minder ontsteking van de darmwand. Blokkade van de CCK-receptoren, die een cruciale rol spelen in de activatie van de nervus vagus, neemt de effecten van voeding weg. Concluderend tonen deze data aan dat lipiderijke voeding vroege aantasting van de darmwand voorkomt via activatie van de vagale reflex.

Wanneer de darmbarrière wordt aangetast, behoren mestcellen tot de eerste cellen van het afweersysteem die immuno-actieve mediatoren uitscheiden. Verschillende recente studies tonen aan dat mestcellen een belangrijk onderdeel vormen van de immunologische barrière tussen de darminhoud en het lichaam. De reactiviteit van mucosale mestcellen wordt nader bestudeerd in het endotoxinemodel, een veel gebruikt model voor de systemische ontstekingsreactie die tijdens de vroege fase van sepsis optreedt (hoofdstuk 6). Toediening van een bolus endotoxine, een component van de celwand van Gramnegatieve bacteriën, roept een respons van het afweersysteem op. Behandeling met histamine receptor-1 blokker en mestcelstabilisator ketotifen leidt tot lagere concentraties ontstekingsstoffen in de circulatie en behoud van de darmbarrière. Hiermee wordt het belang van mestcelactivatie in het ontstaan van ontsteking en aantasting van darmintegriteit bevestigd. Lipiderijke voeding voorafgaand aan de gift endotoxine remt de mestcelactivatie. Blokkade van zowel CCK-1 receptoren als nACh receptoren neemt de remmende effecten van voeding op mestcelactivatie weg, wat een cruciale rol van de CCK-1 receptorafhankelijke vagale reflex aantoont. Deze bevindingen worden ondersteund door in vitro experimenten waarin een dosisafhankelijke mestcelremming wordt aangetoond 
door nicotine en acetylcholine (agonisten van de nACh receptor). Concluderend blijkt uit deze experimenten dat remming van mucosale mestcellen een aangrijpingspunt is voor de door enterale voeding geactiveerde vagale reflex.

In het derde deel van dit proefschrift wordt de werkzaamheid van verrijkte voeding onderzocht in verschillende situaties waarin een ontregelde afweerreactie centraal staat. Al eerder werden patiënten met een ernstig trauma genoemd als een patiëntengroep bij wie een sterke activatie van het immuunsysteem optreedt. Logischerwijs kan bij deze patiënten de behandeling pas worden gestart op het moment dat er al weefselschade is en de ontstekingsrespons zich reeds ontwikkelt. Om deze situatie na te bootsen wordt in het hemorragische shockmodel pas gestart met voeding op het moment dat shock-gerelateerde ontsteking en weefselschade al aanwezig zijn (hoofdstuk 7). Lipiderijke voeding toegediend na shock resulteert in een vermindering van de ontstekingsrespons en behoud van de darmwand in vergelijking met gevaste dieren. Het feit dat blokkers van de CCK-receptor het beschermende effect van voeding na shock wegnemen wijst erop dat stimulatie van de CCK receptor afhankelijke vagale reflex ook in deze situatie cruciaal is.

Afbraak van erytrocyten, oftewel hemolyse, is een fenomeen dat frequent wordt waargenomen bij verschillende groepen (cardio)chirurgische patiënten en patiënten op de intensive care. Recente studies leggen een verband tussen massale hemolyse, het optreden van circulatieproblemen en een verslechterde orgaanfunctie. Tijdens hemolyse komen grote hoeveelheden hemoglobine vrij, dat een onomkeerbare reactie met stikstofmonoxide aangaat. De tekorten aan stikstofmonoxide die vervolgens ontstaan worden verondersteld een belangrijk deel van de circulatieproblemen te verklaren. Stikstofmonoxide zorgt namelijk voor relaxatie van glad spierweefsel. Het is bekend dat de gevoeligheid voor stikstofmonoxide-onafhankelijke vaatverwijders tijdens hemolyse juist toeneemt. Aangezien acetylcholine, een neurotransmitter die vrijkomt door stimulatie van de nervus vagus, als een krachtige en stikstofmonoxideonafhankelijke vaatverwijder functioneert, veronderstelden wij dat lipiderijke voeding via het vrijkomen van acetylcholine de schadelijke gevolgen van acute hemolyse zou kunnen beperken. Het effect van lipiderijke voeding wordt onderzocht in een diermodel waarin hemolyse wordt nagebootst door infusie van gelyseerde erythrocyten (hoofdstuk 8). Conform de hypothese leidt interventie met enterale voeding via activatie van CCK-1 receptoren en $\mathrm{nACh}$ receptoren tot een sterke vermindering van orgaanschade en afname van de systemische ontstekingsreactie. Bovendien wordt met behulp van microsferen (fluorescente bolletjes) aangetoond dat lipiderijke voeding de microcirculatie in de nier, darm en lever verbetert. Deze data impliceren dat stimulatie van de vagale reflex door middel van voeding kan bijdragen aan het voorkomen van complicaties van acute hemolyse. 
Sepsis is een veel voorkomende excessieve reactie van het lichaam op een bacteriële infectie. In hoofdstuk 9 worden de effecten van nervus vagusstimulatie met enterale voeding in het endotoxinemodel beschreven. Zowel lipiderijke voeding als controlevoeding remmen dosisafhankelijk de afgifte van cytokines. Lipiderijke voeding vermindert de ontstekingsreactie in lagere doseringen dan de controlevoeding, wat aangeeft dat het ontstekingsremmende effect van voeding kan worden vergroot door toevoeging van specifieke voedingsstoffen. Ook de mate van enterocytschade en ontsteking in de lever en milt zijn verminderd in dieren die lipiderijke voeding krijgen. De betrokkenheid van de nervus vagus wordt aangetoond door middel van blokkers van CCK receptoren en nACh receptoren. Bovendien leidt lipiderijke voeding tot een toegenomen activiteit van mechanosensitieve zenuwen na rek van de darmwand. Overigens resulteert het oprekken van de maag op zichzelf niet in een significante remming van de ontstekingsrespons, wat er op wijst dat de aanwezigheid van voedingsstoffen essentieel is.

De effecten van lipiderijke voeding op sepsis worden verder onderzocht in een model voor polymicrobiële sepsis waarbij de blinde darm wordt afgebonden en geperforeerd (CLP; cecal ligation and puncture). Ook in dit sepsismodel leidt voedingsinterventie tot een afname van de acute ontstekingsrespons (hoofdstuk 10). Een belangrijk kenmerk van het CLP-model is de ontwikkeling van een immuunsuppressieve periode na de initiële hyperinflammatoire fase. In de kliniek wordt de periode waarin het afweersysteem minder responsief is gekenmerkt door het optreden van opportunistische infecties die moeilijk te behandelen zijn. De verminderde reactiviteit van het immuunsysteem op deze secundaire infecties is gecorreleerd met de mate van ontsteking in de vroege fase van sepsis. Daarom wordt vermindering van de acute ontstekingsrespons als een potentieel aangrijpingspunt beschouwd om de daarop volgende non-responsiviteit van het immuunsysteem te verminderen. $\mathrm{Na}$ het induceren van een secundaire luchtweginfectie met Pseudomonas aeruginosa vier dagen na CLP is de hoeveelheid bacteriën in de long hoger in vergelijking met een controle operatie (niet leidend tot sepsis). Dit geeft een toestand van immunosuppressie tijdens sepsis weer. In dieren die lipiderijke voeding krijgen toegediend, is de kolonisatie in de long echter niet verschillend tussen septische en niet-septische dieren. Het behoud van de afweerrespons gaat gepaard met een toename van de inflammatoire markers IL-12 en IFN- $\gamma$ en een afname van immunosuppressor IL-10. Hiermee wordt aangetoond dat lipiderijke voeding niet alleen de acute ontstekingsrespons remt, maar ook een verzachtende werking uitoefent op de daarop volgende immunosuppressieve fase.

De dierexperimentele studies laten samen een breed beschermend effect van lipiderijke voeding zien en verschaffen bovendien inzicht in de onderliggende vagale 
reflex. Op grond van deze kennis zijn de eerste humane studies met verrijkte voeding uitgevoerd. Eerst wordt gezocht naar een optimale voedingscompositie (hoofdstuk 11). Een veelgebruikte klinische voeding met een hoge lipidenfractie (Diasip) wordt vergeleken met een klinische voeding met een laag lipidengehalte (Respifor). Omdat CCK concentraties in de darmwand niet op een non-invasieve manier gemeten kunnen worden in de mens, worden de CCK spiegels in het bloed bepaald voor en na voeding. Hieruit blijken geen verschillen tussen beide voedingen. Dit is een opvallende bevinding, aangezien de samenstelling van deze klinische voedingen vergelijkbaar is met de lipiderijke en controlevoeding die in de dierexperimentele studies werden toegepast. Uit de literatuur blijkt dat vooral vetzuren met koolstofketens van meer dan twaalf koolstofatomen en gehydrolyseerde eiwitten leiden tot afgifte van CCK. Op basis van deze gegevens werd een speciale eiwit- en lipiderijke voeding ontwikkeld gericht op maximale CCK afgifte. Echter ook deze voeding resulteert niet in hogere CCK-spiegels in het bloed in vergelijking met isocalorische controlevoeding. Deze gegevens wijzen erop dat de serumconcentraties van CCK geen goede maat zijn om een voeding gericht op optimale nervus vagusstimulatie te selecteren. Het gebrek aan onderscheidingsvermogen tussen beide voedingen kan liggen in het feit dat systemische spiegels een overmaat betekenen van lokaal CCK in de darmwand en de mate van nervus vagus-activatie dus niet goed representeren.

Nadere experimenten tonen aan dat ophoging van de voedingsdoseringen niet tot hogere CCK-pieken in het plasma leidt, maar wel tot een langer aanhoudende stijging van de CCK-waarden. Dit fenomeen kan worden verklaard door de vertraagde maaglediging na een grotere hoeveelheid voeding, wat resulteert in verlengde blootstelling van de darmwand aan de voedingsstoffen. Met het oog op klinische toepassing zou voeding, om een aanhoudende afgifte van CCK te bewerkstelligen, ofwel als een bolus in de maag, ofwel continu voorbij de pylorus toegediend moeten worden. Een tweede marker die wordt verondersteld het ontstekingsremmende effect van voeding weer te geven is de variabiliteit van de hartslag (heart rate variability). Uit verschillen tussen de hartslag-intervallen kan de mate van sympatische en parasympatische activiteit worden afgeleid. Echter de variabiliteit van de hartslag blijkt niet te verschillen tussen vrijwilligers die $200 \mathrm{ml}$ Diasip of Respifor drinken (hoofdstuk 12). Mogelijk komen de zenuwbanen die het hart beïnvloeden niet overeen met de nervus vagus-vezels die de ontstekingsrespons remmen. Deze gedachte wordt ook verwoord in een reactie van onze onderzoeksgroep op een studie van dr. Thayer, die een verband aantoonde tussen de hoogte van ontstekingsmarkers en de variabiliteit van de hartslag in een cohort met overwegend gezonde mensen (hoofdstuk 13). 
Eerder werd in muizen aangetoond dat lipiderijke voeding een endotoxinegemedieerde ontstekingsrespons remt (hoofdstuk 9). Wij beschrijven in hoofdstuk 14 een proof-of-principle studie naar het effect van eiwit- en lipiderijke voeding op een endotoxine-gemedieerde ontstekingsrespons in de mens. Bij gezonde vrijwilligers resulteert een bolus endotoxine in ziekteverschijnselen en stijging van ontstekingswaarden in het bloed. Om aspiratie te voorkomen wordt de voeding via een nasojejunale sonde toegediend. Verrijkte voeding leidt tot een significante afname van pro-inflammatoire markers TNF $\alpha$, IL- 6 en IL-1RA en een toename van antiinflammatoire marker IL-10 in vergelijking met zowel controlepersonen die geen voeding krijgen als personen die de controlevoeding ontvangen. Daarmee is dit de eerste studie die een beschermend effect van kortdurende toediening van eiwit- en lipiderijke voeding laat zien tijdens een acute ontsteking in de mens. Toekomstige studies dienen vast te stellen in hoeverre de vagale ontstekingsremmende reflex deze effecten verklaart.

Samenvattend verschaft dit proefschrift inzicht in het mechanisme dat aan de ontstekingsremmende werking van lipiderijke voeding ten grondslag ligt, wordt een breed beschermend effect aangetoond in verschillende modellen voor belangrijke ziektebeelden in chirurgische en intensive care patiënten en wordt tenslotte een vertaalslag van deze bevindingen naar de mens gemaakt. Stimulatie van het autonome zenuwstelsel door enterale voeding sluit goed aan bij de recent aangepaste richtlijnen rondom het voeden van patiënten perioperatief en op de intensive care. In deze richtlijnen wordt aanbevolen om periodes van vasten te reduceren en voeding zo mogelijk enteraal toe te dienen. Wat toekomstige humane studies betreft die zich richten op stimulatie van de vagale reflex, is het van groot belang om te vermelden dat er tot dusver geen bijwerkingen of gezondheidsrisico's naar voren zijn gekomen. Het voeden per duodenumsonde, zoals in deze studie werd uitgevoerd, wordt wereldwijd als een veilige wijze van voedseltoediening beschouwd, ook in hemodynamisch instabiele patiënten. Complicaties van duodenaal voeden worden alleen beschreven in patiënten met een pre-existent aangetaste darm die langdurig werden gevoed. De volgende stap richting klinische toepassing van stimulatie van het autonoom zenuwstelsel door middel van voeding is een studie waarin de specifiek de veiligheid van voedingsinterventie wordt onderzocht en de mate waarin voeding wordt verdragen. Hieruit zal blijken of vervolgstudies uitgevoerd kunnen worden naar de effectiviteit van voedingsinterventies die door modulatie van de ontstekingsrespons het klinisch herstel gunstig beïnvloeden. Aangezien voeding voorafgaand aan de ontsteking tot sterkere bescherming leidt ten opzichte van voeding gestart tijdens een al bestaande ontsteking, vormen patiënten die electieve chirurgie ondergaan een geschikte populatie voor verdere studies. 
Curriculum Vitae 


\section{Curriculum Vitae}

Jacco-Juri de Haan was born on April $30^{\text {th }} 1980$ in Rotterdam. He grew up in Nieuwerkerk aan den IJssel and Markelo and completed high school at De Waerdenborch in Holten in 1998. He attended law school at Maastricht University and became Master of Law (LLM) with a thesis on the legal role of medical professionals in the prevention and surveillance of child abuse. In 2000 he was admitted to medical school at Maastricht University. He developed an interest in science and worked as a research assistant at the Department of Internal Medicine at Maastricht University Medical Center (Dr. M.C. Brouwers and Prof. dr. T.W. de Bruin). In 2004, he started a PhD trajectory at the Department of Surgery and the Nutrition and Toxicology Research Institute Maastricht (NUTRIM), Maastricht University Medical Center, under supervision of Prof. dr. W.A. Buurman and Prof. dr. J.W.M. Greve, which resulted in the present dissertation. He obtained his qualification as a Doctor of Medicine (MD) in 2009 and commenced his specialty training in Internal Medicine in 2010 under supervision of Dr. W. Smit (Medisch Spectrum Twente, Enschede) and Prof. dr. R.O.B. Gans (University Medical Center Groningen). He is engaged to Heike Mayalu Heineman and has a daughter called Fiep. 


\section{List of publications}




\section{List of publications}

Luyer M, Greve JW, de Haan J, Lubbers T, Buurman W. Are we finally taming inflammation? Crit Care Med. 2007;35:2003-2004

Thuijls G, de Haan JJ, Derikx JP, Daissormont I, Hadfoune M, Heineman E, Buurman WA. Intestinal cytoskeleton degradation precedes tight junction loss following hemorrhagic shock. Shock. 2009;31:164-169

de Haan JJ, Lubbers T, Hadfoune M, Luyer MD, Dejong CHC, Buurman WA, Greve JW. Post-shock intervention with high-lipid enteral nutrition reduces inflammation and tissue damage. Ann Surg. 2008;248: 842-848

Lubbers T, Luyer MD, de Haan JJ, Hadfoune M, Buurman WA, Greve JW. Lipid-rich enteral nutrition reduces postoperative ileus in rats via activation of cholecystokininreceptors. Ann Surg. 2009;249:481-487

de Haan JJ, Lubbers T, Greve JW, Buurman WA. Exploring the link between inflammation and the vagus nerve. J Intern Med. 2010;267:130-131

de Haan JJ, Lubbers T, Derikx JP, Relja B, Henrich D, Greve JW, Marzi I, Buurman WA. Rapid development of intestinal cell damage following severe trauma: a prospective observational cohort study. Crit Care. 2009;13:R86

Thuijls G, Derikx JP, de Haan JJ, Grootjans J, de Bruïne A, Masclee AA, Heineman E, Buurman WA. Urine-based Detection of Intestinal Tight Junction Loss. J Clin Gastroenterol. 2010;44:e14-19

de Haan JJ, Thuijls G, Lubbers T, Hadfoune M, Reisinger K, Heineman E, Greve JW, Buurman WA. Protection against early intestinal compromise by lipid-rich enteral nutrition via cholecystokinin-receptors. Crit Care Med. 2010;38:1592-1597

Lubbers T, de Haan JJ, Luyer MD, Verbaeys I, Hadfoune M, Dejong CH, Buurman WA, Greve JW. Cholecystokinin/Cholecystokinin-1 receptor-mediated peripheral activation of the afferent vagus by enteral nutrients attenuates inflammation in rats. Ann Surg. 2010;252:376-382 
Lubbers T, De Haan JJ, Hadfoune M, Zhang Y, Luyer MD, Grundy D, Buurman WA, Greve JW. Lipid-enriched enteral nutrition controls the inflammatory response in murine Gram-negative sepsis. Crit Care Med. 2010;38:1996-2002

Relja B, Szermutzky M, Henrich D, Maier M, de Haan JJ, Lubbers T, Buurman WA, Marzi I.Intestinal-FABP and liver-FABP: Novel markers for severe abdominal injury. Acad Emerg Med. 2010;17:729-735

Grootjans J, Hodin CM, de Haan JJ, Derikx JP, Rouschop KM, Verheyen FK, van Dam $\mathrm{RM}$, Dejong $\mathrm{CH}$, Buurman WA, Lenaerts K. Level of Activation of the Unfolded Protein Response Correlates With Paneth Cell Apoptosis in Human Small Intestine Exposed to Ischemia/Reperfusion. Gastroenterology. 2011;140:529-539

Lubbers T, de Haan JJ, Hadfoune M, Zabeau L, Tavernier J, Zhang Y, Grundy D, Greve JW, Buurman WA. Chylomicron formation and glucagon-like peptide 1 receptor are involved in activation of the nutritional anti-inflammatory pathway. J Nutr Biochem. J Nutr Biochem. 2011;22:1105-1111

Hodin CM, Lenaerts K, Grootjans J, de Haan JJ, Hadfoune M, Verheyen FK, Kiyama H, Heineman E, Buurman WA. Starvation compromises Paneth cells. Am J Pathol. 2011;179:2885-2893

de Haan JJ, Hadfoune M, Lubbers T, Hodin C, Ito A, Verbaeys I, de Jonge WJ, Skynner $M$, Greve JW, Buurman WA. Lipid-rich enteral nutrition regulates mucosal mast cell activation via the vagal anti-inflammatory reflex. Submitted

de Haan JJ, Vermeulen Windsant I, Lubbers T, Hanssen SJ, Hadfoune M, Prinzen FW, Greve JW, Buurman WA. Prevention of hemolysis-induced organ damage by nutritional activation of the vagal anti-inflammatory reflex. Submitted

de Haan JJ, Pastille E, Wirsdörfer F, Lubbers T, Greve JW, Zhang Y, Buurman WA, Flohé SB. Lipid-rich enteral nutrition reduces immunosuppression during polymicrobial sepsis. Submitted

Lubbers T, Kox M, de Haan JJ, Greve JW, Pompe JC, Ramakers BP, Pickkers P, Buurman WA. Continuous administration of enteral lipid- and protein-rich nutrition limits inflammation in a human endotoxemia model. Submitted 


\section{Dankwoord}




\section{Dankwoord}

Wetenschappelijk onderzoek doen is teamwork, om maar eens een open deur te benoemen. Graag wil ik allen bedanken die direct of indirect aan dit proefschrift hebben bijgedragen.

Te beginnen mijn promotores Prof. dr. W.A. Buurman en Prof. dr. J.W.M. Greve. Beste Wim, wie onderzoek bij jou doet kiest niet voor de gemakkelijkste weg, maar dit maakt de voldoening des te groter wanneer het einddoel bereikt wordt. Wat heb ik ongelofelijk veel van je geleerd, zowel op onderzoeksgebied als daarbuiten. Jouw vermogen om door het trekken van dwarsverbanden op een originele manier tegen zaken aan te kijken zorgde, gecombineerd met je gedrevenheid en brede interesse, voor een intensief en spannend onderzoekstraject. Daarbij stimuleerde je mij om mijn eigen weg te zoeken, dank daarvoor. Jeanette, bedankt voor de altijd hartelijke ontvangst in Eijsden. Beste Jan-Willem, op het raakvlak tussen basale en toegepaste wetenschap waarop mijn onderzoek zich afspeelde was jouw scherpe oog voor het klinisch perspectief van groot belang. Ik mocht altijd terugvallen op jouw nauwkeurigheid, constructieve kritiek en duidelijkheid. Meermaals wist je op het juiste moment de zaken een juiste draai te geven. Bedankt voor jouw bijdrage aan het proefschrift.

Dan de overige sterren van de High-Fat Task Force. M'hamed Hadfoune, alias Mo, bedankt voor de jarenlange samenwerking. Of het nu om de bacteriologie ging, het hogere pipetteerwerk, of het deprimerende geploeter met de mestcellen die nooit wilden degranuleren zoals mestcellen behoren te degranuleren, ik kon altijd op je rekenen. Jouw enthousiasme, humor en voorliefde voor verhitte discussies zijn al in een tiental andere boekjes geroemd. Andere eigenschappen die ik zeer in je waardeer zijn je onvoorwaardelijke loyaliteit, mensenkennis en politieke instinct. Minpunt is jouw soms wat gebrekkige voetbalinzicht (eens wordt de Sleeping Giant wakker, mark my words). Ik ben blij dat je mijn paranimf wilt zijn. Tim Lubbers, het was een genoegen om met jou min of meer parallel onze promotietijd te doorlopen met alle hoogte- en dieptepunten. Onze soms wat verschillende karakters bleken elkaar aardig aan te vullen, waardoor de samenwerking altijd soepeltjes verliep en we een hoop hebben bereikt. Hoe langer de labtijd achter ons ligt, hoe meer ik besef wat een bijzondere tijd het was. Bedankt voor de afgelopen jaren. Misha, als laatste wil ik jou bedanken. Je hebt met jouw mooie studies niet alleen een stevige basis gelegd voor mijn onderzoek, ook vormde jouw scherpe blik en duidelijke feedback een belangrijke stimulans voor mijn eerste studies. 
De leden van de leescommissie, te weten Prof. dr. Akkermans, Prof. dr. Ten Cate, Prof. dr. Boeckxstaens, Prof. dr. Soeters en Prof. dr. Schols, wil ik bedanken voor het beoordelen van mijn proefschrift.

$\mathrm{Na}$ een paar prachtige jaren heeft de term 'het lab' een bijzondere lading voor me gekregen. Allereerst wil ik mijn kamergenoten noemen. Gezien de krappe afmetingen van de kamer krijg je nogal wat van elkaar mee. Ik wil jullie bedanken voor de gezelligheid, de scherpe discussies en alle flauwekul. Naast de al eerder genoemde Mo zat daar Caroline verstopt achter de deur, die als rustige Vlaamse opgewassen bleek tussen al het verbale rumoer van die Hollanders. Mijn opmerkingen over jouw hondjes (het suikerbeest en de ballenbijter) waren niet gemeend. Echt niet. Froukje, bedankt voor de reuring die je bracht, en last but not least Johanne, die met de nodige nuchterheid en relativering voor evenwicht zorgde. Dan buiten de kamer wil ik Joep Derikx bedanken, de mastermind achter vrijwel alle bijnamen op het lab, in het bijzonder voor de gouden tip over de vacature, waardoor het balletje is gaan rollen. Joep Grootjans, gedreven zowel in het onderzoek als daarbuiten, het wordt weer eens tijd voor een pot schaak. Geertje, bedankt voor de samenwerking die tot twee mooie publicaties heeft geleid. Iris, ik kijk met plezier terug op ons hemolyseavontuur, dat zowaar een happy end lijkt te krijgen. Tim (Wolfs), ontzettende Sjeng, jij hebt samen met Mo het begrip kantoorhumor naar een hoger plan getild, dank voor de sfeer die je op het lab bracht. Verder veel dank aan Annemarie (ook voor jouw bijdrage aan de trauma studie), Babs, Bas B, Bas $\mathrm{H}$ (voor jouw hulp bij het hemolysemodel), Charlotte, Dennis, Dian, Eva, Guy, Hans, Jeroen, Kaatje, Kim, Kirsten, Kostan, Liliane, Maarten, Maartje, Marcel, Mark, Martien, Nicole, Nina, Pieter, Renske, Robert, Ruben, Sander, Sedigeh, Simon, Sophia, Trudy en Yanti. Dank ook aan de secretaresses Kim Augustin, Sandra Hex en Henriette Oltmans voor de beheren van Wim's agenda, voor zover mogelijk althans. De studenten die tijdens het onderzoek hebben meegedraaid, te weten Adya, Anja, Desi, Ed, Emiel, Emschka, Feyza, Ine, Isabelle, Lisenke en Sebastian, bedankt voor jullie inzet!

Dan wil ik de volgende mensen in het Maastrichtse noemen: Prof. dr. Dejong, beste Cees, bedankt voor de constructieve inbreng, met name in het begin van het onderzoek. Prof. dr. Biessen en dr. Nieuwhuis, bedankt voor het meedenken over de mestcelstudies. Dr. Prinzen, voor de hulp bij de uitvoer en analyse van de microsfeerexperimenten. Dr. Oude Egberink en Viviane, voor de gastvrijheid in het begin van mijn onderzoekstijd. Ingrid Scheffers, voor jouw hulp bij de heart rate variability experimenten. Martijn Brouwers, voor het wekken van mijn wetenschappelijke interesse tijdens de eerste jaren van mijn geneeskundestudie. Antoine Simons, voor jouw enthousiaste medewerking bij de perfusie-experimenten. 
Verder wil ik degenen bedanken die aan de opzet van de helaas niet uitgevoerde scoliose trial hebben bijgedragen: Dr. Bouvy, Dr. Kramer, Prof. dr. Van Rhijn, Prof dr. Soeters, Dr. Van Waardenbrug en Dr. Willigers. Een belangrijk deel van mijn onderzoekstijd heb ik in de dungeons van het CPV doorgebracht. Ik wil de medewerkers van het CPV bedanken voor de hulp bij het faciliteren van mijn experimenten en de toewijding bij de verzorging van de dieren. En tenslotte, onze buren op de gang, de pulmo's, bedankt voor de gezamenlijke activiteiten.

Een waardevol onderdeel van mij promotietijd vormde het contact met onderzoekers buiten Maastricht. In Nijmegen: Prof. dr. Pickkers, Matthijs, Lucas, Bart en Jan, beste koekerts, bedankt voor de plezierige samenwerking, met name in die intensieve week waarin we de voeding hebben getest in het humane endotoxinemodel. In Frankfurt: Prof. dr. Marzi, Borna and Dirk, thank you for your collaboration, which has led to a number of fine studies on the occurrence of intestinal cell damage in trauma patients. In Essen: Prof. dr. Schade, Dr. Stefanie Flohé, Eva and Florian, it was a pleasure to investigate together with you the effects of enteral nutrition in the CLP model. In Amsterdam: Wouter de Jonge, bedankt voor je bereidheid om het mestcelverhaal te versterken. In Leiden: Ilze Bot, bedankt voor jouw hulp om de in vitro mestcelexperimenten op gang te krijgen. In Leuven: Prof. dr. Matthys, bedankt voor de bereidheid om een pilotstudie op te zetten in het CIA-model. In Kortrijk: dr Isabelle Verbaeys, voor uw hulp bij de CCK-gerelateerde experimenten. In Köln: Prof. dr. Neugebauer, Arasch, Marc, Timo and Olli, I enjoyed our meetings and discussions. In Regensburg: Prof. dr. Falk, thank you for your willingness to share your knowlegde and facilities. In Sheffield: Prof. dr. Grundy and Yaping, thank you for your collaboration. In Wageningen (DANONE): Zandrie en Aldwin (en enkele anderen in de loop der jaren), dank voor de prettige samenwerking, hopelijk vormt dit proefschrift geen punt, maar een komma.

$\mathrm{Na}$ het lab kwam ik wat onverwacht in Enschede terecht voor mijn opleiding tot internist. Wat aanvankelijk een koude douche leek, bleek voor ons een warm bad. Om in de temperatuurbeeldspraak te blijven hangen; ik ben de internisten in het MST in het algemeen, en met name mijn opleiders dr. Smit en dr. Wymenga, dankbaar voor het goede en prettige opleidingsklimaat. Alle (oud)assistenten; wat vormen jullie, ondanks de voortdurend wisselende samenstelling, toch een collegiale en fijne groep (vet fijn, in jargon). Hoogtepunten zijn de skireizen, het zeilen in Friesland en de onvoorspelbare avonturen met de Goedheiligman. Dank! De collega's van de MDL, cardiologie en IC wil ik bedanken voor de leerzame stages. 
De mannetjes van herendispuut Rusticus bedank ik voor de talloze mooie momenten tijdens mijn studententijd en daarna; Jasper, Martijn, Joep, Tim, Raph, Marc, Rolf, Roger, Laurent, Bjorn, Stijn, Joep, Pier, Dustin, Tijs, Ruben en alle latere generaties. Verder wil ik de mensen van het Pleitgenootschap Gaius bedanken voor de gezellige dagen door de jaren heen. Aan mijn geneeskundestudie heb ik een waardevolle vriendengroep overgehouden: allereerst Jip, van iedereen die ik ken ben jij degene die het meest in het hier en nu leeft zonder daarvoor een cursus te hebben gevolgd. Geweldig mens, dank voor je vriendschap! Na jouw optreden in de Sint Jan durf ik het paranimfenschap wel aan je over te laten. Denk ik. Ook Tom, Margreet, Floris, Bram, Joost, Janneke, Femke, Thijs, Inge, Gitty, Edgar en het vele grut dat de laatste jaren exponentieel toeneemt, bedankt voor alle gezelligheid en flauwekul in de afgelopen jaren, met Heppenbach als epicentrum. Dan de wollen muizen van de fietsgroep, waarvan de kern wordt uitgemaakt door Martijn, Marc, Luc, Chris, Jan, Anke, Tinneke, Andrea en Elske, bedankt voor de mooie momenten zowel op als van het zadel. Dankzij jullie heb ik geleerd dat je met hard werken tot mooie prestaties kunt komen, zelfs wanneer het talent beperkt is (zie mijn strijd tegen de man met één been). Anderen die ik wil bedanken voor hun vriendschap zijn Geert \& Sanne, Anneke, Oscar, Francisca \& Geert, Lukas \& Tabea en Willem \& Elise. Verder de mannen van de vaste pokeravond in M'streech / Bung: dank!

Mijn ouders bedank ik voor hun onvoorwaardelijke steun en alles wat ze mij hebben meegegeven. Jullie zijn fantastisch. Daniel en Lucia, fijn dat we elkaar de laatste tijd weer wat vaker zien, ik ben blij met jullie als broertje en schoonzusje. Wim, Wilma, Michel en Helene, dank voor jullie betrokkenheid. Erik, Simone, Jikke en Hidde, wat fijn dat ik deel van jullie warme en kleurrijke gezin mag uitmaken, sinds kort samen met Khoa en Sietske. Ook de families Heineman en Bots in ruimer verband wil ik bedanken voor hun gezelligheid en belangstelling, vaak gekoppeld aan mooie wijnen. Met name wil ik Ama bedanken voor alle mooie bezoeken aan het Gergiev-festival en opa Heineman voor de avonturen in IJsland en Noorwegen. Karen, dank voor je gouden tip over Alexander Calder.

Tot slot mijn eigen gezinnetje. Fiep, mijn kleine grote dochter. Wat een feest om jou de wereld te zien ontdekken, met je tomeloze energie, je vrolijkheid en je vermeelmuisde blik. En dat brengt me bij Heike. Zoals het boekje met jouw naam begint als creatief brein achter de kaft, zo zijn ook de laatste woorden voor jou. Lieve Heike, wat ben ik iedere dag weer blij met je! Dank voor alles, met jou heb ik geen stip aan de horizon nodig. 